\title{
Improving the understanding of atrial fibrillation progression and the appropriate use of anticoagulants
}

Citation for published version (APA):

Erküner, Ö. (2021). Improving the understanding of atrial fibrillation progression and the appropriate use of anticoagulants. [Doctoral Thesis, Maastricht University]. Maastricht University. https://doi.org/10.26481/dis.20210604oe

Document status and date:

Published: 01/01/2021

DOI:

10.26481/dis.20210604oe

Document Version:

Publisher's PDF, also known as Version of record

\section{Please check the document version of this publication:}

- A submitted manuscript is the version of the article upon submission and before peer-review. There can be important differences between the submitted version and the official published version of record.

People interested in the research are advised to contact the author for the final version of the publication, or visit the DOI to the publisher's website.

- The final author version and the galley proof are versions of the publication after peer review.

- The final published version features the final layout of the paper including the volume, issue and page numbers.

Link to publication

\footnotetext{
General rights rights.

- You may freely distribute the URL identifying the publication in the public portal. please follow below link for the End User Agreement:

www.umlib.nl/taverne-license

Take down policy

If you believe that this document breaches copyright please contact us at:

repository@maastrichtuniversity.nl

providing details and we will investigate your claim.
}

Copyright and moral rights for the publications made accessible in the public portal are retained by the authors and/or other copyright owners and it is a condition of accessing publications that users recognise and abide by the legal requirements associated with these

- Users may download and print one copy of any publication from the public portal for the purpose of private study or research.

- You may not further distribute the material or use it for any profit-making activity or commercial gain

If the publication is distributed under the terms of Article $25 \mathrm{fa}$ of the Dutch Copyright Act, indicated by the "Taverne" license above, 


\title{
Improving the understanding of atrial fibrillation progression and the appropriate use of anticoagulants
}

\author{
PROEFSCHRIFT \\ ter verkrijging van de graad van doctor aan de Universiteit Maastricht, \\ op gezag van de Rector Magnificus, Prof. dr. Rianne M. Letschert \\ volgens het besluit van het College van Decanen, \\ in het openbaar te verdedigen \\ op vrijdag 4 juni 2021 om 14:00 uur \\ door \\ Ömer Erküner
}




\section{Promotor}

prof. dr. H.J.G.M. Crijns

\section{Copromotor}

dr. J.G.L.M. Luermans

\section{Leden van de beoordelingscommissie}

prof. dr. T. Delhaas (voorzitter)

prof. dr. A.P. Gorgels

prof. dr. L.J. Schurgers

prof. dr. J.L.M.R. Smeets (Radboud UMC, Nijmegen)

prof. dr. L.V.A. Boersma (St. Antonius, Nieuwegein - Amsterdam UMC, Amsterdam)

Financial support by the Dutch Heart Foundation (Nederlandse Hartstichting) and Hart en vaat onderzoekfonds Limburg/Health foundation Limburg at Maastricht for the publication of this thesis is gratefully acknowledged.

The research described in this thesis was supported in part by a grant of the Dutch Heart Foundation (CVON 2014-9).

\section{ISBN:}

9789464191424

\section{Cover design by:}

Evelien Jagtman

Printed by:

Gildeprint 


\section{TABLE OF CONTENTS}

General introduction

$\begin{array}{lll}\text { PART I } & \text { Current practice in atrial fibrillation } & 12\end{array}$

Chapter 1 Contemporary management of atrial fibrillation patients in the

Netherlands and Belgium: a report from the EORP AF Long-Term

Registry

Revisions

$\begin{array}{lll}\text { PART II } & \text { Atrial fibrillation progression }\end{array}$

Chapter 2 Effect of systemic hypertension with versus without left ventricular

hypertrophy on the progression of atrial fibrillation (from the Euro Heart Survey)

American Journal of Cardiology 2018

Chapter 3 The influence of progression of atrial fibrillation on quality of life: a report

from the Euro Heart Survey

Europace 2018

Chapter 4 Differences in pericardial adipose tissue on computed tomography and outcome after pulmonary vein isolation

Submitted

Chapter 5 Temporal Patterns and Short-Term Progression of Paroxysmal Atrial

Fibrillation: Data from RACE V

Europace 2020

\section{PART III Anticoagulant treatment in atrial fibrillation}

Chapter 6 Non-vitamin $\mathrm{K}$ antagonist oral anticoagulants and the development of atrial fibrillation

Submitted

Chapter 7 Point of View: stroke risk in patients with device detected atrial high rate episodes

Netherlands Heart Journal 2018

Chapter 8 Poor anticoagulation relates to extended access times for cardioversion and is associated with long-term major cardiac and cerebrovascular events International Journal of Cardiology 2016

General discussion and summary

Valorization

Samenvatting (voor niet-medici)

Özet

Dankwoord

Curriculum Vitae 


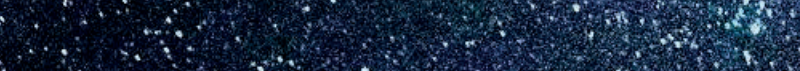

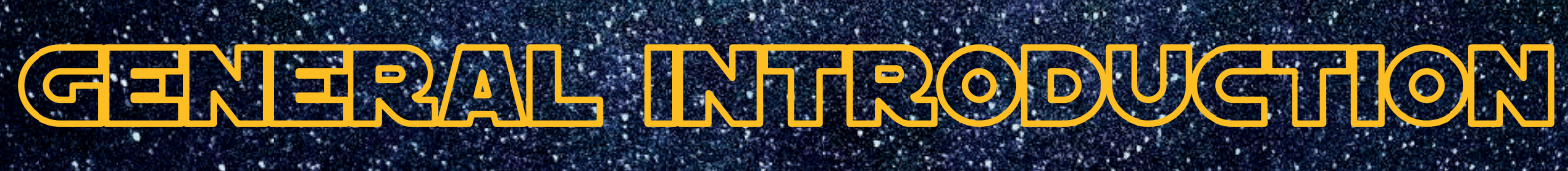

(1)

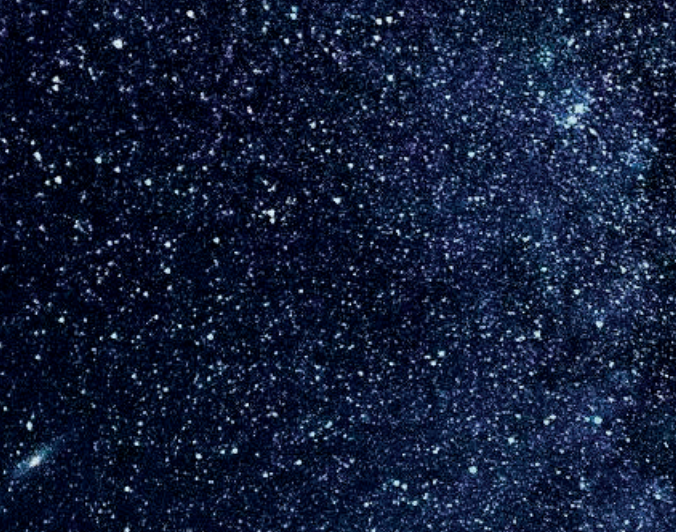

$x, y+\ldots$ 


\section{BACKGROUND}

Atrial fibrillation (AF) is the most common sustained cardiac arrhythmia, with almost 9 million individuals affected in the European Union. In the Netherlands, there are more than 250.000 patients with AF.(1) The incidence of AF increases with age and the presence of comorbidities like hypertension, obesity, coronary artery disease, type II diabetes, and heart failure.(2-4) With the increase of these comorbidities due to the Western lifestyle and an increased life expectancy, the prevalence of AF is estimated to more than double to 550.000 patients in the Netherlands by 2050.(1)

In addition to this widespread occurrence of AF, the arrhythmia is associated with an increased risk of ischemic stroke, making it a major public health problem.(5) This risk is dependent on the presence of risk factors included in the $\mathrm{CHA}_{2} \mathrm{DS}_{2}$-VASc score, i.e. Congestive heart failure, Hypertension, Age $\geq 75$ years (doubled), Diabetes Mellitus, prior Stroke/transient ischemic attack (doubled), Vascular disease, Age 65-74 years and female Sex.(5) In order to reduce this risk, anticoagulation treatment is recommended in patients with a $\mathrm{CHA}_{2} \mathrm{DS}_{2}$-VASc score of $\geq 1$, with the exception of female patients without any additional stroke risk factor.(6)

In the past, vitamin $\mathrm{K}$ antagonists (VKA) were the only oral anticoagulants that could be prescribed for this indication. In order to correctly dose VKA, periodic assessments of international normalized ratio (INR) are needed, determining continuously the degree of anticoagulation in an individual by assessing the prothrombin time and standardizing this value. Since 2008, non vitamin K oral anticoagulants (NOACs), i.e. dabigatran, rivaroxaban, apixaban, and edoxaban, are registered for use in AF patients to reduce the risk of ischemic stroke. For these drugs, only a once yearly assessment of kidney function is sufficient. In the current guidelines for the management of AF, NOACs are preferred above VKA in patients with non-valvular AF, because they are at least as effective as VKA in reducing ischemic stroke and in addition cause less major (intracranial) bleedings.(6)

\section{Progression of AF}

$\mathrm{AF}$ is classically divided into three categories, i.e. paroxysmal, persistent, and permanent AF.(6) Paroxysmal AF is characterized by self-terminating and short-lasting episodes, typically $<48$ hours, by definition maximally lasting 7 days, whereas persistent AF lasts $>7$ days and is not self-terminating. Permanent AF is used when persistent AF is accepted by patient and physician. 
AF progression is defined as paroxysmal AF becoming persistent or permanent AF - in other words, self-terminating AF becoming non-self-terminating AF. For the remainder of this thesis, this definition will be used. Some articles have also included persistent AF "becoming" permanent AF in the definition of AF progression.(7-10) However, since this is a choice made by the patient and the treating physician, and not based on a biological process, we will refrain from including these patients in the definition of $A F$ progression.

The rate of AF progression varies widely, from $0.8-24.1 \%$ per year $(11,12)$, depending on the studied population, the presence of underlying comorbidities, and the detection method of AF progression. A recent meta-analysis has shown a pooled AF progression incidence of 7.1\% per year (95\% Confidence Interval [Cl] 6.2-8.0, p<0.0001) across 42 studies in $\sim 18,500$ patients.(13) Several factors increase the risk of AF progression. These are compiled in the HATCH-score (Heart failure, Age, previous Transient ischemic attack or stroke, Chronic obstructive pulmonary disease, and Hypertension; Figure 1).(14)

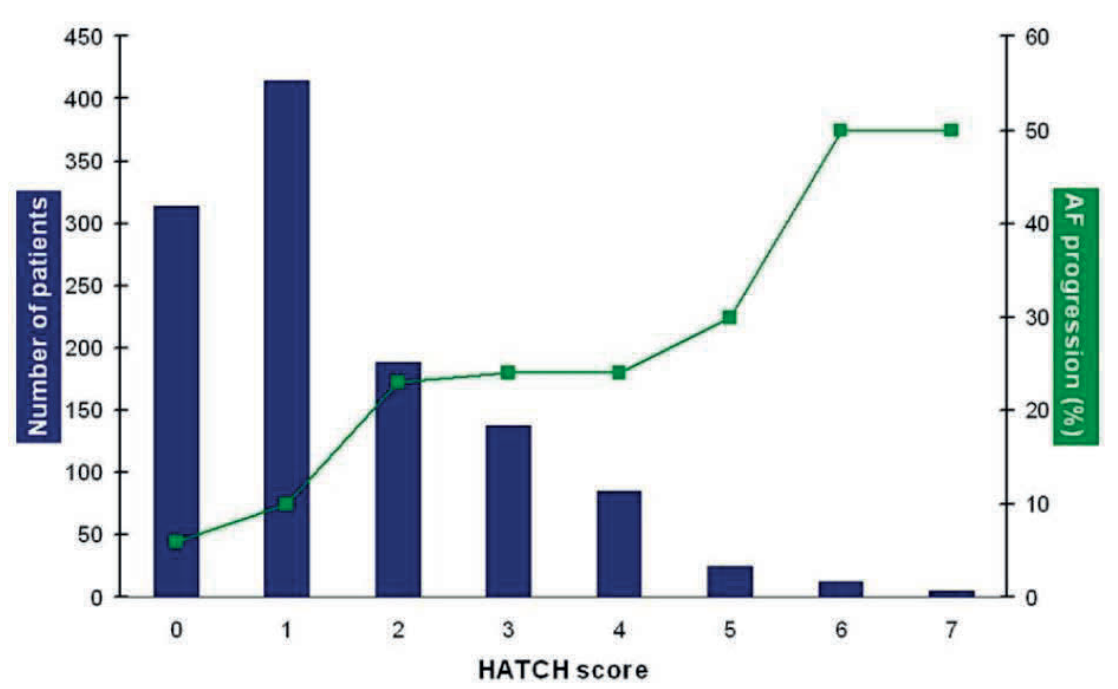

Figure 1. The incidence of AF progression for the different $\mathrm{HATCH}$ scores. Blue bars represent the number of patients in each $\mathrm{HATCH}$ score category, green line represents the percentage of AF progression after 1 year for these different scores. Adapted with permission from de Vos et al. Progression From Paroxysmal to Persistent Atrial Fibrillation: Clinical Correlates and Prognosis. J Am Coll Cardiol. 2010;55(8):725-31.(14)

AF progression is not merely an arrhythmic phenomenon, it is also associated with patient outcomes. The rate of ischemic stroke is higher for patients with persistent AF compared to those with paroxysmal AF, i.e. 3.0\% vs. 2.1\%, Hazard Ratio [HR] 1.43 (95\% Cl 1.04-1.96, $p=0.03)$.(15) In addition, AF progression itself is also associated with more ischemic strokes 
and heart failure hospitalizations.(16) Remarkably, these risks are elevated around the period of progression (HR 4.10, 95\% Cl 1.95-8.24, $\mathrm{p}<0.001$, for thrombo-embolism compared to paroxysmal $A F)$, even when compared to patients with persistent or permanent $A F$ (HR $2.20,95 \% \mathrm{Cl} 1.11-4.00, p=0.025)$. A year after the progression, these risks have decreased and are comparable to the risk in patients with persistent/permanent AF (Figure 2).(16)

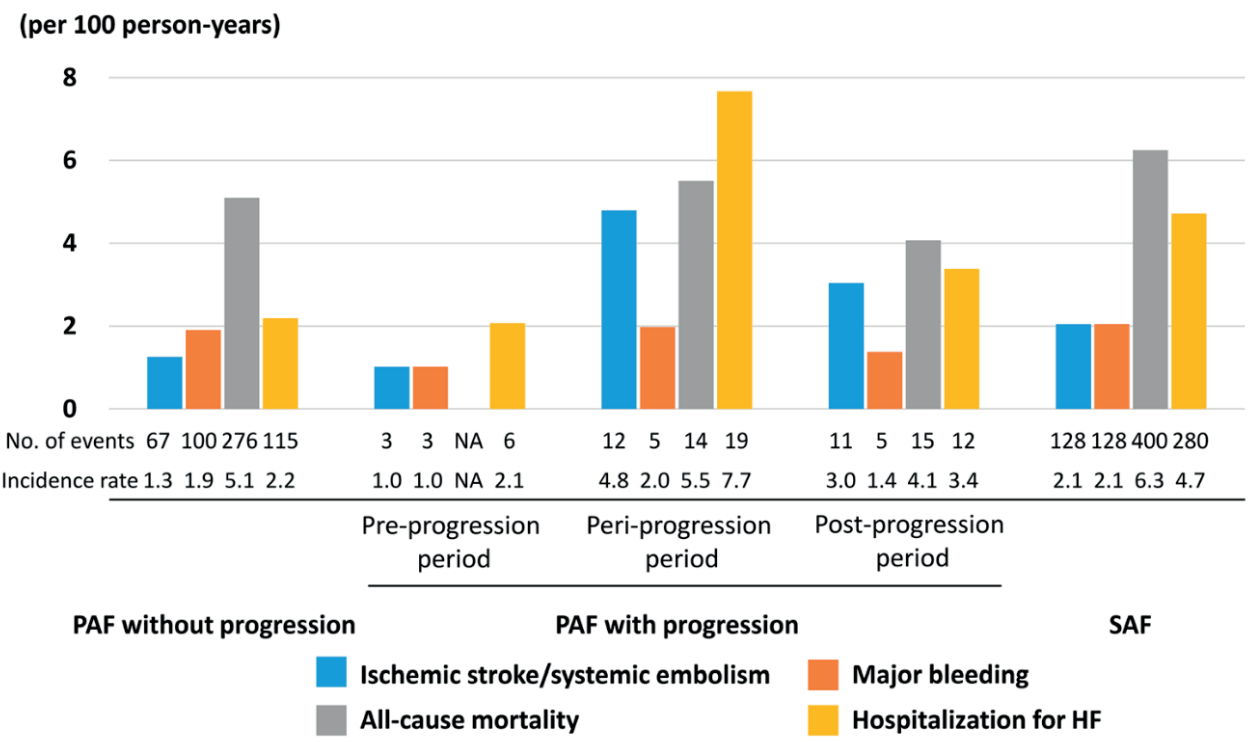

Figure 2. The study outcomes for the different stages of AF. Adapted with permission from Ogawa et al. Progression From Paroxysmal to Sustained Atrial Fibrillation Is Associated With Increased Adverse Events. Stroke. 2018;49(10):2301-8.(16) HF=Heart Failure; NA=Not applicable.

\section{AIMS AND OUTLINE OF THIS THESIS}

This thesis aims to elucidate the role of factors influencing the progression of AF and the consequences of AF progression. In addition, it questions how AF progression is defined and shows the shortcoming of this definition. Furthermore, we investigate the role of anticoagulant treatment in patients without AF and in patients with progressed AF. In the first group, we investigate whether anticoagulants can delay the incidence of AF and whether these drugs can play a role in patients with device detected atrial high rate events (AHRE, also called subclinical AF). In the latter group with persistent AF, we investigate the safety of anticoagulants in patients undergoing electrical cardioversions. 
PART I provides an overview of the characteristics of AF patients in the Netherlands and Belgium, focusing on guideline adherence regarding anticoagulation therapy, AF progression, and the differences observed between the two countries in treatment choices in general (Chapter 1).

PART II concerns the risk factors influencing AF progression (Chapter $2 \& 4$ ) and the effect of AF progression on the quality of life (Chapter 3). Chapter 5 shows that the classical definition of AF progression, which is based on intermittent rhythm monitoring, may not be appropriate in patients with continuous rhythm monitoring.

PART III focuses on anticoagulant treatment in AF. Firstly, the question whether the development of AF can be delayed with daily use of NOACs is investigated (Chapter 6). Secondly, the stroke risk in patients with device detected AHRE is discussed, providing guidance on when to start anticoagulants in these patients (Chapter 7). Chapter 8 shows that in patients with persistent/progressed AF using VKA, subtherapeutic INR values often occur, causing a delay in elective cardioversion and, more importantly, leading to an increased risk of cardiovascular death, ischemic stroke and the need of blood transfusion. 


\section{REFERENCES}

1. Krijthe BP, Kunst A, Benjamin EJ, Lip GY, Franco OH, Hofman A, et al. Projections on the number of individuals with atrial fibrillation in the European Union, from 2000 to 2060. Eur Heart J. 2013;34(35):2746-51.

2. Du X, Ninomiya T, de Galan B, Abadir E, Chalmers J, Pillai A, et al. Risks of cardiovascular events and effects of routine blood pressure lowering among patients with type 2 diabetes and atrial fibrillation: results of the ADVANCE study. Eur Heart J. 2009;30(9):1128-35.

3. Guha K, McDonagh T. Heart failure epidemiology: European perspective. Curr Cardiol Rev. 2013;9(2):123-7.

4. Huxley RR, Misialek JR, Agarwal SK, Loehr LR, Soliman EZ, Chen LY, et al. Physical activity, obesity, weight change, and risk of atrial fibrillation: the Atherosclerosis Risk in Communities study. Circ Arrhythm Electrophysiol. 2014;7(4):620-5.

5. Lip GY, Nieuwlaat R, Pisters R, Lane DA, Crijns HJ. Refining clinical risk stratification for predicting stroke and thromboembolism in atrial fibrillation using a novel risk factorbased approach: the euro heart survey on atrial fibrillation. Chest. 2010;137(2):263-72.

6. Kirchhof P, Benussi S, Kotecha D, Ahlsson A, Atar D, Casadei B, et al. 2016 ESC Guidelines for the management of atrial fibrillation developed in collaboration with EACTS: The Task Force for the management of atrial fibrillation of the European Society of Cardiology (ESC)Developed with the special contribution of the European Heart Rhythm Association (EHRA) of the ESCEndorsed by the European Stroke Organisation (ESO). Eur Heart J. 2016.

7. Holmqvist F, Kim S, Steinberg BA, Reiffel JA, Mahaffey KW, Gersh BJ, et al. Heart rate is associated with progression of atrial fibrillation, independent of rhythm. Heart. 2015;101(11):894-9.

8. Chen $\mathrm{X}$, Lin $\mathrm{M}$, Wang $\mathrm{W}$. The progression in atrial fibrillation patients with COPD: a systematic review and meta-analysis. Oncotarget. 2017;8(60):102420-7.

9. Jahangir A, Lee V, Friedman PA, Trusty JM, Hodge DO, Kopecky SL, et al. Long-term progression and outcomes with aging in patients with lone atrial fibrillation: a 30-year follow-up study. Circulation. 2007;115(24):3050-6.

10. Levy S, Maarek M, Coumel P, Guize L, Lekieffre J, Medvedowsky JL, et al. Characterization of different subsets of atrial fibrillation in general practice in France: the ALFA study. The College of French Cardiologists. Circulation. 1999;99(23):3028-35.

11. Barrett TW, Self WH, Wasserman BS, McNaughton CD, Darbar D. Evaluating the $\mathrm{HATCH}$ score for predicting progression to sustained atrial fibrillation in ED patients with new atrial fibrillation. Am J Emerg Med. 2013;31(5):792-7.

12. Rostagno C, Bacci F, Martelli M, Naldoni A, Bertini G, Gensini G. Clinical course of lone atrial fibrillation since first symptomatic arrhythmic episode. Am $\mathrm{J}$ Cardiol. 1995;76(11):837-9.

13. Blum S, Meyre P, Aeschbacher S, Berger S, Auberson C, Briel M, et al. Incidence and predictors of atrial fibrillation progression: A systematic review and meta-analysis. Heart Rhythm. 2018. 
14. de Vos CB, Pisters R, Nieuwlaat R, Prins MH, Tieleman RG, Coelen RJ, et al. Progression from paroxysmal to persistent atrial fibrillation clinical correlates and prognosis. J Am Coll Cardiol. 2010;55(8):725-31.

15. Vanassche T, Lauw MN, Eikelboom JW, Healey JS, Hart RG, Alings M, et al. Risk of ischaemic stroke according to pattern of atrial fibrillation: analysis of 6563 aspirin-treated patients in ACTIVE-A and AVERROES. Eur Heart J. 2015;36(5):281-7a.

16. Ogawa H, An Y, Ikeda S, Aono Y, Doi K, Ishii M, et al. Progression From Paroxysmal to Sustained Atrial Fibrillation Is Associated With Increased Adverse Events. Stroke. 2018;49(10):2301-8. 


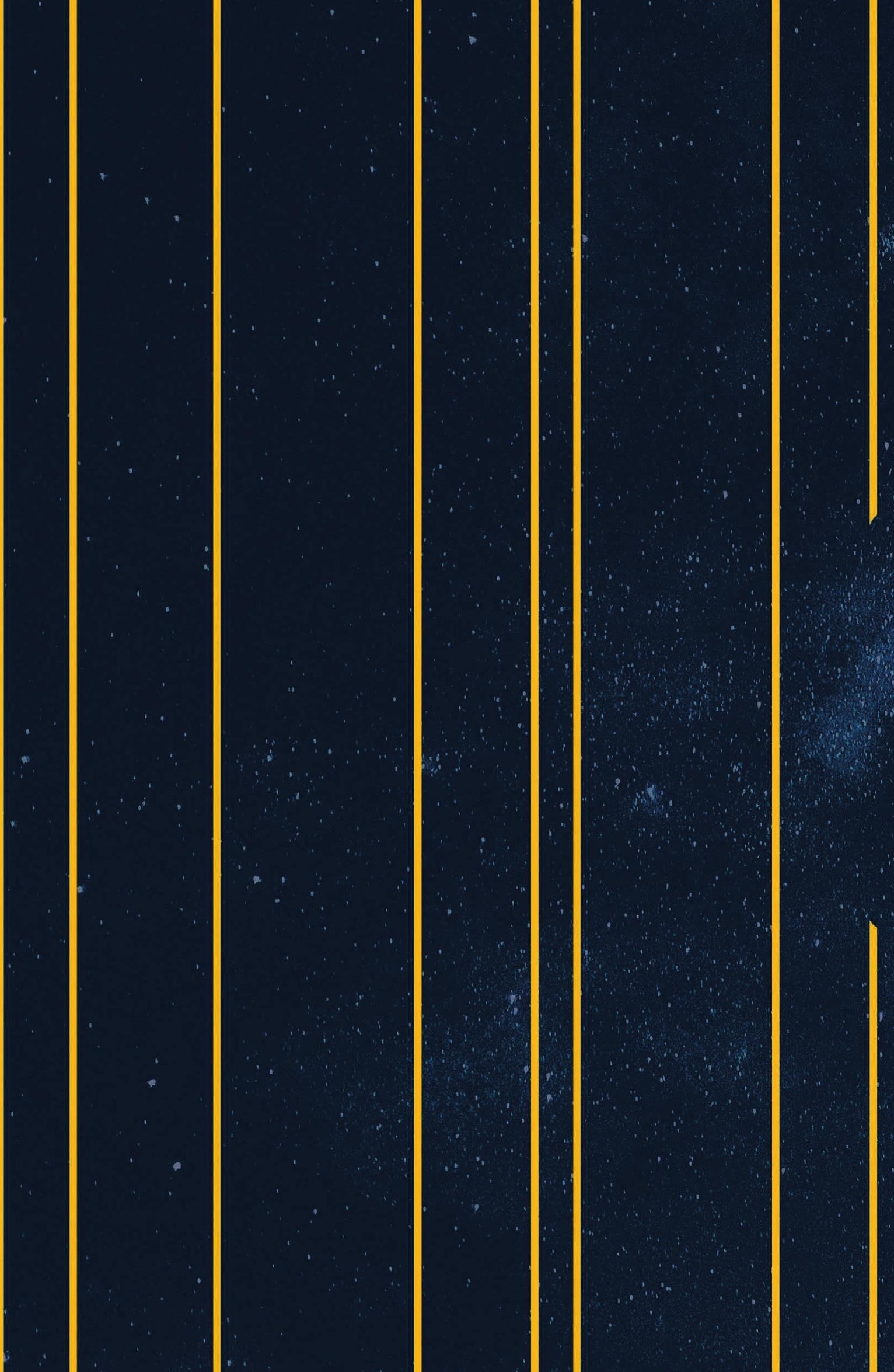



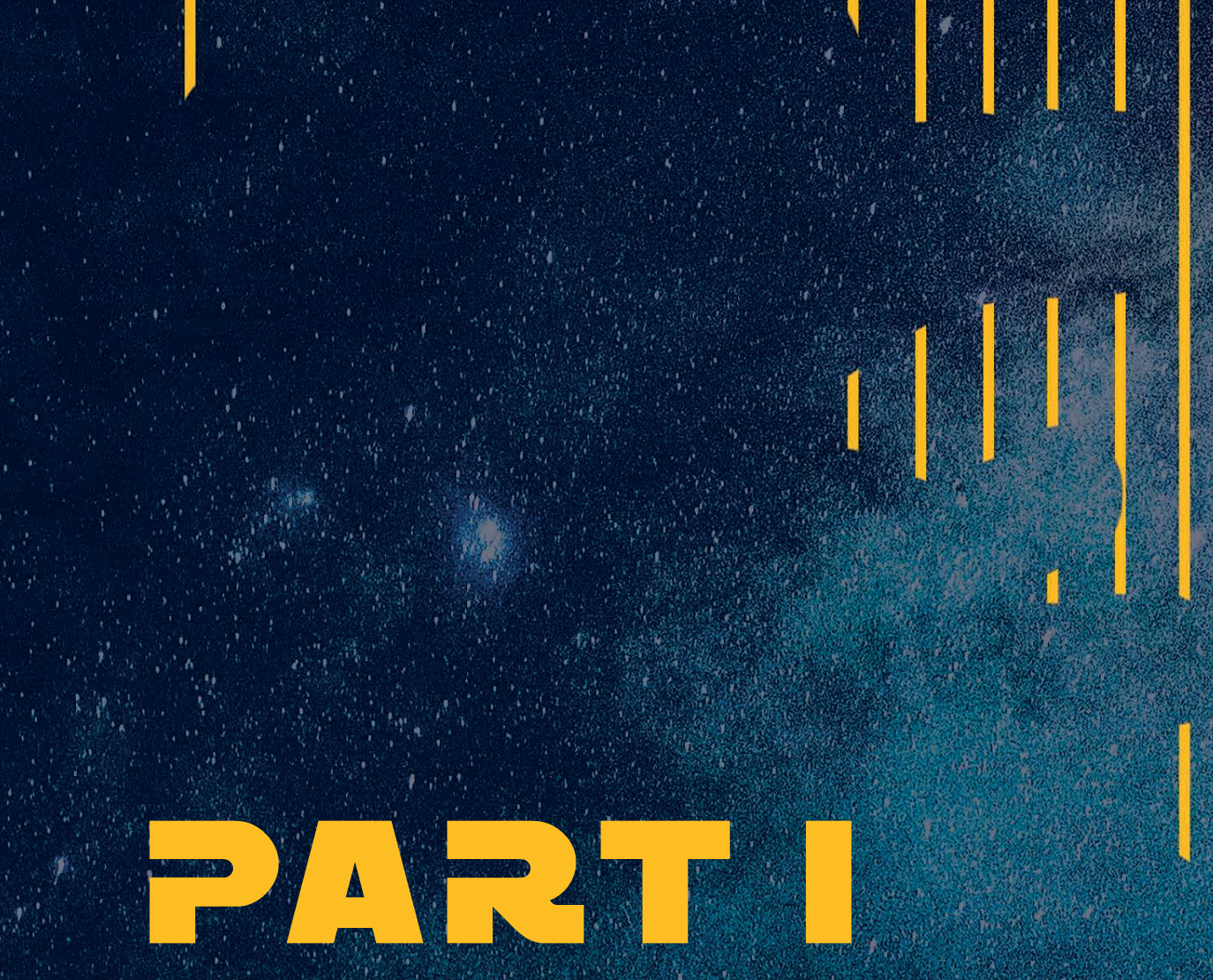

\section{CURBENT PRAGIGI \\ IN ATRIAL FIBRILATON}




\section{C

Contemporary management of atrial fibrillation patients in the

Netherlands and Belgium: a report from the

EORP AF Long-Term Registry

Ömer Erküner, Martijn van Eck, Olivier Xhaet, Harald Verheij, Jolien Neefs, Ayse Duygun,

Gerard Jochemsen, Salah Saïd, Hans Uiterwaal, Vincent Hagens, Rohit Bhagwandien,

Tamas Szili-Torok, Nick Bijsterveld, Geert Tjeerdsma, Johan Vijgen, Alain Friart,

Philippe Evrard, Etienne Hoffer, Joan Meeder, Muriel Srynger, Jurren van Opstal, Joris de Groot, Ronald Gevers, Gregory Lip, Justin Luermans,

Giuseppe Boriani, Harry Crijns, Georges Mairesse 


\section{ABSTRACT}

\section{Background}

Contemporary data regarding the characteristics, treatment and outcomes of atrial fibrillation (AF) patients are needed. We aimed to asses these and guideline adherence in the EORPAF Long-Term General Registry.

\section{Methods}

We analyzed 967 patients from the EORP-AF Long-Term General Registry included in the Netherlands and Belgium from 2013 to 2016. Baseline and 1 year follow-up data were gathered.

\section{Results}

At baseline, 887 patients (92\%) received anticoagulant treatment. In $88(10 \%)$ of these patients, no indication for chronic anticoagulant treatment was present. A rhythm intervention was performed or planned in 52 of these patients, meaning that the remaining $36(41 \%)$ were anticoagulated without an indication. Forty patients were not anticoagulated, even though they had an indication for chronic anticoagulation. Additionally, 63 of the 371 patients (17\%) treated with a Non-vitamin K Oral AntiCoagulant (NOAC) were incorrectly dosed. In total, 50 patients $(5 \%)$ were overtreated and 89 patients $(9 \%)$ were undertreated. However, the occurrence of major adverse cardiac and cerebrovascular events (MACCE) was still low with $4.2 \%$ (37 patients).

\section{Conclusions}

Overtreatment and undertreatment with anticoagulants are still observable in $14 \%$ of this contemporary, West-European AF population. Still, MACCE occurred in only $4 \%$ of the patients after 1 year of follow-up. 


\section{INTRODUCTION}

Atrial fibrillation (AF) is the most common cardiac arrhythmia worldwide. In 2010, the prevalence of AF in the European Union was estimated at 8.8 million individuals. By 2060, this number is likely to more than double to 17.9 million individuals.(1) In addition to this widespread occurrence of AF, the arrhythmia is associated with morbidities as well as with complications, the most important being ischemic stroke, making it a major public health problem with inherent large economic burden.(2)

Registries like the one described in this paper, the EURObservational Research Programme on Atrial Fibrillation Long-Term General (EORP-AF LTG) registry, are important means to assess the characteristics, treatment, and outcomes of contemporary AF patients. Therefore, we aimed to analyze these aspects in the patients from the EORP-AF LTG registry included in the Netherlands and Belgium, focusing on comorbidities at baseline, guideline-adherence in the treatment of AF, consumption of care, and the occurrence of major adverse cardiac and cerebrovascular events (MACCE) after 1 year in these patients.

\section{METHODS}

The EORP-AF LTG registry is a European Society of Cardiology initiated registry, conducted in 27 countries, including a total of 11,096 patients from 2013 to 2016 across 250 centers and is the successor of the EORP-AF Pilot General Registry. $(3,4)$ For this analysis, all patients from the Netherlands and Belgium were included. The study was approved by the Institutional Review Board of each including center. All patients provided written informed consent. Baseline data were obtained of the patients and they were followed for two consecutive years. The exact methods have previously been published.(3) We describe the baseline characteristics and one-year follow-up data of the patients from the Netherlands and Belgium.

MACCE was defined as a composite of cardiovascular death, ischemic stroke/transient ischemic attack (TIA), systemic thromboembolism, myocardial infarction, and major bleeding (intracranial bleeding, bleeding requiring [lengthening of] hospitalization, causing a hemoglobin level drop of $>2 \mathrm{~g} / \mathrm{l}$, or requiring blood transfusion). AF progression was defined as paroxysmal $\mathrm{AF}$ at baseline becoming persistent/permanent $\mathrm{AF}$ at follow-up, whereas $\mathrm{AF}$ regression was defined as persistent/permanent $A F$ at baseline becoming paroxysmal $A F$ at follow-up. For this definition of AF progression, patients classified as first diagnosed AF at baseline were reclassified if possible, i.e. if patients had spontaneous or pharmacological 
conversion at baseline, they were reclassified as paroxysmal AF. Failed attempt of cardioversion was classified as persistent AF. All others were classified as unknown, including those with successful electrical cardioversion. The estimated Glomerular Filtration Rate (eGFR) was calculated with the CKD-EPI (Chronic Kidney Disease Epidemiology) formula, using serum creatinine concentration, gender, age, and race.(5)

\section{Statistical analysis}

Data were analyzed with SPSS statistical software (version 23.0, SPSS Inc., IBM Corp., Armonk, NY, USA). Continuous variables are reported as mean \pm standard deviation if normally distributed and as median and inter quartile range if not. Normally distributed continuous variables were compared between groups using the independent samples t-test, whereas not normally distributed continuous variables were compared using the MannWhitney $U$ test. Categorical variables are reported as observed number of patients and percentage. Among-group comparisons were made using a $X^{2}$ test. Fisher's exact test was used in case of any expected cell count $<5$.

\section{RESULTS}

In total, 967 consecutive patients were included across 23 centers, 648 (67\%) from the Netherlands and $319(33 \%)$ from Belgium. The majority of the patients were included at the outpatient department (57.1\%). A little over one-third of the patients was female $(n=345$, $35.7 \%$ ). Hypertension was the most frequently documented comorbidity with a prevalence of $49 \%$. "Lone AF", defined as the absence of any comorbidity in patients aged $<65$ years, was present in 117 patients (12.1\%).

Baseline characteristics of the total study population, with a comparison between the countries, are shown in Table 1. Noteworthy differences between the countries, among others, are the higher prevalence of heart failure $(21.4 \%$ vs. $15.0 \%, p=0.013)$, obstructive sleep apnea $(14.1 \%$ vs. $4.1 \%, p<0.001)$, type 2 diabetes mellitus (22.6\% vs. $15.5 \%$, $\mathrm{p}=0.007)$, and hyperlipidemia $(58.5 \%$ vs. $36.8 \%, \mathrm{p}<0.001)$ in Belgian patients. Belgian patients also had a higher body mass index on average $(29 \pm 6$ vs. $28 \pm 5, p<0.001)$. In Belgium, more hospitalized patients were included in the registry $(55.2 \%$ vs. $36.9 \%$, $\mathrm{p}<0.001)$. 
Table 1. Baseline characteristics of the study population with a comparison between the Netherlands and Belgium.

\begin{tabular}{|c|c|c|c|c|c|c|c|}
\hline \multirow[b]{2}{*}{ Variable } & \multicolumn{2}{|c|}{$\begin{array}{c}\mathrm{NL} \& \mathrm{BE} \\
\mathrm{N}=967\end{array}$} & \multicolumn{2}{|c|}{$\begin{array}{l}\text { the Netherlands } \\
\mathrm{N}=648\end{array}$} & \multicolumn{2}{|c|}{$\begin{array}{c}\text { Belgium } \\
\mathrm{N}=319\end{array}$} & \multirow{2}{*}{$\begin{array}{l}\text { NL vs. } \\
\text { BE p- } \\
\text { value }\end{array}$} \\
\hline & $\mathrm{N}(\%)$ & $\begin{array}{l}\text { mis- } \\
\text { sing }\end{array}$ & $\mathrm{N}(\%)$ & $\begin{array}{l}\text { mis- } \\
\text { sing }\end{array}$ & $\mathrm{N}(\%)$ & $\begin{array}{l}\text { mis- } \\
\text { sing }\end{array}$ & \\
\hline Female sex & $345(35.7)$ & - & $231(35.6)$ & - & $114(35.7)$ & - & 0.978 \\
\hline Age & $\begin{array}{c}69.1 \\
( \pm 10.8) \\
\end{array}$ & - & $68.7( \pm 10.9)$ & - & $\begin{array}{c}70.0 \\
( \pm 10.6)\end{array}$ & - & 0.072 \\
\hline $\mathrm{BMI}$ & $28.3( \pm 5.3)$ & 45 & $27.9( \pm 4.9)$ & 40 & $29.2( \pm 5.9)$ & 5 & $<0.001$ \\
\hline $\begin{array}{l}\text { Inpatient } \\
\text { Outpatient }\end{array}$ & $\begin{array}{l}415(42.9) \\
552(57.1)\end{array}$ & - & $\begin{array}{l}239(36.9) \\
409(63.1)\end{array}$ & - & $\begin{array}{l}176(55.2) \\
143(44.8)\end{array}$ & - & $<0.001$ \\
\hline $\begin{array}{l}\text { Type of AF } \\
\text { First classified } \\
\text { Paroxysmal } \\
\text { Persistent } \\
\text { Long-standing pers. } \\
\text { Permanent }\end{array}$ & $\begin{aligned} & 92(9.6) \\
& 341(35.5) \\
& 324(33.7) \\
& 23(2.4) \\
& 181(18.8) \\
&\end{aligned}$ & 6 & $\begin{array}{c}65(10.1) \\
256(39.7) \\
196(30.4) \\
12(1.9) \\
116(18.0)\end{array}$ & 3 & $\begin{array}{c}27(8.5) \\
85(26.9) \\
128(40.5) \\
11(3.5) \\
65(20.6)\end{array}$ & 3 & 0.001 \\
\hline EHRA mean & $1.8( \pm 0.8)$ & 1 & $1.7( \pm 0.8)$ & - & $1.8( \pm 0.8)$ & 1 & 0.167 \\
\hline $\begin{array}{ll}\text { EHRA } & 1 \\
& 2 \\
& 3 \\
& 4 \\
\end{array}$ & $\begin{array}{c}448(46.4) \\
329(34.1) \\
171(17.7) \\
18(1.9) \\
\end{array}$ & & $\begin{array}{c}308(47.5) \\
219(33.8) \\
112(17.3) \\
9(1.4) \\
\end{array}$ & & $\begin{array}{c}140(44.0) \\
210(34.6) \\
59(18.6) \\
9(2.8) \\
\end{array}$ & & 0.365 \\
\hline Previous PVI & $107(11.1)$ & - & $67(10.3)$ & - & $40(12.5)$ & - & 0.305 \\
\hline LVEF on echocardiogram & $\begin{array}{c}54.4 \\
( \pm 12.0)\end{array}$ & 367 & $53.8( \pm 11.6)$ & 285 & $\begin{array}{c}55.4 \\
( \pm 12.5)\end{array}$ & 82 & 0.098 \\
\hline $\begin{array}{l}\text { LA diameter on } \\
\text { echocardiogram }\end{array}$ & $\begin{array}{c}47.6 \\
( \pm 10.3) \\
\end{array}$ & 414 & $46.7( \pm 10.6)$ & 283 & $49.4( \pm 9.5)$ & 131 & 0.003 \\
\hline Lone AF & $117(12.1)$ & - & $75(11.6)$ & - & $42(13.2)$ & - & 0.475 \\
\hline Hypertension & $470(49.0)$ & 8 & $311(48.6)$ & 8 & $159(49.8)$ & - & 0.715 \\
\hline Coronary artery disease & $218(22.8)$ & 12 & $152(23.8)$ & 9 & $66(20.9)$ & 3 & 0.315 \\
\hline $\begin{array}{l}\text { Heart failure } \\
\qquad \begin{array}{r}\text { NYHA I } \\
\text { NYHA II } \\
\text { NYHA III } \\
\text { NYHA IV }\end{array}\end{array}$ & $\begin{array}{c}165(17.1) \\
51(30.9) \\
72(43.6) \\
37(22.4) \\
5(3.0) \\
\end{array}$ & 1 & $\begin{array}{c}97(15.0) \\
33(34) \\
50(51.5) \\
12(12.4) \\
2(2.1) \\
\end{array}$ & - & $\begin{array}{l}68(21.4) \\
18(26.5) \\
22(32.4) \\
25(36.8) \\
3(4.4)\end{array}$ & 1 & 0.013 \\
\hline Valvular heart disease & $382(40.5)$ & 24 & $258(41.3)$ & 24 & $124(38.9)$ & - & 0.464 \\
\hline Dilated CMP & $43(4.5)$ & 11 & $17(2.7)$ & 11 & $26(8.2)$ & - & $<0.001$ \\
\hline Congenital heart disease & $16(1.7)$ & 9 & $12(1.9)$ & 9 & $4(1.3)$ & - & 0.478 \\
\hline Hypertrophic CMP & $33(3.5)$ & 11 & $10(1.6)$ & 10 & $23(7.2)$ & 1 & $<0.001$ \\
\hline Pulmonary art. hypertension & $41(4.3)$ & 13 & $3(0.5)$ & 9 & $38(12.1)$ & 4 & $<0.001$ \\
\hline OSAS & $67(7.3)$ & 44 & $26(4.1)$ & 16 & $41(14.1)$ & 28 & $<0.001$ \\
\hline Peripheral vascular disease & $77(8.0)$ & 5 & $47(7.3)$ & 3 & $30(9.5)$ & 2 & 0.242 \\
\hline T2DM & $172(17.9)$ & 4 & $100(15.5)$ & 4 & $72(22.6)$ & - & 0.007 \\
\hline Lipid disorder & $416(44.1)$ & 24 & $231(36.8)$ & 21 & $185(58.5)$ & 3 & $<0.001$ \\
\hline Hypothyroidism & $29(3.2)$ & 8 & $7(1.1)$ & 4 & $22(7.5)$ & 4 & $<0.001$ \\
\hline Hyperthyroidism & $11(1.2)$ & 8 & $6(1.0)$ & 4 & $5(1.6)$ & 4 & 0.548 \\
\hline Prior thromboembolic event & $155(16.0)$ & - & $99(15.3)$ & - & $56(17.6)$ & - & 0.364 \\
\hline Prior hemorrhagic event & $52(5.4)$ & 1 & $30(4.6)$ & 1 & $22(6.9)$ & - & 0.143 \\
\hline
\end{tabular}




\begin{tabular}{|c|c|c|c|c|c|c|c|}
\hline LAA-occlusion & $11(1.2)$ & 34 & $10(1.6)$ & 3 & $1(0.3)$ & 31 & 0.188 \\
\hline $\mathrm{CHA}_{2} \mathrm{DS}_{2}-\mathrm{VASc}$ mean & $2.7( \pm 1.7)$ & 3 & $2.6( \pm 1.7)$ & - & $2.9( \pm 1.7)$ & 3 & 0.010 \\
\hline $\mathrm{CHA}_{2} \mathrm{DS}_{2}-\mathrm{VASc} 0$ & $95(9.9)$ & & $70(10.8)$ & & $25(7.9)$ & & 0.265 \\
\hline 1 & $153(15.9)$ & & $109(16.8)$ & & $44(13.9)$ & & \\
\hline 2 & 199 (20.6) & & 135 (20.8) & & $64(20.3)$ & & \\
\hline 3 & $210(21.8)$ & & 139 (21.5) & & $71(22.5)$ & & \\
\hline 4 & 177 (18.4) & & 117 (18.1) & & $60(19.0)$ & & \\
\hline 5 & $70(7.3)$ & & $45(6.9)$ & & $25(7.9)$ & & \\
\hline 6 & $41(4.3)$ & & $22(3.4)$ & & $19(6.0)$ & & \\
\hline 7 & $13(1.3)$ & & $9(1.4)$ & & $4(1.3)$ & & \\
\hline 8 & $6(0.6)$ & & $2(0.3)$ & & $4(1.3)$ & & \\
\hline HAS-BLED mean & $1.5( \pm 1.0)$ & - & $1.4( \pm 1.0)$ & - & $1.6( \pm 1.0)$ & - & 0.003 \\
\hline HAS-BLED 0 & $162(16.8)$ & & $119(18.4)$ & & $43(13.5)$ & & 0.011 \\
\hline 1 & 357 (36.9) & & $252(38.8)$ & & $105(32.6)$ & & \\
\hline 2 & 300 (31.0) & & 187 (28.9) & & $113(35.4)$ & & \\
\hline 3 & $123(12.7)$ & & $76(11.7)^{\prime}$ & & $47(14.7)^{\prime}$ & & \\
\hline 4 & $18(1.9)$ & & $8(1.2)$ & & $10(3.1)$ & & \\
\hline 5 & $7(0.7)$ & & $6(0.9)$ & & $1(0.3)$ & & \\
\hline Alcohol use & & 296 & & 240 & & 56 & 0.686 \\
\hline None & $250(37.3)$ & & $143(35.0)$ & & $107(40.7)$ & & \\
\hline$<1$ U/day & 196 (29.2) & & $124(30.4)$ & & $72(27.4)^{\prime}$ & & \\
\hline 1 U/day & $93(13.9)$ & & $59(14.5)$ & & 34 (12.9) & & \\
\hline 2-3 U/day & $99(14.8)$ & & $62(15.2)$ & & $37(14.1)$ & & \\
\hline 4 or more & $33(4.9)$ & & $20(4.9)^{\prime}$ & & $13(4.9)$ & & \\
\hline Smoking & & 150 & & 143 & & 7 & 0.237 \\
\hline No smoker & $423(51.8)$ & & $250(49.5)$ & & $173(55.4)$ & & \\
\hline Currently & $103(12.6)$ & & 65 (12.9) & & $38(12.2)$ & & \\
\hline Former & 291 (35.6) & & $190(37.6)$ & & $101(32.4)$ & & \\
\hline
\end{tabular}

$\mathrm{AF}=$ Atrial Fibrillation; $\mathrm{BE}=$ Belgium; $\mathrm{BMI}=$ Body Mass Index; $\mathrm{CMP}=$ Cardiomyopathy;

EHRA=European Heart Rhythm Association; LA=Left Atrial; LAA=Left Atrial Appendage;

LVEF=Left Ventricular Ejection Fraction; NL=Netherlands; NYHA=New York Heart Association; OSAS=Obstructive Sleep Apnea Syndrome; T2DM=Type 2 Diabetes Mellitus.

Baseline laboratory measurements are shown in Table 2. Belgian patients had on average a lower total cholesterol level $(4.3 \pm 1.2$ vs. $4.7 \pm 1.2, p=0.002)$, corresponding with the higher prescription rate of statins $(46.9 \%$ vs. $40.2 \%, p=0.049$, Table 3$)$. Furthermore, NT-proBNP levels were higher in Belgian patients (1714 [IQR 636-2803] vs. 448 [IQR 228-1081], $p=0.018)$, in line with the higher amount of patients with heart failure $(21.4 \%$ vs. $15.0 \%$, $p=0.013$, Table 1), even though the number of NT-proBNP measurements were low in Belgium and disproportionate between the countries, 10 (3\%) vs. 119 (18\%) patients. 


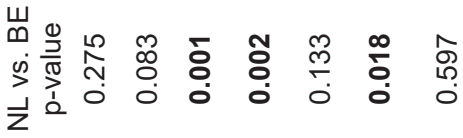

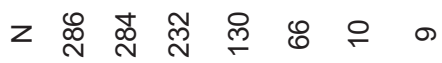

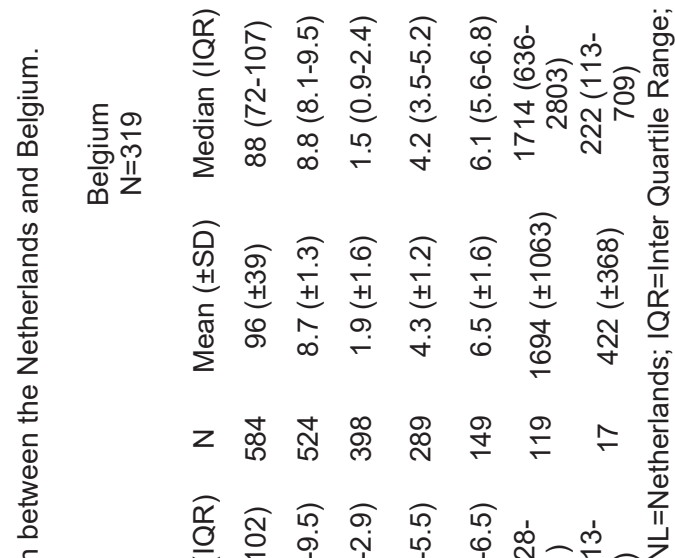

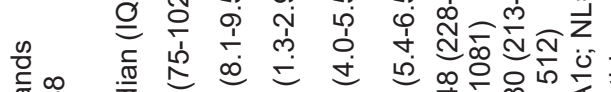

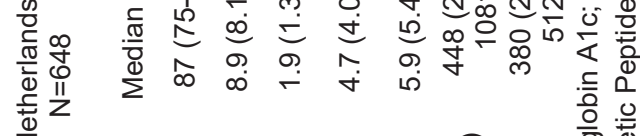

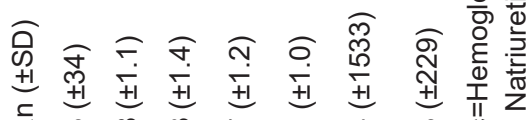

赵

$z$ 잉

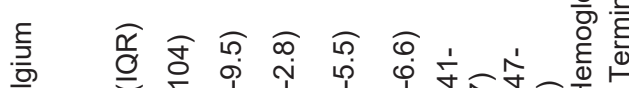

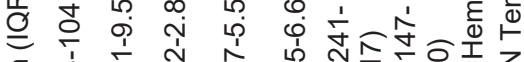

ᄃ

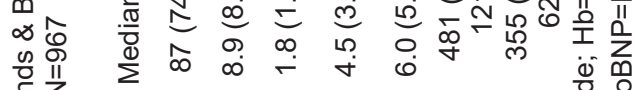

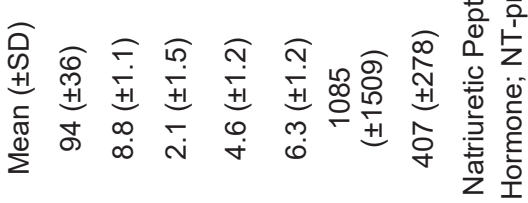

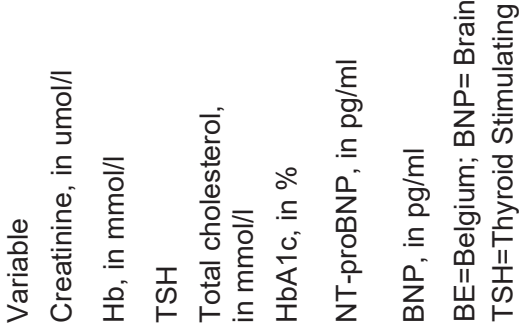




\section{Rate versus rhythm control therapy}

At baseline, the majority of the patients were on a rhythm control strategy according to the treating physician $(n=565,58.6 \%)$, whereas 326 patients $(33.8 \%)$ were on a rate control strategy. For the remainder of the patients $(n=73,7.6 \%)$, no decision regarding the treatment strategy was made yet.

In total, 354 patients (36.7\%) were prescribed an anti-arrhythmic drug (AAD) for daily use and $653(67.7 \%)$ a rate control drug (Table 3). Belgian patients were more frequently on AAD therapy $(47.5 \%$ vs. $31.4 \%, p<0.001)$ with significantly more amiodarone users compared to their Dutch counterparts $(28.3 \%$ vs. $5.9 \%, p<0.001)$, whereas Dutch patients more often received sotalol $(17.2 \%$ vs. $9.4 \%, p=0.001)$. The prescription rates for the other AADs were comparable (Table 3). For rate control drugs, only digoxin use was significantly different between countries, with more frequent prescription in the Netherlands $(19.5 \%$ vs. $4.7 \%$, $\mathrm{p}<0.001)$.

Of the 565 patients with rhythm control as treatment strategy, 313 patients $(55.4 \%)$ were on daily $A A D$ treatment. In the remainder of the patients, 14 (5.6\%) were planned for electrical cardioversion and $1(0.4 \%)$ for surgical AF ablation, meaning that 237 patients $(41.9 \%)$ were on a rhythm control strategy without daily $A A D$ use or a planned rhythm intervention.

Of the 326 patients with rate control as treatment strategy, 280 patients (86.2\%) were on rate control drugs, whereas 45 (13.8\%) were not (for 1 patient medication was missing). Notably, 34 of the 326 patients with rate control as treatment strategy $(10.4 \%)$ were on daily AAD treatment. In the remainder of the patients, $4(1.4 \%)$ were planned for electrical cardioversion, meaning that 38 patients $(11.8 \%)$ were wrongfully classified as rate control and should in fact have been classified as rhythm control regarding the treatment strategy. 
Table 3. Baseline medication of the study population with a comparison between the Netherlands and Belgium.

\begin{tabular}{|c|c|c|c|c|c|c|c|}
\hline \multirow[b]{2}{*}{ Medication } & \multicolumn{2}{|c|}{$\begin{array}{l}\mathrm{NL} \& \mathrm{BE} \\
\mathrm{N}=967\end{array}$} & \multicolumn{2}{|c|}{$\begin{array}{l}\text { the Netherlands } \\
\qquad N=648\end{array}$} & \multicolumn{2}{|c|}{$\begin{array}{c}\text { Belgium } \\
\mathrm{N}=319\end{array}$} & \multirow[b]{2}{*}{$\begin{array}{l}\text { NL vs. BE } \\
\text { p-value }\end{array}$} \\
\hline & N (\%) & $\begin{array}{l}\text { mis- } \\
\text { sing }\end{array}$ & $\mathrm{N}(\%)$ & $\begin{array}{l}\text { mis- } \\
\text { sing }\end{array}$ & $\mathrm{N}(\%)$ & $\begin{array}{l}\text { mis- } \\
\text { sing }\end{array}$ & \\
\hline VKA & $453(46.9)$ & 2 & $344(53.2)$ & 1 & $109(34.3)$ & 1 & $<0.001$ \\
\hline Rivaroxaban & $188(19.5)$ & 2 & $124(19.1)$ & 1 & $64(20.1)$ & 1 & 0.723 \\
\hline Dabigatran & $99(10.3)$ & 2 & $63(9.7)$ & 1 & $36(11.3)$ & 1 & 0.446 \\
\hline Apixaban & $130(13.5)$ & 2 & $57(8.8)$ & 1 & $73(23.0)$ & 1 & $<0.001$ \\
\hline Edoxaban & $5(0.5)$ & 2 & $5(0.8)$ & 1 & - & 1 & 0.178 \\
\hline LMWH & $13(1.3)$ & 2 & $1(0.2)$ & 1 & $12(3.8)$ & 1 & $<0.001$ \\
\hline Any anticoagulation drug & $887(91.9)$ & 2 & $593(91.7)$ & 1 & $294(92.5)$ & 1 & 0.669 \\
\hline ASA & $101(10.5)$ & 2 & $40(6.2)$ & 1 & $61(19.2)$ & 1 & $<0.001$ \\
\hline Clopidogrel & $29(3.0)$ & 2 & $19(2.9)$ & 1 & $10(3.1)$ & 1 & 0.859 \\
\hline Ticagrelor & $4(0.4)$ & 2 & $4(0.6)$ & 1 & - & 1 & 0.309 \\
\hline Dipyridamol & $2(0.2)$ & 2 & $1(0.2)$ & 1 & $1(0.3)$ & 1 & 0.551 \\
\hline $\begin{array}{l}\text { Sotalol } \\
\quad \text { Mean } \pm S D \text { dose per day, mg }\end{array}$ & $\begin{array}{c}141(14.6) \\
155 \pm 74\end{array}$ & 2 & $\begin{array}{c}111(17.2) \\
149 \pm 73\end{array}$ & 1 & $\begin{array}{l}30(9.4) \\
176 \pm 75\end{array}$ & 1 & $\begin{array}{l}0.001 \\
0.056\end{array}$ \\
\hline $\begin{array}{l}\text { Amiodarone } \\
\text { Mean } \pm S D \text { dose per day, mg }\end{array}$ & $\begin{array}{c}128(13.3) \\
232 \pm 105\end{array}$ & 3 & $\begin{array}{l}38(5.9) \\
208 \pm 78\end{array}$ & 2 & $\begin{array}{l}90(28.3) \\
241 \pm 115\end{array}$ & 1 & $\begin{array}{c}<0.001 \\
0.052\end{array}$ \\
\hline $\begin{array}{l}\text { Flecainide } \\
\text { Mean } \pm S D \text { dose per day, mg }\end{array}$ & $\begin{array}{l}80(8.3) \\
151 \pm 57\end{array}$ & 2 & $\begin{array}{l}53(8.2) \\
142 \pm 54\end{array}$ & 1 & $\begin{array}{l}27(8.5) \\
169 \pm 61\end{array}$ & 1 & $\begin{array}{l}0.874 \\
0.078\end{array}$ \\
\hline Propafenone & $4(0.4)$ & 2 & - & 1 & $4(1.3)$ & 1 & 0.012 \\
\hline Disopyramide & $3(0.3)$ & 2 & $2(0.3)$ & 1 & $1(0.3)$ & 1 & 0.999 \\
\hline Any anti-arrhythmic drug & $354(36.7)$ & 2 & $203(31.4)$ & 1 & $151(47.5)$ & 1 & $<0.001$ \\
\hline Betablocker & $541(56.1)$ & 3 & $367(56.8)$ & 2 & $174(54.7)$ & 1 & 0.538 \\
\hline Calcium channel blocker & $171(17.7)$ & 2 & $117(18.1)$ & 1 & $54(17.0)$ & 1 & 0.673 \\
\hline Digoxin & $141(14.6)$ & 2 & $126(19.5)$ & 1 & $15(4.7)$ & 1 & $<0.001$ \\
\hline Any rate control drug & $653(67.7)$ & 2 & $448(69.2)$ & 1 & $205(64.5)$ & 1 & 0.136 \\
\hline ACE-inhibitor & $307(31.8)$ & 2 & $185(28.6)$ & 1 & $122(38.4)$ & 1 & 0.002 \\
\hline Angiotensin receptor blocker & $196(20.3)$ & 2 & $132(20.4)$ & 1 & $64(20.1)$ & 1 & 0.920 \\
\hline Aliskiren & $6(0.6 \%)$ & 2 & - & 1 & $6(1.9)$ & 1 & 0.001 \\
\hline Aldosterone blockers & $65(6.7)$ & 2 & $35(5.4)$ & 1 & $30(9.4)$ & 1 & 0.019 \\
\hline Any RAAS inhibiting drug & $529(54.8)$ & 2 & $327(50.5)$ & 1 & $202(63.5)$ & 1 & $<0.001$ \\
\hline Diuretics & $335(34.7)$ & 2 & $221(34.2)$ & 1 & $114(35.8)$ & 1 & 0.604 \\
\hline Non-DHP CCB & $58(6.0)$ & 2 & $46(7.1)$ & 1 & $12(3.8)$ & 1 & 0.040 \\
\hline Statin & $409(42.4)$ & 2 & $260(40.2)$ & 1 & $149(46.9)$ & 1 & 0.049 \\
\hline Oral anti-diabetics & $133(13.8)$ & 2 & $73(11.3)$ & 1 & $60(18.9)$ & 1 & 0.001 \\
\hline Insulin & $35(3.6)$ & 2 & $24(3.7)$ & 1 & $11(3.5)$ & 1 & 0.845 \\
\hline Thyroid hormones & $64(6.6)$ & 2 & $19(2.9)$ & 1 & $45(14.2)$ & 1 & $<0.001$ \\
\hline Thyroid-suppressing drugs & $10(1.0)$ & 2 & $7(1.1)$ & 1 & $3(0.9)$ & 1 & 0.842 \\
\hline Proton-pump inhibitors & $275(28.5)$ & 2 & $201(31.1)$ & 1 & $74(23.3)$ & 1 & 0.012 \\
\hline
\end{tabular}
ACE=Angiotensin Converting Enzyme; ASA =Acetyl Salicylic Acid; CCB=Calcium Channel Blocker; DHP=Dihydropiridine; LMWH=Low Molecular Weight Heparins; SD=Standard Deviation; VKA= Vitamin K Antagonists. 


\section{Anticoagulant therapy}

At baseline, 887 patients (91.9\%) received anticoagulant treatment, with a larger proportion of patients using a Non-vitamin K Oral AntiCoagulant (NOAC) in Belgium than in the Netherlands (54.4\% vs. 38.4\%). Figure 1 depicts the percentage of patients with and without anticoagulation for the different $\mathrm{CHA}_{2} \mathrm{DS}_{2}$-VASc scores, also specifying the type of anticoagulant. For men with $\mathrm{CHA}_{2} \mathrm{DS}_{2}$-VASc 0 and for women with $\mathrm{CHA}_{2} \mathrm{DS}_{2}-\mathrm{VASc} 1$, the anticoagulation rates were $71.6 \%$ (68/95 patients) and $66.7 \%$ (20/30 patients), respectively. In these patients with anticoagulation, a rhythm intervention was performed during the baseline assessment or planned for the near future in 45 men (66.2\%) and 7 women (35\%). The remaining 23 men (33.8\%) and 13 women (65\%) were on anticoagulant treatment without a clear indication (Figure 2).

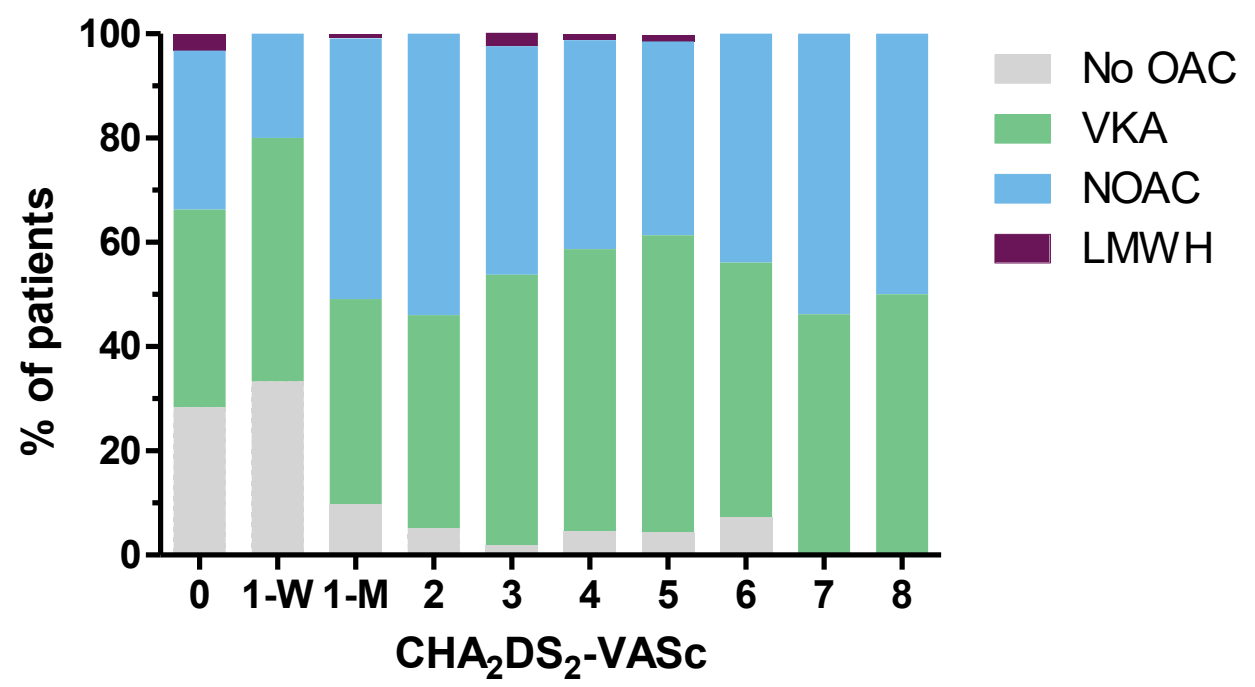

Figure 1. Stacked bar chart showing the percentages of patients with and without anticoagulation per $\mathrm{CHA}_{2} \mathrm{DS}_{2}$-VASc score, also specifying the type of anticoagulant. $\mathrm{CHA}_{2} \mathrm{DS}_{2}-\mathrm{VASc} 1$ is further subdivided by sex. LMWH=Low Molecular Weight Heparins; $\mathrm{M}=$ men; NOAC=Non-vitamin $\mathrm{K}$ Oral AntiCoagulants, OAC=Oral AntiCoagulation; VKA= Vitamin K Antagonists; $\mathrm{W}=$ women.

For patients with NOACs, over- and underdosing of NOACs were checked according to the dose reduction criteria for the respective drug.(6) In total, 14 patients were prescribed the full dose for a NOAC whereas they should have received the reduced dose according to the Summary of Product Characteristics (SmPC). This was the case for 12/148 patients with rivaroxaban and 2/57 with dabigatran ("Overdosed NOAC" in Figure 2). No overdosing was present for both apixaban $(n=70)$ and edoxaban $(n=5)$. Underdosing occurred in 49 patients 
("Underdosed NOAC" in Figure 2), i.e. 38/50 patients with apixaban, 8/24 with rivaroxaban, and $3 / 30$ with dabigatran. Reduced dose of edoxaban was not prescribed. In total, 63 $(16.7 \%)$ of 372 patients were not correctly dosed.

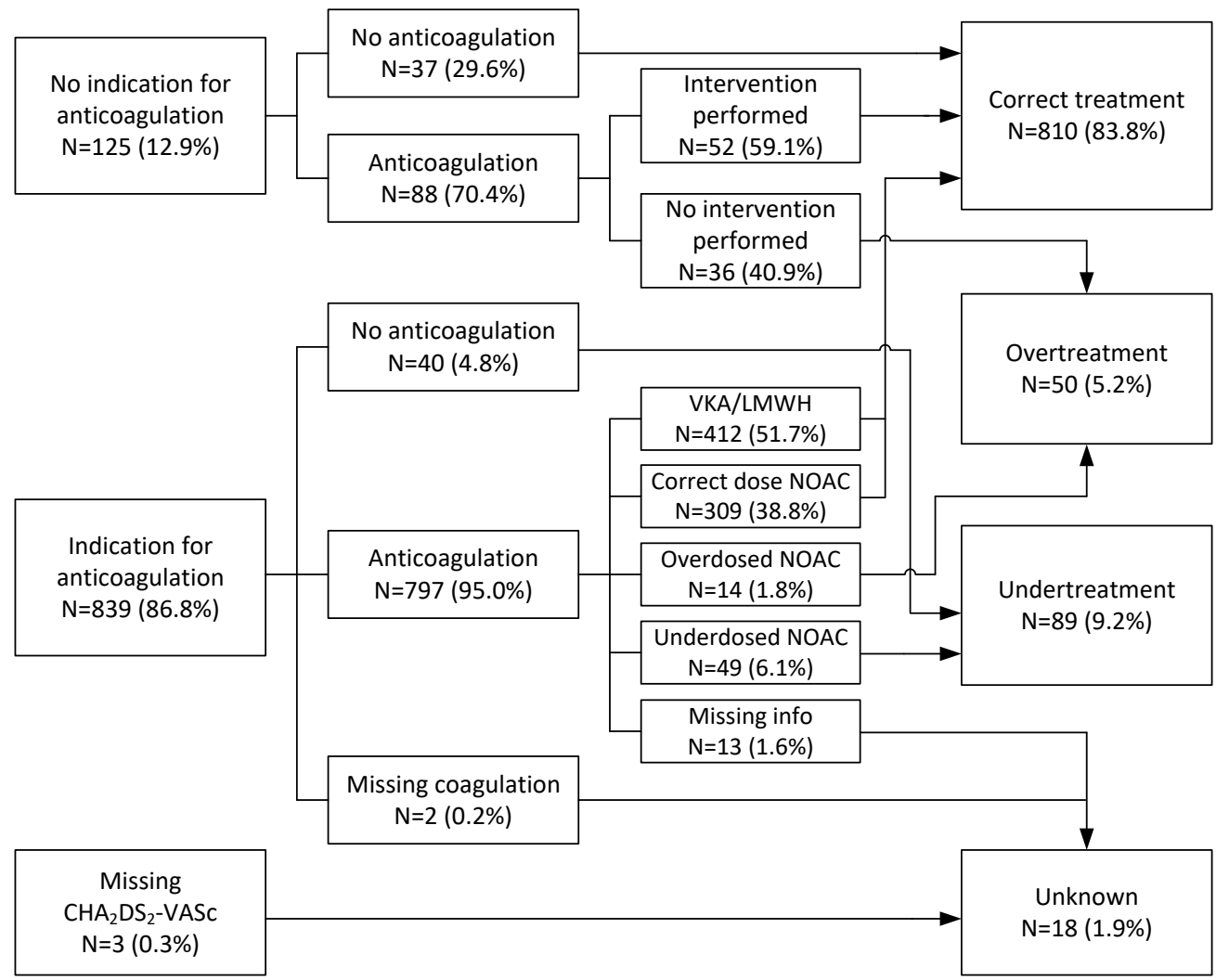

Figure 2. Flowchart for the appropriateness of anticoagulant treatment for the whole population. LMWH=Low Molecular Weight Heparins; NOAC=Non-vitamin K Oral AntiCoagulants, $\mathrm{VKA}=$ Vitamin $\mathrm{K}$ Antagonists.

\section{Undertreatment of diseases}

At baseline, 217 patients had coronary artery disease. Of these patients, $181(83.4 \%)$ were on statin therapy and $36(16.6 \%)$ were not. Unfortunately, prescription of other lipid lowering agents were not assessed. In 34 of 165 (20.6\%) heart failure patients, no angiotensin converting enzyme inhibitor (ACEi), angiotensin receptor blocker (ARB), or aldosterone receptor antagonist (ARA) was prescribed. Similarly, in 10 of $79(12.7 \%)$ heart failure patients with a left ventricular ejection fraction (LVEF) $\leq 45 \%$, no ACEi, ARB, or ARA was prescribed. 


\section{Follow-up}

One year follow-up data was available in 882 (91.2\%) of 967 patients. MACCE occurred in $37(4.2 \%)$ of these patients. In total, $27(3.1 \%)$ patients died within a year, 8 of which from a cardiovascular cause $(0.9 \%)$. Ischemic stroke occurred in 7 patients $(0.8 \%)$ and TIA in 3 $(0.3 \%)$. Two patients $(0.2 \%)$ had an intracranial hemorrhage, one of whom died as a consequence, whereas 14 patients $(1.6 \%)$ had a major extracranial bleeding. Myocardial infarction occurred in 5 patients $(0.6 \%)$, one of these patients also had an ischemic stroke.

Of the patients with ischemic stroke/TIA, 7 out of 10 were on anticoagulant therapy at baseline. The remaining 3 patients were not, despite a $\mathrm{CHA}_{2} \mathrm{DS}_{2}-\mathrm{VASc}$ score of 2, 3, and 5, respectively. However at follow-up, all 3 patients were on anticoagulant therapy, but, 1 of the other 7 patients with an ischemic event had ceased anticoagulant therapy. As for the 16 patients with a major bleeding event during follow-up, all had anticoagulant therapy at baseline. At follow-up, 1 patient had ceased therapy (6.3\%), 14 patients were still on anticoagulant therapy, and 1 had passed away as a consequence of the intracranial hemorrhage. Of the 37 patients with MACCE during follow-up, only 1 was underdosed (major extracranial bleeding event), totaling to 4 patients $(10.8 \%)$ with undertreatment. No overtreatment was seen in these patients.

During follow-up, the most frequently established new diagnosis was heart failure (40 patients, $4.5 \%$ ), followed by CKD, defined as initiation of chronic dialysis, renal transplantation, or serum creatinine $\geq 200 \mu \mathrm{mol} / \mathrm{l}(2.26 \mathrm{mg} / \mathrm{dL})$, in 23 patients $(2.6 \%)$, and hypertension in 16 patients (1.8\%). In addition, new-onset overt coronary artery disease was diagnosed in 15 patients $(1.5 \%)$, diabetes mellitus in $8(0.9 \%)$, and peripheral artery disease in $4(0.5 \%)$ patients.

\section{Rhythm follow-up and interventions}

Rhythm follow-up was available in 839 patients (86.8\%). AF progression and AF regression occurred at a similar rate, with $57(17.3 \%)$ of 329 patients with paroxysmal AF at baseline progressing into persistent or permanent AF after one year of follow-up and 87 (17.6\%) of 494 patients with persistent or permanent AF regressing into PAF. Of the regressors, 38 patients $(43.7 \%)$ were already on $A A D$ treatment at baseline. A rhythm intervention was performed during follow-up in $20(23.0 \%)$ of 87 patients showing regression, i.e. in 12 patients (13.8\%) an AAD was initiated, in 9 patients (10.3\%) a catheter ablation for AF was performed ( 1 of whom also started AAD therapy), and in 2 patients (2.3\%) surgery for atrial 
fibrillation was performed (both of them started AAD therapy as well). The remaining 67 patients $(77 \%)$ showed regression in type of AF without rhythm intervention.

In total, $233(26.4 \%)$ of 882 patients had at least 1 rhythm intervention during follow-up, i.e. 155 patients (17.6\%) underwent electrical cardioversion, 33 patients (3.7\%) pharmacological cardioversion, and 77 patients $(8.7 \%)$ catheter ablation for AF. Of the latter, 72 patients underwent a pulmonary vein isolation and 7 atrioventricular node ablation with pacemaker implantation. Furthermore, 14 patients (1.6\%) underwent surgery for AF, 9 of which as standalone procedure and 5 concomitantly with another intervention, and 19 patients (2.2\%) underwent an ablation for atrial flutter, 6 of which as stand-alone and 13 concomitantly with AF ablation.

Figure 3 shows the changes in treatment strategy for AF from baseline to follow-up. Relatively more patients changed from rate to rhythm control therapy than vice versa (24\% vs. $20 \%$ ), although absolute numbers show the opposite (66 vs. 99 patients). The majority of the patients were on the same treatment strategy at baseline and at one year follow-up, i.e. 610 of 775 patients $(79 \%)$.

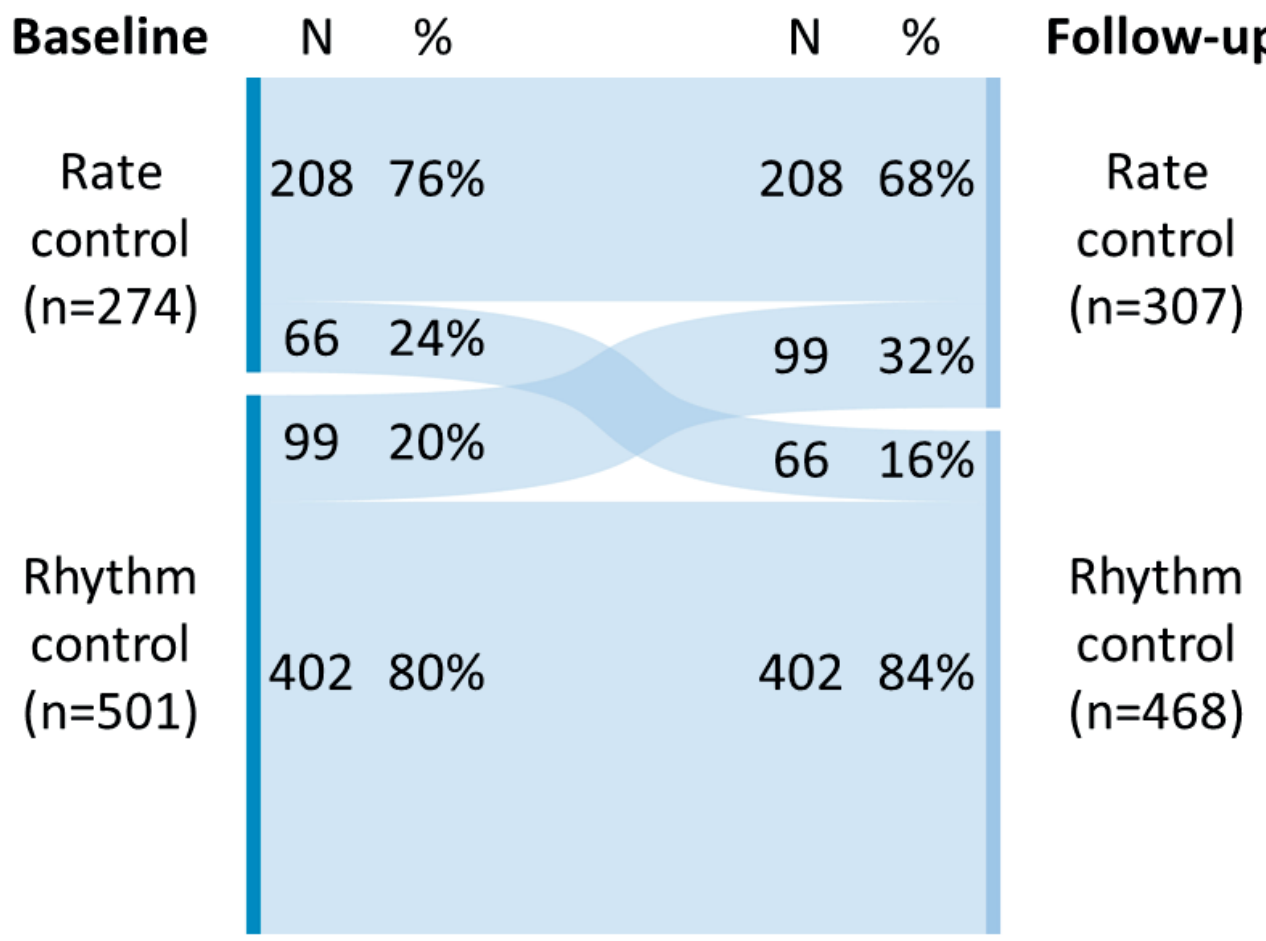

Figure 3. Sankey plot showing the treatment strategy for AF at baseline and follow-up and the changes occurred during follow-up. 


\section{Consumption of care}

During the one year follow-up period, 723 of $881(82.1 \%)$ patients visited the cardiology outpatient department, with a median of 2 (IQR 1-4) visits. Less patients visited the emergency room, 230 of 873 (26.3\%) with a median of 1 (IQR 1-2) visit. In total, 32 patients (3.6\%) underwent implantation of a cardiac implantable electronic device: 18 (2.0\%) pacemakers, $8(0.9 \%)$ cardiac resynchronization therapy (CRT) devices, 3 CRT-P (pacemaker) and 5 CRT-D (defibrillator), and an additional 6 implantable cardioverter defibrillators (ICD). Thus, $11(1.2 \%)$ defibrillators were implanted in total, 10 of which as secondary prevention and 1 as primary prevention. Furthermore, 8 patients $(0.9 \%)$ underwent percutaneous coronary intervention, $7(0.8 \%)$ coronary artery bypass grafting, 8 $(0.9 \%)$ left atrial appendage occlusion, $9(1.0 \%)$ valvular surgery, and $3(0.3 \%)$ transcatheter valve implantation.

\section{DISCUSSION}

In this analysis of the EORP AF LTG registry, we provide a contemporary representation of the characteristics, treatment, and outcomes of AF patients in the Netherlands and Belgium, both inpatient and outpatient. Overall, hypertension was the most frequently documented comorbidity and present in almost half of all patients. "Lone AF" was present in $12 \%$ of the patients, which is comparable to the $10 \%$ seen in the Euro Heart Survey 15 years ago.(7)

Strikingly, a large proportion of patients without an indication for chronic anticoagulant treatment, i.e. men with a $\mathrm{CHA}_{2} \mathrm{DS}_{2}$-VASc score of 0 and women with a score of 1 , are in fact anticoagulated at baseline (70\%). A slim majority (59\%) of these patients underwent a rhythm intervention at or shortly after baseline, resulting in overtreatment of patients with anticoagulant therapy in the remainder, which translates into $5 \%$ of the whole population being overtreated (Figure 2). Undertreatment of patients was even more prevalent, with 9\% of the patients either receiving no anticoagulation at all in the presence of an indication based on the $\mathrm{CHA}_{2} \mathrm{DS}_{2}$-VASc score, or receiving the reduced dose of a NOAC without a reason for dose reduction. In total, $17 \%$ of the patients using a NOAC are incorrectly dosed. Previous reports have shown higher rates, with a Belgian single center study showing $25 \%$ (8) and a Turkish single center study showing $37 \%$ of inappropriate dosing.(9)

MACCE occurred in 37 patients (4.2\%) after 1 year of follow-up, which is relatively low. To put it into perspective, 208 (5.3\%) of 3890 patients in the EHS died of cardiovascular cause or developed an ischemic stroke/TIA after one year, not taking into account major bleedings 
and myocardial infarction, which comprise half of the MACCE in this registry.(10) Given the rather low rate of ischemic complications and major bleedings after one year in this population, it is hard to draw any conclusions regarding the relationship between these endpoints and undertreatment and overtreatment. All patients with a major bleeding event were anticoagulated with correct dosing, whereas in the 10 patients with ischemic stroke/TIA, 7 were correctly treated and 3 were incorrectly not anticoagulated. The rates of ischemic stroke/TIA in patients with and without anticoagulants are in line with previous reports, i.e. $3.75 \%$ (3 of 80 ) in those without and $0.79 \%$ (7 of 887 ) in those with anticoagulants.(11)

Rhythm control was the preferred treatment strategy at baseline in $59 \%$ of the patients, whereas one third of the patients were on a rate control strategy. The majority of the patients $(80 \%)$ were on the same treatment strategy at baseline and at follow-up. Misclassification regarding treatment strategy was observed in $12 \%$ of the patients. In these cases, rate control was the appointed treatment strategy, but patients were either receiving AAD treatment on a daily basis or were planned for an electrical cardioversion. Therefore, more awareness regarding definitions and the correct use of terminology is warranted.(6)

Both AF progression and regression occurred at a similar rate of $17 \%$ per year. In a quarter of the regressors, AAD treatment was initiated or a rhythm intervention was performed during follow-up. The remainder of the patients regressed without a change in rhythm therapy, arising the question whether misclassification also plays a role in this high rate of regression after 1 year.

Some differences are present at baseline between the 2 countries, e.g. the higher prevalence of heart failure, type 2 diabetes, and sleep apnea in Belgium. This is most likely caused by the higher proportion of hospitalized patients included in Belgium when compared to the Netherlands (55\% vs. $37 \%$ ). In addition to these differences in patient characteristics, distinct drug prescription patterns are discernible between the countries, i.e. amiodarone is more frequently used in Belgium and sotalol more frequently in the Netherlands. No differences are seen in the use of flecainide, whereas propafenone is only prescribed in Belgium. In addition, digoxin use is more prevalent in the Netherlands for rate control. Regarding anticoagulant therapy, Belgian patients were more frequently on NOACs compared to their Dutch counterparts (54\% vs. $38 \%$ ), showing the faster implementation and uptake of NOACs in Belgium.

Undertreatment was not only observed with regard to anticoagulant therapy, but also in patients with coronary artery disease, with $17 \%$ not using a statin, and heart failure with reduced left ventricular ejection fraction, with $13 \%$ not using an ACEi, ARB, or ARA. 
Adequate therapy in patients with these comorbidities is important in reducing the occurrence of MACCE on one hand, and optimizing the treatment of AF on the other hand. $(12,13)$

Hospital visits are common in patients with AF. In this registry, $80 \%$ of the patients visited the cardiology outpatient department with a median of 2 visits per patient, a quarter of the patients underwent at least 1 rhythm intervention during follow-up, and another quarter of the patients visited the emergency department. A new diagnosis of heart failure was established in $4.5 \%$ of the patients and a CIED was implanted in $3.6 \%$ of the patients.

\section{Strengths and limitations}

As in all registries, the strength of this registry is dependent upon the completeness of the data obtained by all participating centers, so clinical factors can be both over- and underrepresented. Furthermore, the reported data are observational. In order to reduce selection bias, participating centers were asked to include consecutive AF patients. Nonetheless, we believe the data presented in this article are comprehensive and provide a representative overview of AF patients in the Netherlands and Belgium and the treatment they receive.

Of note, patients were deemed underdosed for dabigatran only if both the regular and the lenient dose reduction criteria, i.e. age 75-80 years and eGFR 30-50 ml/min for which dose reduction can be considered, were not met. In addition, verapamil/diltiazem were checked together in the case report file (CRF), so it is unclear which of the two drugs the patient is using, therefore we cannot be sure whether the dose reduction is adequate. For apixaban, the rate of underdosing is most likely to be overestimated, since in some patients not the daily dose of apixaban was filled in the CRF as requested, but rather the dose for a single gift. In patients with $10 \mathrm{mg}$ and $2.5 \mathrm{mg}$ of apixaban, it is clear whether the patient receives the reduced or full dose, for $5 \mathrm{mg}$ however, this is not clear. These patients were assessed as having the reduced dose of apixaban, meaning that the rate of underdosing might be overestimated as these patients could in fact be on twice daily $5 \mathrm{mg}$ of apixaban.

\section{CONCLUSION}

Overtreatment and undertreatment with anticoagulants are still observable in $14 \%$ of this contemporary, West-European AF population. Still, MACCE occurred in only $4 \%$ of the patients after 1 year of follow-up. 


\section{REFERENCES}

1. Krijthe BP, Kunst A, Benjamin EJ, Lip GY, Franco OH, Hofman A, et al. Projections on the number of individuals with atrial fibrillation in the European Union, from 2000 to 2060. Eur Heart J. 2013;34(35):2746-51.

2. Stewart S, Murphy NF, Walker A, McGuire A, McMurray JJ. Cost of an emerging epidemic: an economic analysis of atrial fibrillation in the UK. Heart. 2004;90(3):286-92.

3. Boriani G, Proietti M, Laroche C, Fauchier L, Marin F, Nabauer M, et al. Contemporary stroke prevention strategies in 11096 European patients with atrial fibrillation: a report from the EURObservational Research Programme on Atrial Fibrillation (EORP-AF) LongTerm General Registry. Europace. 2017.

4. Lip GY, Laroche C, Dan GA, Santini M, Kalarus Z, Rasmussen LH, et al. A prospective survey in European Society of Cardiology member countries of atrial fibrillation management: baseline results of EURObservational Research Programme Atrial Fibrillation (EORP-AF) Pilot General Registry. Europace. 2014;16(3):308-19.

5. Levey AS, Stevens LA, Schmid CH, Zhang YL, Castro AF, 3rd, Feldman HI, et al. A new equation to estimate glomerular filtration rate. Ann Intern Med. 2009;150(9):604-12.

6. Kirchhof P, Benussi S, Kotecha D, Ahlsson A, Atar D, Casadei B, et al. 2016 ESC Guidelines for the management of atrial fibrillation developed in collaboration with EACTS: The Task Force for the management of atrial fibrillation of the European Society of Cardiology (ESC)Developed with the special contribution of the European Heart Rhythm Association (EHRA) of the ESCEndorsed by the European Stroke Organisation (ESO). Eur Heart J. 2016.

7. Nieuwlaat R, Capucci A, Camm AJ, Olsson SB, Andresen D, Davies DW, et al. Atrial fibrillation management: a prospective survey in ESC member countries: the Euro Heart Survey on Atrial Fibrillation. Eur Heart J. 2005;26(22):2422-34.

8. Moudallel S, Steurbaut S, Cornu P, Dupont A. Appropriateness of DOAC Prescribing Before and During Hospital Admission and Analysis of Determinants for Inappropriate Prescribing. Front Pharmacol. 2018;9:1220.

9. Belen E, Canbolat IP, Bayyigit A, Helvaci A, Pusuroglu H, Kilickesmez K. A new gap in the novel anticoagulants' era: undertreatment. Blood Coagul Fibrinolysis. 2015;26(7):793-7.

10. Nieuwlaat R, Prins MH, Le Heuzey JY, Vardas PE, Aliot E, Santini M, et al. Prognosis, disease progression, and treatment of atrial fibrillation patients during 1 year: follow-up of the Euro Heart Survey on atrial fibrillation. Eur Heart J. 2008;29(9):1181-9.

11. Joundi RA, Cipriano LE, Sposato LA, Saposnik G, Stroke Outcomes Research Working G. Ischemic Stroke Risk in Patients With Atrial Fibrillation and CHA2DS2-VASc Score of 1: Systematic Review and Meta-Analysis. Stroke. 2016;47(5):1364-7.

12. Madrid AH, Bueno MG, Rebollo JM, Marin I, Pena G, Bernal E, et al. Use of irbesartan to maintain sinus rhythm in patients with long-lasting persistent atrial fibrillation: a prospective and randomized study. Circulation. 2002;106(3):331-6. 
13. Ueng KC, Tsai TP, Yu WC, Tsai CF, Lin MC, Chan KC, et al. Use of enalapril to facilitate sinus rhythm maintenance after external cardioversion of long-standing persistent atrial fibrillation. Results of a prospective and controlled study. Eur Heart J. 2003;24(23):20908. 


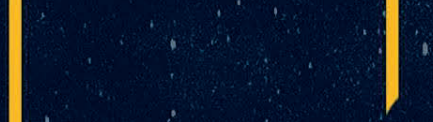

111

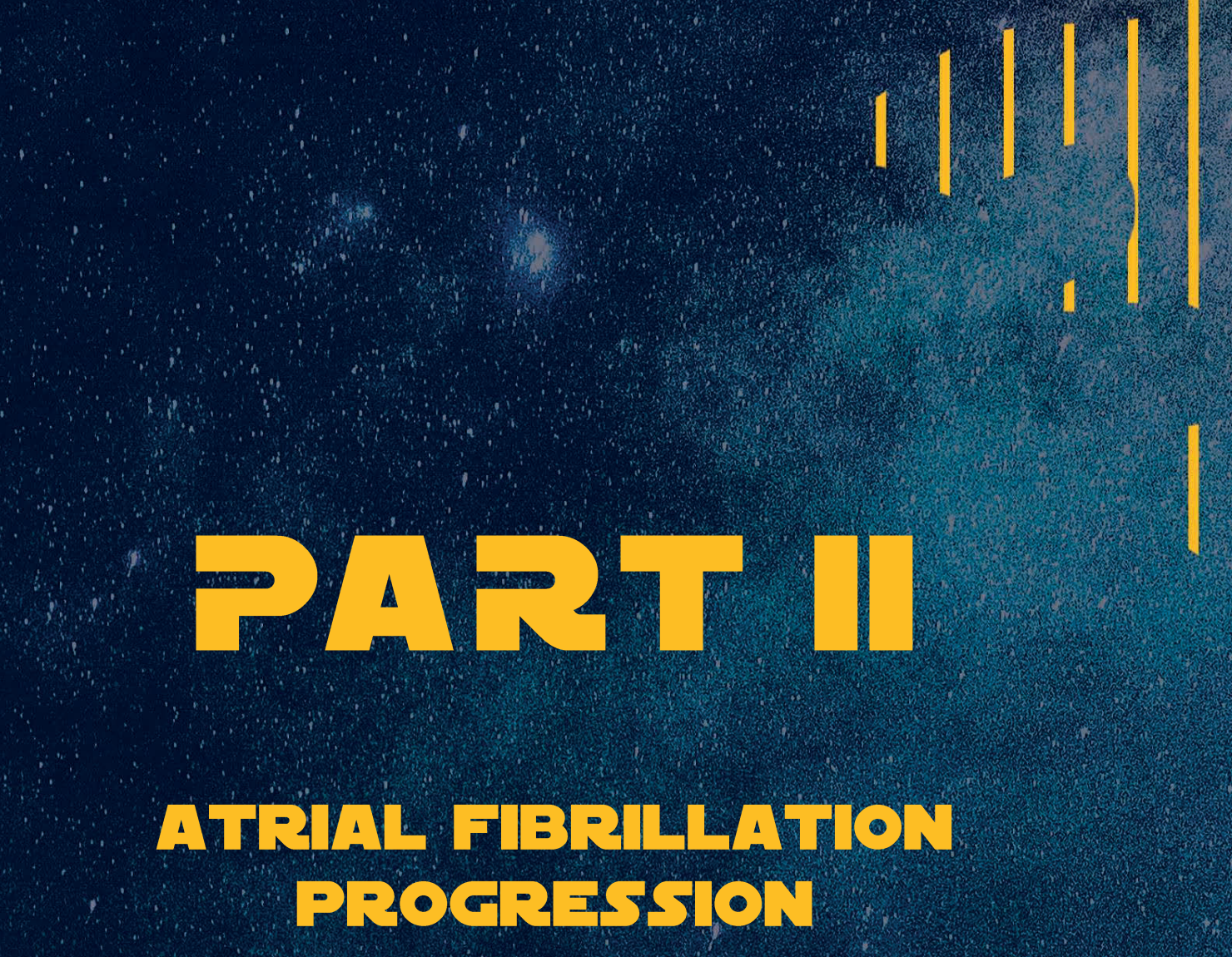

11

\section{ATRIAL FIBRILLATION}

2

1 


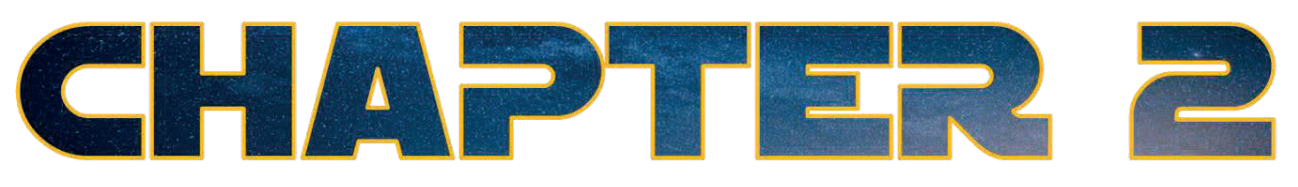

Effect of systemic hypertension with versus without left ventricular hypertrophy on the progression of atrial fibrillation (from the Euro Heart Survey)

Ömer Erküner, Elton Dudink, Robby Nieuwlaat, Michiel Rienstra, Isabelle van Gelder, John Camm, Alessandro Capucci, Günter Breithardt, Jean-Yves LeHeuzey,

Gregory Lip, Harry Crijns, Justin Luermans 


\section{ABSTRACT}

Hypertension is a risk factor for both progression of atrial fibrillation (AF) and development of AF-related complications, i.e. major adverse cardiac and cerebrovascular events (MACCE). It is unknown whether left ventricular hypertrophy $(\mathrm{LVH})$ as a consequence of hypertension is also a risk factor for both these endpoints. We aimed to assess this in low-risk AF patients, also assessing sex related differences. We included 799 patients from the Euro Heart Survey with non-valvular AF and a baseline echocardiogram. Patients with and without hypertension were included. Endpoints after 1 year were occurrence of AF progression, i.e. paroxysmal AF becoming persistent/permanent AF, and MACCE. Echocardiographic LVH was present in $33 \%$ of 379 hypertensive patients. AF progression after 1 year occurred in $10.2 \%$ of 373 patients with rhythm follow-up. In hypertensive patients with LVH, AF progression occurred more frequently as compared to hypertensive patients without LVH $(23.3 \%$ vs. $8.8 \%$, $\mathrm{p}=0.011$ ). Amongst hypertensive AF patients, LVH was the most important multi-variably adjusted determinant of AF progression on multivariable logistic regression (Odds Ratio 4.84, $95 \%$ Confidence Interval $1.70-13.78, p=0.003)$. This effect was only seen in male patients $(27.5 \%$ vs. $5.8 \%, p=0.002)$, while in female hypertensive patients, no differences were found in AF progression rates regarding the presence or absence of LVH (15.2\% vs. $15.0 \%$, $p=0.999$ ). No differences were seen in MACCE for hypertensive patients with and without LVH. In conclusion, in men with hypertension, LVH is associated with AF progression. This association seems to be absent in hypertensive women. 


\section{INTRODUCTION}

Atrial fibrillation (AF) is associated with several comorbidities, the most prevalent being hypertension, affecting $49 \%$ to $90 \%$ of AF patients.(1) Hypertension is a risk factor for both the development(2) and the progression of AF.(3, 4) Moreover, hypertension is a risk factor for the development of AF-related complications, e.g. major adverse cardiac and cerebrovascular events (MACCE).(5) Paroxysmal AF progresses to persistent or permanent AF in $8.6-22 \%$ of patients after 1 year, depending on the underlying comorbidities. $(6,7) \mathrm{AF}$ progression is not merely an arrhythmic phenomenon, but it is also associated with a higher rate of ischemic stroke, i.e. 2, 3, and $4 \%$ per year for paroxysmal, persistent and permanent AF, respectively.(8) Furthermore, AF progression has been associated with hospitalization and all-cause mortality in a primary care study.(9) Even though the relationship of hypertension with AF progression and MACCE is clearly established, it is unknown whether hypertensive end organ damage, i.e. left ventricular hypertrophy (LVH), is also associated with these endpoints and whether this differs across sex. We hypothesized that patients with $\mathrm{LVH}$ as a result of hypertension show more AF progression and subsequent occurrence of MACCE compared to hypertensive AF patients without LVH and non-hypertensive patients. Furthermore, we aimed to investigate whether this differs across sex.

\section{METHODS}

A detailed description of the methods and results of the Euro Heart Survey (EHS) on AF has previously been published. $(10,11)$ In summary, the EHS is a prospective registry conducted between 2003 and 2005 in 182 hospitals across 35 member countries of the European Society of Cardiology. All centers obtained approval from their Institutional Committee on Human Research. Consecutive in- and outpatients with (Holter) electrocardiogram proven AF were included after providing written informed consent. One-year follow-up was completed in 3,978 of the included 5,333 patients.

We included 799 patients from the EHS with non-valvular, paroxysmal AF and a baseline echocardiogram. Patients with and without hypertension were selected. Since we aimed to assess the relationship of hypertension and LVH with the endpoints of AF progression and MACCE, we tried to diminish the influence of other factors related to these endpoints as much as possible. This was done by excluding patients with other stroke risk factors, i.e. congestive heart failure, age $\geq 65$ years, diabetes mellitus, previous stroke/transient ischemic attack, and vascular disease. 
The occurrence of AF progression and MACCE after 1 year were assessed separately for the groups with and without hypertension, subdivided by the presence of echocardiographic LVH. Sex differences were also evaluated. Hypertension was defined as the presence of resting systolic blood pressure (BP) of $>140 \mathrm{mmHg}$ or diastolic $\mathrm{BP}$ of $>90 \mathrm{mmHg}$ on $\geq 2$ occasions or current antihypertensive drug treatment. The presence or absence of echocardiographic LVH was assessed by the treating physician. AF progression was defined as paroxysmal AF at baseline becoming persistent or permanent AF after 1-year of follow-up, like previously defined by de Vos et al.(4) and MACCE was defined as cardiovascular death, stroke, transient ischemic attack, systemic thromboembolism, myocardial infarction, or major bleeding (hemorrhagic stroke or bleeding requiring hospitalization, causing a hemoglobin level drop of $2 \mathrm{~g} / \mathrm{l}$ or requiring blood transfusion). Patients with missing data were excluded and a complete-case analysis was performed.

Data were analyzed with SPSS statistical software (version 22.0, SPSS Inc., Chicago, IL, USA). Continuous variables are reported as mean \pm standard deviation if normally distributed and as median and inter quartile range if not. Normally distributed continuous variables were compared between groups using the independent samples t-test, whereas not normally distributed continuous variables were compared using the Mann-Whitney $U$ test. Categorical variables are reported as observed number of patients and percentage. Among-group comparisons were made using a $X^{2}$ test. Fisher's exact test was used in case of any expected cell count $<5$. All baseline characteristics with a significant univariate association $(p<0.10)$ with one of the endpoints were incorporated into a multivariable logistic regression model with stepwise reduction of the model by excluding variables with $p>0.10$. All variables in the final model were tested for interactions. Remaining variables with $p<0.05$ were considered significant independent determinants for the endpoints of AF progression and the occurrence of MACCE.

\section{RESULTS}

Of the 799 included patients, rhythm follow-up was available in $47 \%$ and information on the occurrence of MACCE in $76 \%$. The majority of the patients was male $(73 \%)$, mean age was $52 \pm 10$ years. AF progression occurred in $38(10.2 \%)$ of 373 patients, whereas MACCE occurred in 21 (3.4\%) of 610 patients. Hypertension was present in $47 \%$. In general, hypertensive AF patients showed more AF progression $(14.2 \%$ vs. $7.1 \%, p=0.025)$ as well as MACCE $(5.3 \%$ vs. $1.8 \%, p=0.018)$, compared to the normotensives (Figure 1$)$. 
LVH was present in 124 (33\%) of 379 hypertensive patients and in 51 (12\%) of 420 normotensive AF patients. The baseline characteristics of the included patients, subdivided by the presence of hypertension and LVH, are presented in Table 1, together with the occurrence of the endpoints for all groups. In patients without hypertension, no differences in AF progression nor in the development of MACCE could be ascertained when comparing patients with LVH to those without (Figure 2).

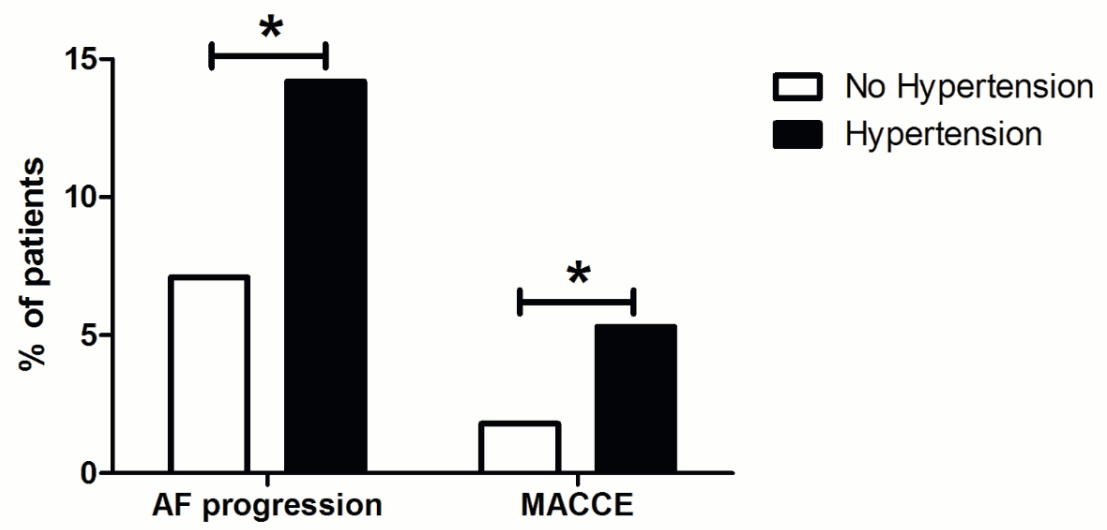

Figure 1. Differences in AF progression and MACCE rates after 1 year of follow-up for patients with and without hypertension. $A F=a t r i a l$ fibrillation; MACCE=major adverse cardiac and cerebrovascular events. ${ }^{*}=$ statistical significance.

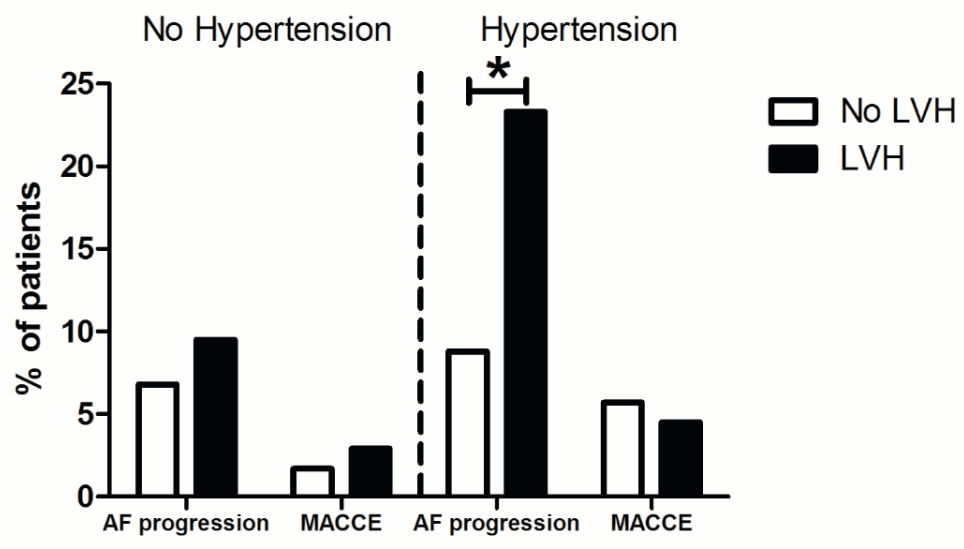

Figure 2. Differences in AF progression and MACCE rates after 1 year for patients with and without hypertension, subdivided by presence of $\mathrm{LVH}$. AF=atrial fibrillation; $\mathrm{LVH}=\mathrm{left}$ ventricular hypertrophy; MACCE=major adverse cardiac and cerebrovascular events. ${ }^{*}=$ statistical significance. 


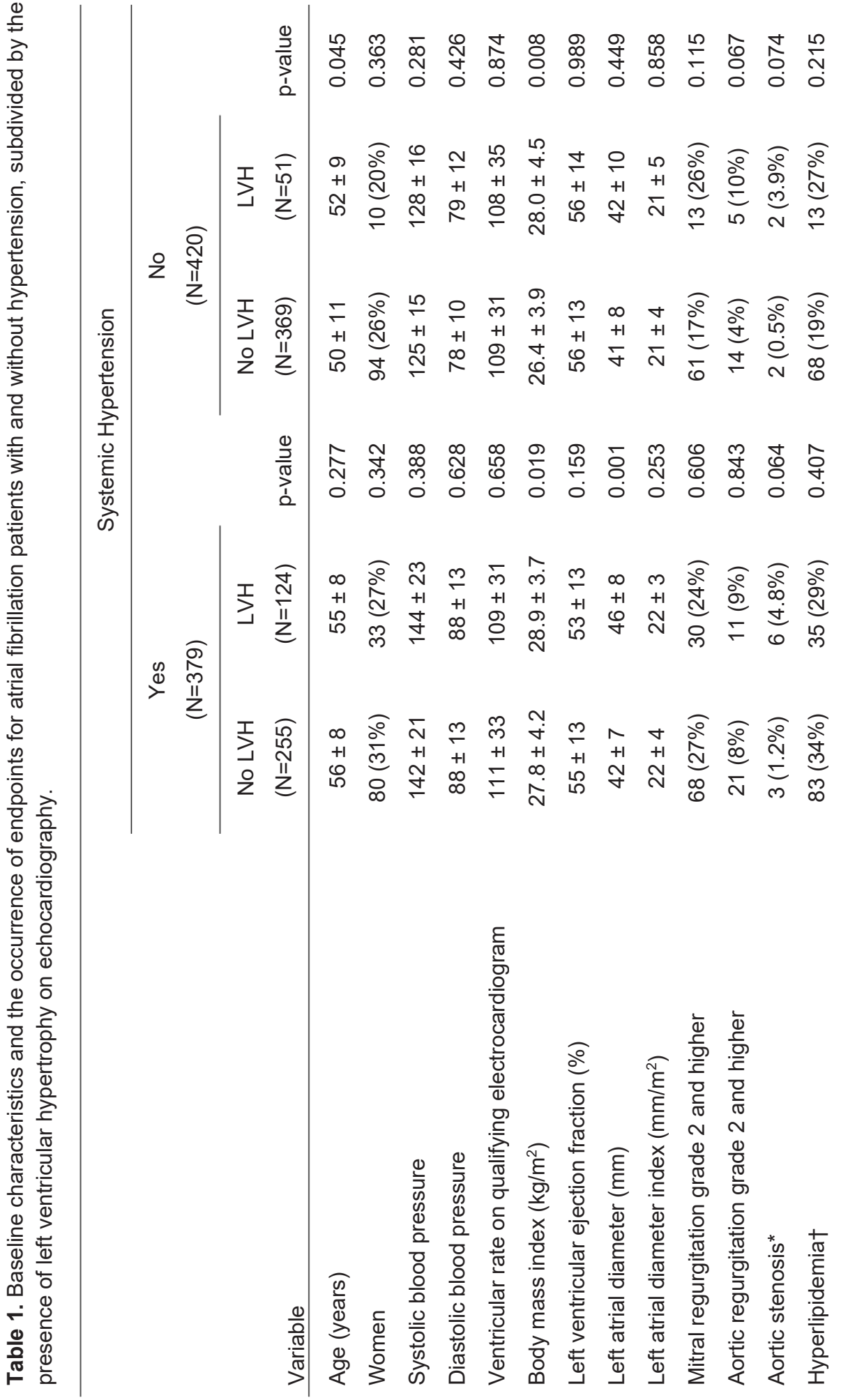




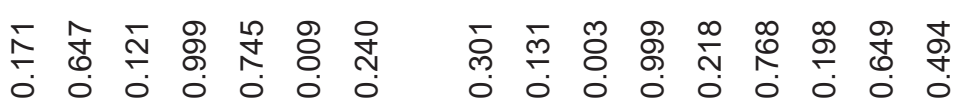

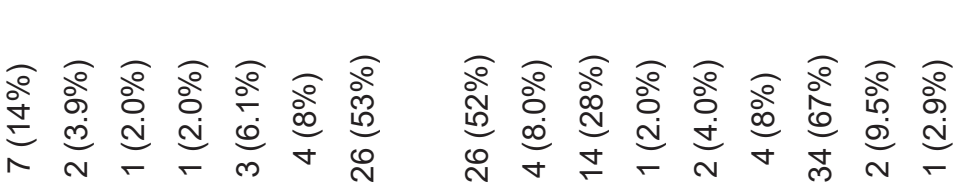

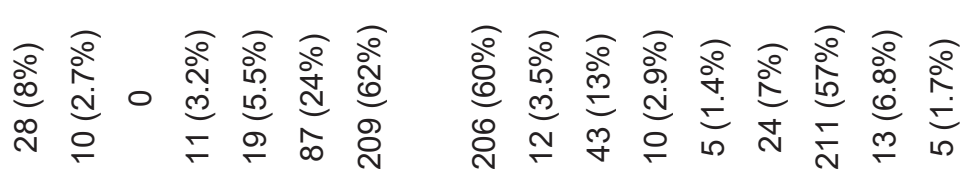

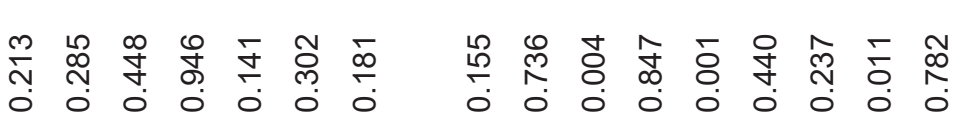

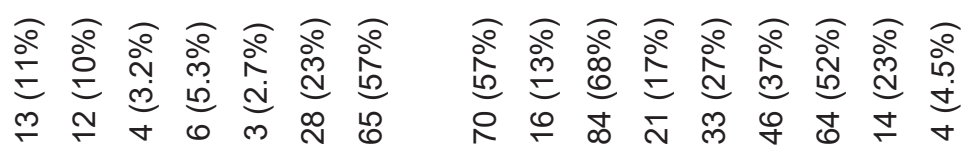

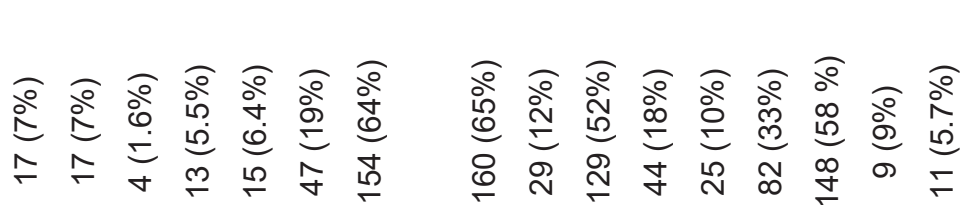
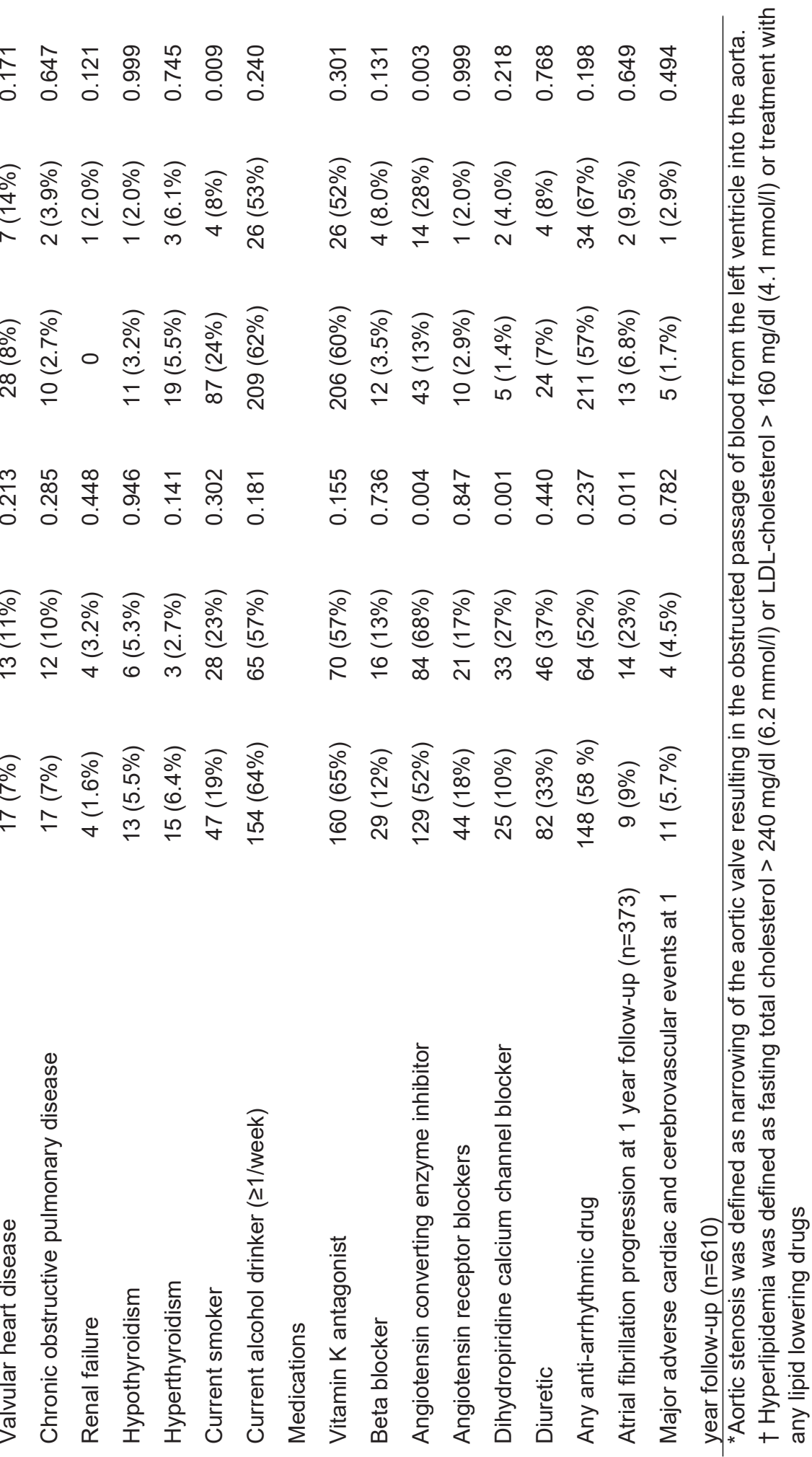
Hypertensive patients with echocardiographic LVH at baseline (124 of 379) had on average a higher body mass index and were more frequently on calcium channel blockers and angiotensin converting enzyme inhibitors, compared to hypertensive patients without LVH (Table 1). AF progression at 1 year was significantly more prevalent in patients with LVH (23.3\% vs. $8.8 \%, p=0.011)$, whereas no differences were found in the development of MACCE (4.5\% vs. $5.7 \%, p=0.782$; Figure 2$)$.

Several determinants of AF progression were identified using multivariable analysis in the patients with hypertension, the most important being LVH on echocardiography (Table 2). Other independent determinants of AF progression were the use of vitamin $\mathrm{K}$ antagonists, age, and diastolic blood pressure. No interactions were present. In hypertensive men, AF progression rates were $27.5 \%$ and $5.8 \%$ per year in those with and without LVH, respectively, similar to the rates seen in the studied overall cohort. In hypertensive women however, AF progression rates in patients with and without LVH did not differ, i.e. $15.2 \%$ vs. $15.0 \%, p=0.999$ (Figure 3). Development of MACCE after 1 year did not differ between men with $\mathrm{LVH}$ vs. without $(3.2 \%$ vs. $6.1 \%, \mathrm{p}=0.507)$, nor in women $(7.4 \%$ vs. $5.0 \%, p=0.644)$.

Table 2. Univariable and multivariable regression for progression of atrial fibrillation in hypertensive patients.

\begin{tabular}{lcccc}
\hline & \multicolumn{2}{c}{ Univariable regression } & \multicolumn{2}{c}{ Multivariable regression } \\
\cline { 2 - 5 } Variable & Odds ratio $(95 \% \mathrm{Cl})$ & p-value & Odds ratio $(95 \% \mathrm{Cl})$ & $\mathrm{p}$-value \\
\hline Left ventricular hypertrophy & $3.15(1.27-7.80)$ & 0.013 & $4.84(1.70-13.78)$ & 0.003 \\
Vitamin K antagonist & $2.71(1.04-7.08)$ & 0.041 & $3.72(1.28-10.83)$ & 0.016 \\
Age & $1.11(1.02-1.20)$ & 0.016 & $1.13(1.04-1.24)$ & 0.007 \\
Diastolic blood pressure, & $0.96(0.93-1.00)$ & 0.058 & $0.95(0.91-0.99)$ & 0.017 \\
per mmHg increase & & & & \\
Left atrial diameter, & $1.12(0.99-1.27)$ & 0.076 & & \\
corrected for body surface area & & & & \\
\hline
\end{tabular}

In male patients with hypertension, the only independent determinant of AF progression was LVH (OR 6.16, 95\% Cl 1.81-20.99, p=0.004). For female patients, independent determinants were age (OR 1.28 for increments of 1 year, 95\% Cl 1.02-1.61, $p=0.036)$, and diastolic BP (OR 0.93 for increments of $1 \mathrm{mmHg}, 95 \% \mathrm{Cl} 0.87-0.99, \mathrm{p}=0.029$ ). In both hypertensive men and women, the use of VKA was not a determinant for AF progression, in contrast to the overall population. The difference between men and women who were prescribed vitamin $\mathrm{K}$ antagonists was statistically significant in the hypertensive patients $(66 \%$ vs. $53 \%, p=0.017)$, but not in the normotensives ( $61 \%$ vs. $53 \%, p=0.178)$. 


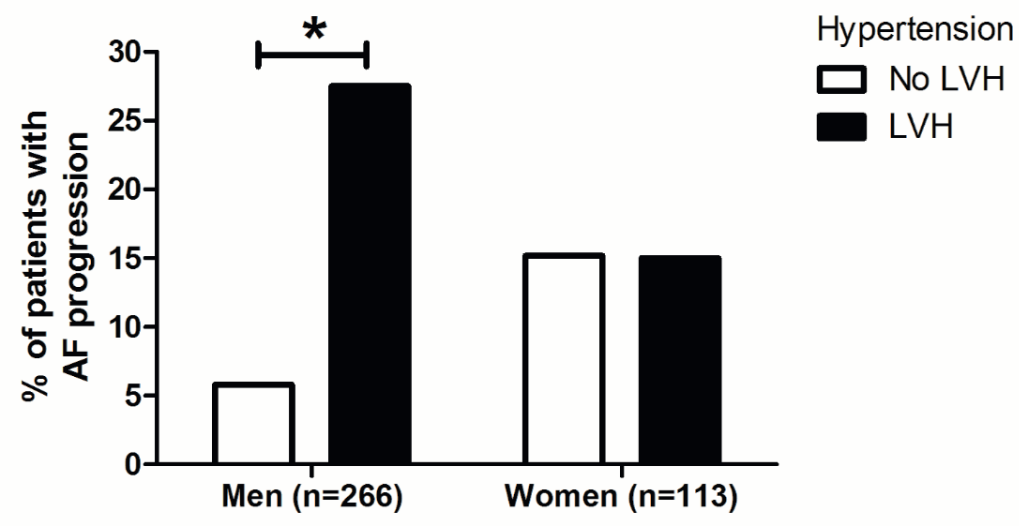

Figure 3. AF progression rates after 1 year of male and female hypertensive AF patients in absence and presence of $\mathrm{LVH}$. AF=atrial fibrillation; $\mathrm{LVH}=$ left ventricular hypertrophy. ${ }^{*}=$ statistical significance.

\section{DISCUSSION}

Almost half of the patients in our cohort had a history of hypertension. These patients showed more often AF progression and MACCE after 1 year compared to patients without hypertension (Figure 1), in accordance with previous data. $(3,5,12) \mathrm{LVH}$ at baseline was present in a third of the patients with hypertension. As hypothesized, a significantly larger proportion of these patients showed AF progression after 1 year when compared to hypertensive patients without LVH on echocardiographic assessment (Figure 2). Recently, Padfield et al. have also shown that LVH is one of the determinants of AF progression after a median follow-up of 6 years.(13) Moreover, the higher progression rate seen in patients with hypertension, could be mainly driven by $L V H$, since AF progression rates in hypertensive patients without LVH and non-hypertensive patients were comparable (Figure 2). Even after correcting for other factors, LVH remained the most important independent determinant of AF progression in the hypertensive group. Thus, LVH seems to be a key marker for AF progression in hypertensive patients with low-risk AF. However, a difference in the occurrence of MACCE could not be ascertained in these patients, possibly due to the overall Iow MACCE-rate in this relatively low-risk AF population and follow-up duration of 1 year. In addition, $60 \%$ of the patients were on vitamin $\mathrm{K}$ antagonists, probably reducing MACCE rates.(14)

It is unknown whether this effect of LVH on AF progression is reversible. Hennersdorf et al.(15) have shown that the prevalence of paroxysmal AF can be diminished in patients with 
regression of LVH by treating hypertension, compared to patients with a progression in LVH despite treatment. In that post-hoc analysis, 24-hour Holter electrocardiograms were performed at baseline and after a mean of 2 years of antihypertensive treatment. The short time-span covered by these Holter electrocardiograms and the absence of a predefined scheme for rhythm follow-up, makes cautious interpretation of these data necessary. However, a similar reduction in AF progression rates could possibly be achieved by adequate treatment of hypertension leading to regression of LVH. Of course, this should be studied in a prospective and randomized manner in order to draw definite conclusions.

Other independent determinants of AF progression in hypertensive AF patients were use of vitamin $\mathrm{K}$ antagonists, age, and diastolic BP. Age is a known risk factor for AF progression and is incorporated in the $\mathrm{HATCH}$-score (Heart failure, Age, previous Transient ischemic attack or stroke, Chronic obstructive pulmonary disease, and Hypertension).(3,4) The use of VKA however is not a known risk factor for AF progression and the effect we observed may be due to confounding. Since stroke risk scores were not in use during the conduct of this registry, the decision to start antithrombotic therapy was made at the discretion of the treating physician. It is possible that this decision was based on clinical parameters, e.g. left atrial diameter, left atrial volume, and general health of the patient. An alternative explanation may be that VKA are known to cause vascular calcification in animal models.(16) Since coronary artery calcification in humans is associated with an increased risk of the development of AF, this process may also be associated with AF progression.(17)

The last independent determinant was diastolic BP. This effect has not been reported in literature before. Although it may be a chance finding, the protective effect of diastolic BP might in part be explained by the relatively higher pulse pressure in patients with a lower diastolic BP. Since a higher pulse pressure is indicative of stiffness of the aorta or major arteries and is related to vascular disease, it might play a role in the progression of AF. Pulse pressure is a known risk factor for new-onset AF, whereas in the same study mean arterial pressure was not related to incident AF.(18) Furthermore, pulse pressure, and not mean arterial pressure, was proven to be related to cardiovascular events in older hypertensive patients.(19) However, pulse pressure was not a significant determinant in our analysis.

In patients without hypertension, LVH was present in a smaller proportion and was not associated with AF progression and MACCE (Figure 2). These patients can be seen as truly low-risk AF, with an overall AF progression rate of $7.1 \%$ and a MACCE rate of $1.8 \%$ per year, both representing a fairly low risk. However, this could be partially caused by the small group of patients with LVH in the non-hypertensive patients. Perhaps in a larger population, LVH 
might lead to a higher AF progression rate via diastolic dysfunction and an increase in left atrial diameter, even in patients without hypertension.

With respect to progression of $\mathrm{AF}$ in male and female patients with hypertension, distinct differences were ascertained regarding the effect of LVH (Figure 3). For male patients with hypertension, the AF progression rates different significantly for those with and without LVH, with LVH being the only independent determinant of AF progression. However, in female patients, the progression rates in patients with and without LVH were similar. So the difference in AF progression seen in the overall group with hypertension is only attributable to the male patients, whereas LVH does not seem to play a role in the progression of AF in female hypertensive patients.

The dissimilar effect of LVH on AF progression in men and women could possibly be explained by the type of LVH. A cardiovascular magnetic resonance imaging study in 741 patients by Rider et al. has shown that male patients predominantly show concentric LVH, whereas female patients show both concentric and eccentric LVH.(20) In another study of 64 middle-aged women with at least 10 years of treated hypertension, eccentric hypertrophy was more prevalent than concentric hypertrophy on echocardiography $(42 \%$ vs. $5 \%$, p<0.001, mean age 54 years).(21) In a post-hoc analysis of the AFFIRM (Atrial Fibrillation Follow-up Investigation of Rhythm Management) trial, concentric LVH was found to be associated with AF recurrences in the rhythm control arm, whereas eccentric LVH was not associated with recurrences.(22) This could be a consequence of diastolic dysfunction in concentric LVH, leading to elevation of filling pressures and left atrial dilatation. It has been shown that concentric LVH has a more profound negative effect on left atrial function and association with LA enlargement compared to eccentric $L V H,(23)$ which could explain the effect seen on AF recurrences in the AFFIRM trial. One could argue that concentric LVH might therefore also be associated with AF progression, explaining the dissimilar effect of LVH on AF progression rates between sexes in our population. Unfortunately, we were not able to assess the type of LVH in our population.

For female patients with hypertension, diastolic BP had a protective effect on AF progression. No prior studies have elaborated on this finding. However, Conen et al.(24) report a higher incidence of new-onset AF in middle-aged women with a diastolic $\mathrm{BP}<65$ $\mathrm{mmHg}$ and suggest a U-shaped association of diastolic BP and new-onset AF. Unfortunately, no male control group was present in this study.(24) It is possible that a low diastolic BP could also be associated with AF progression, like explained above. In conclusion, more research is needed regarding sex differences in $\mathrm{LVH}$ and the progression of AF. 
There are some limitations to the present study. Firstly, we performed a post-hoc subgroup analysis of the EHS. Therefore, the data presented in this article should be interpreted with care. This study was conducted in 2003-2004, yet the described outcomes are still relevant. Rhythm follow-up was performed in $47 \%$ of the included patients and the duration of followup was 1 year, limiting the number of AF progression events. In addition, LVH was a dichotomous parameter in the EHS, i.e. type of LVH was unknown and wall thicknesses were not reported in $\mathrm{mm}$. Furthermore, some patients in the non-hypertensive group used medication like an angiotensin converting enzyme inhibitor, angiotensin receptor blocker, dihydropyridine calcium channel blocker or a diuretic. We were not able to assess whether these drugs were prescribed for hypertension or for another indication. Since in these patients hypertension was not checked as concomitant condition at time of conduct of the registry, they were classified as non-hypertensive in the present study. Lastly, women were underrepresented in this study.

In conclusion, in men with hypertension, LVH is associated with AF progression. This association seems to be absent in hypertensive women. 


\section{REFERENCES}

1. Manolis AJ, Rosei EA, Coca A, Cifkova R, Erdine SE, Kjeldsen S, et al. Hypertension and atrial fibrillation: diagnostic approach, prevention and treatment. Position paper of the Working Group 'Hypertension Arrhythmias and Thrombosis' of the European Society of Hypertension. J Hypertens. 2012;30(2):239-52.

2. Benjamin EJ, Levy D, Vaziri SM, D'Agostino RB, Belanger AJ, Wolf PA. Independent risk factors for atrial fibrillation in a population-based cohort. The Framingham Heart Study. JAMA. 1994;271(11):840-4.

3. De Vos CB, Breithardt G, Camm AJ, Dorian P, Kowey PR, Le Heuzey JY, et al. Progression of atrial fibrillation in the REgistry on Cardiac rhythm disORDers assessing the control of Atrial Fibrillation cohort: clinical correlates and the effect of rhythm-control therapy. Am Heart J. 2012;163(5):887-93.

4. de Vos CB, Pisters R, Nieuwlaat R, Prins MH, Tieleman RG, Coelen RJ, et al. Progression from paroxysmal to persistent atrial fibrillation clinical correlates and prognosis. J Am Coll Cardiol. 2010;55(8):725-31.

5. Lip GY, Nieuwlaat R, Pisters R, Lane DA, Crijns HJ. Refining clinical risk stratification for predicting stroke and thromboembolism in atrial fibrillation using a novel risk factorbased approach: the euro heart survey on atrial fibrillation. Chest. 2010;137(2):263-72.

6. Gianfranchi L, Brignole M, Menozzi C, Lolli G, Bottoni N. Determinants of development of permanent atrial fibrillation and its treatment. Europace. 1999;1(1):35-9.

7. Kerr CR, Humphries KH, Talajic M, Klein GJ, Connolly SJ, Green M, et al. Progression to chronic atrial fibrillation after the initial diagnosis of paroxysmal atrial fibrillation: results from the Canadian Registry of Atrial Fibrillation. Am Heart J. 2005;149(3):489-96.

8. Vanassche T, Lauw MN, Eikelboom JW, Healey JS, Hart RG, Alings M, et al. Risk of ischaemic stroke according to pattern of atrial fibrillation: analysis of 6563 aspirin-treated patients in ACTIVE-A and AVERROES. Eur Heart J. 2015;36(5):281-7a.

9. Vidal-Perez R, Otero-Ravina F, Lado-Lopez M, Turrado-Turrado V, Rodriguez-Moldes E, Gomez-Vazquez JL, et al. The change in the atrial fibrillation type as a prognosis marker in a community study: long-term data from AFBAR (Atrial Fibrillation in the BARbanza) study. Int J Cardiol. 2013;168(3):2146-52.

10. Nieuwlaat R, Capucci A, Camm AJ, Olsson SB, Andresen D, Davies DW, et al. Atrial fibrillation management: a prospective survey in ESC member countries: the Euro Heart Survey on Atrial Fibrillation. Eur Heart J. 2005;26(22):2422-34.

11. Nieuwlaat R, Prins MH, Le Heuzey JY, Vardas PE, Aliot E, Santini M, et al. Prognosis, disease progression, and treatment of atrial fibrillation patients during 1 year: follow-up of the Euro Heart Survey on atrial fibrillation. Eur Heart J. 2008;29(9):1181-9.

12. Olesen JB, Lip GY, Hansen ML, Hansen PR, Tolstrup JS, Lindhardsen J, et al. Validation of risk stratification schemes for predicting stroke and thromboembolism in patients with atrial fibrillation: nationwide cohort study. BMJ. 2011;342:d124.

13. Padfield GJ, Steinberg C, Swampillai J, Qian H, Connolly SJ, Dorian P, et al. Progression of paroxysmal to persistent atrial fibrillation: 10-year follow-up in the Canadian Registry of Atrial Fibrillation. Heart Rhythm. 2017;14(6):801-7. 
14. Hart RG, Pearce LA, Aguilar MI. Meta-analysis: antithrombotic therapy to prevent stroke in patients who have nonvalvular atrial fibrillation. Ann Intern Med. 2007;146(12):857-67.

15. Hennersdorf MG, Schueller PO, Steiner S, Strauer BE. Prevalence of paroxysmal atrial fibrillation depending on the regression of left ventricular hypertrophy in arterial hypertension. Hypertens Res. 2007;30(6):535-40.

16. Schurgers LJ, Spronk HM. Differential cellular effects of old and new oral anticoagulants: consequences to the genesis and progression of atherosclerosis. Thromb Haemost. 2014;112(5):909-17.

17. O'Neal WT, Efird JT, Dawood FZ, Yeboah J, Alonso A, Heckbert SR, et al. Coronary artery calcium and risk of atrial fibrillation (from the multi-ethnic study of atherosclerosis). Am J Cardiol. 2014;114(11):1707-12.

18. Mitchell GF, Vasan RS, Keyes MJ, Parise H, Wang TJ, Larson MG, et al. Pulse pressure and risk of new-onset atrial fibrillation. JAMA. 2007;297(7):709-15.

19. Blacher J, Staessen JA, Girerd X, Gasowski J, Thijs L, Liu L, et al. Pulse pressure not mean pressure determines cardiovascular risk in older hypertensive patients. Arch Intern Med. 2000;160(8):1085-9.

20. Rider OJ, Lewandowski A, Nethononda R, Petersen SE, Francis JM, Pitcher A, et al. Gender-specific differences in left ventricular remodelling in obesity: insights from cardiovascular magnetic resonance imaging. Eur Heart J. 2013;34(4):292-9.

21. Paunovic K, Jakovljevic B, Stojanov V. Left ventricular hypertrophy in hypertensive obese women. Acta Cardiol. 2006;61(6):623-9.

22. Shah N, Badheka AO, Grover PM, Patel NJ, Chothani A, Mehta K, et al. Influence of left ventricular remodeling on atrial fibrillation recurrence and cardiovascular hospitalizations in patients undergoing rhythm-control therapy. Int J Cardiol. 2014;174(2):288-92.

23. Tadic M, Cuspidi C, Pencic B, Kocijancic V, Celic V. The influence of left ventricular geometry on left atrial phasic function in hypertensive patients. Blood Press. 2015;24(6):361-8.

24. Conen D, Tedrow UB, Koplan BA, Glynn RJ, Buring JE, Albert CM. Influence of systolic and diastolic blood pressure on the risk of incident atrial fibrillation in women. Circulation. 2009;119(16):2146-52. 


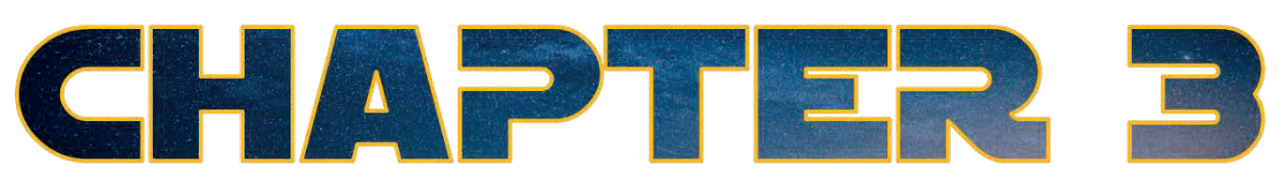

The influence of progression of atrial fibrillation on quality of life: a report from the Euro Heart Survey

Elton Dudink, Ömer Erküner, Jenny Berg, Robby Nieuwlaat, Cees de Vos,

Bob Weijs, Alessandro Capucci, John Camm, Günter Breithardt, Jean-Yves Le Heuzey, Justin Luermans, Harry Crijns 


\section{ABSTRACT}

\section{Background}

Progression of atrial fibrillation (AF) from paroxysmal to persistent forms is an active field of research. The influence of AF progression on health related quality of life (HRQOL) is currently unknown. We aimed to assess the influence of AF progression on HRQoL, and whether this association is mediated through symptoms, treatment and major adverse events.

\section{Methods}

In the Euro Heart Survey, 967 patients were included with paroxysmal AF who filled out EuroQoL-5D at baseline and at 1 year follow-up.

\section{Results}

Those who progressed $(n=132,13.6 \%)$ developed more problems during follow-up than those who did not, on all EuroQoL-5D domains (increase in problems on Mobility $20.5 \%$ vs. $11.4 \%$; Self-care $12.9 \%$ vs. $6.2 \%$; Usual activities $23.5 \%$ vs. $14.0 \%$; Pain / discomfort $20.5 \%$ vs. $13.7 \%$; and Anxiety / depression $22.7 \%$ vs. $15.7 \%$; all $p<0.05$ ), leading to a decrease in utility (baseline 0.744 \pm 0.26 , follow-up 0.674 \pm 0.36 ; difference -0.07 (95\% Cl [-0.126,-0.013], $p=0.02$ ). Multivariate analysis showed that the effect of progression on utility is mediated by a large effect of adverse events (stroke $(-0.27(95 \% \mathrm{Cl}[-0.43,-0.11]) ; p=0.001)$, heart failure ($0.12(95 \% \mathrm{Cl}[-0.20,-0.05]) ; p=0.001)$, malignancy $(-0.31(95 \% \mathrm{Cl}[-0.56,-0.05]) ; p=0.02)$ or implantation of an implantable cardiac defibrillator $(-0.12(95 \% \mathrm{Cl}[-0.23,-0.02]) ; p=0.03))$, as well as symptomatic AF $(-0.04(95 \% \mathrm{Cl}[-0.08,-0.01]) ; \mathrm{p}=0.008)$.

\section{Conclusions}

AF progression is associated with a decrease in HRQoL. However, multivariate analysis revealed that $A F$ progression itself does not have a negative effect on HRQoL, but that this effect can be attributed to a minor effect of the associated symptoms and a major effect of associated adverse events. 


\section{INTRODUCTION}

Atrial fibrillation (AF), the most common cardiac arrhythmia, has been demonstrated to lead to a considerable reduction in health-related quality of life (HRQoL).(1) While rarely lifethreatening in itself, AF is associated with several arrhythmia-associated symptoms, such as palpitations, exercise intolerance, dizziness and dyspnea, which can have substantial influence on the possibility to undertake daily activities.(2) In addition, AF is associated with an increased incidence of major adverse events, such as stroke and heart failure, which are associated with increased mortality, but also have detrimental effects on daily functioning and HRQoL.(3) The consequences of AF treatment, such as side effects of drugs, interventions, and especially hospitalization, may also have a negative impact on HRQoL. Lastly, the diagnosis of AF may be associated with considerable psychological distress.

AF is a progressive disease that clinically may progress from short-lasting self-terminating paroxysms towards more non-self-terminating sustained forms, such as persistent and permanent AF.(4) This progression is usually accompanied by electrical and structural changes of the left atrium.(5) Recent reports suggest that predictors of AF progression lie in factors that represent an impaired vascular status, leading to the observation that patients who progress from paroxysmal to more sustained forms of AF are those who will have adverse events.(6) As AF progression appears to correlate with adverse events, one may hypothesize that AF progression has a detrimental effect on HRQoL.

Current treatment of AF has HRQoL as a major focus, and aims to preserve or improve HRQoL by two strategies(4): on one hand, to prevent serious adverse events through life style changes, anticoagulation upon indication and adequate vascular protective therapy, and on the other hand to alleviate symptoms associated with AF if necessary. In addition to this, prevention of AF progression has recently been proposed as a treatment goal in itself.(7) The influence of AF progression on HRQoL, and whether this is mediated by adverse events and symptoms, is however currently unknown.

In this report, we used the data from the Euro Heart Survey (EHS) on Atrial Fibrillation to assess the influence of AF progression on HRQoL, and whether this association is mediated through symptoms or concomitant vascular disease and major cardiac events.

\section{METHODS}

A description of the methods and data collection of the EHS on AF has been given in detail earlier.(8) In 2003 and 2004, 5,333 consecutive patients with AF on an ECG or Holter 
recording in the previous 12 months were included in the Euro Heart Survey, a large-scale registry, at cardiology departments of 182 hospitals in 35 countries. The study protocol was submitted to the institutional review board or ethical committee of all participating centers and approved or waived for the requirement of formal approval being an observational survey.

Only patients with paroxysmal AF at baseline were included: patients with known paroxysmal AF (spontaneous conversion to sinus rhythm $<7$ days; 1,517 patients) and patients with first detected AF that converted to sinus rhythm spontaneously or through pharmacological cardioversion during the index visit (238 patients). Out of these, rhythm status at follow-up was available in 1,219 patients, and amongst these, complete EuroQoL-5D data at both baseline and follow-up was available for 967 patients. The definition of AF-progression by de Vos et al(6) was used: paroxysmal AF at baseline becoming persistent or permanent AF at 1-year follow-up, or first detected AF at baseline with spontaneous or pharmacological cardioversion to sinus rhythm during admission becoming persistent or permanent AF at 1year follow-up.

\section{Quality of life measurements}

The EuroQol-5D consists of five domains (mobility, self-care, usual activities, pain / discomfort, and anxiety / depression) with three possible answers for each domain (no problems, moderate problems, or severe problems), generating $3^{5}=243$ possible health states. These health states, at baseline and follow-up, were translated into a single index the utility score- using the United Kingdom time trade-off value set.(9) No problems on each of the EuroQol-5D domains corresponds to a utility of 1.0 (best possible health), with deductions for reporting problems on any of the EuroQol-5D. A utility score of 0 is equivalent to death, while negative values are possible (indicating a health status worse than death).

\section{Statistical analysis}

Data analysis was performed with IBM SPSS for Windows statistical software (version 23.0, IBM Corp., Armonk, NY, USA) and regression analysis using Stata Statistical Software Release 10.0 (StataCorp LP, College Station, TX, USA). Baseline characteristics for the groups with and without AF progression are presented as mean \pm SD for continuous variables, or number (percentage) for categorical variables. Baseline characteristics of the groups were compared using an independent $t$-test for continuous variables and a $x^{2}$-test for categorical variables. Increase in problems experienced at each of the EuroQoL-5D domains was defined as 'no problems' at baseline and 'some problems' or 'severe problems' at 1-year follow-up, or 'some problems' at baseline and 'severe problems' at follow-up. The fractions 
showing an increase were compared for the group with and without AF progression using $\mathrm{X}^{2}-$ tests. Utility scores at baseline and follow-up were compared using paired-samples $t$-testing.

\section{Regression analyses}

Apart from AF progression, the following parameters were tested for a significant relation with the change in utility over 1 year $(p<0.1)$ in univariate ordinary least squares regression using robust standard errors: age at inclusion, sex, domestic status, body mass index, level of physical activity, medical history (hypertension, diabetes, coronary artery disease, myocardial infarction, valvular heart disease, congestive heart failure, hyperthyroidism or hypothyroidism, chronic obstructive pulmonary disease, malignancy, peripheral vascular disease, renal failure, transient ischemic attack (TIA), stroke), AF symptoms (palpitations, chest pain, dyspnea, syncope, dizziness, fatigue), events during follow-up (stable angina, acute coronary syndrome, TIA, ischemic or hemorrhagic stroke, peripheral embolism, pulmonary embolism, syncope, asystole, malignancy, heart failure), AF related parameters (AF recurrence, number of pharmacological cardioversions, number of electrical cardioversions, use of beta-blockers, calcium channel blocker, anti-arrhythmic drugs (Vaughan-Williams class 1a, 1c, 3)) and cardiac treatment during follow-up (catheter ablation, AF surgery, pacemaker or ICD implantation, percutaneous coronary intervention, coronary artery bypass surgery, valvular surgery). All parameters that showed a significant relation were included in multivariate linear regression using robust standard errors. No significant correlations between predictors were found. Backward variable elimination $(p>0.05)$ was applied, not forcing any specific variable to be retained. All tests were performed 2 -sided. Overall, a $p$ value of $<0.05$ was considered statistically significant.

\section{RESULTS}

The baseline characteristics of the patients with complete EuroQoL-5D at baseline and follow-up ( $n=967$ ) were comparable to those with incomplete EuroQoL-5D ( $n=252)$, with only differences in regular physical activity $(36.8 \%$ vs. $27.6 \%$; $=0.008)$ and history of stroke (2.4\% vs. $6.5 \% ; p=0.001)$.

In the 967 patients included, progression of AF occurred in 132 patients (13.7\%). Baseline characteristics of patients with and without AF progression are shown in Table 1. Patients with AF progression were on average older (66.1 \pm 11.2 vs. $62.8 \pm 13.1$ years; $p=0.007)$ and had larger left atria (LA diameter $45.9 \pm 8.8$ vs. $42.9 \pm 7.6 \mathrm{~mm} ; \mathrm{p}<0.001)$. Hypertension $(71.2 \%$ vs. $59.8 \%)$, left ventricular hypertrophy $(50.4 \%$ vs. $29.8 \%)$ coronary artery disease $(36.0 \%$ vs. $23.2 \%)$, heart failure (31.5\% vs. $15.5 \%)$, chronic obstructive pulmonary disease $(18.3 \%$ 
vs. $9.6 \%)$ and history of TIA $(10.7 \%$ vs. $5.2 \%$; all $p<0.01)$ were more prevalent in the AF progression group, leading to a higher mean $\mathrm{CHA}_{2} \mathrm{DS}_{2} \mathrm{VASc}-\mathrm{score}$ of $3.2 \pm 1.9$ vs. $2.4 \pm 1.7$ $(p<0.01)$ and HATCH-score of $2.2 \pm 1.5$ vs. $1.3 \pm 1.3(p<0.01)$. Medication use, further medical history and event rates in both groups were reported previously. (6)

Table 1. Baseline characteristics, grouped by the presence of AF progression.

\begin{tabular}{|c|c|c|c|c|}
\hline & $\begin{array}{c}\text { All patients } \\
n=967\end{array}$ & $\begin{array}{c}\text { No AF progression } \\
n=835\end{array}$ & $\begin{array}{c}\text { AF Progression } \\
n=132\end{array}$ & $p$-value \\
\hline Age (years) & $63.3 \pm 12.9$ & $62.8 \pm 13.1$ & $66.1 \pm 11.2$ & 0.007 \\
\hline Female & $417(43.1)$ & $353(42.3)$ & $64(48.5)$ & 0.18 \\
\hline Body Mass Index $\left(\mathrm{kg} / \mathrm{m}^{2}\right)$ & $27.4 \pm 4.2$ & $27.4 \pm 4.1$ & $27.9 \pm 4.9$ & 0.18 \\
\hline Regular physical activity & $356(36.8)$ & $320(40.7)$ & $36(30.0)$ & 0.13 \\
\hline \multicolumn{5}{|l|}{ Echocardiogram } \\
\hline Left atrial diameter $(\mathrm{mm})$ & $43.3 \pm 7.8$ & $42.9 \pm 7.6$ & $45.9 \pm 8.8$ & $<0.001$ \\
\hline Left ventricular hypertrophy & $262(32.7)$ & $205(29.8)$ & $57(50.4)$ & $<0.001$ \\
\hline \multicolumn{5}{|l|}{ Type of AF } \\
\hline First detected & $149(15.3)$ & $127(15.1)$ & $22(16.7)$ & \multirow[t]{2}{*}{0.64} \\
\hline Paroxysmal & $825(84.7)$ & $715(84.9)$ & $110(83.3)$ & \\
\hline \multicolumn{5}{|l|}{ Underlying disease } \\
\hline Hypertension & $593(61.3)$ & $499(59.8)$ & $94(71.2)$ & 0.01 \\
\hline Coronary artery disease & $205(25.0)$ & $164(23.2)$ & $41(36.0)$ & 0.003 \\
\hline Diabetes mellitus & $127(13.1)$ & $102(12.2)$ & $25(18.9)$ & 0.06 \\
\hline Valvular disease & $180(18.8)$ & $149(18.0)$ & $31(24.2)$ & 0.09 \\
\hline Heart failure & $169(17.7)$ & $128(15.5)$ & $41(31.5)$ & $<0.001$ \\
\hline COPD & $103(10.8)$ & $79(9.6)$ & $24(18.3)$ & 0.003 \\
\hline Hyperthyroidism & $50(5.4)$ & $42(5.3)$ & $8(6.2)$ & 0.67 \\
\hline History of stroke & $23(2.4)$ & $17(2.1)$ & $6(4.6)$ & 0.08 \\
\hline History of TIA & $57(5.9)$ & $43(5.2)$ & $14(10.7)$ & 0.01 \\
\hline Malignancy & $41(4.4)$ & $38(4.7)$ & $3(2.4)$ & 0.24 \\
\hline Peripheral vascular disease & $57(6.0)$ & $46(5.6)$ & $11(8.5)$ & 0.19 \\
\hline Renal failure & $41(4.2)$ & $33(4.0)$ & $8(6.1)$ & 0.26 \\
\hline $\mathrm{CHA}_{2} \mathrm{DS}_{2}$-VASc score & $2.5 \pm 1.8$ & $2.4 \pm 1.7$ & $3.2 \pm 1.9$ & $<0.001$ \\
\hline HATCH score & $1.5 \pm 1.4$ & $1.3 \pm 1.3$ & $2.2 \pm 1.5$ & $<0.001$ \\
\hline
\end{tabular}

$\mathrm{AF}=$ atrial fibrillation; TIA = transient ischemic attack; $\mathrm{CHA}_{2} \mathrm{DS}_{2}$-VASc-score = Congestive heart failure (1 point), Hypertension (1 point), Age $>75$ years (2 points), Diabetes mellitus (1 point), Prior Stroke or TIA (2 points), Vascular disease (1 point), Age 65 - 74 years (1 point), Sex category (female $=1$ point); HATCH-score $=$ Hypertension ( 1 point), Age $>75$ years $(1$ point), Stroke or transient ischemic attack (2 points), Chronic obstructive pulmonary disease (1 point), and Heart failure (2 points); COPD = Chronic obstructive pulmonary disease.

At baseline, patients that will progress experienced more problems (some problems or severe problems) on each domain of the EuroQoL-5D than those who did not progress (Table 2). Furthermore, in the patients that progressed, the percentage of patients that experienced more problems on each of the domains at 1-year follow-up than at baseline was significantly higher than in the patients that did not progress (Figure 1; Mobility $20.5 \%$ vs. $11.4 \%$; Self-care $12.9 \%$ vs. $6.2 \%$; Usual activities $23.5 \%$ vs. $14.0 \%$; Pain / discomfort $20.5 \%$ vs. $13.7 \%$; and Anxiety / depression $22.7 \%$ vs. $15.7 \%$; all $p<0.05$ ). 
Table 2. Percentage of progressors $(n=835)$ versus non-progressors $(n=132)$, that report no, some and severe problems on the five domains of EuroQoL-5D at baseline and after 1 year. $\mathrm{P}$-values are derived from the comparison between non-progressors and progressors, a $\mathrm{p}$ value $<0.05$ is considered significant.

\begin{tabular}{|c|c|c|c|c|c|c|c|c|c|c|c|c|c|c|}
\hline Problems: & \multicolumn{3}{|c|}{ Non-progressors } & \multicolumn{3}{|c|}{ Progressors } & $p$ & \multicolumn{3}{|c|}{ Non-progressors } & \multicolumn{3}{|c|}{ Progressors } & $p$ \\
\hline Mobility & 67.2 & 32.1 & 0.7 & 57.6 & 40.9 & 1.5 & 0.09 & 68.9 & 30.5 & 0.6 & 51.5 & 42.4 & 6.1 & $<0.001$ \\
\hline Self-care & 89.3 & 10.3 & 0.4 & 80.3 & 19.7 & 0.0 & 0.006 & 88.5 & 11.3 & 0.2 & 78.8 & 15.9 & 5.3 & $<0.001$ \\
\hline $\begin{array}{l}\text { Usual } \\
\text { activities }\end{array}$ & 72.9 & 25.9 & 1.2 & 56.8 & 42.4 & 0.8 & $<0.001$ & 70.4 & 28.0 & 1.6 & 50.0 & 41.7 & 8.3 & $<0.001$ \\
\hline $\begin{array}{l}\text { Pain/ } \\
\text { discomfort }\end{array}$ & 61.7 & 35.9 & 2.4 & 53.8 & 43.9 & 2.3 & 0.21 & 65.7 & 32.3 & 1.9 & 53.8 & 40.2 & 6.1 & 0.002 \\
\hline $\begin{array}{l}\text { Anxiety/ } \\
\text { depression }\end{array}$ & 62.9 & 32.5 & 4.7 & 50.0 & 43.9 & 6.1 & 0.02 & 64.1 & 32.5 & 3.5 & 47.7 & 43.2 & 9.1 & $<0.001$ \\
\hline
\end{tabular}

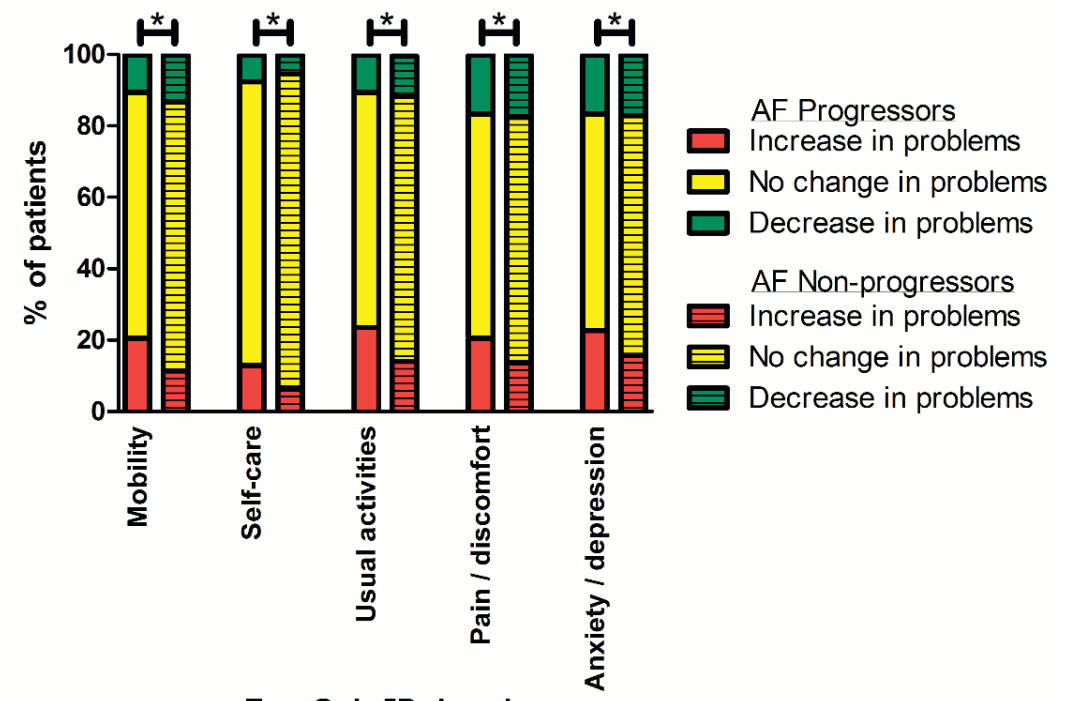

EuroQoL-5D domain

Figure 1. Percentage of patients reporting an increase, no change and a decrease problems on the EuroQoL-5D domain at 1 year than at baseline, for the groups without and with AFprogression. * indicates $\mathrm{p}<0.05$.

While the calculated utility for the group without AF progression increases during 1 year (baseline 0.796 $\pm 0.23,1$ year 0.814 $\pm 0.23 ; p=0.04$; difference $+0.018(95 \% \mathrm{Cl}[0.008,0.033])$ ), the utility decreased significantly in the group with AF progression (baseline $0.744 \pm 0.26$, follow-up 0.674 $\pm 0.36 ; p=0.02$; difference -0.07 (95\% Cl [-0.126,-0.013])) (Figure 2). 


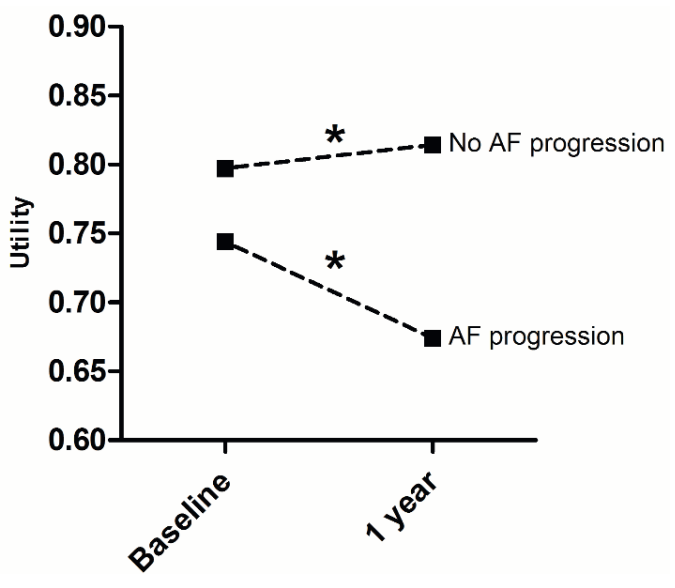

Figure 2. In patients without progression of atrial fibrillation (AF), the utility increases from $0.796 \pm 0.23$ at baseline to $0.814 \pm 0.23$ at 1 year $(p=0.04)$, while in patients with AF progression it decreases from $0.744 \pm 0.26$ to $0.674 \pm 0.36(p=0.02)$. Utility scores range from 0 (health state equivalent to death) to 1.0 (best possible health), negative values are possible. * indicates $\mathrm{p}<0.05$.

Multivariate analysis showed that stroke $(-0.27(95 \% \mathrm{Cl}[-0.43,-0.11]) ; \mathrm{p}=0.001)$, heart failure $(-0.12$ (95\% Cl [-0.20,-0.05]); $p=0.001)$, malignancy $(-0.31$ (95\% Cl $[-0.56,-0.05]) ; p=0.017)$ or implantation of an implantable cardiac defibrillator $(-0.12(95 \% \mathrm{Cl}[-0.23,-0.02]) ; p=0.03)$ during follow-up had the largest negative effect on the change in utility during this year. Patients with symptomatic AF had a reduction in utility of $-0.04(95 \% \mathrm{Cl}[-0.08,-0.01]$; $\mathrm{p}=0.008)$, except when this symptom was dizziness $(+0.06(95 \% \mathrm{Cl}[0.02,0.10]) ; \mathrm{p}=0.004)$. Patients with diabetes mellitus experienced an increase of utility during follow-up of 0.04 $(95 \% \mathrm{Cl}$ [0.01,0.07]; $\mathrm{p}=0.006)$ (Table 3). Notably, in multivariate regression analysis, progression of AF is not a determinant of change in utility.

Table 3. Determinants of the change in utility during one year of follow-up. Notably, progression of atrial fibrillation (AF) is not a determinant of change in utility.

\begin{tabular}{|l|c|c|}
\hline & Coefficient & $p$ \\
\hline Diabetes mellitus & $0.04[0.01,0.07]$ & 0.006 \\
\hline Symptomatic AF & $-0.04[-0.08,-0.01]$ & 0.008 \\
\hline Dizziness & $0.06[0.02,0.10]$ & 0.004 \\
\hline Stroke during FU & $-0.27[-0.43,-0.11]$ & 0.001 \\
\hline Heart failure during FU & $-0.12[-0.20,-0.05]$ & 0.001 \\
\hline Malignancy during FU & $-0.31[-0.56,-0.05]$ & 0.017 \\
\hline ICD during FU & $-0.12[-0.23,-0.02]$ & 0.030 \\
\hline
\end{tabular}

Shown are the coefficient $[95 \% \mathrm{Cl}]$ and $\mathrm{p}$-value of multivariate ordinary least squares regression. $\mathrm{Cl}=$ Confidence Interval; $\mathrm{FU}=$ Follow-up; $I \mathrm{CD}=$ Implantable Cardiac Defibrillator. 


\section{DISCUSSION}

This report is the first to show the association between AF progression and HRQoL. From this report, it can be concluded that AF progression is associated with a decrease in quality of life (HRQoL) during the year in which progression occurs, indicated by an increase in problems reported on each of the EuroQoL-5D domains, leading to a change in utility of -0.07 (95\% Cl $[-0.126,-0.013])$ which appears clinically significant.(10) Upon correcting for major adverse events and symptoms during follow-up, this association disappears. This suggests that the decrease of HRQoL associated with AF progression is mediated by adverse events and symptoms: there is a significant relationship between AF progression and adverse events and symptoms,(6) a significant relation between utility and both adverse events and symptoms and progression, and the relationship between progression and utility becomes non-significant upon correction for adverse events and symptoms.

The main determinants of a reduction in utility in this population of patients with paroxysmal AF were the occurrence of stroke, heart failure, malignancy and ICD implantation during follow-up, which was already known for AF patients in general(3). Already, one of the cornerstones of current treatment is focusing on the reduction of the incidence of cardiac adverse events,(4) but the fact that these events still occur indicates that our current treatment strategies are not sufficient yet. Although the percentage of patients that will experience such an event is low, the effect on HRQoL is large. This report emphasizes that strategies focused on the prevention of adverse events may ultimately have a major influence on $\mathrm{HRQ}$ L, irrespective of their influence on AF progression.

Next to adverse events, symptomatic AF is a determinant of the change in utility during one year. The utility of patients that remain symptomatic is reduced modestly $(-0.04(95 \% \mathrm{Cl}$ $[-0.08,-0.01] ; p=0.008))$. This effect is cancelled out if the symptom is dizziness, as this symptom is usually readily treatable by reducing the dose of negative chronotropic drugs or implanting a pacemaker in case of sinus arrest. If patients remain symptomatic, despite the efforts of patient and physician, it is only to be expected that this has a detrimental effect on the quality of life. (3) Furthermore, this underlines the need to continue focusing on reducing AF symptoms through more modern rhythm control strategies, with pharmacological as well as interventional measures.

Patients in this cohort who suffered from diabetes experienced an increase in quality of life during one year. This may be explained by the correction for events in the multivariate analysis, as diabetes without complications may have little influence on the perceived HRQoL. The increase in HRQoL may be explained by the fact that these patients visit a 
doctor more frequently than patients without diabetes, which may have a beneficial effect, or they get more comfortable living with their diabetes as time passes since their diagnosis.

On one hand, one may hypothesize that AF progression in itself is a cause for adverse events. Based on this hypothesis, preventing AF progression may be instrumental in preventing the associated events and the associated decrease in HRQoL. Although trials have never shown benefit of rhythm over rate control in the long term on clinical endpoints, $(11,12)$ more recent reports have shown signals that there is an association between the duration of $\mathrm{AF}$ episodes and stroke risk, $(13,14)$ and that rhythm control may reduce the number of strokes(15) and mortality.(16) Furthermore, our current strategy of rhythm control has not been shown to improve HRQoL to a clinically significant extent.(17, 18) This led to the design of the EAST trial, that aims to inhibit AF progression through modern and early rhythm control, in which HRQoL will be a key secondary outcome.(7) Results from this trial should show whether early rhythm control could limit progression - and thereby retain HRQoL more effectively than a rate control strategy. Our current study suggests that preventing AF progression may only influence HRQoL if indeed this focus on inhibition of rhythm deterioration prevents major adverse cardiac and cerebrovascular events. As rhythm control generally encompasses intensive treatment, including potentially hazardous anti-arrhythmic drug use and invasive therapy, the net effect of inhibition of progression of AF on the quality of life remains to be determined.

On the other hand, based on the association between the occurrence of major adverse events and AF progression, it may be hypothesized that both AF progression and adverse events are the result of an underlying common mechanism. One of the proposed underlying mechanisms is an early state of hypercoagulability leading to both an atrial substrate for more persistent forms of AF and adverse events.(19) Early intervention in this hypercoagulable state may thus improve both progression rates and incidence of adverse events. Furthermore, this hypothesis implicates a less stringent need for rhythm control, as events do not relate to the rhythm status, such that side effects of intensive treatment associated with aggressive rhythm control can be averted.(20)

Lastly, the results reported here support the notion that - also from the perspective of HRQoL - the current daily practice of classifying AF by the duration of the episodes - i.e. paroxysmal and persistent $\mathrm{AF}$ - rather than the underlying pathology may need reconsideration,(21) as the results indicate that $\mathrm{HRQOL}$ is not so much determined by the duration of the episodes of the arrhythmia, but more by the associated events and symptoms. 


\section{Strengths and Limitations}

The major strength of this report lies in the fact that the Euro Heart Survey provided longitudinal data on a large group of real life patients across Europe, which represent the daily clinical population better than results acquired in clinical trials.

For this report, only those patients who filled out the HRQoL questionnaires both at baseline and follow-up were used, which may have led to excluding those patients that were too sick or frail to fill out the questionnaires, or who died during follow-up. This may have influenced HRQoL measures, especially since from a previous report on the study population from which this cohort is selected, it is known that responders differed from non-responders on both demographic and disease-related characteristics.(3) Furthermore, HRQoL was measured using EuroQoL-5D as disease specific HRQoL questionnaires were not yet available. We corrected for treatments chosen, but were not able to assess the effectiveness of these treatments. The data from this study were acquired in 2003-2004, yet the outcomes we describe have remained relevant over the past decade, as AF progression is still a clinically identifiable problem, as well as the importance of stroke, heart failure, malignancy, ICD implantation and symptomatic AF with respect to HRQoL remain relevant. We were not able to determine whether AF progression preceded events. Lastly, assessment of personality was not included in the EHS, which did not allow us to correct the user reported QoL for differences in personality and thus coping strategies to deal with adverse events.

\section{CONCLUSION}

To conclude, quality of life in patients with AF progression decreases, which is largely caused by adverse events and to a smaller extent by AF symptoms. An effect of inhibition of AF progression on HRQoL is thus mainly to be expected if future studies show that inhibiting AF progression leads to fewer adverse events. 


\section{REFERENCES}

1. Thrall G, Lane D, Carroll D, Lip GY. Quality of life in patients with atrial fibrillation: a systematic review. Am J Med. 2006 May;119(5):448 e1-19. PubMed PMID: 16651058.

2. Aliot E, Botto GL, Crijns $H J$, Kirchhof $P$. Quality of life in patients with atrial fibrillation: how to assess it and how to improve it. Europace. 2014 Jun;16(6):787-96. PubMed PMID: 24469433.

3. Berg J, Lindgren $\mathrm{P}$, Nieuwlaat $\mathrm{R}$, Bouin $\mathrm{O}$, Crijns $\mathrm{H}$. Factors determining utility measured with the EQ-5D in patients with atrial fibrillation. Qual Life Res. 2010 Apr;19(3):381-90. PubMed PMID: 20108048.

4. Kirchhof P, Benussi S, Kotecha D, Ahlsson A, Atar D, Casadei B, et al. 2016 ESC Guidelines for the management of atrial fibrillation developed in collaboration with EACTS. Europace. 2016 Nov;18(11):1609-78. PubMed PMID: 27567465.

5. Walters TE, Nisbet A, Morris GM, Tan G, Mearns M, Teo E, et al. Progression of atrial remodeling in patients with high-burden atrial fibrillation: Implications for early ablative intervention. Heart Rhythm. 2016 Feb;13(2):331-9. PubMed PMID: 26484789.

6. de Vos CB, Pisters R, Nieuwlaat R, Prins MH, Tieleman RG, Coelen RJ, et al. Progression from paroxysmal to persistent atrial fibrillation clinical correlates and prognosis. J Am Coll Cardiol. 2010 Feb 23;55(8):725-31. PubMed PMID: 20170808.

7. Kirchhof P, Breithardt G, Camm AJ, Crijns HJ, Kuck KH, Vardas $P$, et al. Improving outcomes in patients with atrial fibrillation: rationale and design of the Early treatment of Atrial fibrillation for Stroke prevention Trial. Am Heart J. 2013 Sep;166(3):442-8. PubMed PMID: 24016492.

8. Nieuwlaat R, Capucci A, Camm AJ, Olsson SB, Andresen D, Davies DW, et al. Atrial fibrillation management: a prospective survey in ESC member countries: the Euro Heart Survey on Atrial Fibrillation. Eur Heart J. 2005 Nov;26(22):2422-34. PubMed PMID: 16204266.

9. Dolan P. Modeling valuations for EuroQol health states. Med Care. 1997 Nov;35(11):1095-108. PubMed PMID: 9366889.

10. Walters SJ, Brazier JE. Comparison of the minimally important difference for two health state utility measures: EQ-5D and SF-6D. Qual Life Res. 2005 Aug;14(6):1523-32. PubMed PMID: 16110932.

11. Van Gelder IC, Hagens VE, Bosker HA, Kingma JH, Kamp O, Kingma T, et al. A comparison of rate control and rhythm control in patients with recurrent persistent atrial fibrillation. N Engl J Med. 2002 Dec 05;347(23):1834-40. PubMed PMID: 12466507.

12. Wyse DG, Waldo AL, DiMarco JP, Domanski MJ, Rosenberg Y, Schron EB, et al. A comparison of rate control and rhythm control in patients with atrial fibrillation. $\mathrm{N}$ Engl $\mathrm{J}$ Med. 2002 Dec 05;347(23):1825-33. PubMed PMID: 12466506.

13. Vanassche T, Lauw MN, Eikelboom JW, Healey JS, Hart RG, Alings M, et al. Risk of ischaemic stroke according to pattern of atrial fibrillation: analysis of 6563 aspirin-treated patients in ACTIVE-A and AVERROES. Eur Heart J. 2015 Feb 01;36(5):281-7a. PubMed PMID: 25187524. 
14. Steinberg BA, Hellkamp AS, Lokhnygina Y, Patel MR, Breithardt G, Hankey GJ, et al. Higher risk of death and stroke in patients with persistent vs. paroxysmal atrial fibrillation: results from the ROCKET-AF Trial. Eur Heart J. 2015 Feb 01;36(5):288-96. PubMed PMID: 25209598. Pubmed Central PMCID: PMC4313363.

15. Tsadok MA, Jackevicius CA, Essebag V, Eisenberg MJ, Rahme E, Humphries KH, et al. Rhythm versus rate control therapy and subsequent stroke or transient ischemic attack in patients with atrial fibrillation. Circulation. 2012 Dec 04;126(23):2680-7. PubMed PMID: 23124034.

16. Ionescu-Ittu R, Abrahamowicz M, Jackevicius CA, Essebag V, Eisenberg MJ, Wynant $W$, et al. Comparative effectiveness of rhythm control vs rate control drug treatment effect on mortality in patients with atrial fibrillation. Arch Intern Med. 2012 Jul 09;172(13):997-1004. PubMed PMID: 22664954.

17. Hagens VE, Ranchor AV, Van Sonderen E, Bosker HA, Kamp O, Tijssen JG, et al. Effect of rate or rhythm control on quality of life in persistent atrial fibrillation. Results from the Rate Control Versus Electrical Cardioversion (RACE) Study. J Am Coll Cardiol. 2004 Jan 21;43(2):241-7. PubMed PMID: 14736444.

18. Ha AC, Breithardt G, Camm AJ, Crijns HJ, Fitzmaurice GM, Kowey PR, et al. Healthrelated quality of life in patients with atrial fibrillation treated with rhythm control versus rate control: insights from a prospective international registry (Registry on Cardiac Rhythm Disorders Assessing the Control of Atrial Fibrillation: RECORD-AF). Circ Cardiovasc Qual Outcomes. 2014 Nov;7(6):896-904. PubMed PMID: 25387780.

19. Spronk HM, De Jong AM, Verheule S, De Boer HC, Maass AH, Lau DH, et al. Hypercoagulability causes atrial fibrosis and promotes atrial fibrillation. Eur Heart J. 2017 Jan 01;38(1):38-50. PubMed PMID: 27071821.

20. Dudink E, Essers B, Holvoet W, Weijs B, Luermans J, Ramanna H, et al. Acute cardioversion vs a wait-and-see approach for recent-onset symptomatic atrial fibrillation in the emergency department: Rationale and design of the randomized ACWAS trial. Am Heart J. 2017 Jan;183:49-53. PubMed PMID: 27979041.

21. Fabritz L, Guasch E, Antoniades C, Bardinet I, Benninger G, Betts TR, et al. Expert consensus document: Defining the major health modifiers causing atrial fibrillation: a roadmap to underpin personalized prevention and treatment. Nat Rev Cardiol. 2016 Apr;13(4):230-7. PubMed PMID: 26701216. 


\section{CHAPTER 4 \\ Differences in pericardial adipose tissue on computed tomography and outcome after pulmonary vein isolation}

Ömer Erküner, Sibel Altıntaş, Luuk Heckman, Jules Olsthoorn, Elton Dudink, Muhammet Dural, Bob Weijs, Sander Verheule, Bart Maesen, Kevin Vernooy, Laurent Pison, Harry Crijns, Justin Luermans 


\section{ABSTRACT}

\section{Background}

Pulmonary vein isolation (PVI) is a successful treatment option for atrial fibrillation (AF). Several predictors for AF recurrence after PVI have been identified. We hypothesized that cardiac computed tomography (CCT) detected pericardial adipose tissue (PAT) and coronary artery disease (CAD) predicts AF recurrence after $\mathrm{PVI}$.

\section{Methods}

We analyzed 299 patients who underwent a CCT prior to PVI between 2010 and 2015. PAT volume was assessed with semi-automated Siemens software. The rhythm outcome after ablation was assessed after 1 year and at maximum follow-up. Success after PVI was defined as freedom from $A F$, atrial flutter and atrial tachycardia in the absence of antiarrhythmic drugs. Stepwise multivariable logistic regression was performed to assess independent associations with rhythm outcome after PVI.

\section{Results}

Median follow-up was 766 (377-1496) days. The mean PAT volume was significantly lower in patients with successful PVI at maximum follow-up compared to those without (176 \pm 77 vs. $203 \pm 90 \mathrm{ml}, \mathrm{p}=0.017$ ). The presence or the extent of CAD did not differ between the groups. Stepwise multivariable logistic regression only ascertained left atrial volume indexed to body surface area (LAVI) as independent predictor for PVI outcome at maximum follow-up.

\section{Conclusions}

Patients with successful PVI showed less PAT on CCT at baseline, compared to patients with AF recurrences after a median follow-up of 2 years. However, multivariable logistic regression only ascertained LAVI as a predictor of unfavorable PVI outcome. 


\section{INTRODUCTION}

Pulmonary vein isolation ( $\mathrm{PVI}$ ) is a widely performed procedure for the treatment of atrial fibrillation (AF). Several predictors for the recurrence of AF after PVI have been identified, i.e. AF type (paroxysmal vs. persistent or longstanding persistent AF), age, left atrial size, hypertension, obesity, obstructive sleep apnea, concomitant cardiac disease and left atrial fibrosis detected on cardiac magnetic resonance imaging.(1, 2) However, the evidence regarding some of these predictors is conflicting and cannot be ascertained in all populations.(1) In addition, the predictive power of these variables is weak.(3)

Cardiac computed tomography angiography (CCTA) is currently a well-implemented diagnostic imaging modality both in the work up for AF ablation and to diagnose coronary artery disease (CAD) in patients with stable chest pain. Conventional CCTA reading includes assessment of the coronary calcium score, luminal stenosis severity, and extent of CAD. Subclinical CAD, i.e. CAD detected on CCTA in the absence of clinically overt CAD, is associated with AF.(4) In addition to CAD assessment, CCTA is also capable to measure pericardial adipose tissue (PAT) volume, based upon an adequate resolution and high reproducibility. Since PAT also takes the localization of fatty depositions into account, it can be important in predicting AF recurrences over regular obesity indices as body mass index (BMI). Thus, we hypothesized that both PAT and CAD as assessed on CCTA prior to PVI are predictors of rhythm outcome after PVI.

\section{METHODS}

\section{Study population}

We identified 299 patients who underwent a cardiac computed tomography (CCT) as part of the work-up for PVI between 2010 and 2015 at the Maastricht University Medical Center+, a tertiary hospital in the Netherlands. Both PVI and CCT were performed as part of routine clinical care. Baseline characteristics and follow-up data were collected retrospectively. Written informed consent was waived because data were retrospectively analyzed anonymously in accordance with the IRB guidelines. This study complies with the ethical principles of the Declaration of Helsinki.

One year outcome after PVI was assessed using the definitions as described in the 2017 expert consensus statement on catheter and surgical ablation of AF.(2) Success was defined as freedom from AF, atrial flutter and atrial tachycardia on Holter monitoring and electrocardiograms in the absence of antiarrhythmic drugs, from the end of the 3 months 
blanking period to 12 months after the index PVI.(2) If Holter monitoring was lacking during the first year of follow-up, patients could not be classified as having successful PVI. The outcome after ablation at maximum follow-up was assessed in a similar way, but without the requisite of Holter monitoring. Partially successful PVI was defined as having a $>75 \%$ reduction of AF burden with or without regular antiarrhythmic drug use or after redo-ablation. Not successful PVI was defined as having a $<75 \%$ reduction of AF burden based on Holter monitoring and review of patient records.

\section{Cardiac computed tomography assessment}

All scans were performed using a second generation dual-source CT-scanner (Somatom Definition Flash, Siemens Medical Solutions, Forchheim, Germany). Data acquisition parameters were: pitch 3.4 , slice collimation $2 \times 128 \times 0.6 \mathrm{~mm}$, gantry rotation time $280 \mathrm{~ms}$, tube voltage $120 \mathrm{kV}$, tube current 100-150 reference mAs and slice thickness of $3 \mathrm{~mm}$; reconstruction was performed with a B35f kernel. The coronary calcium score was calculated according to the Agatston method using dedicated software according (Syngo.Via Calcium scoring, Siemens Healthcare, Forchheim, Germany). A radiologist together with an imaging cardiologist quantified the extent of CAD using the 16-segments American Heart Association model, blinded to the rhythm outcome after PVI.(5) An involvement score and a segment score was calculated based on these assessments. The involvement score is the number of segments with at least a mild plaque present, leading to a maximum score of 16 . The segment score is a measure of the extent of CAD in the 16 segments, with a score from 0 to 3 for the severity of plaques in each segment (no plaque $=0$, mild plaque $=1$, moderate plaque $=2$, severe plaque $=3$ ), leading to a maximum score of 48 .

Dedicated volumetric software (Volume, Leonardo, Siemens Healthcare, Forchheim, Germany) was used to quantify total pericardial adipose tissue in ml (Figure 1). Total PAT was chosen since it was not possible to reliably and reproducibly delineate the pericardium or the atrioventricular border in an automated manner and quantify left atrial epicardial tissue selectively. The quantification of total PAT was performed on both contrast and non-contrast CT scans. Different Hounsfield Units (HU) upper thresholds were used, i.e. -15 HU, -30 HU and $-45 \mathrm{HU}$, in both systolic and diastolic cardiac phase separately. It has previously been shown that the quantification of PAT correlates excellently between the different thresholds.(6) As an internal control, we compared the PAT values for the different HU thresholds, in and between both cardiac phase scans. 
Chapter 4

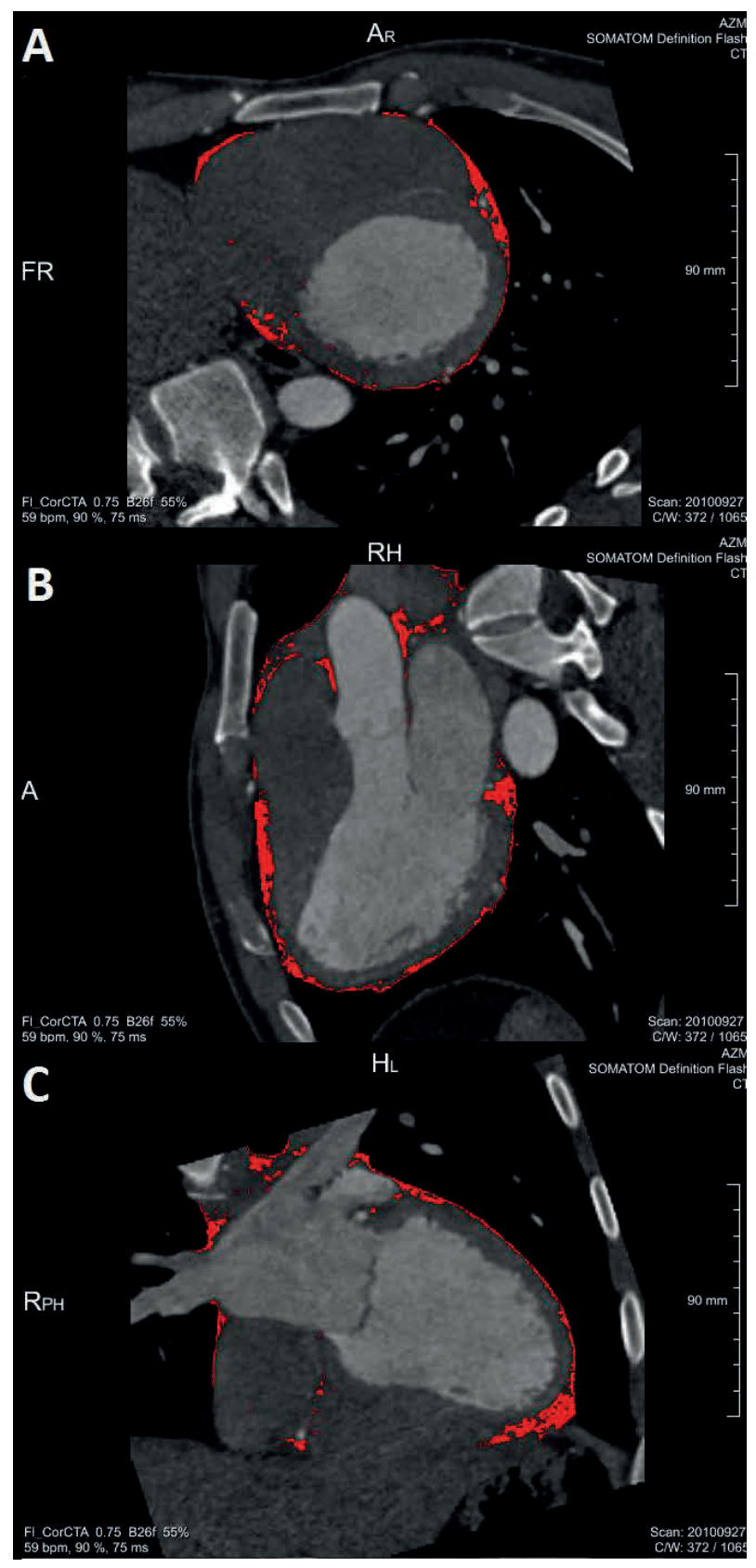

Figure 1. Automated pericardial adipose tissue assessment on a cardiac computed tomography scan with contrast, panel A: short axis view of left and right ventricle, panel B: five chamber view, panel C: two chamber view with distal pulmonary veins. 


\section{Statistical analysis}

Data were analyzed with SPSS statistical software version 22.0 (IBM Corp., Armonk, NY, USA). Continuous variables are reported as mean \pm standard deviation for normally distributed variables. For not normally distributed variables, median and inter quartile range is given. Normally distributed continuous variables were compared between groups using the independent samples t-test. Not normally distributed continuous variables were compared using the Mann-Whitney $U$ test. Categorical variables are reported as observed numbers and percentages with among-group comparisons using a $X 2$ test. Fisher's exact test was used in case of any expected cell count $<5$. The correlation between the PAT quantifications with the different HU thresholds was assessed using the Pearson correlation coefficient.

All clinically relevant baseline characteristics with a significant univariable association $(p<0.10)$ with the endpoint were incorporated into a multivariable logistic regression model with stepwise reduction of the model by excluding variables with $p>0.05$. All variables in the final model were tested for interactions. Remaining variables with $p<0.05$ were considered independently associated with the endpoint.

\section{RESULTS}

Rhythm follow-up was available in 292 (97.7\%) of the 299 patients with a CCT within the work-up for PVI. Median follow-up duration was 766 (377-1496) days. Ninety (30.8\%) of 292 patients had no AF recurrences after ablation and were classified as having a successful $\mathrm{PVI}$. The remainder of the patients were classified as having a not successful or partially successful PVI, with 89 (30.5\%) of 292 patients having a $>75 \%$ reduction of AF burden with or without regular antiarrhythmic drug use, 59 patients $(20.2 \%)$ having $>75 \%$ reduction of AF burden after redo-ablation, and 54 patients (18.5\%) having no or $<75 \%$ reduction in $\mathrm{AF}$ burden. Baseline characteristics of the population are shown in Table 1, comparing patients with successful PVI at maximum follow-up to those with partial or no success.

Patients with successful PVI tended to have a shorter history of AF (median 30 vs. 48 months, $p=0.055)$. Additionally, these patients were less frequently prescribed AADs $(37.8 \%$ vs. $53.0 \%, p=0.016$ ) and were less frequently cardioverted electrically or pharmacologically $(51.1 \%$ vs. $65.9 \%, p=0.017)$ prior to the baseline assessment. Furthermore, left atrial volume indexed to body surface area (LAVI) was also lower in patients with successful PVI $(39 \pm 10$ $\mathrm{ml} / \mathrm{kg} 2$ vs. $43 \pm 11, \mathrm{p}=0.031)$. 
Table 1. Baseline characteristics for the whole population divided by success of PVI at maximum follow-up.

\begin{tabular}{|c|c|c|c|c|}
\hline \multirow{2}{*}{ Age, mean \pm SD } & & $\begin{array}{l}\text { Not or partially } \\
\text { successful PVI } \\
\quad(n=202)\end{array}$ & $\begin{array}{l}\text { Successful } \\
\text { PVI } \\
(n=90)\end{array}$ & $\begin{array}{c}\mathrm{p}- \\
\text { value }\end{array}$ \\
\hline & & $60 \pm 10$ & $58 \pm 8$ & 0.134 \\
\hline Female sex, $\mathrm{n}(\%)$ & & $63(31.2)$ & $24(26.7)$ & 0.435 \\
\hline $\mathrm{CHA}_{2} \mathrm{DS}_{2}-\mathrm{VASc}$, mean & & $1.4 \pm 1.4$ & $1.2 \pm 1.3$ & 0.145 \\
\hline Body Mass Index, $\mathrm{kg} / \mathrm{m}^{2}$, & lean $\pm S D$ & $27.6 \pm 4.1$ & $27.0 \pm 3.6$ & 0.226 \\
\hline \multicolumn{5}{|c|}{ Medical history, $n(\%)$} \\
\hline \multicolumn{2}{|l|}{ Atrial flutter } & $42(20.8)$ & $20(22.2)$ & 0.783 \\
\hline \multicolumn{2}{|c|}{ Cavotricuspid isthmus ablation } & $21(10.4)$ & $12(13.3)$ & 0.464 \\
\hline \multicolumn{2}{|c|}{ Hypertension } & $78(38.6)$ & $36(40.0)$ & 0.823 \\
\hline \multicolumn{2}{|l|}{ Ischemic stroke/TIA } & $13(6.4)$ & $9(10.0)$ & 0.287 \\
\hline \multicolumn{2}{|c|}{ Type II diabetes mellitus } & $18(8.9)$ & $2(2.2)$ & 0.037 \\
\hline \multicolumn{2}{|c|}{ Percutaneous coronary intervention } & $12(5.9)$ & $4(4.4)$ & 0.783 \\
\hline \multicolumn{2}{|c|}{ Congestive heart failure } & $4(2.0)$ & 0 & 0.315 \\
\hline \multicolumn{5}{|c|}{ Atrial fibrillation characteristics } \\
\hline \multicolumn{2}{|c|}{ Paroxysmal AF, n (\%) } & $151(74.8)$ & $74(82.2)$ & 0.161 \\
\hline \multicolumn{2}{|c|}{ Persistent AF, n (\%) } & $51(25.2)$ & $16(17.8)$ & 0.161 \\
\hline \multicolumn{2}{|c|}{ Total AF history in months, median (IQR) } & $48(21-84)$ & $30(12-72)$ & 0.055 \\
\hline \multicolumn{5}{|c|}{ Previous treatment of $A F, n(\%)$} \\
\hline \multicolumn{2}{|c|}{ Pulmonary vein isolation } & $26(12.9)$ & $8(8.9)$ & 0.327 \\
\hline \multirow{3}{*}{$\begin{array}{l}\text { Previous AAD tried } \\
\text { (apart from current } \\
\text { treatment) }\end{array}$} & None & $95(47.0)$ & $56(62.2)$ & \multirow[t]{3}{*}{0.016} \\
\hline & 1 & $72(35.6)$ & $26(28.9)$ & \\
\hline & 2 or more & $35(17.4)$ & $8(8.9)$ & \\
\hline \multirow{3}{*}{$\begin{array}{l}\text { Previous electrical or } \\
\text { pharmacological } \\
\text { cardioversion }\end{array}$} & None & $69(34.2)$ & $44(48.9)$ & \multirow[t]{3}{*}{0.017} \\
\hline & 1 & $29(14.4)$ & $10(11.1)$ & \\
\hline & 2 or more & $104(51.5)$ & $36(40.0)$ & \\
\hline \multicolumn{2}{|c|}{$\begin{array}{l}\text { Previous or current rhythm control (AAD, PVI or } \\
\text { cardioversion) }\end{array}$} & $185(91.6)$ & $76(84.4)$ & 0.067 \\
\hline \multicolumn{5}{|c|}{ Current medication, $n(\%)$} \\
\hline \multirow[t]{3}{*}{ Anti-thrombotic therapy } & VKA & $176(87.1)$ & $74(82.3)$ & \multirow[t]{3}{*}{0.718} \\
\hline & NOAC & $25(12.3)$ & $15(16.7)$ & \\
\hline & DAPT & $1(0.5)$ & $1(1.1)$ & \\
\hline Anti-arrhythmic treatment & Any AAD & $141(69.8)$ & $59(65.6)$ & 0.471 \\
\hline & Flecainide & $65(32.2)$ & $24(26.7)$ & 0.478 \\
\hline & Sotalol & $50(24.8)$ & $25(27.8)$ & 0.271 \\
\hline & Amiodarone & $25(12.4)$ & $9(10.0)$ & 0.559 \\
\hline & Disopyramide & $2(1.0)$ & $1(1.1)$ & 0.999 \\
\hline & Propafenone & $2(1.0)$ & $1(1.1)$ & 0.999 \\
\hline Beta blocker & & $86(42.6)$ & $36(40.0)$ & 0.680 \\
\hline Statin & & $61(30.2)$ & $11(12.2)$ & 0.001 \\
\hline Verapamil/Diltiazem & & $28(13.9)$ & $12(13.3)$ & 0.904 \\
\hline Digoxin & & $28(13.9)$ & $9(10.0)$ & 0.360 \\
\hline Any RAAS inhibitor (ACEi & ARB/ARA) & $84(41.6)$ & $31(34.4)$ & 0.249 \\
\hline
\end{tabular}




\begin{tabular}{|c|c|c|c|c|}
\hline \multicolumn{5}{|l|}{ PVI characteristics, $n(\%)$} \\
\hline \multirow[t]{4}{*}{ Type of PVI } & Cryoballoon & $136(67.3)$ & $62(68.9)$ & \multirow[t]{4}{*}{0.195} \\
\hline & Laser & $4(2.0)$ & $5(5.6)$ & \\
\hline & RF/WACA & $34(16.8)$ & $9(10.0)$ & \\
\hline & Surgical & $28(13.9)$ & $14(15.6)$ & \\
\hline \multicolumn{2}{|l|}{ Complete PV isolation } & $199(98.5)$ & $89(98.9)$ & 0.999 \\
\hline \multicolumn{2}{|c|}{ CTI ablation in same session } & $30(14.9)$ & $10(11.1)$ & 0.391 \\
\hline \multicolumn{2}{|c|}{ Any complication } & $18(8.9)$ & $12(13.3)$ & 0.250 \\
\hline \multicolumn{5}{|c|}{ Echocardiography } \\
\hline \multicolumn{2}{|c|}{ LVEF in $\%$, mean \pm SD $(n=282)$} & $58 \pm 7$ & $60 \pm 7$ & 0.019 \\
\hline \multicolumn{2}{|c|}{ LA diameter in $\mathrm{mm}$, mean $\pm \mathrm{SD}(\mathrm{n}=238)$} & $43 \pm 6$ & $41 \pm 5$ & 0.015 \\
\hline \multicolumn{2}{|c|}{ LA volume in $\mathrm{ml}$, mean $\pm \mathrm{SD}(\mathrm{n}=225)$} & $88 \pm 25$ & $80 \pm 20$ & 0.024 \\
\hline \multicolumn{2}{|c|}{ LA volume indexed to $B S A, m l / \mathrm{kg}^{2}$ mean $\pm S D(n=197)$} & $43 \pm 11$ & $39 \pm 10$ & 0.031 \\
\hline \multicolumn{2}{|c|}{ RA volume in $\mathrm{ml}$, mean $\pm \mathrm{SD}(\mathrm{n}=190)$} & $67 \pm 23$ & $68 \pm 27$ & 0.787 \\
\hline \multicolumn{5}{|c|}{ Coronary computed tomography } \\
\hline \multicolumn{2}{|c|}{ Calcium mass score, median (IQR) $(n=282)$} & $4.4(0-29.7)$ & $2.2(0-15.7)$ & 0.442 \\
\hline \multicolumn{2}{|c|}{ Agatston score, median (IQR) $(n=286)$} & $22(0-165)$ & $14(0-83)$ & 0.373 \\
\hline \multirow{4}{*}{$\begin{array}{l}\text { Agatston score } \\
\text { categorized, n (\%) }\end{array}$} & $0-10$ & $85(43.4)$ & $44(48.9)$ & \multirow[t]{4}{*}{0.555} \\
\hline & $10-100$ & $56(28.6)$ & $26(28.9)$ & \\
\hline & $100-400$ & $26(13.3)$ & $12(13.3)$ & \\
\hline & $>400$ & $29(14.8)$ & $8(8.9)$ & \\
\hline \multicolumn{2}{|c|}{ No plaque present, $(\mathrm{n}=280)$} & $82(41.6)$ & $33(39.8)$ & 0.772 \\
\hline \multicolumn{2}{|c|}{ Any plaque present, $(n=280)$} & $115(58.4)$ & $50(60.2)$ & \\
\hline \multicolumn{2}{|c|}{ Involvement score, median (IQR) $(\mathrm{n}=280)$} & $1(0-4)$ & $1(0-3)$ & 0.953 \\
\hline \multirow[t]{4}{*}{ Involvement score, n (\%) } & 0 & $82(41.6)$ & $33(39.8)$ & \multirow[t]{4}{*}{0.848} \\
\hline & $1-2$ & $51(25.9)$ & $24(28.9)$ & \\
\hline & $3-4$ & $29(14.7)$ & $14(16.8)$ & \\
\hline & $>5$ & $35(17.8)$ & $12(11.0)$ & \\
\hline \multicolumn{2}{|c|}{ Segment score, median (IQR) $(n=280)$} & $1(0-4)$ & $1(0-4)$ & 0.946 \\
\hline \multirow[t]{4}{*}{ Segment score, n (\%) } & 0 & $82(41.6)$ & $33(39.8)$ & \multirow[t]{4}{*}{0.841} \\
\hline & $1-2$ & $48(24.2)$ & $23(27.7)$ & \\
\hline & $3-4$ & $25(12.7)$ & $8(9.6)$ & \\
\hline & $>5$ & $42(21.3)$ & $19(22.9)$ & \\
\hline Pericardial adipose tissue & n ml, mean $\pm S D(n=282)$ & $203 \pm 90$ & $176 \pm 77$ & 0.017 \\
\hline \multicolumn{2}{|c|}{ Pericardial adipose tissue indexed to $B M I$, mean $\pm S D(n=281)$} & $7.3 \pm 2.7$ & $6.5 \pm 2.6$ & 0.024 \\
\hline
\end{tabular}

$\mathrm{AAD}=$ Anti-Arrhythmic Drugs; $\mathrm{BMI}=$ Body mass index; $\mathrm{BSA}=$ Body Surface Area; COPD=Chronic Obstructive Pulmonary Disease; DAPT=Dual Anti-Platelet Therapy; LA=Left Atrial; LVEF=Left Ventricular Ejection Fraction; NOAC=Non vitamin $\mathrm{K}$ antagonist Oral AntiCoagulation; IQR=Inter-Quartile Range; $\mathrm{PVI}=$ Pulmonary Vein Isolation; RA=Right Atrial; $\mathrm{RF}=$ Radio Frequency; SD=Standard Deviation; TIA=Transient Ischemic Attack; VKA=Vitamin K Antagonist; WACA=Wide Antral Circumferential Ablation. 
PAT could be quantified in 97\% (282/292) of the CCTs within the diastolic phase and in 93\% (272/292) within the systolic phase. There was a strong positive correlation between the diastolic and systolic phase measured PAT for a certain HU threshold, as well as across the assessments with different $\mathrm{HU}$ thresholds in both cardiac phases (Table 2). For the remainder of the analysis, the $-30 \mathrm{HU}$ threshold was used since this is the most widely used threshold in available literature. There was a moderate positive correlation between PAT and BMI, $r=0.51, n=288, p<0.001$, and a weak positive correlation between PAT and left atrial volume (LAV), $r=0.29, n=218, p<0.001$.

Table 2. Pearson's correlations for the different pericardial adipose tissue assessments, $r$ values are depicted with $p<0.001$ for all correlations.

\begin{tabular}{lc|ccc|ccc} 
& & \multicolumn{3}{|c|}{ Diastolic phase } & \multicolumn{3}{c}{ Systolic phase } \\
\cline { 3 - 8 } & & $-15 \mathrm{HU}$ & $-30 \mathrm{HU}$ & $-45 \mathrm{HU}$ & $-15 \mathrm{HU}$ & $-30 \mathrm{HU}$ & $-45 \mathrm{HU}$ \\
\hline Diastolic phase & $-15 \mathrm{HU}$ & - & 0.997 & 0.991 & 0.949 & 0.950 & 0.949 \\
\cline { 2 - 8 } & $-30 \mathrm{HU}$ & 0.997 & - & 0.998 & 0.951 & 0.954 & 0.955 \\
\cline { 2 - 8 } & $-45 \mathrm{HU}$ & 0.991 & 0.998 & - & 0.946 & 0.952 & 0.954 \\
\hline Systolic phase & $-15 \mathrm{HU}$ & 0.949 & 0.951 & 0.946 & - & 0.998 & 0.995 \\
\cline { 2 - 8 } & $-30 \mathrm{HU}$ & 0.950 & 0.954 & 0.952 & 0.998 & - & 0.999 \\
\cline { 2 - 8 } & $-45 \mathrm{HU}$ & 0.949 & 0.955 & 0.954 & 0.995 & 0.999 & -
\end{tabular}

$\mathrm{HU}=$ Hounsfields Units.

Mean PAT volume was statistically significantly lower in the patients with successful PVI at maximum follow-up compared to those with AF recurrence (176 \pm 77 vs. $203 \pm 90 \mathrm{ml}, \mathrm{p}=0.017$; Figure 2). Correction for body mass index yielded comparable results (6.5 \pm 2.6 vs. $7.3 \pm 2.7$ $\mathrm{ml}, \mathrm{p}=0.024$; Figure 3). At 1-year follow-up, the difference was not statistically significant (190 \pm 94 vs. $203 \pm 89 \mathrm{ml}, \mathrm{p}=0.269)$. Furthermore, no differences were observed between patients with successful and not/partially successful PVI regarding the presence or the extent of CAD on CCTA, i.e. Agatston, calcium mass, segment score, or involvement score (Table 1). This was also the case for the 1-year follow-up. 


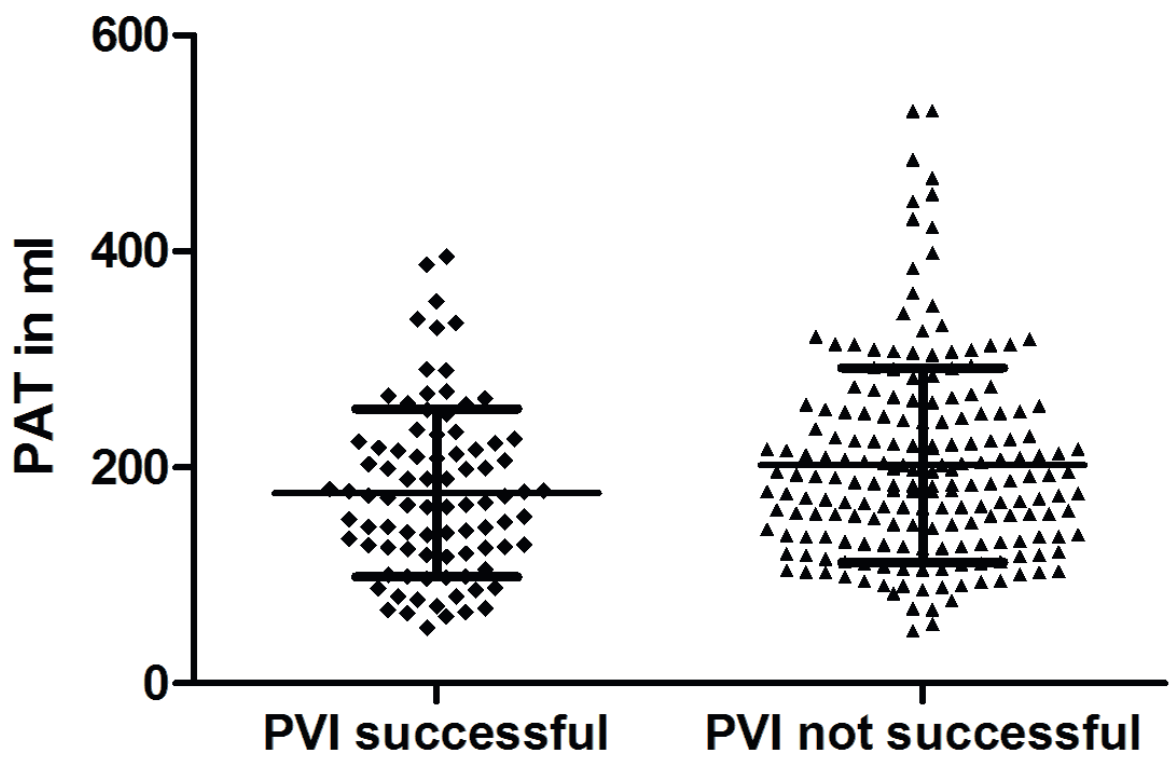

Figure 2. Pericardial adipose tissue volumes in $\mathrm{ml}$ for all patients, grouped by success of pulmonary vein isolation at maximum follow-up, with mean and standard deviation. PAT=Pericardial Adipose Tissue; PVI=Pulmonary Vein Isolation.

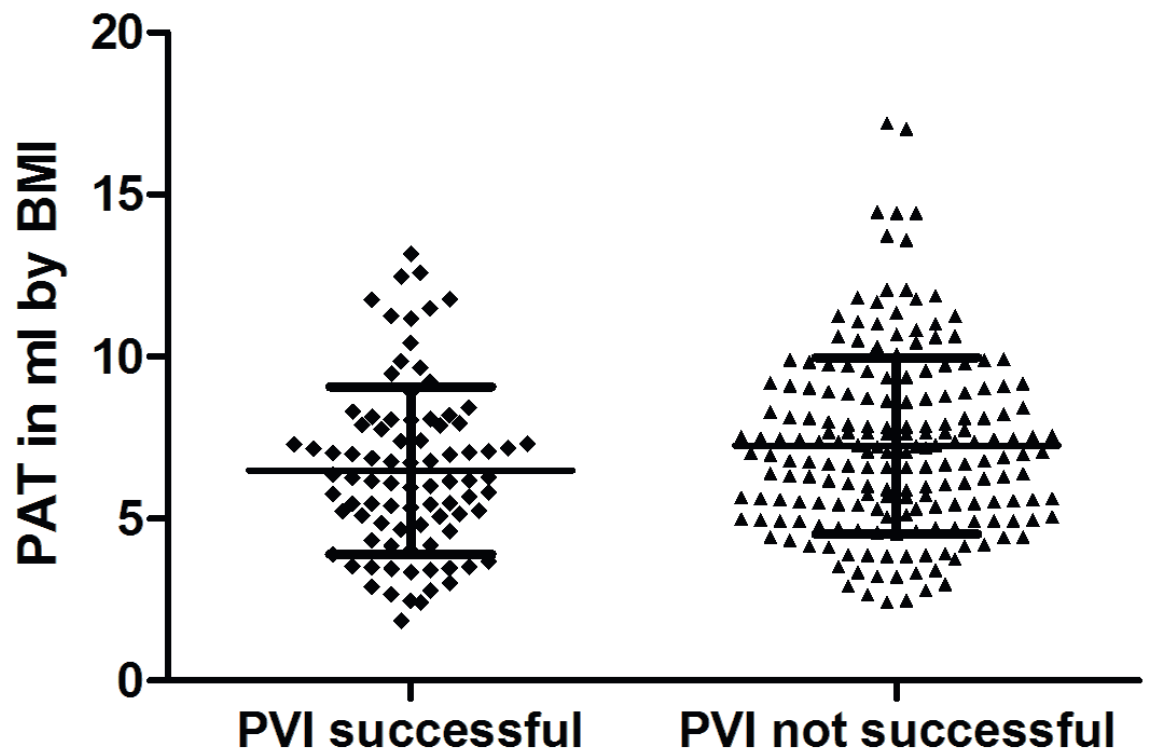

Figure 3. Pericardial adipose tissue volumes in $\mathrm{ml}$ corrected for BMI for all patients, grouped by success of pulmonary vein isolation at maximum follow-up, with mean and standard deviation. BMI=Body Mass Index; PAT=Pericardial Adipose Tissue; PVI=Pulmonary Vein Isolation. 
After multivariable logistic regression, LAVI was the only variable independently associated with PVI outcome at maximum follow-up (Table 3). With increasing LAVI, the chance of having a successful PVI decreased (Odds Ratio [OR] per ml/kg2 increase: 0.987; 95\% Confidence Interval [Cl] 0.974-0.999; p=0.039).

Table 3. Univariable and multivariable regression for success of PVI at maximum follow-up. Univariable Regression Multivariable Regression

\begin{tabular}{|c|c|c|c|c|}
\hline & Odds Ratio & p-value & Odds Ratio & p-value \\
\hline $\begin{array}{l}\text { Left atrial volume indexed to } \\
\mathrm{BSA}, \mathrm{ml} / \mathrm{kg}^{2}\end{array}$ & $0.967(0.939-0.996)$ & 0.033 & $0.967(0.939-0.996)$ & 0.033 \\
\hline Type II diabetes mellitus & $0.23(0.05-1.02)$ & 0.054 & & \\
\hline $\begin{array}{l}\text { Pericardial adipose tissue } \\
\text { indexed to BMI }\end{array}$ & $0.90(0.83-0.97)$ & 0.009 & & \\
\hline Total duration of atrial fibrillation & $0.998(0.994-1.001)$ & 0.206 & & \\
\hline Previous/current rhythm control & $0.50(0.23-1.06)$ & 0.071 & & \\
\hline $\begin{array}{l}\text { Left ventricular ejection fraction } \\
\text { on echocardiogram, in } \%\end{array}$ & $1.05(1.10-1.09)$ & 0.021 & & \\
\hline
\end{tabular}

A wave on echocardiogram

$1.010(1.001-1.020)$

0.029

BMI=Body mass index; BSA=Body Surface Area;

\section{DISCUSSION}

This study demonstrates that patients with maintenance of sinus rhythm after PVI show less pericardial adipose tissue on CCT prior to ablation, compared to patients with AF recurrences during follow-up. However, levels of PAT at baseline were not predictive of rhythm outcome after PVI in this cohort. In fact, LAVI was the only independent predictor of rhythm outcome after ablation, which is in accordance with several previous reports showing that left atrial volume is one of the strongest predictors of outcome after PVI.(7-11)

The relationship between PAT and prevalent AF is already established, i.e. patients with AF are characterized by higher volumes of PAT compared to those without.(12) Similarly, patients with persistent AF show higher volumes of PAT than patients with paroxysmal AF.(12) Regarding rhythm outcome after AF ablation, Wong et al. have shown that higher volumes of cardiac magnetic resonance imaging detected PAT are associated with poorer outcome after PVI.(13)

As for semi-automatically detected PAT on CCT, the evidence is conflicting. In a study with 40 AF patients, both left atrial pericardial adipose tissue (LA-PAT) and total PAT predicted 
AF recurrences after ablation.(14) In a different study with 274 patients, LA-PAT indexed to body surface area predicted AF recurrences after PVI.(15) No comparison was made with total PAT. Kim et al. (16) have performed the largest study regarding the association between PAT assessments on CCT and rhythm outcome after PVI. In 665 patients, PAT volumes at baseline could only predict AF recurrences in patients with persistent $A F$ and not in patients with paroxysmal AF.

Stojanovska et al. (17) conducted a study comparing epicardial adipose tissue (EAT) with extrapericardial AT, showing that only EAT could predict AF recurrences after ablation. The pericardium was manually traced in all patients and formed the border between what was considered EAT and extrapericardial AT. Extrapericardial AT alone as well as combined with EAT were not predictive of rhythm outcome after PVI, contrary to the conclusion of the studies mentioned above. Those and the present study combined EAT and extrapericardial AT volumes, since delineation of pericardium is hard to perform reliably and reproducibly in a semi-automatic manner.

PAT interacts with AF and the atria in various ways. Firstly, PAT is believed to stimulate a pro-inflammatory response in the atria through paracrine effects.(18) In addition, PAT contains ganglionated plexi, which also stimulate inflammation through an increase in cardiac autonomic nerve activity.(19) Moreover, PAT can lead to fibrotic remodeling of the atrial myocardium through secretion of inflammatory cytokines, growth factors, and matrix metalloproteinases.(20) All these processes combined lead to increased atrial remodeling and can possibly give cause for AF recurrences post ablation.

In addition to the paracrine effects, adipose tissue also exerts systemic effects, e.g. hypercoagulability, through thrombocyte activation, inhibiting fibrinolysis, and stimulating the synthesis of coagulation factors.(21) Hypercoagulability is known to cause atrial fibrosis in a mouse model, and as a consequence leading to an increased incidence of AF in these mice compared to wild-type mice.(22) The same pathophysiological mechanisms might partly explain the association between PAT and AF in man.

Contrary to our hypothesis, neither the presence nor the extent of CAD as detected by CCT differed between the patients with and without favorable rhythm outcome after PVI, similar to previous findings of a lack of association between clinically overt CAD and outcome after AF ablation.(23-25) 


\section{Limitations}

Firstly, the lack of continuous monitoring can lead to a possible underestimation of AF recurrences due to asymptomatic AF episodes after PVI. Secondly, we assessed total PAT as a surrogate marker for LA-PAT, since it was not possible to reliably and reproducibly quantify LA-PAT selectively. However, as described above, Nagashima et al. (14) have shown that both total PAT and LA-PAT predict AF recurrences after ablation in a relatively small population, suggesting that LA-PAT could be a derivative of total PAT.

\section{CONCLUSION}

Patients with successful pulmonary vein isolation after a median follow-up of 2 years showed less pericardial adipose tissue on cardiac CT at baseline, compared to patients with AF recurrences during follow-up. However, multivariable logistic regression only ascertained LAVI as a predictor of unfavorable PVI outcome. 


\section{REFERENCES}

1. Balk EM, Garlitski AC, Alsheikh-Ali AA, Terasawa T, Chung M, Ip S. Predictors of atrial fibrillation recurrence after radiofrequency catheter ablation: a systematic review. J Cardiovasc Electrophysiol. 2010;21(11):1208-16.

2. Calkins H, Hindricks G, Cappato R, Kim YH, Saad EB, Aguinaga L, et al. 2017 HRS/EHRA/ECAS/APHRS/SOLAECE expert consensus statement on catheter and surgical ablation of atrial fibrillation: Executive summary. Europace. 2017.

3. Kirchhof P, Benussi S, Kotecha D, Ahlsson A, Atar D, Casadei B, et al. 2016 ESC Guidelines for the management of atrial fibrillation developed in collaboration with EACTS: The Task Force for the management of atrial fibrillation of the European Society of Cardiology (ESC)Developed with the special contribution of the European Heart Rhythm Association (EHRA) of the ESCEndorsed by the European Stroke Organisation (ESO). Eur Heart J. 2016.

4. Weijs B, Pisters R, Haest RJ, Kragten JA, Joosen IA, Versteylen M, et al. Patients originally diagnosed with idiopathic atrial fibrillation more often suffer from insidious coronary artery disease compared to healthy sinus rhythm controls. Heart Rhythm. 2012;9(12):1923-9.

5. Austen WG, Edwards JE, Frye RL, Gensini GG, Gott VL, Griffith LS, et al. A reporting system on patients evaluated for coronary artery disease. Report of the Ad Hoc Committee for Grading of Coronary Artery Disease, Council on Cardiovascular Surgery, American Heart Association. Circulation. 1975;51(4 Suppl):5-40.

6. Bucher AM, Joseph Schoepf U, Krazinski AW, Silverman J, Spearman JV, De Cecco $\mathrm{CN}$, et al. Influence of technical parameters on epicardial fat volume quantification at cardiac CT. Eur J Radiol. 2015;84(6):1062-7.

7. Abecasis J, Dourado R, Ferreira A, Saraiva C, Cavaco D, Santos KR, et al. Left atrial volume calculated by multi-detector computed tomography may predict successful pulmonary vein isolation in catheter ablation of atrial fibrillation. Europace. 2009;11(10):1289-94.

8. Helms AS, West JJ, Patel A, Lipinski MJ, Mangrum JM, Mounsey JP, et al. Relation of left atrial volume from three-dimensional computed tomography to atrial fibrillation recurrence following ablation. Am J Cardiol. 2009;103(7):989-93.

9. Hof I, Chilukuri K, Arbab-Zadeh A, Scherr D, Dalal D, Nazarian S, et al. Does left atrial volume and pulmonary venous anatomy predict the outcome of catheter ablation of atrial fibrillation? J Cardiovasc Electrophysiol. 2009;20(9):1005-10.

10. Parikh SS, Jons C, McNitt S, Daubert JP, Schwarz KQ, Hall B. Predictive capability of left atrial size measured by CT, TEE, and TTE for recurrence of atrial fibrillation following radiofrequency catheter ablation. Pacing Clin Electrophysiol. 2010;33(5):532-40.

11. Shin SH, Park MY, Oh WJ, Hong SJ, Pak HN, Song WH, et al. Left atrial volume is a predictor of atrial fibrillation recurrence after catheter ablation. J Am Soc Echocardiogr. 2008;21(6):697-702. 
12. Gaeta M, Bandera F, Tassinari F, Capasso L, Cargnelutti M, Pelissero G, et al. Is epicardial fat depot associated with atrial fibrillation? A systematic review and metaanalysis. Europace. 2017;19(5):747-52.

13. Wong CX, Abed HS, Molaee P, Nelson AJ, Brooks AG, Sharma G, et al. Pericardial fat is associated with atrial fibrillation severity and ablation outcome. J Am Coll Cardiol. 2011;57(17):1745-51.

14. Nagashima K, Okumura Y, Watanabe I, Nakai T, Ohkubo K, Kofune T, et al. Association between epicardial adipose tissue volumes on 3-dimensional reconstructed CT images and recurrence of atrial fibrillation after catheter ablation. Circ J. 2011;75(11):2559-65.

15. Sanghai SR, Sardana M, Hansra B, Lessard DM, Dahlberg ST, Aurigemma GP, et al. Indexed Left Atrial Adipose Tissue Area Is Associated With Severity of Atrial Fibrillation and Atrial Fibrillation Recurrence Among Patients Undergoing Catheter Ablation. Front Cardiovasc Med. 2018;5:76.

16. Kim TH, Park J, Park JK, Uhm JS, Joung B, Lee MH, et al. Pericardial fat volume is associated with clinical recurrence after catheter ablation for persistent atrial fibrillation, but not paroxysmal atrial fibrillation: an analysis of over 600-patients. Int J Cardiol. 2014;176(3):841-6.

17. Stojanovska J, Kazerooni EA, Sinno M, Gross BH, Watcharotone K, Patel S, et al. Increased epicardial fat is independently associated with the presence and chronicity of atrial fibrillation and radiofrequency ablation outcome. Eur Radiol. 2015;25(8):2298-309.

18. Schotten U, Verheule S, Kirchhof P, Goette A. Pathophysiological mechanisms of atrial fibrillation: a translational appraisal. Physiol Rev. 2011;91(1):265-325.

19. Po SS, Nakagawa H, Jackman WM. Localization of left atrial ganglionated plexi in patients with atrial fibrillation. J Cardiovasc Electrophysiol. 2009;20(10):1186-9.

20. Hatem SN, Redheuil A, Gandjbakhch E. Cardiac adipose tissue and atrial fibrillation: the perils of adiposity. Cardiovasc Res. 2016;109(4):502-9.

21. Faber DR, de Groot PG, Visseren FL. Role of adipose tissue in haemostasis, coagulation and fibrinolysis. Obes Rev. 2009;10(5):554-63.

22. Spronk HM, De Jong AM, Verheule S, De Boer HC, Maass AH, Lau DH, et al. Hypercoagulability causes atrial fibrosis and promotes atrial fibrillation. Eur Heart J. 2017;38(1):38-50.

23. Arya A, Hindricks G, Sommer P, Huo Y, Bollmann A, Gaspar T, et al. Long-term results and the predictors of outcome of catheter ablation of atrial fibrillation using steerable sheath catheter navigation after single procedure in 674 patients. Europace. 2010;12(2):173-80.

24. McCready JW, Smedley T, Lambiase PD, Ahsan SY, Segal OR, Rowland E, et al. Predictors of recurrence following radiofrequency ablation for persistent atrial fibrillation. Europace. 2011;13(3):355-61.

25. Pappone C, Rosanio S, Augello G, Gallus G, Vicedomini G, Mazzone P, et al. Mortality, morbidity, and quality of life after circumferential pulmonary vein ablation for atrial fibrillation: outcomes from a controlled nonrandomized long-term study. J Am Coll Cardiol. 2003;42(2):185-97. 


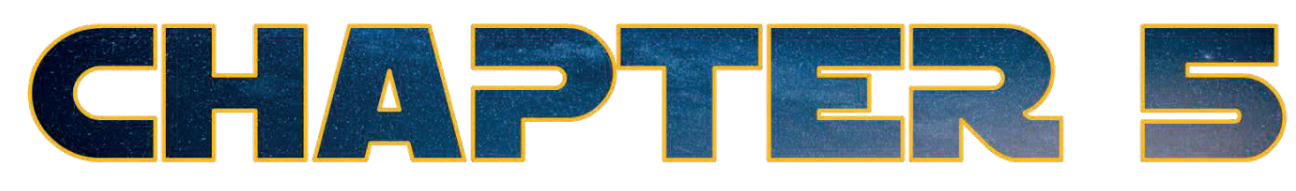

Temporal Patterns and Short-Term Progression of Paroxysmal Atrial Fibrillation: Data from RACE $V$

Ömer Erküner*, Ruben de With*, Michiel Rienstra, Bao-Oanh Nguyen, Frank Körver, Dominik Linz, Hugo ten Cate, Henri Spronk, Abraham Kroon, Alexander Maass, Yuri Blaauw, Robert Tieleman, Martin Hemels, Joris de Groot, Arif Elvan, Mirko de Melis, Coert Scheerder, Meelad Al-Jazairi, Ulrich Schotten, Justin Luermans, Harry Crijns, Isabelle van Gelder

* Both authors contributed equally 


\section{ABSTRACT}

\section{Background}

Atrial fibrillation (AF) often starts as a paroxysmal selfterminating arrhythmia. Limited information is available on AF patterns and episode duration of paroxysmal AF. In paroxysmal AF patients we longitudinally studied the temporal AF patterns, the association with clinical characteristics, and prevalence of AF progression.

\section{Methods and results}

In the Reappraisal of AF: Interaction Between HyperCoagulability, Electrical Remodelling, and Vascular Destabilisation in the Progression of AF (RACE V) registry 202 patients with paroxysmal AF were followed with continuous rhythm monitoring (implantable loop recorder or pacemaker) for 6 months. Mean age was $64 \pm 9$ years, $42 \%$ were women. AF history was

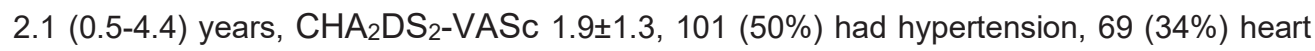
failure. One third did not show any AF during follow-up. Patients with long episodes (>12 hours) were often men with more comorbidities (heart failure, coronary artery disease, higher left ventricular mass). Patients with higher AF burden $(>2.5 \%)$ were older with more comorbidities (worse renal function, higher calcium score, thicker intima media thickness). In $179(89 \%)$ patients 1-year rhythm follow-up was available. On a quarterly basis, average daily AF burden increased from $3.2 \%$ to $3.8 \%, 5.2 \%$ and $6.1 \%$. Compared to the first 6 months, $111(62 \%)$ patients remained stable during the second 6 months, 39 (22\%) showed progression to longer AF episodes, 8 (3\%) developed persistent AF, 29 (16\%) patients showed AF regression.

\section{Conclusions}

In paroxysmal AF, temporal patterns differ suggesting that paroxysmal AF is not one entity. $\mathrm{AF}$ burden is low and determined by number of comorbidities. Modest AF progression occurs in a substantial number. 


\section{INTRODUCTION}

Traditionally, atrial fibrillation (AF) is clinically categorized into paroxysmal, persistent, longstanding persistent and permanent AF.(1) Often starting as short-lasting, paroxysmal episodes, AF commonly progresses over time to persistent and permanent, nonselfterminating AF.(2) Progression of AF is associated with a higher incidence of major adverse cardiovascular and cerebrovascular events. $(3,4)$ However, most data on AF and AF progression is obtained with intermittent rhythm monitoring, providing limited information on the total burden and the temporal pattern of AF.(5-7) In the era of implantable loop recorders, it is now possible to assess progression of AF more precisely.(8) These devices also provide information on the exact temporal AF pattern and number and duration of AF episodes, which may help explaining differences in underlying pathophysiological AF mechanisms and related clinical outcomes. Ultimately this could aid to personalize AF therapy and may have clinical utility for the assessment of AF treatment response.

Recently, the first initiatives for an improved classification for paroxysmal AF have been proposed, based on single-lead electrocardiogram (ECG) monitoring.(9) The Reappraisal of Atrial Fibrillation: Interaction Between HyperCoagulability, Electrical Remodelling, and Vascular Destabilisation in the Progression of Atrial Fibrillation (RACE V) registry aims to elucidate the factors associated with AF progression. At baseline, deep phenotyping of patients with paroxysmal selfterminating AF is performed. Exact longitudinal assessment of episode number and duration and AF burden is provided by continuous rhythm monitoring through an implantable loop recorder or pacemaker with the same AF detection algorithm. In the present interim analysis, we aim to study paroxysmal AF temporal patterns, burden and short-term progression, and their association with clinical characteristics.

\section{METHODS}

\section{Patient population}

The RACE $V$ is an investigator-initiated, prospective, multicenter registry aiming to include 750 patients in multiple centers in The Netherlands. A total of 202 patients were included in 5 centers for the current interim analysis between June 2016 and December 2017. Inclusion criteria included patients aged $>18$ years with paroxysmal AF; a maximum history of 10 years since diagnosis at the moment of inclusion; a maximum $\mathrm{CHA}_{2} \mathrm{DS}_{2}-\mathrm{VASc}$ score of 5 ; and no other indication for anticoagulation drugs (e.g. mechanical valve prosthesis). Patients had to have at least two documented episodes of paroxysmal AF in the past year or one documented episode combined with at least two symptomatic episodes in the past year 
suspected to be AF. In patients with a Medtronic pacemaker, atrial high rate episodes $($ AHRE) $>190$ beats per minute lasting $>6$ minutes were qualified as AF episodes. Patients with other types of pacemakers, defibrillators or cardiac resynchronization therapy could not participate due to differences in AHRE algorithm or incompatibility with the type of home monitoring. Patients with a history of persistent AF, currently treated with amiodarone, current pregnancy or a life expectancy $<2.5$ years were not eligible to participate. Patients with AF caused exclusively by transient triggers (e.g. postoperative, due to infection) could also not participate, as well as patients with a previous pulmonary vein isolation (PVI), or intention to undergo PVI. The study was performed in concordance with the Declaration of Helsinki. The Institutional Review Board approved the protocol and the study was registered at Clinicaltrials.gov (identifier NCT02726698). All centers approved the protocol and all patients gave written informed consent. Intended median total follow-up duration is 2.5 years.

\section{Study procedures}

All patients received causal therapy for $\mathrm{AF}$, as well as rate and rhythm control according to the European Society of Cardiology AF guidelines.(1) At baseline, information on clinical characteristics, medical history, AF characteristics, symptomatology and current medication were collected. Additionally, all patients underwent physical examination, a 12-lead ECG, echocardiography, cardiac computed tomography (CT), vascular assessment and blood sampling. After baseline, additional follow-up visits were planned at 1 and 2.5 years.

The cardiac CT was performed as a non-contrast ECG-gated scan with slice collimation of $0.6 \mathrm{~mm}$ and a tube voltage of $120 \mathrm{kV}$. Cranial demarcation was placed at the aortic arch or higher and caudal demarcation was placed to include the whole heart. Automated coronary calcium scores (Agatston) were collected.

Vascular assessment included pulse wave velocity (PWV) and intima media thickness (IMT) measurements. PWV velocity was measured by SphygmoCor (Atcor Medical Blood Pressure Analysis System, Australia) or Complior (Alam Medical, France) at the carotid and femoral arteries. To determine aortic PWV, $\geq 20$ consecutive pressure waveforms were collected at the carotid artery and the femoral artery. The system software calculated the wave transit time, using the $\mathrm{R}$ wave of the simultaneously recorded ECG. Distance between both measure points was determined and corrected by multiplying the distance by 0.8 . The PWV was calculated by dividing the corrected distance by the wave transit time. IMT measurements were performed by ultrasound (Siemens Acuson S2000) with the Syncho US Workplace 3.5, Arterial Health Package for automated IMT measurement. IMT was bilaterally assessed in the common carotid artery, the carotid bifurcation and internal carotid artery. 


\section{Rhythm follow-up}

All patients had continuous rhythm monitoring to detect the exact AF burden (time spent in $\mathrm{AF}$ ) and temporal AF pattern (the number and duration of AF episodes). Patients either received a Medtronic Reveal $L I N Q \circledR$ implantable loop recorder subcutaneously or had a Medtronic pacemaker implanted prior to inclusion. All patients received a home monitoring device (Medtronic Carelink ${ }^{\circledR}$ ) in order to collect all data regarding cardiac arrhythmias on the Carelink Network $®$. Patients were instructed to perform at least weekly manual data transmissions to prevent potential data loss. AT/AF detection setting was set to AF detection only. Additional settings included a tachy-pause-brady data storage priority and balanced sensitivity for AF detection with nominal ectopy rejection for all patients. All episodes of AF $\geq 2$ minutes were automatically detected. Episodes $\geq 182$ beats per minute with a duration of $\geq 24$ beats were automatically classified as tachycardia and if applicable, corrected to AF episodes. First, a dedicated service (Fysiologic, Amsterdam, The Netherlands) adjudicated all episodes. As a second assessment all episodes were independently adjudicated by 2 physicians (R.R.D.W.; Ö.E.) and corrected if needed. Information on changes in antiarrhythmic drug (AAD) therapy, electrical cardioversion (ECV) and PVI were collected during follow-up.

\section{Atrial fibrillation patterns}

AF patterns during 6 months (183 days) were visualized by custom-made software using Microsoft Visual Basic. First day of monitoring started at midnight the day after loop recorder implantation or at midnight the day after inclusion in patients with a pacemaker. AF patterns were independently adjudicated by 4 physicians (R.R.D.W.; Ö.E.; H.J.G.M.C.; I.C.V.G.). At first, all patients were divided into having no recurrence of $A F$ or $\geq 1$ episode of $A F$ during follow-up. Secondly, patients with AF episodes were divided by into short AF episodes duration ( $<6$ hours), intermediate ( $6-12$ hours), and long AF episodes ( $>12$ hours) by their longest AF episode during the first 6 months. Third, AF burden was calculated by the cumulative time in AF divided by the total follow-up time, expressed as a percentage. In addition, patients were divided according to degree of AF burden: low AF burden $(>0-0.5 \%)$, intermediate $(>0.5-2.5 \%)$, and high AF burden $(>2.5 \%)$. The aforementioned cut-offs for AF burden were used to create equally-sized groups.

AF progression was assessed in 179 patients in whom 1 year (366 days) of rhythm follow-up was available. These patients were also divided into no AF, short, intermediate and long episodes according to the second 6 months of rhythm follow-up. AF progression was defined as deterioration of episode duration category (e.g. short to intermediate episodes) in the 
second 6 months, as compared to the first 6 months. Regression was defined as episode category improvement (e.g. intermediate to short episodes). Daily averaged AF burden was calculated by the sum of the daily AF burden from all patients and divided by the number of patients. Patients with episodes $>7$ days were considered to have persistent AF.

\section{Statistical analysis}

Data was presented as means \pm standard deviation or median with interquartile range, depending on normality of the data. Categorical data was presented as numbers with percentages. Differences between patients with and without AF recurrence were tested by Student's T-test, Man-Whitney $U$ test or Fisher's exact (2 categories) or X2 (>2 categories). Differences between different AF patterns were analyzed by one-way ANOVA in normally distributed data, Kruskall-Wallis test in non-normally distributed data or $x 2$ in categorical data. Additional sensitivity analyses were performed excluding the following groups: (1) patients that underwent PVI or ECV during follow-up; (2) patients that underwent PVI, ECV or had changes in AAD therapy during follow-up; and (3) patients that underwent PVI, ECV or any AAD therapy during follow-up. Spearman's correlation coefficient, including 95\% confidence interval $(\mathrm{Cl})$, was calculated to assess the relation of $A F$ burden and the duration of the longest AF episode. Changes in the duration of longest AF episode category in the first 6 months and second 6 months were visualized using a Sankey diagram. All analyses were performed by IBM SPSS Statistics for Windows version 23.0 (Armonk, New York, USA) and GraphPad Prism version 7.02 (GraphPad Software, La Jolla, USA). A P-value $<0.05$ was considered statistically significant.

\section{RESULTS}

\section{Patient characteristics}

Baseline characteristics are shown in Table 1. Mean age was $64 \pm 9$ years, $85(42 \%)$ were women and median history of AF at baseline was 2.1 (0.5-4.4) years. The majority had an implantable loop recorder (185 [92\%]); 17 (8\%) had a pacemaker. Patients with a pacemaker were older $(72 \pm 9$ versus $64 \pm 9$ years, $\mathrm{P}<0.001)$ and had more comorbidities $(2.9 \pm 1.5$ versus $2.3 \pm 1.3, p=0.049)$. 
Table 1. Baseline characteristics of the total population, and split on recurrence of AF during 6-months follow-up.

\begin{tabular}{|c|c|c|c|c|}
\hline & $\begin{array}{c}\text { Total } \\
(\mathrm{N}=202)\end{array}$ & $\begin{array}{c}\text { No Recurrence } \\
\text { of } A F \\
(N=63)\end{array}$ & $\begin{array}{c}\text { Recurrence } \\
\text { of AF } \\
(N=139)\end{array}$ & $\begin{array}{c}\mathrm{p}- \\
\text { value }\end{array}$ \\
\hline Age (years) & $64 \pm 9$ & $64 \pm 10$ & $64 \pm 9$ & 0.900 \\
\hline Male sex & $117(58 \%)$ & $36(57 \%)$ & $81(58 \%)$ & 0.880 \\
\hline Total history AF (years) & $2.1(0.5-4.4)$ & $1.9(0.5-5.3)$ & $2.2(0.6-4.5)$ & 0.574 \\
\hline Heart failure & $69(34 \%)$ & $21(33 \%)$ & $48(35 \%)$ & 0.868 \\
\hline Hypertension & $101(50 \%)$ & $40(64 \%)$ & $61(44 \%)$ & 0.010 \\
\hline Diabetes mellitus & $19(9 \%)$ & $8(13 \%)$ & $11(8 \%)$ & 0.304 \\
\hline Coronary artery disease & $23(11 \%)$ & $5(8 \%)$ & $18(13 \%)$ & 0.299 \\
\hline Thromboembolic events & $22(11 \%)$ & $9(14 \%)$ & $13(9 \%)$ & 0.297 \\
\hline Chronic obstructive pulmonary disease & $11(5 \%)$ & $3(5 \%)$ & $8(6 \%)$ & 0.773 \\
\hline Number of Comorbidities* & $2.3 \pm 1.3$ & $2.5 \pm 1.3$ & $2.3 \pm 1.3$ & 0.199 \\
\hline $\mathrm{CHA}_{2} \mathrm{DS}_{2}$-VASc & $1.9 \pm 1.3$ & $2.2 \pm 1.3$ & $1.8 \pm 1.3$ & 0.030 \\
\hline 0 & $25(12 \%)$ & $4(6 \%)$ & $21(15 \%)$ & \\
\hline 1 & $56(28 \%)$ & $14(22 \%)$ & $42(30 \%)$ & \\
\hline 2 & $60(30 \%)$ & $25(39 \%)$ & $35(25 \%)$ & \\
\hline 3 & $35(17 \%)$ & $8(12 \%)$ & $27(19 \%)$ & \\
\hline 4 & $18(9 \%)$ & $7(11 \%)$ & $11(8 \%)$ & \\
\hline 5 & $8(4 \%)$ & $5(8 \%)$ & $3(2 \%)$ & \\
\hline EHRA class & & & & 0.143 \\
\hline I & $22(11 \%)$ & $9(14 \%)$ & $13(9 \%)$ & \\
\hline II & $84(42 \%)$ & $24(38 \%)$ & $60(43 \%)$ & \\
\hline III & $78(39 \%)$ & $28(44 \%)$ & $50(36 \%)$ & \\
\hline IV & $18(9 \%)$ & $2(3 \%)$ & $16(12 \%)$ & \\
\hline Height (cm) & $176 \pm 10$ & $176 \pm 10$ & $176 \pm 11$ & 0.873 \\
\hline Weight (kg) & $86 \pm 17$ & $85 \pm 15$ & $86 \pm 18$ & 0.747 \\
\hline BMI $\left(\mathrm{kg} / \mathrm{m}^{2}\right)$ & $28 \pm 5$ & $28 \pm 5$ & $28 \pm 5$ & 0.956 \\
\hline Obesity (BMI>30) & $50(25 \%)$ & $17(27 \%)$ & $33(24 \%)$ & 0.621 \\
\hline Waist circumference (cm) & $102 \pm 13$ & $103 \pm 14$ & $102 \pm 13$ & 0.692 \\
\hline \multicolumn{5}{|l|}{ Blood pressure (mmHg) } \\
\hline Systolic & $136 \pm 18$ & $135 \pm 17$ & $137 \pm 19$ & 0.458 \\
\hline Diastolic & $81 \pm 10$ & $80 \pm 11$ & $81 \pm 9$ & 0.649 \\
\hline NT-proBNP (pg/ml) & $50(22-144)$ & $54(27-123)$ & $48(19-159)$ & 0.540 \\
\hline Creatinine $(\mu \mathrm{mol} / \mathrm{L})$ & $82(70-92)$ & $82(70-92)$ & $82(71-92)$ & 0.476 \\
\hline
\end{tabular}




\begin{tabular}{|c|c|c|c|c|}
\hline eGFR (mL/min) & $80(68-88)$ & $82(68-91)$ & $79(68-88)$ & 0.491 \\
\hline \multicolumn{5}{|l|}{ Medications } \\
\hline$\beta$-blocker & $104(52 \%)$ & $33(52 \%)$ & $71(51 \%))$ & 0.864 \\
\hline Verapamil/Diltiazem & $31(15 \%)$ & $9(14 \%)$ & $22(16 \%)$ & 0.778 \\
\hline Class I antiarrhythmic drugs & $41(20 \%)$ & $6(10 \%)$ & $35(25 \%)$ & 0.013 \\
\hline Class III antiarrhythmic drugs & $11(5 \%)$ & $3(5 \%)$ & $8(6 \%)$ & 1.000 \\
\hline Digoxin & $2(1 \%)$ & - & $2(1.4 \%)$ & 0.339 \\
\hline ACE-inhibitor & $43(21 \%)$ & $18(29 \%)$ & $25(18 \%)$ & 0.089 \\
\hline Angiotensin Receptor Blocker & $44(22 \%)$ & $22(35 \%)$ & $22(16 \%)$ & 0.002 \\
\hline Mineralocorticoid Receptor Antagonist & $3(2 \%)$ & - & $3(2 \%)$ & 0.240 \\
\hline Statin & $80(40 \%)$ & $27(43 \%)$ & $53(38 \%)$ & 0.524 \\
\hline Diuretic & $33(16 \%)$ & $17(26 \%)$ & $16(12 \%)$ & 0.006 \\
\hline Anticoagulant & & & & 0.079 \\
\hline Vitamin $\mathrm{K}$ antagonist & $33(16 \%)$ & $11(17 \%)$ & $22(16 \%)$ & \\
\hline NOAC & $114(56 \%)$ & $40(63 \%)$ & $74(53 \%)$ & \\
\hline \multicolumn{5}{|l|}{ Echocardiographic variables } \\
\hline Left atrial volume $(\mathrm{mL})$ & $69 \pm 23$ & $62 \pm 20$ & $72 \pm 24$ & 0.013 \\
\hline Left atrial volume index $\left(\mathrm{mL} / \mathrm{m}^{2}\right)$ & $35 \pm 12$ & $31 \pm 10$ & $37 \pm 12$ & 0.002 \\
\hline Left ventricular ejection fraction (\%) & $58(55-60)$ & $58(55-60)$ & $58(55-60)$ & 0.661 \\
\hline Left ventricular ejection fraction $<45 \%$ & $4(2 \%)$ & $2(3 \%)$ & $2(1 \%)$ & 0.412 \\
\hline Left ventricular mass $(\mathrm{g})$ & $162 \pm 47$ & $156 \pm 45$ & $164 \pm 47$ & 0.417 \\
\hline Left ventricular mass index $\left(\mathrm{g} / \mathrm{m}^{2}\right)$ & $79 \pm 18$ & $77 \pm 17$ & $80 \pm 19$ & 0.468 \\
\hline Left ventricular hypertrophy & $8(4 \%)$ & $2(3 \%)$ & $6(4 \%)$ & 0.700 \\
\hline CT Calcium score (Agatston) & $31(0-227)$ & $41(0-262)$ & $26(0-216)$ & 0.733 \\
\hline \multicolumn{5}{|l|}{ Vascular assessment } \\
\hline IMT-CCA (mm) & $\begin{array}{c}0.72 \\
(0.63-0.87)\end{array}$ & $\begin{array}{c}0.71 \\
(0.62-0.88)\end{array}$ & $\begin{array}{c}0.73 \\
(0.64-0.87)\end{array}$ & 0.418 \\
\hline IMT-all segments (mm) & $\begin{array}{c}0.73 \\
(0.62-0.90)\end{array}$ & $\begin{array}{c}0.70 \\
(0.60-0.94)\end{array}$ & $\begin{array}{c}0.74 \\
(0.63-0.87)\end{array}$ & 0.835 \\
\hline Pulse wave velocity $(\mathrm{m} / \mathrm{s})$ & $8.3(7.3-9.7)$ & $8.6(7.2-9.7)$ & $8.1(7.3-9.7)$ & 0.382 \\
\hline
\end{tabular}

Data are presented as mean \pm standard deviation, number of patients (\%), or median (interquartile range). Abbreviations: $\mathrm{ACE}=$ angiotensin-converting enzyme; $\mathrm{AF}=$ atrial fibrillation; $\mathrm{BMI}=$ body mass index; $\mathrm{CCA}=$ common carotid artery; eGFR=estimated glomerular filtration rate; $E H R A=$ European Heart Rhythm Association class for symptoms; IMT=intima media thickness; NOAC $=$ novel oral anticoagulation; NT-pro BNP=N-terminal pro-brain natriuretic peptide; *The number of comorbidities was calculated by awarding points for hypertension, heart failure, age >65 years, diabetes mellitus; coronary artery disease, $\mathrm{BMI}>25 \mathrm{~kg} / \mathrm{m} 2$, moderate or severe mitral valve regurgitation and kidney dysfunction $(\mathrm{eGFR}<60)$; 


\section{AF episodes}

A total of 13,657 episodes of AF in 202 patients were automatically detected by the implanted device during a median follow-up of 183 days, of which 2,231 (16\%) episodes were adjudicated as false positive for AF, for example due to premature atrial beats, ventricular extra beats or artefacts. Most (93\%) false positive episodes lasted $\leq 10$ minutes. Forty episodes of AF were originally classified as tachycardia. After applying all corrections, 11,466 episodes of AF remained, with a median AF burden of $0.3 \%$ (0-2.1\%, maximal burden $61.1 \%$ ) during 6-months follow-up (total of 36,966 days of continuous day-to-day heart rhythm data for analysis). Of these 11,466 episodes, 11,456 (>99.9\%) episodes were selfterminating. Ten episodes in 8 patients were non-selfterminating AF. These patients underwent an ECV. Of these 8 patients, 2 had short, 3 had intermediate and 3 had long selfterminating AF episodes. Changes in AAD therapy were made in 6 patients (4 started with flecainide; 1 started sotalol; and in 1 patient flecainide was stopped). Three patients underwent a PVI within 6 months (at day 64, 163 and 171 of follow-up, respectively), of which 1 patient had episodes of intermediate duration and 2 had long episodes.

\section{AF patterns}

During follow-up 63 patients (31\%) had no recurrence of AF (Table 1). Patients without AF recurrence had more often hypertension, a higher $\mathrm{CHA}_{2} \mathrm{DS}_{2}-\mathrm{VASc}$ score, smaller left atria, and were more often treated with angiotensin converting enzyme inhibitors (ACE) or angiotensin receptor blockers (ARB) and diuretics. The estimated number of AF episodes the year before inclusion was not different from the ones with AF recurrences [9 (2-50) versus 10 (4-50) episodes, $p=0.357$ ]. Forty-five (22\%) patients had short, 38 (19\%) had intermediate, and $56(28 \%)$ had long episodes. Figure 1 shows examples of patients with short, intermediate and long episodes. Patients with long episodes were more often men, had more often heart failure, coronary artery disease, a higher number of comorbidities, a larger waist circumference and higher left ventricular mass (Table 2). Several sensitivity analyses were performed, excluding patients with AAD therapy, ECV or PVI during follow-up. Although not all differences remained significant, similar trends were observed.

Fifty (25\%) patients had low, $44(22 \%)$ intermediate, and $45(22 \%)$ had high AF burden (Table 3). Patients with high AF burden were older, had a higher number of comorbidities, a higher $\mathrm{CHA}_{2} \mathrm{DS}_{2}$-VASc score, a lower eGFR, higher coronary calcium score and a thicker IMT. Figure 2 shows the correlation between AF burden and the duration of the longest AF episode [Spearman's $\rho 0.917$ (95\% Cl 0.891-0.937), $\mathrm{P}<0.001$ ]. Only 4 patients had long episodes accompanied by a low AF burden and 2 had short episodes with a high AF burden. 

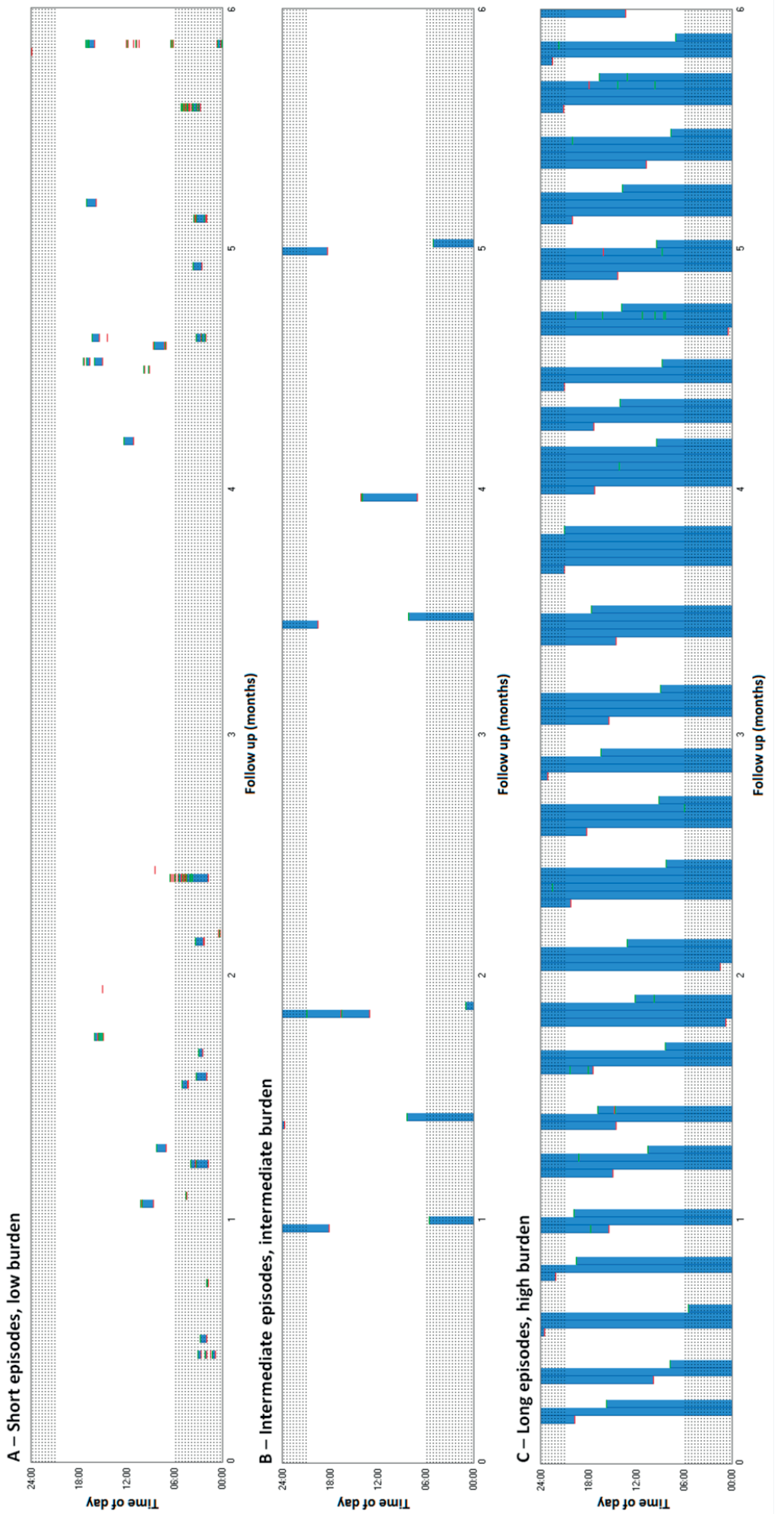

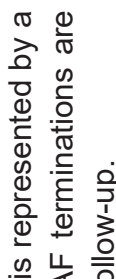

तेष

등 을

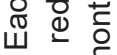

을 E

光衣告

응 क

든 은

들 들

일

高.

눈을

ब

워

응

(ิ) 임

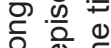

음요 으

ธิ

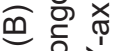

崩

등

$\varepsilon$ ळ

힏이음

두을

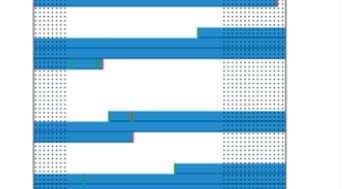

는흐ㅇㅡㅡ

के 든

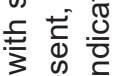

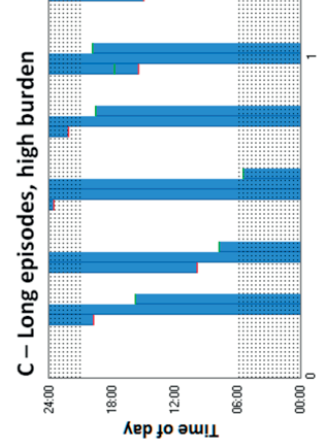

일

娄

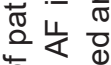

棺

क ल क

으 त

ฟั) ญ ญ

ய. क

는

흐 흥 음 
Table 2. Patients' characteristics and longest AF episode duration during 6-month follow-up.

\begin{tabular}{|c|c|c|c|c|}
\hline & $\begin{array}{c}\text { Short } \\
\text { episodes } \\
(\mathrm{N}=45)\end{array}$ & $\begin{array}{l}\text { Intermediate } \\
\text { episodes } \\
(\mathrm{N}=38)\end{array}$ & $\begin{array}{c}\text { Long } \\
\text { episodes } \\
(\mathrm{N}=56)\end{array}$ & $\begin{array}{c}\mathrm{p}- \\
\text { value }\end{array}$ \\
\hline Age (years) & $63 \pm 10$ & $63 \pm 10$ & $67 \pm 7$ & 0.068 \\
\hline Male sex & $17(38 \%)$ & $23(61 \%)$ & $41(73 \%)$ & 0.002 \\
\hline Total history AF (years) & $2.1(0.7-4.5)$ & $1.8(0.4-3.9)$ & $2.5(0.6-4.8)$ & 0.384 \\
\hline Heart failure & $9(20 \%)$ & $16(42 \%)$ & $23(41 \%)$ & 0.044 \\
\hline Hypertension & $20(44 \%)$ & $13(34 \%)$ & $28(50 \%)$ & 0.317 \\
\hline Diabetes mellitus & $3(7 \%)$ & $1(3 \%)$ & $7(13 \%)$ & 0.205 \\
\hline Coronary artery disease & $3(7 \%)$ & $3(8 \%)$ & $12(21 \%)$ & 0.049 \\
\hline Thromboembolic events & $6(13 \%)$ & $3(8 \%)$ & $4(7 \%)$ & 0.533 \\
\hline Chronic obstructive pulmonary disease & $2(4 \%)$ & $2(5 \%)$ & $4(7 \%)$ & 0.836 \\
\hline Number of comorbidities* & $1.9 \pm 1.2$ & $2.0 \pm 1.2$ & $2.7 \pm 1.4$ & 0.007 \\
\hline $\mathrm{CHA}_{2} \mathrm{DS}_{2}-\mathrm{VASc}$ & $1.9 \pm 1.1$ & $1.6 \pm 1.4$ & $1.9 \pm 1.2$ & 0.407 \\
\hline 0 & $4(9 \%)$ & $11(29 \%)$ & $6(11 \%)$ & \\
\hline 1 & $14(31 \%)$ & $10(26 \%)$ & $18(32 \%)$ & \\
\hline 2 & $14(31 \%)$ & $7(18 \%)$ & $14(25 \%)$ & \\
\hline 3 & $10(22 \%)$ & $5(13 \%)$ & $12(21 \%)$ & \\
\hline 4 & $2(4 \%)$ & $4(11 \%)$ & $5(9 \%)$ & \\
\hline 5 & $1(2 \%)$ & $1(3 \%)$ & $1(2 \%)$ & \\
\hline EHRA class & & & & 0.965 \\
\hline 1 & $4(9 \%)$ & $3(8 \%)$ & $6(11 \%)$ & \\
\hline II & $17(38 \%)$ & $17(45 \%)$ & $26(46 \%)$ & \\
\hline III & $22(49 \%)$ & $15(40 \%)$ & $13(23 \%)$ & \\
\hline IV & $2(4 \%)$ & $3(8 \%)$ & $11(20 \%)$ & \\
\hline Height $(\mathrm{cm})$ & $173 \pm 10$ & $176 \pm 11$ & $178 \pm 11$ & 0.057 \\
\hline Weight (kg) & $82 \pm 18$ & $86 \pm 16$ & $90 \pm 18$ & 0.084 \\
\hline BMI $\left(\mathrm{kg} / \mathrm{m}^{2}\right)$ & $27 \pm 5$ & $28 \pm 4$ & $28 \pm 5$ & 0.353 \\
\hline Obesity (BMI>30) & $9(20 \%)$ & $8(21 \%)$ & $16(29 \%)$ & 0.543 \\
\hline Waist circumference (cm) & $97 \pm 13$ & $101 \pm 11$ & $105 \pm 13$ & 0.010 \\
\hline \multicolumn{5}{|l|}{ Blood pressure $(\mathrm{mmHg})$} \\
\hline Systolic & $135 \pm 18$ & $139 \pm 20$ & $136 \pm 18$ & 0.675 \\
\hline Diastolic & $80 \pm 10$ & $82 \pm 10$ & $81 \pm 8$ & 0.616 \\
\hline NT-proBNP (pg/ml) & $33(14-130)$ & $62(23-165)$ & $48(22-197)$ & 0.312 \\
\hline Creatinine $(\mu \mathrm{mol} / \mathrm{L})$ & $76(67-85)$ & $80(71-92)$ & $86(77-95)$ & 0.009 \\
\hline eGFR (mL/min) & $83(69-90)$ & $79(66-86)$ & $76(65-87)$ & 0.297 \\
\hline
\end{tabular}




\begin{tabular}{|c|c|c|c|c|}
\hline \multicolumn{5}{|l|}{ Medications } \\
\hline$\beta$-blocker & $21(47 \%)$ & $18(47 \%)$ & $32(57 \%)$ & 0.501 \\
\hline Verapamil/diltiazem & $6(13 \%)$ & $9(24 \%)$ & $7(13 \%)$ & 0.296 \\
\hline Class I antiarrhythmic drugs & $17(38 \%)$ & $11(29 \%)$ & $7(13 \%)$ & 0.012 \\
\hline Class III antiarrhythmic drugs & $2(4 \%)$ & $1(3 \%)$ & $5(9 \%)$ & 0.393 \\
\hline Digoxin & $1(2 \%)$ & - & $1(2 \%)$ & 0.671 \\
\hline ACE-inhibitor & $7(16 \%)$ & $5(13 \%)$ & $13(23 \%)$ & 0.403 \\
\hline Angiotensin Receptor Blocker & $5(11 \%)$ & $5(13 \%)$ & $12(21 \%)$ & 0.321 \\
\hline Mineralocorticoid Receptor Antagonist & - & $1(3 \%)$ & $2(4 \%)$ & 0.458 \\
\hline Statin & $14(31 \%)$ & $8(21 \%)$ & $31(55 \%)$ & 0.002 \\
\hline Diuretic & $4(9 \%)$ & $4(11 \%)$ & $8(15 \%)$ & 0.683 \\
\hline Anticoagulant & & & & 0.128 \\
\hline Vitamin $\mathrm{K}$ antagonist & $5(9 \%)$ & $5(13 \%)$ & $12(21 \%)$ & \\
\hline NOAC & $24(53 \%)$ & $18(47 \%)$ & $32(57 \%)$ & \\
\hline \multicolumn{5}{|l|}{ Echocardiographic variables } \\
\hline Left atrial volume (mL) & $71 \pm 25$ & $71 \pm 23$ & $72 \pm 24$ & 0.973 \\
\hline Left atrial volume index $\left(\mathrm{mL} / \mathrm{m}^{2}\right)$ & $37 \pm 13$ & $37 \pm 11$ & $36 \pm 11$ & 0.850 \\
\hline Left ventricular ejection fraction (\%) & $58(55-60)$ & $58(55-62)$ & $58(55-61)$ & 0.573 \\
\hline Left ventricular ejection fraction $<45 \%$ & $1(2 \%)$ & $1(3 \%)$ & - & 0.498 \\
\hline Left ventricular mass $(\mathrm{g})$ & $141 \pm 36$ & $166 \pm 36$ & $178 \pm 55$ & 0.009 \\
\hline Left ventricular mass index $\left(\mathrm{g} / \mathrm{m}^{2}\right)$ & $74 \pm 14$ & $78 \pm 18$ & $85 \pm 21$ & 0.046 \\
\hline Left ventricular hypertrophy & $1(2 \%)$ & $1(3 \%)$ & $4(7 \%)$ & 0.402 \\
\hline CT Calcium score (Agatston) & $20(0-149)$ & $6(0-143)$ & $58(1-299)$ & 0.090 \\
\hline \multicolumn{5}{|l|}{ Vascular assessment } \\
\hline IMT-CCA (mm) & $\begin{array}{c}0.71(0.62- \\
0.82)\end{array}$ & $\begin{array}{c}0.72(0.63- \\
0.89)\end{array}$ & $\begin{array}{c}0.76(0.69- \\
0.89)\end{array}$ & 0.192 \\
\hline IMT-all segments (mm) & $\begin{array}{c}0.71(0.62- \\
0.79)\end{array}$ & $\begin{array}{c}0.72(0.62- \\
0.87) \\
\end{array}$ & $\begin{array}{c}0.77(0.64- \\
0.94)\end{array}$ & 0.101 \\
\hline Pulse wave velocity (m/s) & $7.9(7.2-9.8)$ & $7.9(7.4-10.0)$ & $8.3(7.4-9.4)$ & 0.976 \\
\hline
\end{tabular}

Data are presented as mean \pm standard deviation, number of patients (\%), or median

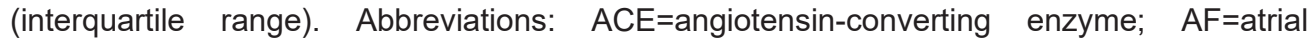
fibrillation; $\mathrm{BMI}=$ body mass index; $\mathrm{CCA}=$ common carotid artery; eGFR=estimated glomerular filtration rate; $E H R A=$ European Heart Rhythm Association class for symptoms; IMT=intima media thickness; NOAC $=$ novel oral anticoagulation; NT-pro BNP $=\mathrm{N}$-terminal pro-brain natriuretic peptide; *The number of comorbidities was calculated by awarding points for hypertension, heart failure, age $>65$ years, diabetes mellitus; coronary artery disease, $\mathrm{BMI}>25 \mathrm{~kg} / \mathrm{m} 2$, moderate or severe mitral valve regurgitation and kidney dysfunction $($ eGFR<60); 
Table 3. Patients' characteristics and AF burden during 6-month follow-up..

\begin{tabular}{|c|c|c|c|c|}
\hline & $\begin{array}{c}\text { Low } \\
\text { AF burden } \\
(\mathrm{N}=50)\end{array}$ & $\begin{array}{l}\text { Intermediate } \\
\text { AF burden } \\
(\mathrm{N}=44)\end{array}$ & $\begin{array}{c}\text { High } \\
\text { AF burden } \\
(\mathrm{N}=45)\end{array}$ & $\begin{array}{c}\mathrm{p}- \\
\text { value }\end{array}$ \\
\hline Age (years) & $62 \pm 10$ & $64 \pm 8$ & $68 \pm 8.8$ & 0.005 \\
\hline Male sex & $24(48 \%)$ & $29(66 \%)$ & $28(62 \%)$ & 0.173 \\
\hline Total history AF (years) & $1.8(0.6-4.8)$ & $2.9(0.9-4.6)$ & $1.9(0.3-4.0)$ & 0.530 \\
\hline Heart failure & $13(26 \%)$ & $17(39 \%)$ & $18(40 \%)$ & 0.282 \\
\hline Hypertension & $21(42 \%)$ & $21(48 \%)$ & $19(42 \%)$ & 0.824 \\
\hline Diabetes mellitus & $3(6 \%)$ & $1(2 \%)$ & $7(16 \%)$ & 0.056 \\
\hline Coronary artery disease & $3(6 \%)$ & $5(11 \%)$ & $10(22 \%)$ & 0.059 \\
\hline Thromboembolic events & $5(10 \%)$ & $3(7 \%)$ & $5(11 \%)$ & 0.770 \\
\hline Chronic obstructive pulmonary disease & $2(4 \%)$ & $3(7 \%)$ & $3(7 \%)$ & 0.801 \\
\hline Number of comorbidities* & $1.9 \pm 1.2$ & $2.3 \pm 1.1$ & $2.2 \pm 1.3$ & 0.032 \\
\hline $\mathrm{CHA}_{2} \mathrm{DS}_{2}$-VASc & $1.6 \pm 1.1$ & $1.6 \pm 1.3$ & $2.2 \pm 1.3$ & 0.019 \\
\hline 0 & $9(18 \%)$ & $8(18 \%)$ & $4(9 \%)$ & \\
\hline 1 & $14(28 \%)$ & $18(41 \%)$ & $10(22 \%)$ & \\
\hline 2 & $16(32 \%)$ & $8(18 \%)$ & $11(24 \%)$ & \\
\hline 3 & $9(18 \%)$ & $6(14 \%)$ & $12(27 \%)$ & \\
\hline 4 & $2(4 \%)$ & $2(5 \%)$ & $7(16 \%)$ & \\
\hline 5 & - & $2(5 \%)$ & $1(2 \%)$ & \\
\hline EHRA class & & & & 0.017 \\
\hline I & $3(6 \%)$ & $3(7 \%)$ & $7(16 \%)$ & \\
\hline II & $21(42 \%)$ & $15(34 \%)$ & $24(53 \%)$ & \\
\hline III & $24(48 \%)$ & $18(41 \%)$ & $8(18 \%)$ & \\
\hline IV & $2(4 \%)$ & $8(18 \%)$ & $6(13 \%)$ & \\
\hline Height $(\mathrm{cm})$ & $176 \pm 10$ & $177 \pm 11$ & $177 \pm 11$ & 0.785 \\
\hline Weight (kg) & $85 \pm 18$ & $90 \pm 18$ & $84 \pm 17$ & 0.280 \\
\hline BMI $\left(\mathrm{kg} / \mathrm{m}^{2}\right)$ & $28 \pm 5$ & $29 \pm 5$ & $27 \pm 5$ & 0.253 \\
\hline Obesity (BMI>30) & $13(26 \%)$ & $11(25 \%)$ & $9(20 \%)$ & 0.768 \\
\hline Waist circumference (cm) & $100 \pm 14$ & $103 \pm 12$ & $102 \pm 13$ & 0.486 \\
\hline \multicolumn{5}{|l|}{ Blood pressure $(\mathrm{mmHg})$} \\
\hline Systolic & $137 \pm 18$ & $139 \pm 19$ & $135 \pm 19$ & 0.631 \\
\hline Diastolic & $82 \pm 9$ & $84 \pm 10$ & $78 \pm 8$ & 0.012 \\
\hline NT-proBNP (pg/ml) & $32(12-127)$ & $46(22-125)$ & $53(24-214)$ & 0.101 \\
\hline Creatinine $(\mu \mathrm{mol} / \mathrm{L})$ & $79(68-89)$ & $83(74-87)$ & $83(73-100)$ & 0.056 \\
\hline eGFR (mL/min) & $85(71-90)$ & $79(73-87)$ & $73(62-86)$ & 0.020 \\
\hline
\end{tabular}




\begin{tabular}{|c|c|c|c|c|}
\hline \multicolumn{5}{|l|}{ Medications } \\
\hline$\beta$-blocker & $25(50 \%)$ & $21(48 \%)$ & $21(56 \%)$ & 0.748 \\
\hline Verapamil/diltiazem & $6(12 \%)$ & $10(23 \%)$ & $6(13 \%)$ & 0.312 \\
\hline Class I antiarrhythmic drugs & $19(38 \%)$ & $11(25 \%)$ & $5(11 \%)$ & 0.011 \\
\hline Class III antiarrhythmic drugs & $1(2 \%)$ & $3(7 \%)$ & $4(9 \%)$ & 0.332 \\
\hline Digoxin & - & $1(2 \%)$ & $1(2 \%)$ & 0.565 \\
\hline ACE-inhibitor & $8(16 \%)$ & $6(14 \%)$ & $11(24 \%)$ & 0.373 \\
\hline Angiotensin Receptor Blocker & $6(12 \%)$ & $7(16 \%)$ & $9(20 \%)$ & 0.566 \\
\hline Mineralocorticoid Receptor Antagonist & - & $1(2 \%)$ & $2(4 \%)$ & 0.330 \\
\hline Statin & $13(26 \%)$ & $19(43 \%)$ & $21(47 \%)$ & 0.083 \\
\hline Diuretic & $4(8 \%)$ & $7(16 \%)$ & $5(11 \%)$ & 0.485 \\
\hline Anticoagulant & & & & 0.025 \\
\hline Vitamin $\mathrm{K}$ antagonist & $5(10 \%)$ & $7(16 \%)$ & $10(22 \%)$ & \\
\hline NOAC & $26(52 \%)$ & $20(45 \%)$ & $28(62 \%)$ & \\
\hline \multicolumn{5}{|l|}{ Echocardiographic variables } \\
\hline Left atrial volume (mL) & $73 \pm 26$ & $71 \pm 24$ & $71 \pm 22$ & 0.927 \\
\hline Left atrial volume index $\left(\mathrm{mL} / \mathrm{m}^{2}\right)$ & $37 \pm 12$ & $37 \pm 13$ & $37 \pm 10$ & 0.989 \\
\hline Left ventricular ejection fraction (\%) & $58(55-60)$ & $58(55-61)$ & $58(58-61)$ & 0.333 \\
\hline Left ventricular ejection fraction $<45 \%$ & $1(2 \%)$ & $1(2 \%)$ & - & 0.611 \\
\hline Left ventricular mass $(\mathrm{g})$ & $152 \pm 38$ & $177 \pm 52$ & $165 \pm 50$ & 0.151 \\
\hline Left ventricular mass index $\left(\mathrm{g} / \mathrm{m}^{2}\right)$ & $73 \pm 17$ & $84 \pm 19$ & $83 \pm 20$ & 0.054 \\
\hline Left ventricular hypertrophy & $1(2 \%)$ & $2(5 \%)$ & $3(7 \%)$ & 0.533 \\
\hline CT Calcium score (Agatston) & $21(0-161)$ & $6(0-96)$ & $94(16-360)$ & 0.012 \\
\hline \multicolumn{5}{|l|}{ Vascular assessment } \\
\hline IMT-CCA (mm) & $\begin{array}{c}0.71(0.61- \\
0.80)\end{array}$ & $\begin{array}{c}0.74(0.67- \\
0.91)\end{array}$ & $\begin{array}{c}0.78(0.68- \\
0.91)\end{array}$ & 0.029 \\
\hline IMT-all segments (mm) & $\begin{array}{c}0.72(0.61- \\
0.81) \\
\end{array}$ & $\begin{array}{c}0.72(0.62- \\
0.86) \\
\end{array}$ & $\begin{array}{c}0.78(0.64- \\
0.95) \\
\end{array}$ & 0.104 \\
\hline Pulse wave velocity (m/s) & $8.0(7.2-9.9)$ & $8.3(7.5-9.7)$ & $8.1(7.3-9.4)$ & 0.903 \\
\hline
\end{tabular}

Data are presented as mean \pm standard deviation, number of patients (\%), or median (interquartile range). Abbreviations: $\mathrm{ACE}=$ angiotensin-converting enzyme; $\mathrm{AF}=$ atrial fibrillation; $\mathrm{BMI}=$ body mass index; $\mathrm{CCA}=$ common carotid artery; eGFR=estimated glomerular filtration rate; $E H R A=$ European Heart Rhythm Association class for symptoms; IMT=intima media thickness; NOAC $=$ novel oral anticoagulation; NT-pro BNP $=\mathrm{N}$-terminal pro-brain natriuretic peptide; *The number of comorbidities was calculated by awarding points for hypertension, heart failure, age $>65$ years, diabetes mellitus; coronary artery disease, $\mathrm{BMI}>25 \mathrm{~kg} / \mathrm{m} 2$, moderate or severe mitral valve regurgitation and kidney dysfunction $($ eGFR<60); 


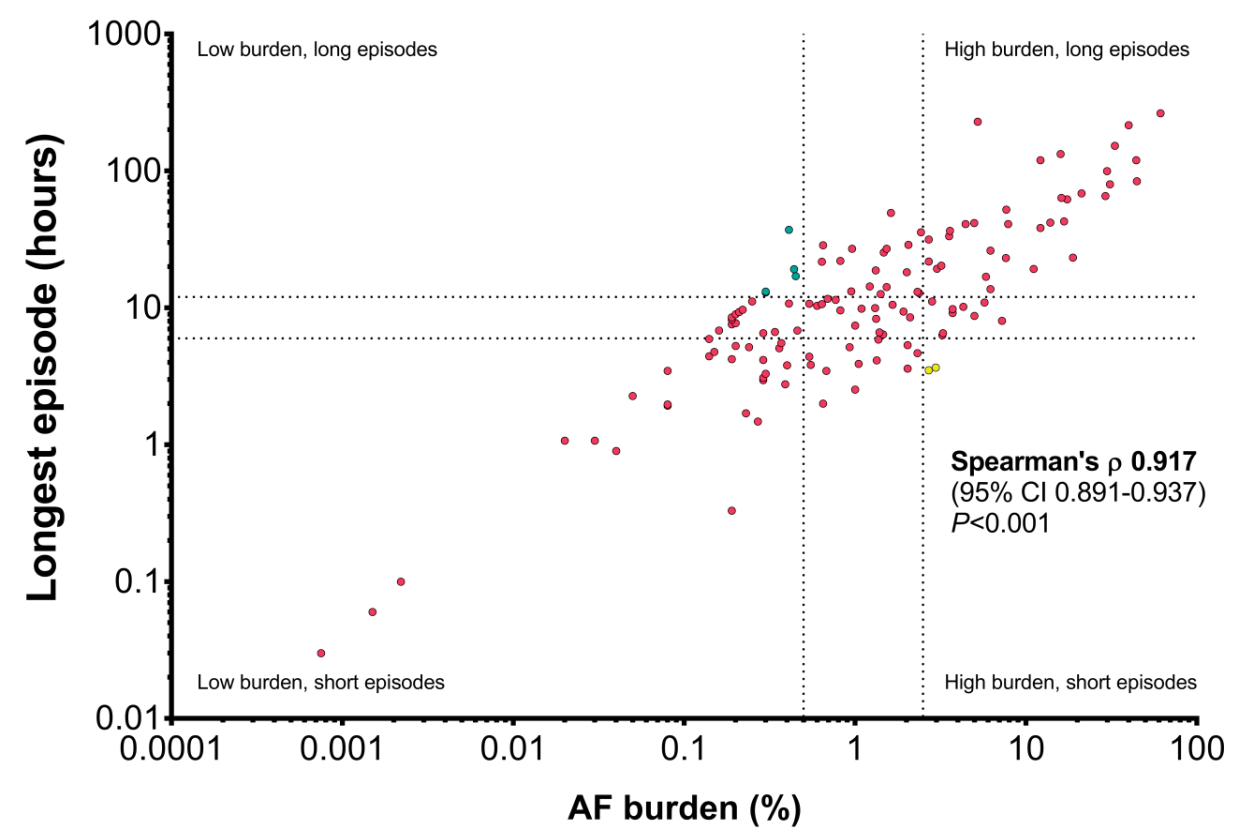

Figure 2. Scatterplot showing a high rate of agreeability between the AF burden (X-axis) and the duration of the longest AF episode (Y-axis), both on logarithmic scales. Data shown for 139 patients with AF recurrence during 6-month follow-up. In green 4 patients are identified with long AF episodes, with low AF burden. In yellow, 2 patients are identified with short episodes, and high AF burden. Abbreviations: $\mathrm{AF}=$ Atrial fibrillation; $\mathrm{Cl}=$ confidence interval.

\section{AF progression}

In 179 (89\%) patients 1-year rhythm follow-up was available. Figure 3 shows the categorization of patients based on the longest AF episode duration during the first 6 months as compared to the second 6 months. During follow-up, $111(62 \%)$ patients remained in the same category, 39 (22\%) had progression, and 29 (16\%) had regression. Twenty-nine (74\%) out of 39 patients with progression only progressed to the next category (e.g. short to intermediate or intermediate to long episodes). Eight patients developed persistent AF. A total of 5 patients started antiarrhythmic drugs, 3 showed AF regression and 2 remained in the same category. Six patients underwent PVI, 3 showed regression and 3 remained in the same category. On a quarterly basis, average daily AF burden increased from $3.2 \%$ to $3.8 \%$, $5.2 \%$ and $6.1 \%$. When only selecting episodes $>1$ hour (instead of all episodes $\geq 2$ minutes) the numbers remained similar: $3.1 \%$ to $3.6 \%, 5.0 \%$ and $5.9 \%$. 


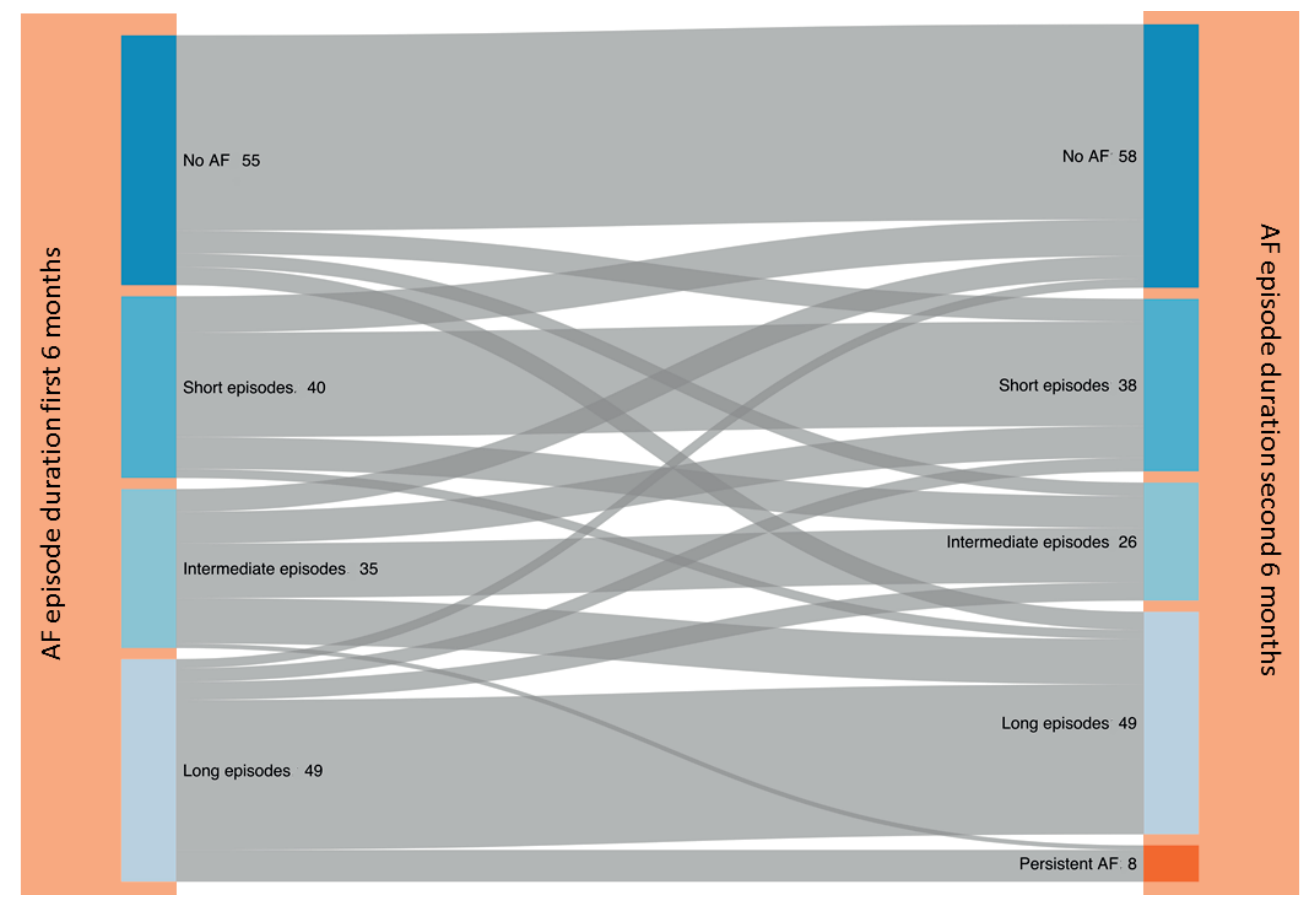

Figure 3. Sankey diagram illustrating the categorization based on the longest AF episode during the first 6 months on the left, and the second 6 months on the right.

\section{DISCUSSION}

In patients with paroxysmal selfterminating AF we longitudinally investigated the temporal pattern, burden and progression of $\mathrm{AF}$ and the association with clinical characteristics using continuous rhythm monitoring. We found that: 1) paroxysmal selfterminating AF has a very heterogeneous temporal arrhythmia pattern. One third of the patients with previous documented AF did not show any recurrence during 6 months of follow-up. In those with recurrences, AF patterns varied both with respect to duration of AF episodes as well as AF burden. Patients with longer episodes had a higher AF burden; 2) patients with longer AF episodes and higher AF burden had more severe underlying comorbidities; and 3) modest AF progression within 1-year occurred in a substantial number of patients.

\section{Quantifying paroxysmal AF}

The currently used clinical AF classification poorly reflects the temporal pattern and burden of AF.(8-10) Patients classified in the same clinical AF category may be inherently heterogeneous in terms of temporal AF persistence and AF burden. In patients known with clinical paroxysmal selfterminating AF we now observed that one third of our patients did not 
show any recurrence during follow-up. In those with recurrent AF our data disclose that paroxysmal AF is a heterogeneous arrhythmia consisting of different patterns, both when classified according to duration of AF episode and according to AF burden. Patients either had short episodes of AF, or only longer AF episodes. There was, however, a strong correlation between duration of the selfterminating AF episodes and AF burden. In general, in our population AF burden was low. Only 10 episodes were electrically cardioverted, all other episodes remained selfterminating during follow-up.

Recently, it was acknowledged that an important knowledge gap includes understanding the best parameter for AF quantification, including specific thresholds, e.g. for starting oral anticoagulation, as well as the relation of the amount of AF and stroke and other major adverse cardiovascular events.(11) The first initiatives for an improved classification for paroxysmal AF have been proposed, based on single-lead ECG monitoring for a mean of 11 days in 13,000 patients.(9) Patients were categorized into either the 'staccato' AF subtype with frequent and short episodes of paroxysmal AF, or the 'legato' AF subtype with infrequent and long episodes of paroxysmal AF. Unfortunately, no exact cutoff values for this classification were provided nor were AF patterns correlated to clinical characteristics. In general, intermittent short term monitoring precludes optimal classification of the type of AF. Both continuous ECG monitoring and data from intracardiac monitoring provide now new evidence for the heterogeneity of AF.(12) Our study extends these findings by proposing three patterns of paroxysmal selfterminating AF based on the duration of the longest episode.

\section{Comorbidities and AF}

The duration of AF episodes may reflect the severity of the atrial cardiomyopathy which itself relates to the presence of risk factors and comorbidities next to AF burden.(13) Our data support this concept by showing differences in clinical and echocardiographic characteristics within the three groups of AF episode duration and of AF burden, e.g. more male patients with coronary artery disease, a higher left ventricular mass as well as more comorbidities in patients with longer AF episodes. Comparably, patients with a higher AF burden were older, had more comorbidities and a higher $\mathrm{CHA}_{2} \mathrm{DS}_{2}-\mathrm{VASc}$ score, more chronic kidney disease, a higher coronary calcium score and a thicker IMT. Episode duration might reflect the degree of the substrate, while the number of shorter AF episodes may be mainly driven by the amount of triggers. The latter may explain the lack of association between very short episodes and cardiovascular outcome.(14) Both AF episode duration and AF burden may be correlated to symptoms, thereby influencing quality of life. Proietti et al. showed that daily 
activity level correlated with the daily AF burden, with decrease in daily activity in patients with a higher AF burden.(15)

\section{No recurrence of AF}

Despite selecting patients with at least 2 episodes of AF in the past year, approximately one third of our patients did not show any recurrent AF episode during the first 6 months of follow-up. The lower left atrial volume in these patients might indicate less severe structural remodeling. On the other hand, the number of comorbidities in patients in this group was similar to that in patients with recurrences. The higher proportion of hypertension and higher $\mathrm{CHA}_{2} \mathrm{DS}_{2}$-VASc score in these patients at baseline together with higher rates of antihypertensive drugs (ARBs and diuretics) may indicate that comorbidities were more frequently diagnosed and potentially treated more appropriately. As has been shown by The Routine versus Aggressive risk factor driven upstream rhythm Control for prevention of Early atrial fibrillation in heart failure (RACE 3) and The AggRessive Risk factor rEduction STudy for Atrial Fibrillation (ARREST-AF) trials, risk factor management improves sinus rhythm maintenance in patients with AF.(16,17) Alternatively, patients without recurrences during 6 months of follow-up may belong to a group of patients who only very infrequently suffer from $\mathrm{AF}$, which is also an interesting and important observation.

\section{AF progression}

To assess AF progression, the transition from selfterminating to non-selfterminating persistent or permanent $A F$, or from persistent to permanent $A F$ is frequently used, since this can be determined fairly well even with intermittent rhythm monitoring. Using this definition, a recent meta-analysis showed a pooled incidence of AF progression of 8.1 per 100 patientyears of follow-up.(18) This meta-analysis, however, was hampered by differences in followup duration and patient characteristics between the respective studies, and the use of intermittent rhythm monitoring. Continuous rhythm monitoring may better define AF progression.(12) The relevance of AF progression is that it is associated with worse clinical outcome. In clinical AF, De Vos et al. showed that progression from selfterminating to nonselfterminating AF had prognostic clinical value, which was supported by other studies. $(5,14)$ Also in subclinical AF (SCAF) prolongation of duration of SCAF episodes from $\leq 24$ to $>24$ hours was associated with more strokes as well as more heart failure hospitalizations.(4,19) In a recent high risk elderly population (mean age 76 years, median $\mathrm{CHA}_{2} \mathrm{DS}_{2}$-VASc score 3.9) without known AF, the median $A F$ burden was $0.13 \%$ during 40 months of follow-up. Progression to 24-hour episodes occurred in 33 of 590 patients (5.6\%) indicating that in these high risk patients AF burden was low, and progression was limited.(12) In our cohort 
with lower risk paroxysmal AF patients (mean age 64 years, median $\mathrm{CHA}_{2} \mathrm{DS}_{2}$-VASc score 1.9), we observed a small increase in averaged AF burden throughout follow-up. The averaged daily AF burden increased from 3.2\% during the first 3 months to $6.1 \%$ during the last 3 months. Using our definition of AF progression, $22 \%$ of patients showed AF episode prolongation during 1 year. This indicates that AF progression is a slow and subtle process. Interestingly, we also found a significant number of patients with AF regression, which has also been shown previously.(20) Factors such as changes in antiarrhythmic therapy, which only occurred in a few patients, or more intense risk factor control may partially explain this interesting observation. $(16,20)$

\section{Clinical implications}

Continuous rhythm monitoring enables an improved characterization of patients with AF. Diverse patterns may reflect differences in underlying diseases and mechanisms, warranting personalized therapeutic interventions and patient tailored therapies. More details on AF patterns may aid in selecting patients for specific AAD, PVI or other therapies. For example, episodes that occur frequently and are of short duration may reflect presence of triggers combined with the absence of a strong substrate for AF. Such patients may well respond to $\mathrm{PVI}$ while in those with longer episodes, AF could be sustained by a substrate present outside of the PVs. Additionally, since AF classification is dynamic, observed longitudinal changes in AF patterns may have clinical utility for assessing the progression of the underlying substrate as well as monitoring response to therapeutic interventions.

\section{Strengths and Limitations}

Strengths of the current study include the well-phenotyped cohort and availability of continuous rhythm monitoring, for the vast majority in patients without implanted cardiac devices prior to study enrolment. In contrast, most other studies with continuous rhythm monitoring were performed in patients with a pacemaker or defibrillator. $(5,8,12,19)$

Limitations include the modest sample size, the limited follow-up time and the observational nature. At this point it is not yet possible to show any prognostic value of the different paroxysmal AF entities. Another limitation is the changes made in antiarrhythmic therapies or modification of risk factors which is inherent to the nature of the arrhythmia. To correct for this, sensitivity analyses were performed that showed similar results, although not all differences remained significant. This is most likely due to a lack of power. 


\section{CONCLUSION}

Our main findings include that paroxysmal selfterminating AF is a very heterogeneous arrhythmia: one third of the patients did not show any recurrence during 6 months of followup. In those with recurrences, AF patterns varied considerably both with respect to duration of AF episodes as well as AF burden. Patients with longer episodes and higher AF burden had more severe underlying comorbidities. Finally, modest AF progression occurred in a substantial number. Thus, assessment of the temporal AF patterns by continuous rhythm monitoring may help to personalize AF therapies. 


\section{REFERENCES}

1. Kirchhof P, Benussi S, Kotecha D, Ahlsson A, Atar D, Casadei B, Castella M, Diener HC, Heidbuchel H, Hendriks J, Hindricks G, Manolis AS, Oldgren J, Popescu BA, Schotten U, Van Putte B, Vardas P, ESC Scientific Document Group. 2016 ESC Guidelines for the management of atrial fibrillation developed in collaboration with EACTS. Eur Heart J 2016;37:2893-2962.

2. Nattel S, Guasch E, Savelieva I, Cosio FG, Valverde I, Halperin JL, Conroy JM, AIKhatib SM, Hess PL, Kirchhof P, De Bono J, Lip GY, Banerjee A, Ruskin J, Blendea D, Camm AJ. Early management of atrial fibrillation to prevent cardiovascular complications. Eur Heart J 2014;35:1448- 1456.

3. Steinberg BA, Hellkamp AS, Lokhnygina Y, Patel MR, Breithardt G, Hankey GJ, Becker RC, Singer DE, Halperin JL, Hacke W, Nessel CC, Berkowitz SD, Mahaffey KW, Fox KA, Califf RM, Piccini JP, ROCKET-AF Steering Committee and Investigators. Higher risk of death and stroke in patients with persistent vs. paroxysmal atrial fibrillation: results from the ROCKET-AF Trial. Eur Heart J 2015;36:288-296.

4. Wong JA, Conen D, Van Gelder IC, Mclntyre WF, Crijns HJ, Wang J, Gold MR, Hohnloser SH, Lau CP, Capucci A, Botto G, Gronefeld G, Israel CW, Connolly SJ, Healey JS. Progression of Device-Detected Subclinical Atrial Fibrillation and the Risk of Heart Failure. J Am Coll Cardiol 2018;71:2603-2611.

5. De Vos CB, Pisters R, Nieuwlaat R, Prins MH, Tieleman RG, Coelen RJ, van den Heijkant AC, Allessie MA, Crijns HJ. Progression from paroxysmal to persistent atrial fibrillation clinical correlates and prognosis. J Am Coll Cardiol 2010;55:725-731.

6. Vanassche T, Lauw MN, Eikelboom JW, Healey JS, Hart RG, Alings M, Avezum A, Diaz R, Hohnloser SH, Lewis BS, Shestakovska O, Wang J, Connolly SJ. Risk of ischaemic stroke according to pattern of atrial fibrillation: analysis of 6563 aspirin-treated patients in ACTIVE-A and AVERROES. Eur Heart J 2015;36:281-7a.

7. De With RR, Marcos EG, Van Gelder IC, Rienstra M. Atrial fibrillation progression and outcome in patients with young-onset atrial fibrillation. Europace 2018;20:1750-1757.

8. Charitos El, Stierle U, Ziegler PD, Baldewig M, Robinson DR, Sievers HH, Hanke T. A comprehensive evaluation of rhythm monitoring strategies for the detection of atrial fibrillation recurrence: insights from 647 continuously monitored patients and implications for monitoring after therapeutic interventions. Circulation 2012;126:806-814.

9. Wineinger NE, Barrett PM, Zhang Y, Irfanullah I, Muse ED, Steinhubl SR, Topol EJ. Identification of paroxysmal atrial fibrillation subtypes in over 13,000 individuals. Heart Rhythm 2019; 16:26-30. 10. De With RR, Marcos EG, Dudink EAMP, Spronk HM, Crijns HJGM, Rienstra M, Van Gelder IC. Atrial fibrillation progression risk factors and associated cardiovascular outcome in well-phenotyped patients: data from the AF-RISK study. Europace 2019; doi:10.1093/europace/euz339.

11. Chen LY, Chung MK, Allen LA, Ezekowitz M, Furie KL, McCabe P, Noseworthy PA, Perez MV, Turakhia MP, American Heart Association Council on Clinical Cardiology, Council on Cardiovascular and Stroke Nursing, Council on Quality of Care and Outcomes Research, and Stroke Council. Atrial Fibrillation Burden: Moving Beyond 
Atrial Fibrillation as a Binary Entity: A Scientific Statement From the American Heart Association. Circulation 2018;137:e623-e644.

12. Diederichsen SZ, Haugan KJ, Brandes A, Lanng MB, Graff C, Krieger D, Kronborg C, Holst AG, Kober L, Hojberg S, Svendsen JH. Natural History of Subclinical Atrial Fibrillation Detected by Implanted Loop Recorders. J Am Coll Cardiol 2019;74:27712781.

13. Goette A, Kalman JM, Aguinaga L, Akar J, Cabrera JA, Chen SA, Chugh SS, Corradi D, D'Avila A, Dobrev D, Fenelon G, Gonzalez M, Hatem SN, Helm R, Hindricks G, Ho SY, Hoit B, Jalife J, Kim YH, Lip GY, Ma CS, Marcus GM, Murray K, Nogami A, Sanders P, Uribe W, Van Wagoner DR, Nattel S, Document Reviewers:. EHRA/HRS/APHRS/SOLAECE expert consensus on atrial cardiomyopathies: definition, characterization, and clinical implication. Europace 2016;18:1455-1490.

14. Steinberg BA, Piccini JP. When Low-Risk Atrial Fibrillation Is Not So Low Risk: Beast of Burden. JAMA Cardiol 2018;3:558-560.

15. Proietti R, Birnie D, Ziegler PD, Wells GA, Verma A. Postablation Atrial Fibrillation Burden and Patient Activity Level: Insights From the DISCERN AF Study. J Am Heart Assoc 2018;7:e010256.

16. Rienstra M, Hobbelt AH, Alings M, Tijssen JGP, Smit MD, Brugemann J, Geelhoed B, Tieleman RG, Hillege HL, Tukkie R, Van Veldhuisen DJ, Crijns HJGM, Van Gelder IC, RACE 3 Investigators. Targeted therapy of underlying conditions improves sinus rhythm maintenance in patients with persistent atrial fibrillation: results of the RACE 3 trial. Eur Heart J 2018;39:2987-2996.

17. Pathak RK, Middeldorp ME, Meredith M, Mehta AB, Mahajan R, Wong CX, Twomey D, Elliott AD, Kalman JM, Abhayaratna WP, Lau DH, Sanders P. Long-Term Effect of GoalDirected Weight Management in an Atrial Fibrillation Cohort: A Long-Term Follow-Up Study (LEGACY). J Am Coll Cardiol 2015;65:2159-2169.

18. Blum S, Meyre P, Aeschbacher S, Berger S, Auberson C, Briel M, Osswald S, Conen D. Incidence and Predictors of Atrial Fibrillation Progression: A Systematic Review and Meta-Analysis. Heart Rhythm 2019; 16:502-510.

19. Van Gelder IC, Healey JS, Crijns HJGM, Wang J, Hohnloser SH, Gold MR, Capucci A, Lau CP, Morillo CA, Hobbelt AH, Rienstra M, Connolly SJ. Duration of device-detected subclinical atrial fibrillation and occurrence of stroke in ASSERT. Eur Heart J 2017;38:1339-1344.

20. Middeldorp ME, Pathak RK, Meredith M, Mehta AB, Elliott AD, Mahajan R, Twomey D, Gallagher C, Hendriks JML, Linz D, McEvoy RD, Abhayaratna WP, Kalman JM, Lau DH, Sanders P. PREVEntion and regReSsive Effect of weight-loss and risk factor modification on Atrial Fibrillation: the REVERSE-AF study. Europace 2018;20:19291935. 


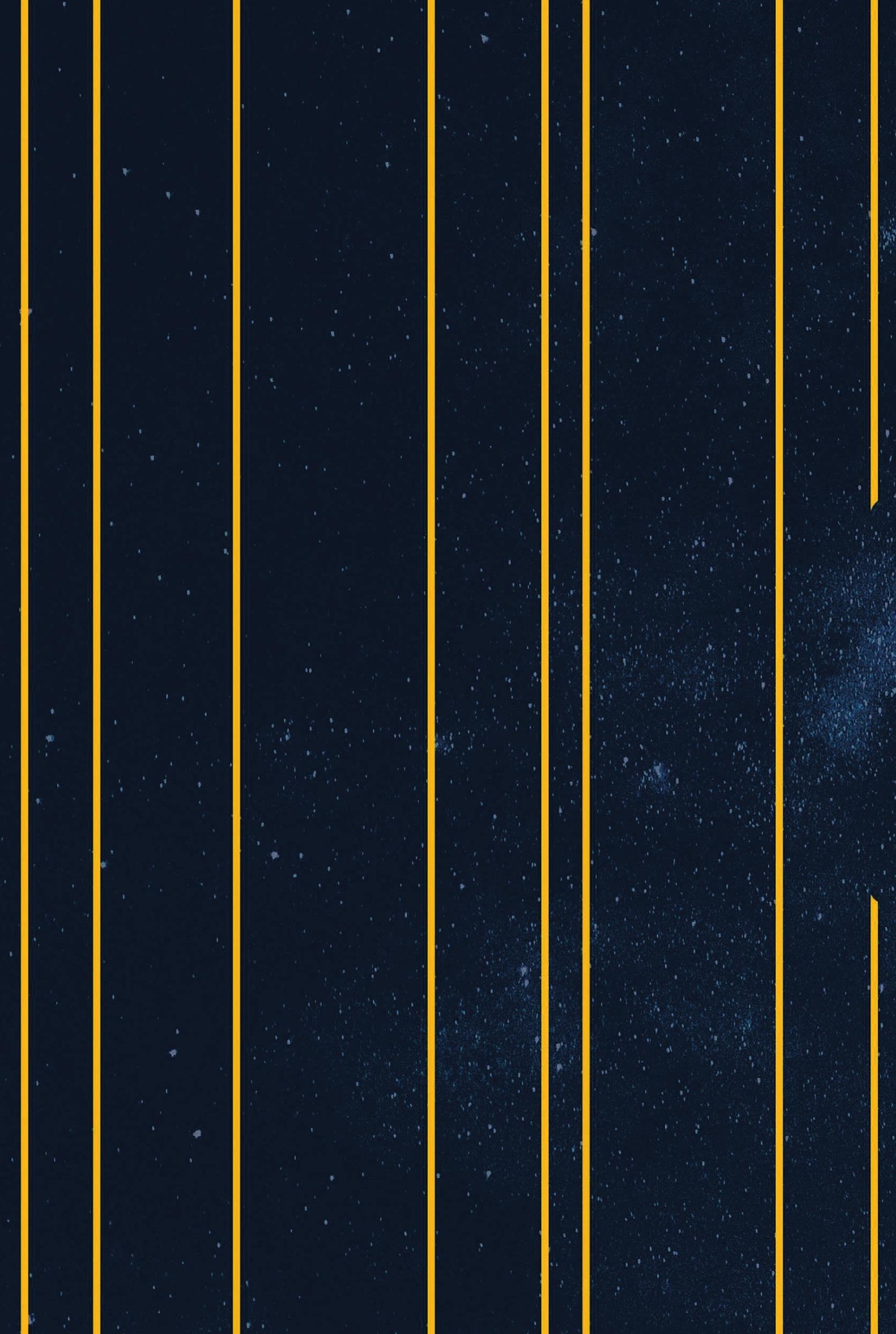




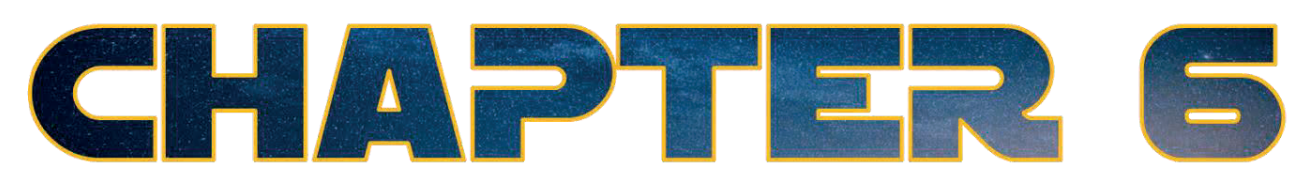

Non-vitamin K antagonist oral anticoagulants and the development of atrial fibrillation

Ömer Erküner, Michiel Rienstra, Isabelle van Gelder, John Eikelboom, Ulrich Schotten, Harry Crijns, Justin Luermans

Submitted 
Experimental data show that a hypercoagulable state, i.e. enhanced thrombin activity, induces pro-fibrotic and pro-inflammatory changes in the atria in mice, leading to the development of a substrate for atrial fibrillation (AF).(1) In addition, counter-acting thrombin through administration of nadroparin leads to attenuation of atrial fibrosis and AF substrate complexity in goats.(1) This effect is likely to be mediated by protease activated receptors (PAR), which can be activated by low-molecular weight heparins, i.e. nadroparin, and nonvitamin $\mathrm{K}$ antagonist oral anticoagulants (NOAC), but not by vitamin $\mathrm{K}$ antagonists (VKA), i.e. warfarin.(1)

In man, the relationship between hypercoagulability and the development of a substrate for AF has not been studied yet. We hypothesized that in patients without a history of AF, treatment with NOAC could prevent or delay the development of a substrate for AF via thrombin inhibition and PAR activation, resulting in a lower occurrence of AF, compared to treatment with warfarin or placebo.

To address this hypothesis, we performed a post-hoc analysis of clinical trials that randomized patients without a history of $A F$ to treatment with either a NOAC or warfarin/placebo, i.e. Hokusai-VTE,(2) RE-COVER I,(3) RE-COVER II,(3) RE-MEDY,(4) RESONATE,(4) and RE-DEEM.(5) In these trials, the occurrence of AF was reported as an adverse event. No periodic electrocardiograms were performed to detect AF. Trials in AF populations were excluded, since intervention with a NOAC is unlikely to favorably modify an already established substrate for AF. Trials of thromboprophylaxis after orthopedic surgery were also excluded, since the treatment duration with NOACs is relatively short in these studies.

Data of these trials were acquired through http://www.clinicalstudydatarequest.com. A request for research was proposed, explaining the background and hypothesis of our study. The proposal was honored by the consortium of clinical study sponsors and funders. Primary endpoint was development of atrial fibrillation during follow-up. Patients with atrial fibrillation at baseline were excluded and could not take part in these trials in the first place.

We included a total of 19,424 patients from 6 randomized controlled trials (Table). AF was diagnosed in $120(0.62 \%)$ patients, with similar incidence in those randomized to receive a NOAC compared with warfarin or placebo.

There are some limitations to this analysis. First, the overall incidence of AF was lower than expected $(0.9 \% /$ year), particularly since these trials were conducted in populations with venous thrombo-embolism or coronary artery disease. This may be due to underreporting or underdetection, since electrocardiograms were not routinely performed to check for the 
development of AF. Second, in 2 of the 5 trials, i.e. RE-MEDY and RE-SONATE,(4) patients previously treated with warfarin were also included, possibly diminishing the positive effect of NOACs on incidence of AF. Lastly, the treatment duration with NOAC in these trials might be too short in order to see differences in AF incidence.

In conclusion, randomized treatment with dabigatran or edoxaban in patients without a history of AF did not reduce the occurrence of AF, when compared to treatment with placebo or warfarin, which is inconsistent with the experimental data. Further research is needed to quantify the possible protective effect of NOACs on atrial remodeling. 


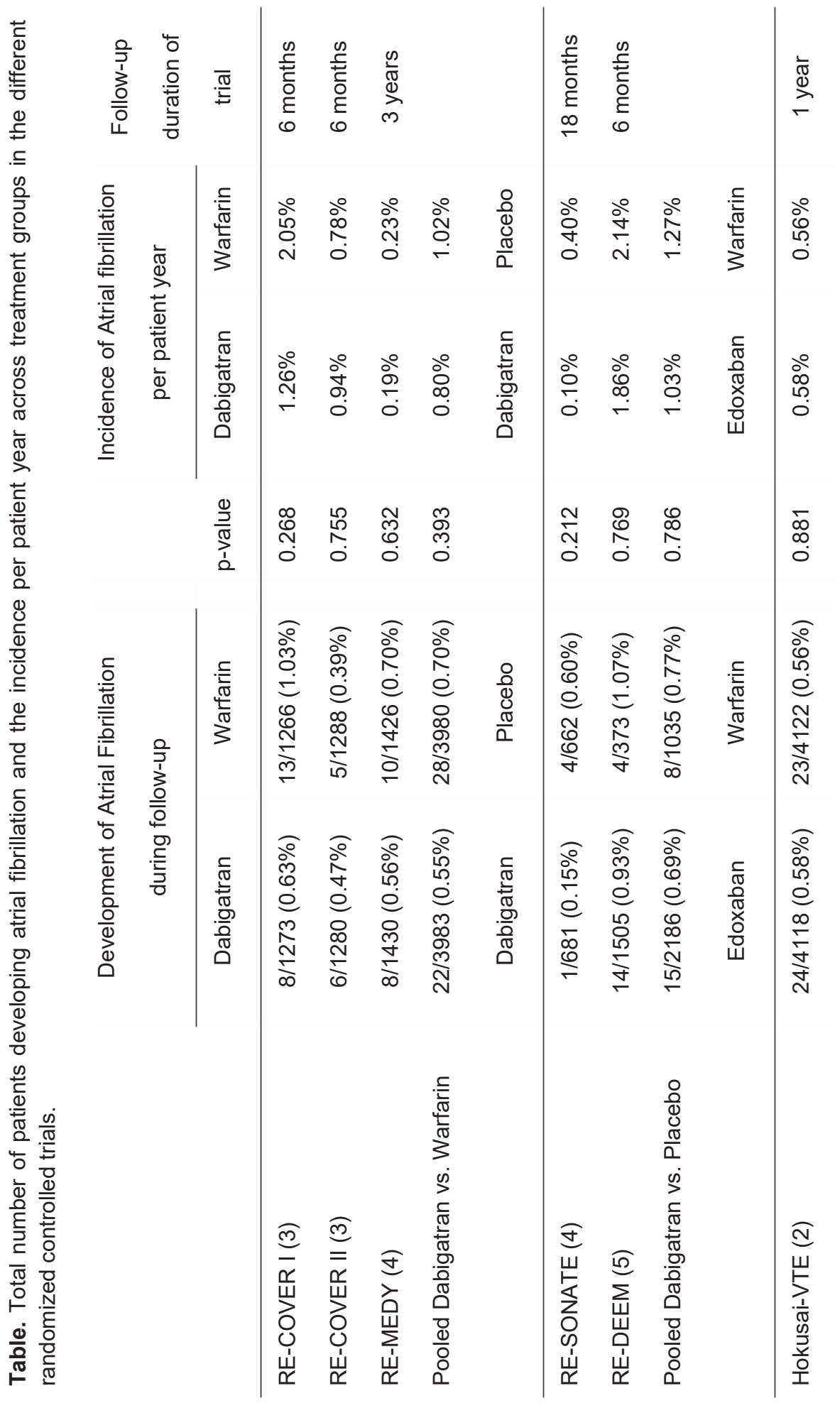




\section{REFERENCES}

1. Spronk HM, De Jong AM, Verheule S, De Boer HC, Maass AH, Lau DH, et al. Hypercoagulability causes atrial fibrosis and promotes atrial fibrillation. Eur Heart $\mathrm{J}$. 2017;38(1):38-50.

2. Hokusai VTEI, Buller HR, Decousus H, Grosso MA, Mercuri M, Middeldorp S, et al. Edoxaban versus warfarin for the treatment of symptomatic venous thromboembolism. $\mathrm{N}$ Engl J Med. 2013;369(15):1406-15.

3. Schulman S, Kakkar AK, Goldhaber SZ, Schellong S, Eriksson H, Mismetti P, et al. Treatment of acute venous thromboembolism with dabigatran or warfarin and pooled analysis. Circulation. 2014;129(7):764-72.

4. Schulman S, Kearon C, Kakkar AK, Schellong S, Eriksson H, Baanstra D, et al. Extended use of dabigatran, warfarin, or placebo in venous thromboembolism. N Engl J Med. 2013;368(8):709-18.

5. Oldgren J, Budaj A, Granger CB, Khder Y, Roberts J, Siegbahn A, et al. Dabigatran vs. placebo in patients with acute coronary syndromes on dual antiplatelet therapy: a randomized, double-blind, phase II trial. Eur Heart J. 2011;32(22):2781-9. 


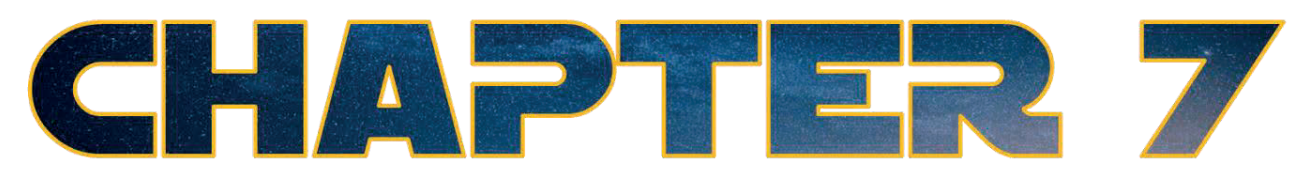

Point of View:

Stroke risk in patients with device detected atrial high rate episodes

Ömer Erküner, Michiel Rienstra, Isabelle van Gelder,

Ulrich Schotten, Harry Crijns, Justin Luermans

Netherlands Heart Journal 2018 


\section{ABSTRACT}

Cardiovascular implantable electronic devices (CIEDs) are able to detect atrial arrhythmias, i.e. atrial high rate episodes (AHRE). The thrombo-embolic risk in patients showing AHRE appears to be lower than in patients with clinical AF and it is unclear whether the former will benefit from oral anticoagulants. Based on currently available evidence, it seems reasonable to consider antithrombotic therapy in patients without documented AF showing AHRE >24 hours and a $\mathrm{CHA}_{2} \mathrm{DS}_{2}-\mathrm{VASc} \geq 1$, awaiting definite answers from ongoing randomized clinical trials. In patients with AHRE $<24$ hours, current literature does not support starting oral anticoagulation. In these patients, intensifying CIED read-outs can be considered to find progression in AHRE duration sooner, enhancing timely stroke prevention. The notion that AHRE and stroke coincide perseveres but should be abandoned since CIED data show a clear disconnect. 


\section{INTRODUCTION}

Cardiovascular implantable electronic devices (CIEDs) with an atrial lead are able to detect episodes of atrial arrhythmias, regardless of the presence of symptoms. Device detected atrial high rate episodes (AHRE), in the absence of symptoms referred to as subclinical atrial tachy-arrhythmias, are actually quite common. The incidence of AHRE in patients without a history of atrial fibrillation (AF) is approximately $25 \%$ after 1 year and $35 \%$ after 2 years of follow-up.(1-3) For patients with a history of AF, the incidence of AHRE is approximately 56$71 \%$ after 1 year.(4-6)

AHRE differ from clinical AF in the mode of documentation, i.e. clinical AF is ascertained on an electrocardiogram, whereas AHRE are solely recorded on a CIED read-out.(7) Furthermore, AHRE and AF differ regarding thrombo-embolic risk. Clinical AF is associated with an increased risk of thrombo-embolism (TE) depending on the presence of risk factors, i.e. the $\mathrm{CHA}_{2} \mathrm{DS}_{2}-\mathrm{VASc}$ score (Congestive heart failure, Hypertension, Age $\geq 75$ years [doubled], Diabetes Mellitus, prior Stroke [doubled], Vascular disease, Age 65-74 years and female Sex).(8) In AHRE patients however, the TE risk appears to be lower than in clinical AF.(2,6,9-11) The lower TE rate could be caused by the fact that AHRE is viewed as one entity, whilst there may be different types of AHRE. AHRE with a lower mean atrial rate, i.e. $<300$ beats per minute (bpm), may not represent AF but rather an atrial tachycardia, which confers a lower TE risk (12), whereas AHRE with a mean atrial rate $>300 \mathrm{bpm}$ might more robustly represent AF or atrial flutter, leading to an increased TE risk. (13)

Current guidelines recommend starting anticoagulant therapy in AF patients with a $\mathrm{CHA}_{2} \mathrm{DS}_{2}$ VASc score $\geq 2$ and considering antithrombotic therapy in patients with a $\mathrm{CHA}_{2} \mathrm{DS}_{2}-\mathrm{VASc}$ score of 1. $(7,14)$ For AHRE however, no recommendations regarding antithrombotic therapy are made in the guidelines, largely because of lack of evidence for any benefit of antithrombotic treatment in patients with AHRE. $(7,14)$

In this point of view paper, we summarize the evidence regarding TE risk in patients with AHRE, elaborating on the duration of AHRE and on the temporal relationship of AHRE and thrombo-embolism. To conclude, we propose a flowchart for antithrombotic management of these patients. 


\section{CURRENT EVIDENCE}

\section{Duration of AHRE and thrombo-embolic risk in patients without a history of atrial fibrillation}

The Asymptomatic Atrial Fibrillation and Stroke Evaluation in Pacemaker Patients and the Atrial Fibrillation Reduction Atrial Pacing Trial (ASSERT) is the only large, prospective trial to assess AHRE and thrombo-embolism in patients without a history of clinical AF.(2) In this study, 2580 patients with a recently implanted pacemaker or defibrillator were included. All patients were 65 years of age or older and had hypertension. The devices of these patients were interrogated at regular six-monthly intervals in order to detect AHRE, which was defined as an atrial rate of at least $190 \mathrm{bpm}$ lasting for at least 6 minutes. All AHRE were blindly adjudicated. Three months after inclusion, 261 patients $(10.1 \%)$ already showed at least one AHRE. After a mean follow-up of 2.5 years, this was the case in $34.7 \%$ of the patients.

During the follow-up period of the ASSERT study, a stroke or systemic embolism occurred in 11 of 261 patients (4.2\%) in whom AHRE was detected within 3 months after inclusion, compared to 40 of the remaining 2319 patients (1.7\%). This translates into an annual TE event rate of $1.7 \%$ in patients with AHRE within 3 months after inclusion, compared to $0.7 \%$ in patients who did not show AHRE within 3 months after inclusion (hazard ratio [HR] 2.49; 95\% Confidence Interval [Cl], 1.28-4.85; $\mathrm{p}=0.007$ ). In this analysis however, the 633 patients who developed AHRE after the initial monitoring period of 3 months were included in the control group of 2319 patients, possibly leading to a higher TE rate in this group.

In a subanalysis of the ASSERT study regarding the duration of AHRE and TE risk, all AHRE during monitoring and follow-up were taken into account, irrespective of the time of occurrence.(15) In a time-dependent Cox regression model, the TE risk only increased in patients showing AHRE $>24$ hours $(\mathrm{HR} 3.24,95 \% \mathrm{Cl} 1.51-6.95, \mathrm{p}=0.003$ compared to patients without AHRE). For AHRE lasting $<24$ hours, the TE risk seems to be comparable to patients without AHRE. Even in patients showing 6-24 hours of AHRE, the TE risk was not increased (HR 1.32, 95\% Cl 0.40-4.37, p=0.646). In addition, the number of AHRE did not affect TE risk.(2) 


\section{Duration of AHRE and thrombo-embolic risk in patients with a history of atrial fibrillation}

In the remainder of the studies regarding AHRE, patients with a history of AF were also included, ranging from $20 \%$ of the patients in TRENDS to all included patients in the Italian AT500 Registry (Table).(4-6,16) Therefore, the sole effect of AHRE on TE risk cannot be reliably assessed based on these studies.

Table. Overview of trials regarding AHRE and stroke rates.

\begin{tabular}{|c|c|c|c|c|c|c|c|c|c|c|}
\hline \multirow[b]{2}{*}{ Trial } & \multirow[b]{2}{*}{$\mathrm{n}$} & \multirow{2}{*}{$\begin{array}{l}\text { Prior } \\
\text { AF } \\
(\%)\end{array}$} & \multirow{2}{*}{$\begin{array}{c}\text { Mean } \\
\mathrm{CHADS}_{2}\end{array}$} & \multirow{2}{*}{$\begin{array}{l}\text { Prior } \\
\text { OAC } \\
(\%)\end{array}$} & \multicolumn{2}{|c|}{ Definition of AHRE } & \multirow{2}{*}{$\begin{array}{l}\text { AHRE+ } \\
\text { annual } \\
\text { TE (\%) }\end{array}$} & \multirow{2}{*}{$\begin{array}{c}\text { AHRE- } \\
\text { annual } \\
\text { TE (\%) }\end{array}$} & \multirow{2}{*}{$\begin{array}{l}\text { RR } \\
\text { for } \\
\text { TE }\end{array}$} & \multirow[b]{2}{*}{$\mathrm{p}$} \\
\hline & & & & & Atrial rate & Duration & & & & \\
\hline ASSERT (2) & 2850 & 0 & 2.2 & 7.5 & $\begin{array}{l}>190 \\
\text { bpm }\end{array}$ & $>6 \min$ & 1.7 & 0.7 & 2.5 & 0.007 \\
\hline TRENDS (6) & 2486 & 20 & 2.2 & 20.8 & $\begin{array}{l}>175 \\
\mathrm{bpm}\end{array}$ & $\geq 5.5 \mathrm{~h}$ & 2.4 & 1.1 & 2.2 & 0.06 \\
\hline $\begin{array}{l}\text { Turakhia et al. } \\
\text { (17) }\end{array}$ & 9850 & 41 & 3.2 & 5.4 & AT/AF & $\geq 5.5 \mathrm{~h}$ & - & - & 4.2 & $<0.05$ \\
\hline MOST (16) & 312 & 60 & - & - & $\begin{array}{l}>220 \\
\text { bpm }\end{array}$ & $>5 \min$ & - & - & $2.8^{*}$ & 0.001 \\
\hline AT500 (4) & 725 & 100 & - & 36.4 & AT/AF & $>24 \mathrm{~h}$ & - & - & 3.1 & 0.044 \\
\hline
\end{tabular}

${ }^{*}=$ Combined endpoint of death and non-fatal stroke.

$\mathrm{AF}=$ Atrial Fibrillation; AHRE = Atrial High Rate Events; $\mathrm{AT}=$ Atrial Tachycardia; $\mathrm{CHADS}_{2}=$ Congestive heart failure, Hypertension, Age $\geq 75$ years, Diabetes Mellitus and prior Stroke (doubled); OAC = Oral Anti Coagulation; RR = Relative Ratio; TE = Thrombo-Embolism

In the TRENDS trial, 2486 patients with a CIED and a $\mathrm{CHADS}_{2}$ (Congestive heart failure, Hypertension, Age $\geq 75$ years, Diabetes Mellitus and prior Stroke [doubled]) score $\geq 1$ were analyzed.(6) Mean age was 71 years in this population and 498 patients (20\%) had a history of AF. Atrial tachycardia (AT)/AF, defined as an atrial rate $>175 \mathrm{bpm}$ lasting $\geq 20$ seconds, was observed in $47 \%$ of these patients during an average follow-up of 1.4 years. When patients were divided in groups based on the maximum AT/AF burden on any day during follow-up, the annual TE risk tended to double in patients with a high AT/AF burden of $\geq 5.5$ hours per day, compared to patients with zero or low burden, i.e. $<5.5$ hours per day $(2.4 \%$ 
vs. $1.1 \%$ per year; HR 2.20, 95\% $\mathrm{Cl} 0.96-5.05, \mathrm{p}=0.06) .(6)$ The annual TE rates in the AHRE populations were lower than in AF patients with a comparable risk profile.(8)

In the Italian AT500 Registry (4), 725 patients with atrial fibrillation and a pacemaker with a mean age of 71 years were included. Device-detected AF episodes were defined as $\geq 5$ minutes in duration, no minimally required atrial rate was reported. AF episodes of $>24$ hours were associated with an increased risk of TE after a median follow-up of 22 months (HR 3.1, $95 \% \mathrm{Cl}$ 1.1-10.5, $\mathrm{p}=0.044$; no percentages reported for patients with and without AHRE). Botto et al. (5) further elaborated on this finding by combining the duration of device-detected AF with the $\mathrm{CHADS}_{2}$ score. This way, two subpopulations with a significant difference in annual TE risk were determined $(0.8 \%$ vs. $5 \%, p=0.035)$. With increasing $\mathrm{CHADS}_{2}$ scores, a decreasing duration of AHRE is sufficient to provoke a high risk of stroke.(5)

In a subgroup analysis of the MOde Selection Trial (MOST) (16), 312 patients with a median age of 74 years were included, of whom $60 \%$ had a history of supraventricular arrhythmias. AHRE was defined as an atrial rate $>220$ bpm lasting $>5$ minutes and was present in 160 (51.3\%) patients over a follow-up of 27 months. These patients had an increased risk of death or nonfatal stroke when compared to those without AHRE (20.6\% vs. $10.5 \%$; HR 2.79, $95 \% \mathrm{Cl} 1.51-5.15, \mathrm{p}=0.001$; no annual rates reported).(16) This rate is higher than in the studies discussed above, most likely due to the population of the MOST being older and having more comorbidities.

\section{Temporal relationship of AHRE and thrombo-embolism}

The classical pathophysiological idea is that atrial fibrillation causes TE via mechanical stasis in the atrium, leading to clot formation. In this respect, it seems logical that a higher AHRE or AF burden is associated with a higher TE risk, which has been shown in the ASSERT trial. In this study, an AHRE episode of $\geq 24$ hours compared to AHRE $<24$ hours or no AHRE at all was associated with TE within 30 days.(15) Similarly, Turakhia et al. have shown in a Veterans Administration population with stroke that patients showed more often AHRE $\geq 5.5$ hours in the 30 days preceding the stroke compared to a control period of days 91 to 120 prior to the stroke in the same patients (HR 4.2, 95\% Cl 1.5-13.4).(17)

In contrast to the classical pathophysiology of TE in AF however, in a substantial proportion of patients with AHRE and TE a clear temporal relationship cannot be well established, i.e. TE is not preceded by AHRE or AF, but the arrhythmia rather occurs after the TE. This has been studied in subanalyses of both the ASSERT and TRENDS study. Brambatti et al. (18) 
showed that only 26 of the 51 patients (51\%) with a TE during follow-up in the ASSERT study showed AHRE, of which 8 patients (30.8\%) only showed AHRE after the embolic event. Daoud et al. (19) showed similarly that in only 20 (50\%) of the 40 patients with TE in the TRENDS study, AT/AF was detected prior to the event, nine of whom did not show any AT/AF in the 30 days prior to the event (Figure 1).

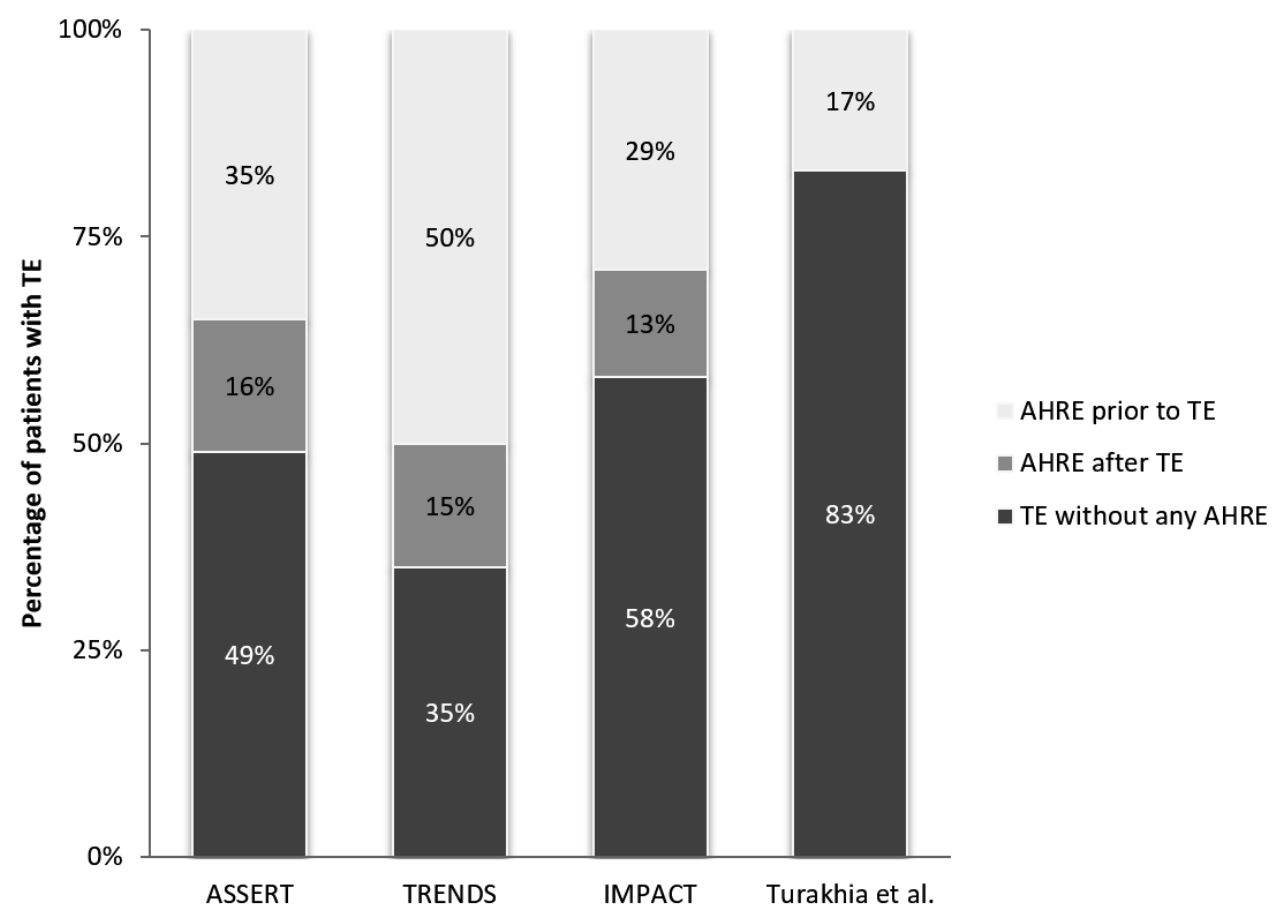

Figure 1. Temporal Relationship between AHRE and TE. The stacked bar chart depicts the patients with a TE in the ASSERT, TRENDS and IMPACT studies. The percentages represent the proportion of patients who showed AHRE before TE, after TE, and the patients who did not show any AHRE at all. AHRE = Atrial High Rate Events; TE = ThromboEmbolism.

Furthermore, in the IMPACT trial (20), 2718 CIED patients were randomized to usual officebased follow-up with anticoagulation determined by standard clinical criteria or starting and stopping anticoagulation based on remote rhythm monitoring. AHRE was defined as $\geq 36$ of 48 atrial beats with an atrial rate $\geq 200 \mathrm{bpm}$. Of the included patients, $330(12.1 \%)$ had a history of AF or atrial flutter. The compared antithrombotic therapy strategies did not show any differences in ischemic stroke (0.7 vs. 1.3 per 100 patient-years; HR $0.55,95 \% \mathrm{Cl} 0.23-$ 1.34, $p=0.188$ ), even though there was an association between AHRE burden and thromboembolism.(20) However, there are some limitations to the IMPACT study, i.e. the low AHRE 
rate, the predominant use of vitamin $\mathrm{K}$ antagonists as anticoagulation therapy, the time to adequate INR (international normalized ratio), and the strategy of discontinuation and reinitiating OAC based on the presence/absence of AHRE.

All together, these findings suggest that AHRE/AF and stroke do not always occur in the classical pathophysiological order. To address this issue, Kamel et al. (21) proposed an updated model for thrombo-embolic stroke. In this model, atrial cardiomyopathy plays a key role and can result in both $\mathrm{AHRE} / \mathrm{AF}$ and in TE, explaining the situations in which TE precedes the occurrence of AHRE/AF. Ageing and systemic vascular risk factors can cause an abnormal atrial substrate leading to atrial cardiomyopathy, which can be characterized by atrial dilatation, mechanical dysfunction, fibrosis, and/or endothelial dysfunction.(21) One of these factors causing an abnormal atrial substrate might be hypercoagulability, the increased potential of blood or plasma to generate thrombin and fibrin.(22) Spronk et al. have shown that hypercoagulability can induce atrial fibrosis and lead to a substrate for AF.(22) Similarly, the increased risk of thrombo-embolism in patients with atrial cardiomyopathy might be mediated by hypercoagulability (Figure 2).

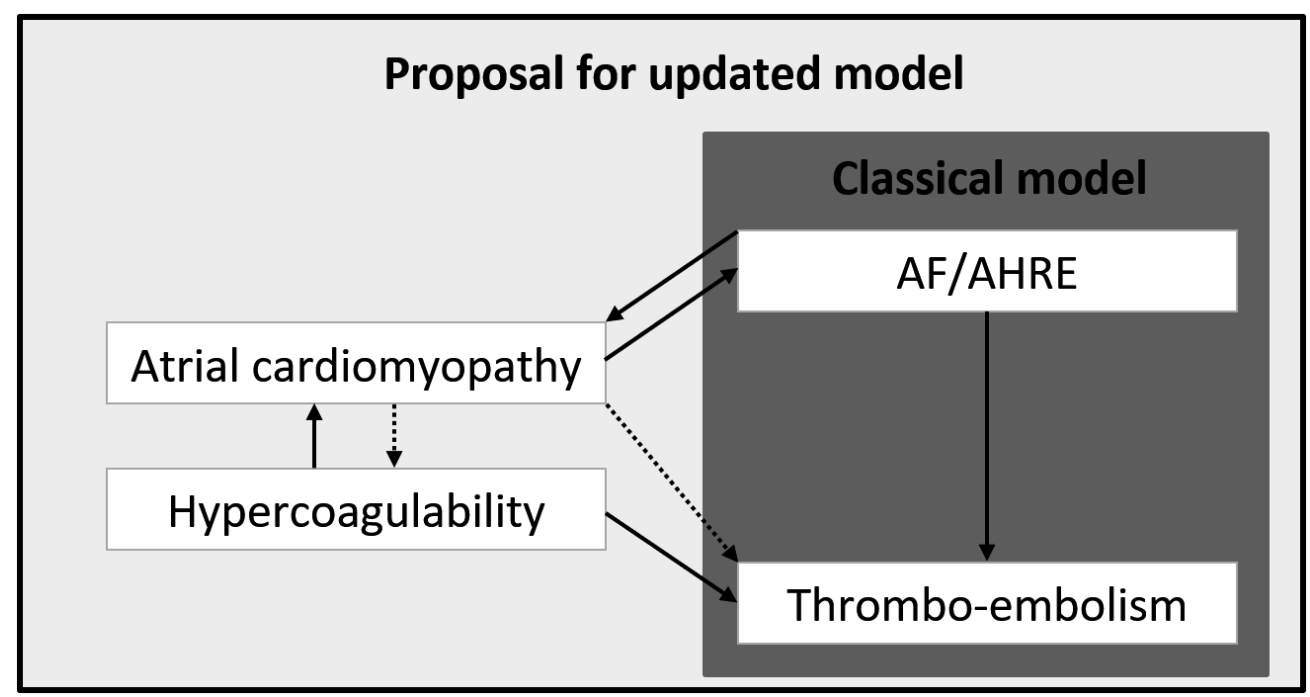

Figure 2. Proposed Updated Model of TE in AF/AHRE. The figure depicts the classical model of thrombo-embolic stroke in AF and AHRE and a proposal for an updated model. In this proposal, atrial cardiomyopathy can lead to TE through hypercoagulability and hypercoagulability can lead to AF/AHRE through atrial cardiomyopathy. AF = Atrial Fibrillation; AHRE = Atrial High Rate Events. 
In addition to the temporal disconnect of AHRE and TE observed in the trials described above, some patients even developed a stroke without showing any AHRE at all. In ASSERT, 25 (49\%) of the 51 patients with a stroke did not show any AHRE, in TRENDS this was the case in $20(50 \%)$ of 40 patients, in IMPACT in $40(58 \%)$ of 69 patients, and in the study by Turakhia et al. in 156 (83\%) of 187 patients (Figure 1). These strokes were either the result of other pathophysiological mechanisms, i.e. cardiac embolism not related to AHRE/AF, lacunar infarction, arterial dissection, and atherosclerosis or perhaps due to atrial cardiomyopathy in an early phase, with no manifestation of AF/AHRE yet, compatible with the model as presented in Figure 2.

\section{When to start antithrombotic therapy in patients with AHRE without a history of atrial fibrillation}

Taking the available literature into consideration, it seems reasonable to consider antithrombotic therapy in patients without documented AF showing AHRE $>24$ hours and a $\mathrm{CHA}_{2} \mathrm{DS}_{2}$-VASc $\geq 1$, awaiting definite answers from ongoing randomized clinical trials (Figure 3). In patients with shorter episodes of AHRE, current evidence does not support starting antithrombotic therapy in the absence of clinical AF. Duration should be the only AHRE characteristic to take into consideration before deciding to start antithrombotic therapy, since the timing or number of AHRE do not seem to be useful in identifying patients at high risk for TE. For patients with $<24$ hours of AHRE, one could consider intensifying CIED read-outs in order to find a progression in AHRE relatively early. As a result, the delay to starting antithrombotic therapy can be reduced. As for the cut-off point of the $\mathrm{CHA}_{2} \mathrm{DS}_{2}-\mathrm{VASc}$ score, considering antithrombotic therapy in patients with a score of $\geq 1$, analogous to clinical AF patients, seems reasonable, even though the $\mathrm{CHA}_{2} \mathrm{DS}_{2}$-VASc has not been validated in an AHRE cohort.

Currently recruiting trials ARTESiA (Apixaban for the Reduction of Thrombo-Embolism in patients with Device-Detected Sub-Clinical Atrial fibrillation, ClinicalTrials.gov Identifier: NCT01938248) and NOAH-AFNET 6 (Non-vitamin K Antagonist Oral Anticoagulants in Patients With Atrial High Rate Episodes - Atrial Fibrillation NETwork 6, ClinicalTrials.gov Identifier: NCT02618577) will give us more insights in the role of antithrombotic therapy in patients with AHRE without a history of atrial fibrillation. In these prospective, parallel group, randomized, double-blind trials, patients with AHRE will receive either placebo or a Nonvitamin $\mathrm{K}$ antagonist Oral AntiCoagulant (NOAC), respectively apixaban and edoxaban. In ARTESiA, AHRE is defined as an atrial rate of $>175$ bpm lasting $\geq 6$ minutes, whereas in 
NOAH-AFNET 6 the definition is slightly different, i.e. an atrial rate of $\geq 180 \mathrm{bpm}$ and $\geq 6$ minutes in duration.

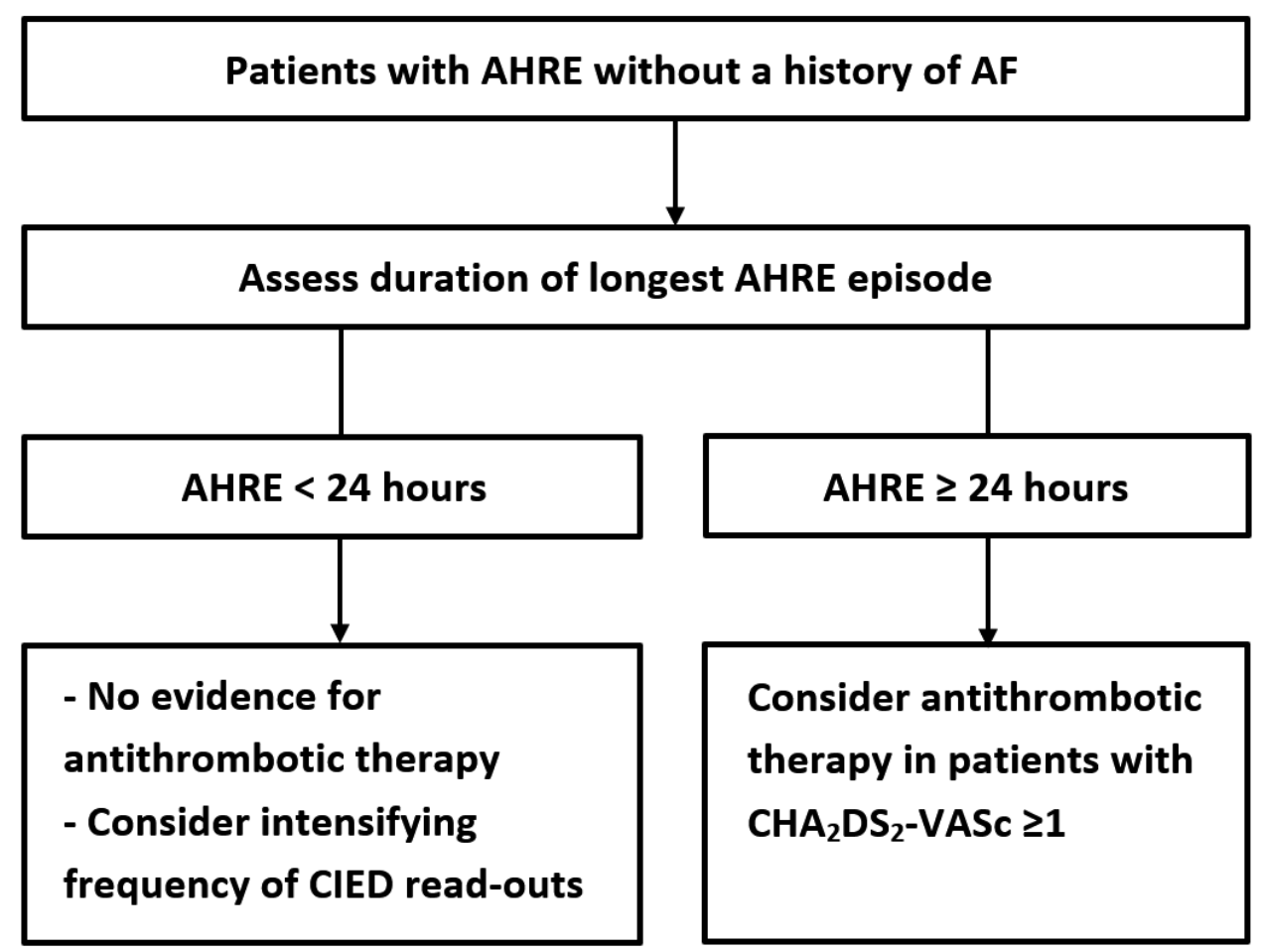

Figure 3. Recommendations for Patients Showing AHRE. The figure is a proposed flowchart for the antithrombotic therapy of patients with atrial high rate events. AF = Atrial Fibrillation; $\mathrm{AHRE}=$ Atrial High Rate Events; $\mathrm{CHA}_{2} \mathrm{DS}_{2}-\mathrm{VASc}=$ Congestive heart failure, Hypertension, Age $\geq 75$ years (doubled), Diabetes Mellitus, prior Stroke (doubled), Vascular disease, Age 65-74 years and female Sex; CIED = Cardiac Implantable Electronic Devices.

\section{CONCLUSION}

AHRE are a common finding in patients with pacemakers and defibrillators without a history of atrial fibrillation. AHRE are associated with an increased thrombo-embolic risk, in part depending on the duration of the AHRE and albeit lower than in clinical AF. Based on currently sparse literature, it seems reasonable to start antithrombotic therapy in patients without clinical $A F$ with a $\mathrm{CHA}_{2} \mathrm{DS}_{2}$-VASc $\geq 1$ in whom at least one episode of AHRE lasting $>24$ hours has been detected, irrespective of the timing and number of AHRE, awaiting definite answers from ongoing randomized clinical trials. In patients with shorter episodes of AHRE, current evidence to start antithrombotic therapy in the absence of clinical AF is lacking. 


\section{REFERENCES}

1. Cheung JW, Keating RJ, Stein KM et al. Newly detected atrial fibrillation following dual chamber pacemaker implantation. J Cardiovasc Electrophysiol 2006;17:1323-8.

2. Healey JS, Connolly SJ, Gold MR et al. Subclinical atrial fibrillation and the risk of stroke. N Engl J Med 2012;366:120-9.

3. Ziegler PD, Glotzer TV, Daoud EG et al. Detection of previously undiagnosed atrial fibrillation in patients with stroke risk factors and usefulness of continuous monitoring in primary stroke prevention. Am J Cardiol 2012;110:1309-14.

4. Capucci A, Santini $M$, Padeletti $L$ et al. Monitored atrial fibrillation duration predicts arterial embolic events in patients suffering from bradycardia and atrial fibrillation implanted with antitachycardia pacemakers. J Am Coll Cardiol 2005;46:1913-20.

5. Botto GL, Padeletti L, Santini M et al. Presence and duration of atrial fibrillation detected by continuous monitoring: crucial implications for the risk of thromboembolic events. $J$ Cardiovasc Electrophysiol 2009;20:241-8.

6. Glotzer TV, Daoud EG, Wyse DG et al. The relationship between daily atrial tachyarrhythmia burden from implantable device diagnostics and stroke risk: the TRENDS study. Circ Arrhythm Electrophysiol 2009;2:474-80.

7. Kirchhof P, Benussi S, Kotecha D et al. 2016 ESC Guidelines for the management of atrial fibrillation developed in collaboration with EACTS. Eur Heart J 2016;37:2893-2962.

8. Lip GY, Nieuwlaat R, Pisters R, Lane DA, Crijns HJ. Refining clinical risk stratification for predicting stroke and thromboembolism in atrial fibrillation using a novel risk factorbased approach: the euro heart survey on atrial fibrillation. Chest 2010;137:263-72.

9. Gage BF, van Walraven C, Pearce $L$ et al. Selecting patients with atrial fibrillation for anticoagulation: stroke risk stratification in patients taking aspirin. Circulation 2004;110:2287-92.

10. Stroke Risk in Atrial Fibrillation Working G. Comparison of 12 risk stratification schemes to predict stroke in patients with nonvalvular atrial fibrillation. Stroke 2008;39:1901-10.

11. Healey JS, Martin JL, Duncan A et al. Pacemaker-detected atrial fibrillation in patients with pacemakers: prevalence, predictors, and current use of oral anticoagulation. Can J Cardiol 2013;29:224-8.

12. Fuchs T, Torjman A. Atrial Tachycardia in Patients with Cryptogenic Stroke: Is there a Need For Anticoagulation? Isr Med Assoc J 2015;17:669-72.

13. Wolf PA, Abbott RD, Kannel WB. Atrial fibrillation as an independent risk factor for stroke: the Framingham Study. Stroke 1991;22:983-8.

14. January CT, Wann LS, Alpert JS et al. 2014 AHA/ACC/HRS guideline for the management of patients with atrial fibrillation: a report of the American College of Cardiology/American Heart Association Task Force on Practice Guidelines and the Heart Rhythm Society. J Am Coll Cardiol 2014;64:e1-76.

15. Van Gelder IC, Healey JS, Crijns HJ et al. Duration of Device-detected Subclinical Atrial Fibrillation and Occurrence of Stroke in ASSERT. Eur Heart J 2017;0:1-6. 
16. Glotzer TV, Hellkamp AS, Zimmerman $\mathrm{J}$ et al. Atrial high rate episodes detected by pacemaker diagnostics predict death and stroke: report of the Atrial Diagnostics Ancillary Study of the MOde Selection Trial (MOST). Circulation 2003;107:1614-9.

17. Turakhia MP, Ziegler PD, Schmitt SK et al. Atrial Fibrillation Burden and Short-Term Risk of Stroke: Case-Crossover Analysis of Continuously Recorded Heart Rhythm From Cardiac Electronic Implanted Devices. Circ Arrhythm Electrophysiol 2015;8:1040-7.

18. Brambatti M, Connolly SJ, Gold MR et al. Temporal relationship between subclinical atrial fibrillation and embolic events. Circulation 2014;129:2094-9.

19. Daoud EG, Glotzer TV, Wyse DG et al. Temporal relationship of atrial tachyarrhythmias, cerebrovascular events, and systemic emboli based on stored device data: a subgroup analysis of TRENDS. Heart Rhythm 2011;8:1416-23.

20. Martin DT, Bersohn MM, Waldo AL et al. Randomized trial of atrial arrhythmia monitoring to guide anticoagulation in patients with implanted defibrillator and cardiac resynchronization devices. Eur Heart J 2015;36:1660-8.

21. Kamel H, Okin PM, Elkind MS, ladecola C. Atrial Fibrillation and Mechanisms of Stroke: Time for a New Model. Stroke 2016;47:895-900.

22. Spronk HM, De Jong AM, Verheule $S$ et al. Hypercoagulability causes atrial fibrosis and promotes atrial fibrillation. Eur Heart J 2017;38:38-50. 


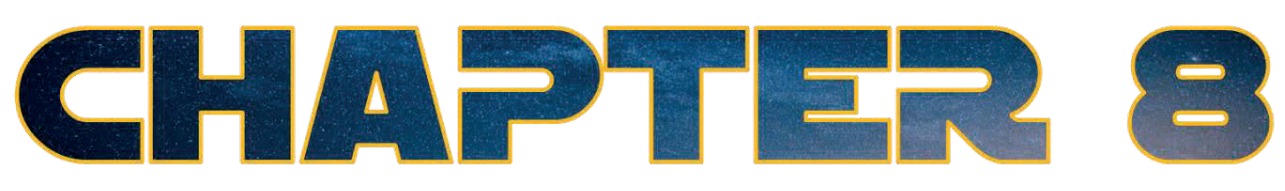

Poor anticoagulation relates to extended access times for cardioversion and is associated with long-term major cardiac and cerebrovascular events

Ömer Erküner, Roy Claessen, Ron Pisters, Germaine Schulmer, Roos Ramaekers, Laura Sonneveld, Elton Dudink, Theo Lankveld, lone Limantoro, Bob Weijs, Laurent Pison, Yuri Blaauw, Cees de Vos, Harry Crijns 


\section{ABSTRACT}

\section{Background}

Patients undergoing elective electrical cardioversion (ECV) for atrial fibrillation have a temporarily increased risk of thromboembolism. Current guidelines recommend adequate anticoagulation for $\geq 3$ consecutive weeks precardioversion, i.e. consecutive INR values 2.03.0 in patients with vitamin $\mathrm{K}$ antagonists (VKA). We aimed to evaluate the occurrence and impact of subtherapeutic INRs precardioversion and to study factors associated with these unwanted fluctuations.

\section{Methods}

We recruited 346 consecutive patients undergoing elective ECV in the Maastricht University Medical Center between 2008 and 2013. Predictors of subtherapeutic INR values were identified and incorporated into a logistic regression model.

\section{Results}

A subtherapeutic INR precardioversion occurred in $55.2 \%$ of patients. The only statistically significant predictor was VKA-naivety (Odds Ratio (OR) 4.78, 95\% Confidence Interval (Cl) 2.67-8.58, $\mathrm{p}<0.001)$. In patients with $\geq 1$ subtherapeutic INR precardioversion, time from referral until cardioversion was $91.1 \pm 42.8$ days, compared to $41.7 \pm 26.6$ days $(p<0.001)$ in patients without subtherapeutic INRs. No thromboembolic events occurred $<30$ days after the ECV. Independent predictors for the combined endpoint of cardiovascular death, ischemic stroke and the need of blood transfusion ( $n=30$, median follow-up of 374 days) were coronary artery disease in the history (OR $3.35,95 \% \mathrm{Cl} 1.54-7.25, \mathrm{p}=0.002)$ and subtherapeutic INR precardioversion (OR $3.64,95 \% \mathrm{Cl} 1.43-9.24, \mathrm{p}=0.007$ ).

\section{Conclusions}

Use of VKA often results in subtherapeutic INRs precardioversion and is associated with a significant delay until cardioversion, especially in patients with recent initiation of VKA therapy. Furthermore, subtherapeutic INR levels prior to ECV are associated with the combined endpoint of cardiovascular death, ischemic stroke and the need of blood transfusion. 


\section{BACKGROUND}

Atrial fibrillation (AF) is the most common sustained cardiac arrhythmia. It is a major health problem, not merely due to its vastness but also because of the associated risks, in particular of thromboembolism (TE). Besides the intrinsic TE risk there is an independent, transient risk of TE in AF patients in case of cardioversion. Of note, all types of cardioversion - i.e. spontaneous, pharmacological and electrical - carry a similar TE risk. $(1,2)$

The temporarily increased TE risk pericardioversion is mainly believed to be caused by stasis of blood in the fibrillating atria, especially in the left atrial appendage. Even following restoration of sinus rhythm, mechanical dysfunction of the atria - so-called atrial stunning may persist, thereby prolonging the temporary increased TE risk.(3) Thus, pericardioversion oral anticoagulation is warranted to significantly decrease the rate of thromboembolic complications from $5.3 \%$ to $0.8-1.0 \% .(4,5)$

Current international guidelines recommend adequate anticoagulation for at least three weeks prior, and four weeks following cardioversion in patients with AF of $>48$ hours or of unknown duration.(6) When using vitamin $\mathrm{K}$ antagonists (VKA), this means achieving and maintaining an INR between 2.0 and 3.0 during the above defined pericardioversion window. However, the well-known VKA hurdles result in large inter- and intraindividual fluctuations of anticoagulation levels $(7,8)$ and proof particularly challenging during initiation.(9) Importantly, sub- and supratherapeutic levels are clearly related to increased mortality and serious adverse outcomes, such as thromboembolism and major bleeding. $(8,10)$

Furthermore, inadequate anticoagulation management can also cause a time delay to cardioversion (11-13) and thereby postpone alleviating AF related symptoms, which is usually the primary goal of cardioversion.(14) Whether the same delay has a significant effect on the total AF duration and consequent success of conversion to, and long-term maintenance of, sinus rhythm - explained by structural and electrical remodeling (11) remains debatable.(15-17)

The objective of this study is to evaluate the occurrence, extent and impact of subtherapeutic INR values prior to and following elective electrical cardioversion (ECV) and to study factors associated with these unwanted fluctuations. 


\section{METHODS}

\section{Study design}

We recruited consecutive unique patients with atrial fibrillation and flutter undergoing elective, direct current (DC) cardioversions between December 2008 and February 2013 in the Maastricht University Medical Center the Netherlands using the prospective Maastricht Cardioversion Registry. Ethical approval for the registry was obtained from the Institutional Review Board. Patients were eligible for inclusion given an age $\geq 18$ years and persistent AF or atrial flutter confirmed by a 12-lead electrocardiogram (ECG). Exclusion criteria were AF duration $<48$ hours or the need for urgent cardioversion because of hemodynamic instability.

Patients already using VKA were scheduled for weekly INR measurements and VKA-naive patients were prescribed acenocoumarol and referred to local Thrombosis Services. Our hospitals elective cardioversion protocol is in line with the international guidelines on AF recommending three weeks of adequate anticoagulation (INR 2.0-3.0) prior to and four weeks following cardioversion. We defined subtherapeutic anticoagulation as any INR $<2.0$ from the moment the patient was referred for cardioversion.

On the scheduled day of cardioversion, a 12-lead ECG was performed to determine heart rhythm and a venous blood sample was drawn to determine INR and potassium levels. In case of an INR $<2.0$ or significant potassium disturbances, cardioversion was postponed. In case of spontaneous conversion to sinus rhythm, cardioversion was cancelled.

All cardioversions were carried out according to protocol. Cardioversion was performed by a cardiology resident using a biphasic waveform defibrillator (Medtronic LIFEPAK® PhysioControl 20) with anterolateral paddle position. Antero-posterior position could be preferred or necessary in selected patients, i.e. in patients with cardiac implantable electronic devices. In case of unsuccessful defibrillation, increasing energy levels were applied with a maximum of three attempts to restore sinus rhythm (200 - 300 - $360 \mathrm{~J})$. Propofol or etomidate was used for sedation at the discretion of the anesthesiologist.

Cardioversion was considered successful upon sinus rhythm restoration and maintenance until discharge the same day. A standard follow up outpatient clinic visit was planned one month following discharge or earlier if deemed clinically necessary. Follow-up was performed until June 2013. 


\section{Data analysis}

Baseline demographics, medical history, medication use, echocardiographic findings and specific information about anticoagulation management were obtained from our digital hospital records. Sinus rhythm maintenance was evaluated during follow-up on the basis of all available 12 lead ECGs from the routine follow-up outpatient clinic visits. The occurrence of ischemic or hemorrhagic stroke was also assessed by reviewing the digital hospital records. Clinically relevant bleeding events were retrieved by identifying patients who needed blood transfusion.

During the course of this study, the target range for INRs in AF patients was 2.5-3.5 in the Netherlands, as recommended at that time by the Federation of Dutch Thrombosis Services. However, given the minimum INR value of 2.0 to safely perform a cardioversion, we only considered an INR $<2.0$ as subtherapeutic. We reviewed all INR measurements between referral and performance of cardioversion. To evaluate a possible delay we calculated the time between referral and the actual cardioversion.

\section{Statistical analysis}

Data were analyzed using SPSS 22.0 (SPSS Inc., Chicago, IL, USA). Continuous variables are reported as mean \pm standard deviation or median (25-75\% quartiles) and categorical variables as number of observed patients (percentage). Chi square test was used for comparison of categorical variables between groups. Fisher's exact test was used if any expected cell count was $<5$. Normally distributed continuous variables were compared between two groups using the independent samples t-test, whereas not normally distributed continuous variables were compared using the Mann-Whitney $U$ test. The distribution of continuous variables were visually checked for normality.

Predictors of subtherapeutic INR values were identified by incorporating all baseline characteristics with a significant univariate relationship and biologically plausible variables into a logistic regression model, with stepwise reduction of the model for variables with a $p$ value $<0.1$. All variables in the final model with a $p$ value $<0.05$ were considered significant independent predictors and were tested for interactions.

\section{RESULTS}

A total of 386 patients were planned to undergo an elective ECV between 2008 and 2013. Of these, $40(10.4 \%)$ were cancelled and 29 (7.5\%) were postponed on the day of cardioversion 
and performed later (see breakdown Figure 1). Baseline rhythm before cardioversion was atrial fibrillation in $90 \%$ and atrial flutter in $10 \%$ of the patients. An antero-lateral paddle position was used in $92.5 \%$ of cardioversions. One shock was sufficient to restore sinus rhythm in $76 \%$ with a total success rate of electrical cardioversion of $90 \%$.

\section{Anticoagulation management before cardioversion}

At least one subtherapeutic INR prior to the cardioversion occurred in 191 of 346 patients $(55.2 \%)$, with an average of $2.8 \pm 2.3$ subtherapeutic INR values. The baseline characteristics of these patients and their adequately anticoagulated counterparts are displayed in the Table below. In $23.7 \%$ of the patients with inadequate anticoagulation management, the subtherapeutic INR was preceded by a supratherapeutic INR (>3.5). In addition, despite adequate anticoagulation prior to the cardioversion, 29 cardioversions (8.4\%) were postponed on the planned day of cardioversion due to a subtherapeutic INR value and were performed later (Figure 1). The time in therapeutic range (TTR) in the time period between referral and performing of cardioversion was $0.79 \pm 0.12$ in the patients with subtherapeutic INRs.

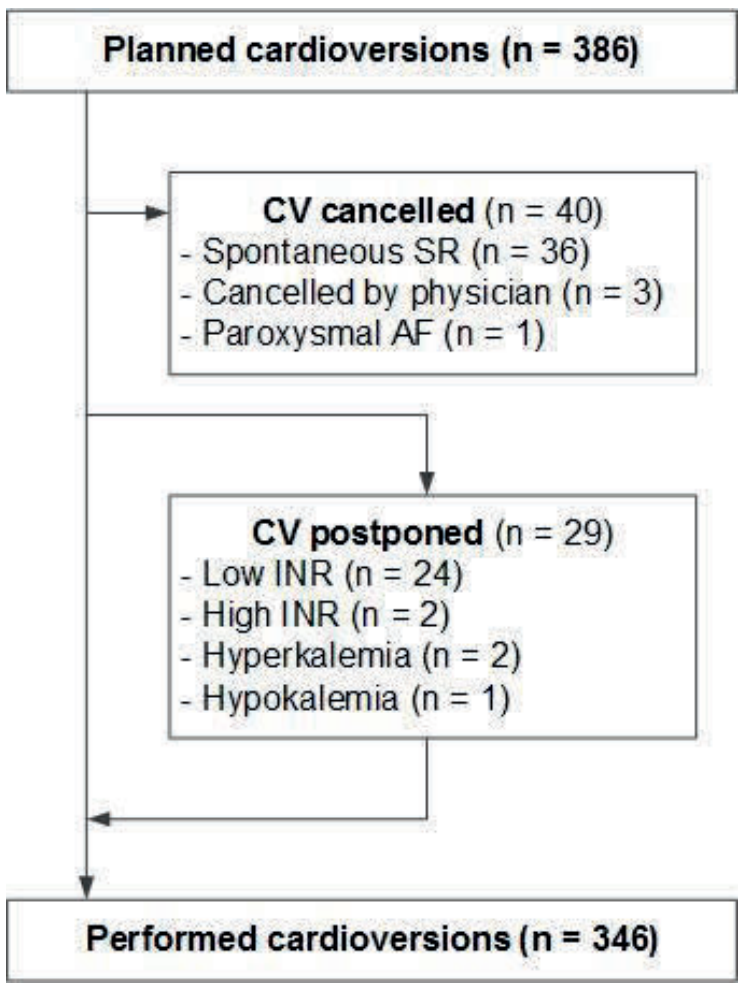

Figure 1. Study flow chart. 
Table. Baseline characteristics.

\begin{tabular}{|c|c|c|c|}
\hline & $\begin{array}{l}\text { Subtherapeutic INR } \\
\qquad(n=191)\end{array}$ & $\begin{array}{l}\text { No subtherapeutic INR } \\
\qquad(\mathrm{n}=155)\end{array}$ & $P$ value \\
\hline \multicolumn{4}{|l|}{ Demographics } \\
\hline Age at ECV & $66.9 \pm 10.5$ & $68.0 \pm 10.2$ & 0.336 \\
\hline Age at first presentation $\mathrm{AF}^{\mathrm{b}}$ & $65.6 \pm 11.0$ & $64.9 \pm 11.8$ & 0.598 \\
\hline Female sex & $60(31.4 \%)$ & $55(35.5 \%)$ & 0.424 \\
\hline $\begin{array}{ll}\mathrm{CHA}_{2} \mathrm{DS}_{2} \text {-VASc } & 0 \\
& 1 \\
& 2 \\
& 3 \\
& 4 \\
& 5 \\
& 6 \\
& 7 \\
& 8-9 \\
\end{array}$ & $\begin{array}{c}15(7.9 \%) \\
44(23.0 \%) \\
39(20.4 \%) \\
41(21.5 \%) \\
22(11.5 \%) \\
19(9.9 \%) \\
9(4.7 \%) \\
2(1.0 \%) \\
0 \\
\end{array}$ & $\begin{array}{c}13(8.4 \%) \\
25(16.1 \%) \\
40(25.8 \%) \\
31(20.0 \%) \\
26(16.8 \%) \\
15(9.7 \%) \\
4(2.6 \%) \\
1(0.6 \%) \\
0 \\
\end{array}$ & $\begin{array}{l}0.694 \\
0.079 \\
0.181 \\
0.715 \\
0.086 \\
0.582 \\
0.300 \\
0.688\end{array}$ \\
\hline Body mass index & $28.9 \pm 5.3(n=176)$ & $28.8 \pm 5.1(n=145)$ & 0.822 \\
\hline \multicolumn{4}{|l|}{ Patient History } \\
\hline Hypertension & $108(56.5 \%)$ & $85(54.8 \%)$ & 0.751 \\
\hline Heart failure & $43(22.5 \%)$ & $32(20.6 \%)$ & 0.675 \\
\hline Type II diabetes & $33(17.3 \%)$ & $16(10.3 \%)$ & 0.065 \\
\hline Coronary artery disease & $60(31.4 \%)$ & $47(30.3 \%)$ & 0.827 \\
\hline Ischemic CVA & $6(3.1 \%)$ & $7(4.5 \%)$ & 0.504 \\
\hline Hemorrhagic CVA & $0(0 \%)$ & $1(0.6 \%)$ & 0.448 \\
\hline TIA & $9(4.7 \%)$ & $11(7.1 \%)$ & 0.345 \\
\hline Hypercholesterolemia & $41(21.5 \%)$ & $23(14.8 \%)$ & 0.114 \\
\hline Peripheral thromboembolism & $6(3.1 \%)$ & 0 & $0.035^{*}$ \\
\hline COPD & $12(6.3 \%)$ & $9(5.8 \%)$ & 0.854 \\
\hline OSAS & $8(4.2 \%)$ & $6(3.9 \%)$ & 0.882 \\
\hline \multicolumn{4}{|l|}{ Echocardiography at baseline } \\
\hline LVEF & $47.6 \pm 12.4(n=188)$ & $51.2 \pm 12.0(n=151)$ & $0.007^{*}$ \\
\hline LA dimension, $\mathrm{mm}$ & $45.5 \pm 6.6(n=183)$ & $45.9 \pm 6.4(n=144)$ & 0.575 \\
\hline \multicolumn{4}{|l|}{ Medication at baseline } \\
\hline VKA-naivety & $70(37.2 \%, n=188)$ & $17(11.0 \%, n=154)$ & $<0.001^{*}$ \\
\hline Acetylsalicylic acid & $2(1.0 \%)$ & $3(1.9 \%)$ & 0.660 \\
\hline $\begin{array}{ll}\text { AAD } & \text { Amiodarone } \\
& \text { Sotalol } \\
& \text { Flecainide }\end{array}$ & $\begin{array}{c}22(11.5 \%) \\
12(6.3 \%) \\
3(1.6 \%)\end{array}$ & $\begin{array}{c}28(18.1 \%) \\
14(9.0 \%) \\
7(4.5 \%)\end{array}$ & $\begin{array}{l}0.085 \\
0.335 \\
0.119\end{array}$ \\
\hline Beta blocker ${ }^{\mathrm{C}}$ & $159(83.2 \%)$ & $119(76.8 \%)$ & 0.132 \\
\hline Digitalis & $54(28.3 \%)$ & $42(27.1 \%)$ & 0.808 \\
\hline Verapamil/diltiazem & $10(5.2 \%)$ & $15(9.7 \%)$ & 0.113 \\
\hline Isosorbide mononitrate & $25(13.1 \%)$ & $20(12.9 \%)$ & 0.959 \\
\hline ACE-inhibitor & $74(38.7 \%)$ & $56(36.1 \%)$ & 0.618 \\
\hline ATII receptor antagonist & $61(31.9 \%)$ & $49(31.6 \%)$ & 0.949 \\
\hline Diuretic & $92(48.2 \%)$ & $72(46.5 \%)$ & 0.751 \\
\hline Dihydropyridine & $29(15.2 \%)$ & $19(12.3 \%)$ & 0.434 \\
\hline Statin & $79(41.4 \%)$ & $75(48.4 \%)$ & 0.191 \\
\hline
\end{tabular}

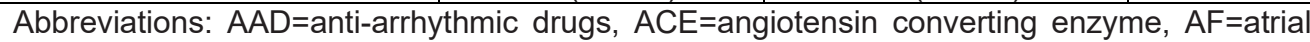
fibrillation, $A T I I=$ angiotensin II, CVA=cerebrovascular accident, COPD=chronic obstructive pulmonary disease, ECV=electrical cardioversion, $L A=l e f t$ atrium, $L V E F=l e f t$ ventricular ejection fraction, OSAS=obstructive sleep apnea syndrome, TIA=transient ischemic attack, VKA=vitamin $\mathrm{K}$ antagonist. 
a Data are presented as means \pm standard deviation or no. (\%). $\mathrm{N}=191$ or 155 , unless otherwise specified.

${ }^{\mathrm{b}}$ Confirmed by ECG recording.

c Sotalol excluded.

* Statistically significant

Possible predictors for subtherapeutic INR values precardioversion were assessed using logistic regression. After stepwise reduction of the model, the only remaining statistically significant predictor was VKA-naivety (Odds Ratio (OR) 4.78, 95\% Confidence Interval (Cl) 2.67-8.58, $p<0.001)$.

In patients with $\geq 1$ subtherapeutic INR value prior to cardioversion, time from referral until cardioversion was $91.1 \pm 42.8$ days, compared to $41.7 \pm 26.6$ days $(p<0.001$ ) in patients without a subtherapeutic INR value before cardioversion. The relationship between the number of subtherapeutic INRs and the time to cardioversion is depicted in Figure 2. In VKA naive patients, time from referral until cardioversion was $84.5 \pm 40.6$ days, compared to $63.6 \pm 44.0$ days $(p<0.001)$ in patients already on vitamin $K$ antagonists before referral to cardioversion.

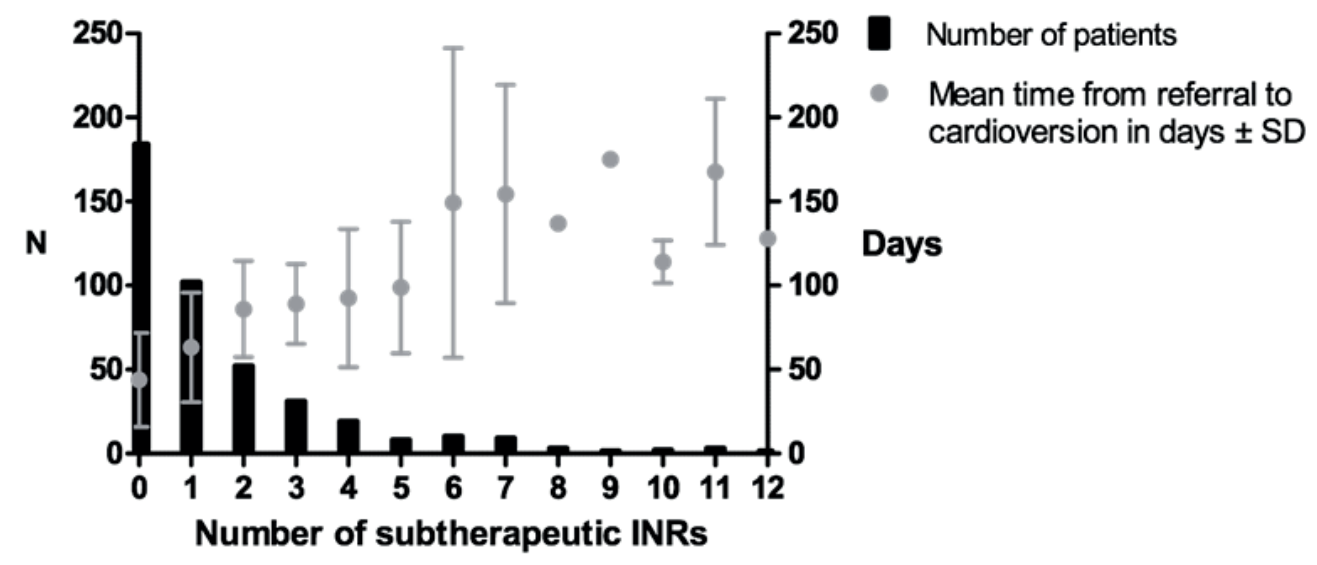

Figure 2. Mean time from referral to cardioversion for patients subdivided by number of subtherapeutic INRs (right y-axis) and the sample size per group (left y-axis).

\section{Anticoagulation management postcardioversion}

INR measurements $1,2,3$, and 4 weeks after cardioversion could be retrieved in $87.9 \%$, $85.5 \%, 72.8 \%$ and $37.0 \%$ of the patients, respectively. A subtherapeutic INR was found in $11.5 \%, 11.1 \%, 11.1 \%$ and $12.5 \%$ of these patients. In total, $30.0 \%$ of patients with available follow-up on INR values postcardioversion showed at least one subtherapeutic INR. Possible 
predictors for subtherapeutic INR values postcardioversion were assessed using logistic regression in a similar manner to the analysis of precardioversion subtherapeutic INRs. However, no statistically significant predictors could be identified.

\section{Mortality, strokes and events requiring blood transfusion during follow-up}

The median follow-up was 374 days (147-818 days), 31 patients $(9.0 \%)$ were lost to followup. A total of 20 patients died during follow-up, of whom 5 died of cardiovascular causes. One death occurred 4 days after cardioversion. This patient lived alone and was found dead at home by her family. Autopsy showed severe coronary artery disease and myocarditis. Cerebral autopsy showed no signs of ischemic stroke, thus a direct relationship with the cardioversion could not be established. No other deaths occurred within 30 days after the cardioversion.

Ischemic stroke occurred in 5 patients (1.5\%) during follow-up. None of the strokes occurred within 30 days following cardioversion (range of 204-1658 days). Thus, no direct relationship with the cardioversion could be established.

No hemorrhagic strokes occurred during follow-up. A total of 22 patients received blood transfusion postcardioversion. None of these occurred within 30 days after cardioversion. Median time to transfusion was 420 days (139-762 days).

For the combined endpoint of cardiovascular death, ischemic stroke and the need of blood transfusion $(n=30)$, statistically significant predictors were subtherapeutic INR values prior to ECV (OR 3.64, 95\% Cl 1.43-9.24, p=0.007) and coronary artery disease in the history (OR $3.35,95 \% \mathrm{Cl} 1.54-7.25, \mathrm{p}=0.002)$.

\section{DISCUSSION}

In this cohort of patients undergoing elective electrical cardioversion we observed that subtherapeutic INR levels prior to cardioversion occurred frequently (55.2\%) and were associated with a significant prolongation of the time from referral until cardioversion ( 91 vs. 42 days, $p<0.001)$. In nearly a quarter of these patients, the subtherapeutic INR value was preceded by a supratherapeutic INR value (>3.5). This implies that VKA dose adjustments should be made with precaution in patients on the waiting list for elective cardioversion, since one subtherapeutic INR value means a delay of cardioversion of at least 4 weeks.

Recent initiation of VKA was associated with inadequate INRs precardioversion. Time to cardioversion for VKA-naive patients was on average 85 days, compared to 64 days for 
patients already on VKA. This difference is probably accountable to the initial fluctuation of INRs after starting with VKA therapy and the time needed to acquire stable and adequate INR values.

Despite adequate anticoagulation management prior to the cardioversion, a substantial amount of patients $(8.4 \%)$ had a subtherapeutic INR value on the day they were planned to undergo the cardioversion. This not only means the patient has to wait for an additional 4 weeks at best, but also impedes reduction of the waiting list since another patient could have undergone the ECV on that day. This could partly explain the fact that the mean time to cardioversion in the group with adequate anticoagulation management prior to the cardioversion is 42 days, which is still much longer than the required 21 days according to the guidelines.(6)

After cardioversion, we observed at least one subtherapeutic INR value in $30 \%$ of the patients with known anticoagulation follow-up. No thromboembolic events occurred within 30 days of the ECV, whereas we would have expected 4 events based on a prevalence of 0.8 $1.0 \%$.(5) Furthermore, no major bleedings occurred within 30 days of cardioversion.

Factors associated with the combined endpoint of cardiovascular death, ischemic stroke and the need of blood transfusion were subtherapeutic INRs prior to cardioversion and a history of coronary artery disease (CAD). CAD likely acts as a general marker of vascular weakness, resulting in both thromboembolism and bleeding events. Inadequate anticoagulation management prior to the cardioversion could be a marker of long term cardiovascular events, but could also be the underlying mechanism of these events via chronically suboptimal anticoagulation management. This is in line with a previous report showing that time in therapeutic range (TTR) in the initial phase after starting VKA therapy is highly predictive for the long term TTR.(18) Furthermore, subtherapeutic INRs precardioversion are comparable to "labile INR" as used in the bleeding risk score HAS-BLED (Hypertension, Abnormal renal/liver function, Stroke, Bleeding history or predisposition, Labile INR, Elderly (> 65 years), Drugs/alcohol concomitantly).(19) Patients with subtherapeutic INRs prior to cardioversion could therefore be seen as the patients who have a higher risk of developing bleeding events on the long run due to frequently occurring supratherapeutic INRs. Switching to a non-VKA oral anticoagulant drug (NOAC) could be beneficial in these patients by eliminating a fluctuating anticoagulation level, not only leading to a reduced access time for elective cardioversion but also possibly leading to less bleeding events by eliminating supratherapeutic INRs. 
At the time of inclusion and follow-up of this study, the INR range used by the Federation of Dutch Thrombosis Services for patients with AF was higher than the international recommendations (2.5-3.5 vs. 2.0-3.0). This would in theory translate into a smaller number of subtherapeutic INR levels and subsequent postponement since there is a buffer for the occurrence of subtherapeutic INRs. Also meaning that the prevalence of subtherapeutic INRs can be higher than reported in this study in countries using the internationally recommended INR range. As of January $1^{\text {st }} 2016$, the INR target range in the Netherlands has been changed and is now the same as used internationally. This could mean that subtherapeutic INR values precardioversion will be more prevalent in the Netherlands from now on when compared to the results found in this study.

Our study highlights the struggles of achieving adequate anticoagulation with VKA in patients undergoing an ECV. The fluctuations in the level of anticoagulation, expressed in INR values, substantially affects the time to cardioversion. However, in our study, no adverse effects on patient outcomes were observed.

NOACs appear to be good alternatives to VKAs in patients planned for ECV, especially for those who are more likely to have subtherapeutic INR values, i.e. patients who have not yet started an anticoagulant drug. Both dabigatran and rivaroxaban have proven to be noninferior to VKA treatment regarding safety endpoints in patients undergoing electrical cardioversion. $(5,20,21)$ Additionally, NOACs have the advantage of not being dependent on a fluctuating anticoagulation level when taken as prescribed. This advantage can shorten both the time to cardioversion for the patient and the waiting list for elective cardioversion in general.

\section{Limitations}

Not all patients undergoing elective ECV could be included due to missing INR data. Furthermore, only clinically relevant major bleedings were taken into account since minor bleedings could not be uniformly obtained from the patient files.

At the time of inclusion and follow-up of this study, the INR range used by the Federation of Dutch Thrombosis Services was higher compared to international recommendations. This potentially translates into an underestimation of the prevalence of subtherapeutic INR values in countries using the internationally recommended INR range, like the Netherlands at present, possibly leading to an even longer mean time to cardioversion than reported in this study. 


\section{CONCLUSIONS}

Use of vitamin $\mathrm{K}$ antagonists often results in subtherapeutic INR levels prior to elective ECV and is associated with a significant delay until cardioversion, especially in patients with recent initiation of VKA therapy. Furthermore, subtherapeutic INR levels prior to ECV are associated with the combined endpoint of cardiovascular death, ischemic stroke and the need of blood transfusion. 


\section{REFERENCES}

1. Nieuwlaat R, Prins MH, Le Heuzey JY, Vardas PE, Aliot E, Santini M, et al. Prognosis, disease progression, and treatment of atrial fibrillation patients during 1 year: follow-up of the Euro Heart Survey on atrial fibrillation. Eur Heart J. 2008;29(9):1181-9.

2. Pisters R, Nieuwlaat R, Prins MH, Le Heuzey JY, Maggioni AP, Camm AJ, et al. Clinical correlates of immediate success and outcome at 1-year follow-up of real-world cardioversion of atrial fibrillation: the Euro Heart Survey. Europace. 2012;14(5):666-74.

3. Khan IA. Atrial stunning: basics and clinical considerations. Int J Cardiol. 2003;92(23):113-28.

4. Bjerkelund CJ, Orning OM. The efficacy of anticoagulant therapy in preventing embolism related to D.C. electrical conversion of atrial fibrillation. Am J Cardiol. 1969;23(2):208-16.

5. Cappato R, Ezekowitz MD, Klein AL, Camm AJ, Ma CS, Le Heuzey JY, et al. Rivaroxaban vs. vitamin $\mathrm{K}$ antagonists for cardioversion in atrial fibrillation. Eur Heart $\mathrm{J}$. 2014;35(47):3346-55.

6. Camm AJ, Lip GY, De Caterina R, Savelieva I, Atar D, Hohnloser SH, et al. 2012 focused update of the ESC Guidelines for the management of atrial fibrillation: an update of the 2010 ESC Guidelines for the management of atrial fibrillation--developed with the special contribution of the European Heart Rhythm Association. Europace. 2012;14(10):1385-413.

7. Ansell J, Hirsh J, Hylek E, Jacobson A, Crowther M, Palareti G, et al. Pharmacology and management of the vitamin $\mathrm{K}$ antagonists: American College of Chest Physicians Evidence-Based Clinical Practice Guidelines (8th Edition). Chest. 2008;133(6 Suppl):160S-98S.

8. Jones M, McEwan P, Morgan CL, Peters JR, Goodfellow J, Currie CJ. Evaluation of the pattern of treatment, level of anticoagulation control, and outcome of treatment with warfarin in patients with non-valvar atrial fibrillation: a record linkage study in a large British population. Heart. 2005;91(4):472-7.

9. Hylek EM, Evans-Molina C, Shea C, Henault LE, Regan S. Major hemorrhage and tolerability of warfarin in the first year of therapy among elderly patients with atrial fibrillation. Circulation. 2007;115(21):2689-96.

10. Wan Y, Heneghan C, Perera R, Roberts N, Hollowell J, Glasziou P, et al. Anticoagulation control and prediction of adverse events in patients with atrial fibrillation: a systematic review. Circ Cardiovasc Qual Outcomes. 2008;1(2):84-91.

11. Cutro R, Jr., Burkart TA, Curtis AB. Rapid achievement of therapeutic anticoagulation positively affects outcome in patients undergoing cardioversion for persistent atrial fibrillation. Clin Cardiol. 2006;29(2):78-82.

12. Kim MH, Krishnan K, Jain S, Decena BF. Time course and frequency of subtherapeutic anticoagulation for newly prescribed warfarin anticoagulation before elective cardioversion of atrial fibrillation or flutter. Am J Cardiol. 2001;88(12):1428-31, A8.

13. Ryman J, Frick M, Frykman V, Rosenqvist M. Duration of warfarin sodium therapy prior to electrical cardioversion of atrial fibrillation. J Intern Med. 2003;253(1):76-80. 
14. Van Gelder IC, Hagens VE, Bosker HA, Kingma JH, Kamp O, Kingma T, et al. A comparison of rate control and rhythm control in patients with recurrent persistent atrial fibrillation. N Engl J Med. 2002;347(23):1834-40.

15. Asher CR, Klein AL. The ACUTE trial. Transesophageal echocardiography to guide electrical cardioversion in atrial fibrillation. Assessment of Cardioversion Using Transesophageal Echocardiography. Cleve Clin J Med. 2002;69(9):713-8.

16. Dethy M, Chassat C, Roy D, Mercier LA. Doppler echocardiographic predictors of recurrence of atrial fibrillation after cardioversion. Am J Cardiol. 1988;62(10 Pt 1):723-6.

17. Klein AL, Grimm RA, Jasper SE, Murray RD, Apperson-Hansen C, Lieber EA, et al. Efficacy of transesophageal echocardiography-guided cardioversion of patients with atrial fibrillation at 6 months: a randomized controlled trial. Am Heart J. 2006;151(2):3809.

18. Veeger NJ, Piersma-Wichers M, Tijssen JG, Hillege HL, van der Meer J. Individual time within target range in patients treated with vitamin $\mathrm{K}$ antagonists: main determinant of quality of anticoagulation and predictor of clinical outcome. A retrospective study of 2300 consecutive patients with venous thromboembolism. Br J Haematol. 2005;128(4):513-9.

19. Pisters R, Lane DA, Nieuwlaat R, de Vos CB, Crijns HJ, Lip GY. A novel user-friendly score (HAS-BLED) to assess 1-year risk of major bleeding in patients with atrial fibrillation: the Euro Heart Survey. Chest. 2010;138(5):1093-100.

20. Nagarakanti R, Ezekowitz MD, Oldgren J, Yang S, Chernick M, Aikens TH, et al. Dabigatran versus warfarin in patients with atrial fibrillation: an analysis of patients undergoing cardioversion. Circulation. 2011;123(2):131-6.

21. Coquard C, Moubarak G, Baudet M, Logeart D, Dillinger J-G, Cohen-Solal A. Clinical experience of dabigatran and rivaroxaban in electrical cardioversion of atrial fibrillation. International Cardiovascular Forum Journal. 2015;4:71-2. 


\section{GتNERAL DISCUSSION ANDD SUTMMARY}




\section{GENERAL OUTLINE OF THIS THESIS}

"In many patients, AF progresses from short, infrequent episodes to longer and more frequent attacks. Over time, many patients will develop sustained forms of AF. In a small proportion of patients, AF will remain paroxysmal over several decades $(2-3 \%$ of $A F$ patients)."

This passage is the only part discussing AF progression in the 62 pages of text from the ESC guidelines on AF.(1) Similarly, little attention is given to the progression of AF in daily clinical practice, even though it harbors valuable information.

This thesis provides more insight in factors influencing the progression of $A F$, the effect of AF progression on the quality of life, how AF progression may be defined, and the shortcoming of this definition in the contemporary era of continuous atrial rhythm monitoring with implantable loop recorders. Furthermore, the use of anticoagulation in the present-day management of AF is discussed and its possible effect on the progression of AF. This chapter critically reflects on the obtained results, places these in the context of the available literature, and ends with proposing future research directions.

\section{THE PROGRESSION OF ATRIAL FIBRILLATION}

The progression of AF can be influenced by several factors. Well-known factors can be seen in the HATCH-score, i.e. heart failure, age, previous stroke/transient ischemic attack, chronic obstructive pulmonary disease, and hypertension. A recent meta-analysis has reported that the mean follow-up duration also is predictive of AF progression, with shorter studies demonstrating higher rates of progression. $(2,3)$ This remarkable finding can be explained by the more thorough rhythm follow-up in a formal study as compared to a survey in routine clinical care from which the $\mathrm{HATCH}$ score was derived. More intense monitoring in a formal study obviously boosts the AF progression rate compared to observational surveys, especially in the beginning of the study since the increased monitoring will lead to improved detection of AF progression. No differences were seen between studies in patients with newonset $\mathrm{AF}$ and patients with a longer history of AF.(3)

Since hypertension is a known risk factor for the progression of AF, we hypothesized that patients with more severe forms of hypertension would also have a higher risk of AF progression. To this aim, we compared the AF progression rates in patients with hypertension and hypertensive end-organ damage, i.e. left ventricular hypertrophy (LVH) on 
echocardiography, to those with hypertension without LVH in the Euro Heart Survey (EHS; Chapter 2). As expected, the AF progression rate was higher in the hypertensive patients with LVH $(24 \%$ vs. $9 \%, p=0.011)$. A similar conclusion was drawn by Padfield et al. in a Canadian registry.(4) In addition, mitral regurgitation, aortic stenosis, and left atrial dilatation were also associated with progression of AF in this study.

Remarkably, the effect of the presence of LVH on AF progression could only be ascertained in male patients $(28 \%$ vs. $6 \%)$ and not in female patients (15\% vs. $15 \%)$ in our population. This dissimilar effect of LVH on AF progression in men and women could possibly be explained by the type of LVH, with men showing predominantly concentric LVH and women both concentric and eccentric LVH.(5) Since concentric LVH is associated with AF recurrences,(6) one could argue that it may also play a role in the progression of AF. Unfortunately, it was not possible to assess the type of LVH in our population.

In Chapter 3, a different selection was made from the patients included in the EuroHeartSurvey on AF (EHS). All patients who had filled in the baseline and follow-up quality of life (QoL) questionnaire were analyzed. As hypothesized, patients with AF progression showed decrease in QoL, whereas the patients without AF progression remained stable over time. Remarkably, the decrease was not due to the progression of AF itself, as was concluded from the multivariate regression analysis, but rather from symptoms due to AF or the occurrence of adverse events, i.e. stroke, heart failure, malignancy, or implantation of an implantable cardioverter defibrillator (ICD). So, patients with AF progression had more adverse events and were more symptomatic, thereby causing more decrease in the QoL, which corroborates the findings in one of our previous studies with QoL assessments in AF patients.(7)

In Chapter 4, we aimed to assess the role of pericardial adipose tissue (PAT) using a more liberal definition of $A F$ progression, i.e. recurrence of $A F$ after ablation. AF ablation is generally performed in symptomatic patients in whom anti-arrhythmic drug therapy is not tolerated or ineffective in reducing symptoms.(1) In the work-up for ablation, a cardiac computed tomography (CCT) scan is frequently performed, predominantly to visualize the pulmonary vein anatomy. We used semi-automatic software to reliably detect the amount of PAT in almost 300 patients and correlated this to the rhythm outcome after ablation. We found that patients with a favorable outcome after ablation, i.e. no recurrences of $A F$ in the absence of anti-arrhythmic drugs (AAD), indeed had less PAT than patients with recurrences of AF after ablation. This univariable association did not hold, since multivariable logistic regression only ascertained left atrial volume to be independently associated with the rhythm outcome after AF ablation. 
Several studies have also investigated the association between PAT and arrhythmia recurrence, with conflicting evidence. Not to mention a possible publication bias with nonsignificant studies not published. In a study with 40 patients, both left atrial PAT (LA-PAT) and total PAT predicted AF recurrences after ablation.(8) In a different study with 274 patients in which only LA-PAT was assessed, extent of PAT predicted AF recurrences after ablation.(9) In the largest study with 665 patients, total PAT could only predict AF recurrences in patients with persistent/progressed $A F$, and not in patients with paroxysmal AF.(10)

Apart from the question whether only left atrial PAT should be determined or total heart PAT, there is also the question whether only epicardial adipose tissue (EAT), i.e. inside of the pericardium, should be determined or that all adipose tissue (AT) around the heart should be measured, without delineating the pericardium. Stojanovska et al. compared EAT with extrapericardial AT, showing that only EAT could predict AF recurrences after ablation in 169 patients.(11) The pericardium was manually traced in these patients. Extrapericardial AT alone as well as combined with EAT (total heart PAT) were not predictive of rhythm outcome after AF ablation, contrary to the conclusion of the studies mentioned above and our own study.

From a pathophysiological point of view, both epicardial and extrapericardial AT should be able to have effects on the atria and the heart in general. The paracrine effects of AT are most likely greater for epicardial than for extrapericardial AT, given the location of the fatty tissue. AT is believed to stimulate a pro-inflammatory response in the atria through secretion of inflammatory cytokines, growth factors, and matrix metalloproteinases and thus lead to fibrotic remodeling of the atrial myocardium. $(12,13)$ This evoked atrial remodeling may influence the recurrences of AF after ablation. In addition to these paracrine effects, AT can also have systemic effects on the heart and the atria, e.g. through hypercoagulability. It has previously been shown that AT can activate thrombocytes, inhibit fibrinolysis, and stimulate the synthesis of coagulation factors, leading to an increased hypercoagulability.(14) This in turn has been shown to cause atrial fibrosis in a mouse model, and as a consequence leading to an increased incidence of AF in these mice compared to wild-type mice.(15) The same pathophysiological mechanisms might partly explain the association between adipose tissue and AF in man. The role of hypercoagulability in AF progression is also the central hypothesis of the RACE $\vee$ registry (Chapter 5). 


\section{Shortcoming of current definition for AF progression}

"The diagnosis of AF requires rhythm documentation using an electrocardiogram (ECG) showing the typical pattern of AF... By accepted convention, an episode lasting at least 30 seconds is diagnostic."(1)

Similar to the threshold for documentation of AF, the cut-offs for the classification of AF into paroxsymal and persistent are also based on accepted convention, with paroxsymal AF being characterized by self-terminating episodes of typically $<48$ hours and maximally lasting 7 days, and persistent AF by non-self-terminating episodes lasting $>7$ days.(1) Based on this classification, important therapeutic decisions are made, such as scheduling for electrical cardioversion (ECV), ablation strategies, prescription of AADs, and rate control. This classification, in turn, is mostly based on the combination of patient-reported symptoms and one or more 10-second ECGs, which is not accurate in determining the type of AF.

Firstly, patient-reported symptoms are unreliable when it comes to assessing the AF burden, i.e. the percentage of time in AF divided by total time. Asymptomatic episodes frequently occur, even in patients who are highly symptomatic.(16-18) In addition, therapeutic interventions reduce symptoms in AF patients. This is not only the case for $A A D$ and ablations(19-21), but even for rate control drugs(22), leading to more AF episodes going unnoticed, underestimating the AF burden in a patient.

Secondly, occasional rhythm monitoring in the form of 10-second ECGs, or even Holter devices with longer monitoring time capacity, always bear a certain sampling error with them, inherent to the incidental character of the monitoring modality. This is best visualized by the opposite monitoring modality, continuous rhythm monitoring. In figure 1 of Chapter 5, the first six months of rhythm follow-up is visualized for three patients from the RACE V registry, all showing a distinct form of paroxysmal AF. Without the continuous rhythm monitoring, all three patients could be classified in a similar manner, and therefore most likely treated similarly as well. Furthermore, a 24-hour Holter monitoring, or routine 10-second ECGs, could result in totally different AF burdens and underestimate as well as overestimate the burden, depending on the time on the $\mathrm{X}$-axis the monitoring is performed.

In a post-hoc analysis of the OMNI(23) and TRENDS(24) studies combined, the correlation between clinical classification of AF and the continuous rhythm monitoring was assessed. In 1200 patients with an implantable device, the agreement between the AF classification as determined by the treating physician and the device-derived assessment was poor (Cohen's $\mathrm{k}=0.12,95 \% \mathrm{Cl} 0.05-0.18, \mathrm{p}=0.01) .(25)$ Only $47 \%$ of the patients classified as paroxysmal 
$A F$ indeed had paroxysmal AF. For persistent AF, this was even worse at $33 \%$ agreement. The AF burden distribution was very heterogeneous in both types of AF.(25)

This misclassification of AF by physicians is common, but not always very evident. In Chapter 1 for example, we saw an AF progression rate of $17 \%$, which is high, but the AF regression rate, which is presumed to occur much less often,(1) was also $17 \%$. A similar conclusion can be drawn from the 30-year follow-up of the Olmsted County population.(26) Of the 37 patients with persistent AF at baseline, 8 were classified as permanent AF after a mean follow-up of 25 years, 4 as persistent and 25 (68\%) as paroxysmal. Of the 34 patients with paroxysmal AF at baseline, 16 progressed (47\%) to persistent AF during follow-up.(26) In Chapter 8, we included patients with persistent AF scheduled for an elective cardioversion, $36(9 \%)$ of the 386 patients had "spontaneous" cardioversion. A proportion of the patients from these 3 examples must have been misclassified. In Chapter 5, we also observed patients having paroxysms lasting $>7$ days but with spontaneous conversion to sinus rhythm, with a 1 week Holter recording these patients could be misclassified as having persistent AF, in case symptomatology was unclear. This and previous examples emphasize that the current definition and classification of AF and the progression of AF do not reflect the true nature of the arrhythmia.

Since determining the type of AF is not accurate with occasional rhythm monitoring and patient-reported symptoms, determining AF progression, which is based on a change in the type of AF, is also inaccurate. Therefore, in a preliminary analysis of the first 202 patients from the RACE $V$ registry (Chapter 5), we assessed the different patterns of paroxysmal AF and progression of $A F$ using continuous rhythm monitoring. Patients were divided in four groups based on the longest AF episode duration and on their AF burden, i.e. no AF, short ( $<6$ hours), intermediate (6-12 hours), and long episodes ( $>12$ hours) and no AF, low $(<0.5 \%)$, intermediate $(0.5-2.5 \%)$, and high AF burden $(>2.5 \%)$. Differences in baseline characteristics were comparable among AF duration and AF burden subgroups. Patients with long episodes or high burden were more often male, had more often heart failure and coronary artery disease, and had a higher left ventricular mass. In 179 (89\%) patients, 1-year rhythm follow-up was available. Daily averaged AF burden increased from $3.2 \%$ in the first 3 months, to $6.1 \%$ in the last 3 months. Compared to the first 6 months, 111 patients (62\%) remained in the same category of episode duration in the second 6 months, $39(22 \%)$ had progression, and 29 (16\%) had regression. Eight patients (4.5\%) developed persistent AF. Overall, we observed a subtle increase in averaged AF burden throughout a short follow-up period. About 1 in 5 patients showed progression to a higher AF category based on the 
longest AF duration, indicating that in most cases, AF progression is a process of subtle AF episode prolongation.

Even though AF begets AF in the long term,(27) in the short term a regression in burden can be seen, as we saw in a proportion of the patients in Chapter 5. This is a consequence of clustering of AF episodes, which has been observed both in normal conditions(28) and in the period before death.(29) In a way, the progression of AF can be seen as a mountain stage in the Tour de France. The finish will be at the top, that is out of question, but the road to that finish will have some ascends as well as some descends. The fact that a cyclist is currently descending (or the burden of AF in a patient is decreasing), does not mean that eventually the road will not ascend (or the burden of AF in a patient will not increase). In addition, some patients will not get to see persistent AF, just like some cyclists will not make it to the end of the stage.

Similar findings were ascertained by Diederichsen et al. in a Danish population.(30, 31) Patients without a history of AF aged $\geq 70$ and at least one of the following risk factors, i.e. hypertension, diabetes, previous stroke, or heart failure, were included and underwent implantation of a loop recorder. One third of the patients showed AF of at least 6 minutes, of whom $16 \%$ showed progression to at least 1 episode lasting $\geq 24$ hours during follow-up.(30) Furthermore, cardiac biomarkers like NT-proBNP and troponin T were associated with incidence of AF and improved the prediction of long term episodes.(31)

In conclusion: the more you look, the more you see. Continuous rhythm monitoring has improved our understanding of patterns and progression of AF, and will continue to do so. Perhaps we should change the way we look at AF progression and stop looking at it as a simple, dichotomous phenomenon, especially given the widespread occurrence of misclassification of AF type. The RACE $V$ registry will, once finished, provide us with more answers.

\section{ANTICOAGULANT TREATMENT IN ATRIAL FIBRILLATION}

\section{Correct use of anticoagulation}

In Chapter 1, we provide a contemporary representation of the characteristics, treatment, and outcomes of AF patients in the Netherlands and Belgium, with special reference to anticoagulation treatment. In this registry, 967 patients were included in 23 centers. At baseline, 887 patients (92\%) received anticoagulant treatment. Strikingly, a large proportion 
of patients without an indication for chronic anticoagulant treatment, i.e. men with a $\mathrm{CHA}_{2} \mathrm{DS}_{2}$-VASc score of 0 and women with a score of 1 , were in fact anticoagulated at baseline (70\%). A slim majority (59\%) of these patients underwent a rhythm intervention at or shortly after baseline (justifying the initiation of anticoagulants in these patients), resulting in overtreatment of patients with anticoagulant therapy in the remainder, which translated into $5 \%$ of the whole population being overtreated (Chapter 1 , Figure 2 ).

Undertreatment of patients was even more prevalent, with $9 \%$ of the patients either receiving no anticoagulation at all in the presence of an indication based on the $\mathrm{CHA}_{2} \mathrm{DS}_{2}-\mathrm{VASc}$ score, or receiving the reduced dose of a NOAC without a reason for dose reduction. This did not lead to more adverse events, but the occurrence of major adverse cardiac and cerebrovascular events was low in the first place, i.e. $4 \%$ per year, making it very hard to draw conclusions regarding the effects of undertreatment on adverse events.

In total, $17 \%$ of the patients using a NOAC were incorrectly dosed. Previous reports have shown higher rates of incorrect dosing of $25-37 \% .(32,33)$ Even though with time, incorrect use of NOACs seems to reduce, there is still more room for improvement. Raising awareness regarding correct use of anticoagulation is important, so that adverse events can be limited to the minimum.

In Chapter 8, we investigated another variant of undertreatment. In patients with VKA undergoing elective cardioversions, we observed that subtherapeutic INRs precardioversion occurred in more than half of all patients, leading to a significant delay until cardioversion, especially in patients with recent initiation of VKA therapy. Moreover, subtherapeutic INR levels prior to ECV were associated with the combined endpoint of cardiovascular death, ischemic stroke and the need of blood transfusion.

NOACs appear to be good alternatives to VKAs in patients planned for ECV, since they are at least as effective as VKA and cause less bleedings(1,34-36), and are not dependent on a fluctuating anticoagulation level when taken as prescribed, leading to a reduction in waiting time to elective cardioversion and shortening the waiting list for elective cardioversion in general. However, in order to benefit from these advantages, the correct dosing and use of NOACs is of paramount importance. 


\section{Anticoagulation and the progression of atrial fibrillation}

The main hypothesis of the RACE $V$ registry (Chapter 5 ) is that hypercoagulability is an important factor in the progression of AF. Experimental data show that a hypercoagulable state, i.e. enhanced thrombin activity, induces pro-fibrotic and pro-inflammatory changes in the atria in mice, leading to the development of a substrate for atrial fibrillation.(15) Furthermore, counter-acting thrombin through administration of nadroparin leads to attenuation of atrial fibrosis and AF substrate complexity in goats, which is most likely mediated by protease activated receptors (PAR). These can be activated by low-molecular weight heparins, i.e. nadroparin, and NOACs, but not by VKA. Therefore, anticoagulation treatment might influence the progression of atrial fibrillation. This is one of the hypotheses we aim to investigate in the RACE $\vee$ registry (Chapter 5) and the RACE V consortium in general.

In Chapter 6, we aimed to answer a similar question, only not for the progression of AF but for the development of AF, i.e. at the start of the disease. We performed a post-hoc analysis of clinical trials that randomized patients without a history of AF to treatment with either a NOAC or warfarin/placebo, i.e. Hokusai-VTE(37), RE-COVER I(38), RE-COVER II(38), REMEDY(39), RE-SONATE(39), and RE-DEEM(40). In these trials, the occurrence of AF was reported as an adverse event. Unfortunately, no periodic electrocardiograms were performed to detect AF.

We hypothesized that a hypercoagulable state, i.e. enhanced thrombin activity, induces profibrotic and pro-inflammatory changes in the atria, leading to the development of a substrate for atrial fibrillation, as shown in experimental data.(15) A total of 19,424 patients were included from 6 randomized controlled trials for this analysis. AF was diagnosed in 120 $(0.62 \%)$ patients, with similar incidence in those randomized to receive a NOAC compared with VKA or placebo. The overall incidence of AF was lower than expected (0.9\%/year), possibly due to underdiagnosing of asymptomatic AF. In addition, in 2 of the 5 trials, i.e. REMEDY and RE-SONATE(39), patients previously treated with warfarin were also included, possibly diminishing the positive effect of NOACs on incidence of AF. Furthermore, the treatment duration with NOAC in these trials might be too short in order to see differences in AF incidence. 


\section{Atrial high rate episodes and anticoagulation}

Cardiovascular implantable electronic devices (CIEDs), i.e. pacemakers and ICDs, are able to detect episodes of atrial arrhythmias by continuous rhythm monitoring, regardless of the presence of symptoms. These atrial arrhythmias are called atrial high rate episodes (AHRE) and occur frequently. In patients without a history of AF with a CIED, the incidence of AHRE is approximately $25 \%$ after 1 year and $35 \%$ after 2 years of follow-up.(41-43)

AHRE differ from clinical AF in a couple of characteristics. Firstly, clinical AF is ascertained on an electrocardiogram, whereas AHRE are solely recorded on a CIED read-out.(1) Secondly, patients with AHRE have a lower thrombo-embolic risk compared to AF patients.(42, 44-47) Current guidelines recommend starting anticoagulant therapy in AF patients with a $\mathrm{CHA}_{2} \mathrm{DS}_{2}$-VASc score $\geq 2$ and considering antithrombotic therapy in patients with a $\mathrm{CHA}_{2} \mathrm{DS}_{2}$-VASc score of 1.(1) For AHRE however, no recommendations regarding antithrombotic therapy are made in the guidelines, largely because of lack of evidence for any benefit of antithrombotic treatment in patients with AHRE.(1) In Chapter 7, we propose a decision making flow-chart (Figure 1) regarding anticoagulant treatment for patients with AHRE, after reviewing the available literature on this matter, awaiting further research.

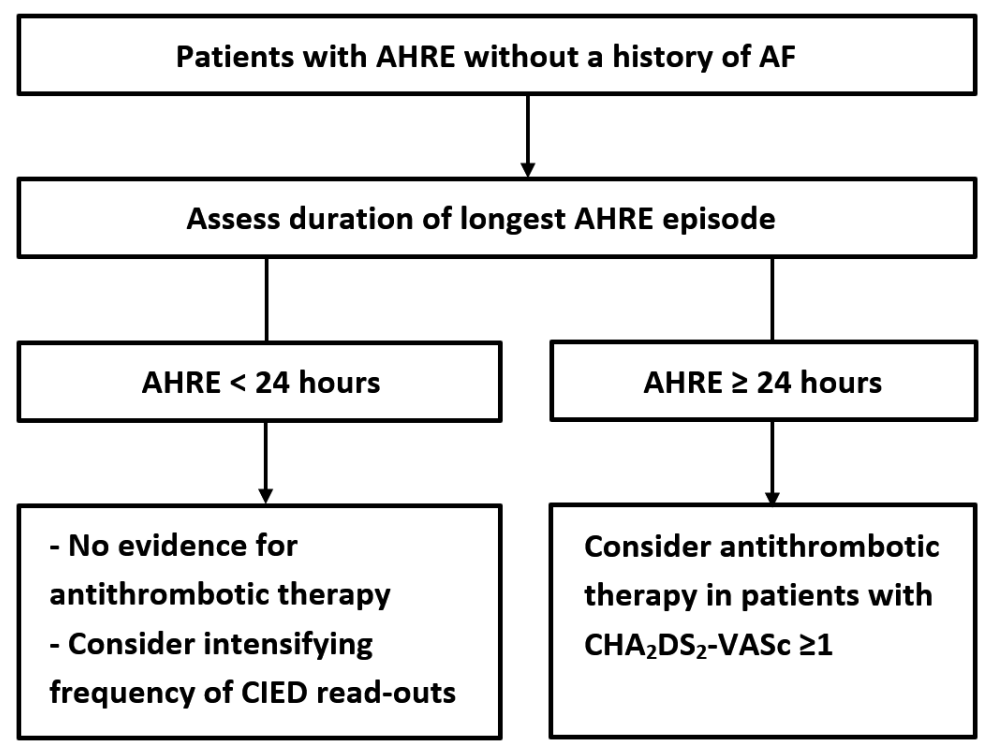

Figure 1. Decision making flow-chart regarding anticoagulant treatment for patients with AHRE. 
After publication of this point of view paper, Kaplan et al.(48) showed in a population with more than 21000 patients with a CIED, of whom $18 \%$ had clinical $A F$, that with increasing duration of $\mathrm{AHRE} / \mathrm{AF}$, the stroke risk also increases. Additionally, with increasing $\mathrm{CHA}_{2} \mathrm{DS}_{2}-$ VASc score, a shorter period of AHRE/AF was sufficient to increase the risk of thromboembolism, i.e. patients with $\mathrm{CHA}_{2} \mathrm{DS}_{2}$-VASc score of 2 with $>23.5$ hours of AHRE/AF had an increased stroke risk, as was for patients with a $\mathrm{CHA}_{2} \mathrm{DS}_{2}-\mathrm{VASc}$ score of 3 to 4 with $>6$ minutes of $A H R E / A F$, and those with a $\mathrm{CHA}_{2} \mathrm{DS}_{2}$-VASc score $\geq 5$ even with no AHRE/AF. This interaction between AHRE/AF duration and $\mathrm{CHA}_{2} \mathrm{DS}_{2}-\mathrm{VASc}$ score should also be investigated in the future for AF patients in general. The results of the RACE $V$ trial can provide more answers regarding this matter.

The fact that stroke risk is even increased in patients with no AHRE/AF and a $\mathrm{CHA}_{2} \mathrm{DS}_{2}$ VASc score $\geq 5$, has previously been reported.(49, 50) Saliba et al.(50) analyzed over 1 million Israelian patients without $A F$ and ascertained a high predictive value of the $\mathrm{CHA}_{2} \mathrm{DS}_{2}-$ VASc score for stroke in patients without AF, similar to the predictive value in those with AF. Ording et al.(49) had an equivalent conclusion in their Danish cohort.

Furthermore, we propose an update to the model of Kamel et al.(51) for thrombo-embolic risk in AF/AHRE in Chapter 7. The classical model of thrombo-embolism in AF is usually explained by Virchow's triad, i.e. hypercoagulability, stasis of blood, and endothelial dysfunction.(52) AF patients are known to have a hypercoagulable state of the blood,(53-56) endothelial dysfunction in the atria,(57-61) and stasis of blood in predominantly the left atrium. $(62,63)$ In contrast to this classical pathophysiology of TE in AF however, in a substantial proportion of patients with AHRE and TE, a clear temporal relationship cannot be well established, i.e. TE is not preceded by AHRE or AF, but the arrhythmia rather occurs after the TE. Brambatti et al.(64) showed in a substudy of the ASSERT trial that only 26 (51\%) of the 51 patients with a TE during follow-up showed AHRE, of which 8 patients (30.8\%) only showed AHRE after the embolic event. Similarly, Daoud et al. showed in a substudy of the TRENDS trial that in only $20(50 \%)$ of the 40 patients with TE, AT/AF was detected prior to the event, nine of whom did not show any AT/AF in the 30 days prior to the event.(65) These findings suggest that AHRE/AF and stroke do not always occur in the classical pathophysiological order.

To address this issue, Kamel et al. proposed an updated model for thrombo-embolic stroke.(51) In this model, atrial cardiomyopathy plays a key role and can result in both AHRE/AF and in TE, explaining the situations in which TE precedes the occurrence of AHRE/AF. Ageing and systemic vascular risk factors can cause an abnormal atrial substrate leading to atrial cardiomyopathy, which can be characterized by atrial dilatation, mechanical 
dysfunction, fibrosis, and/or endothelial dysfunction.(51) One of these factors causing an abnormal atrial substrate might be hypercoagulability. Spronk et al. have shown that hypercoagulability can induce atrial fibrosis and lead to a substrate for AF.(15) Similarly, the increased risk of thrombo-embolism in patients with atrial cardiomyopathy might be mediated by hypercoagulability (Figure 2 ).

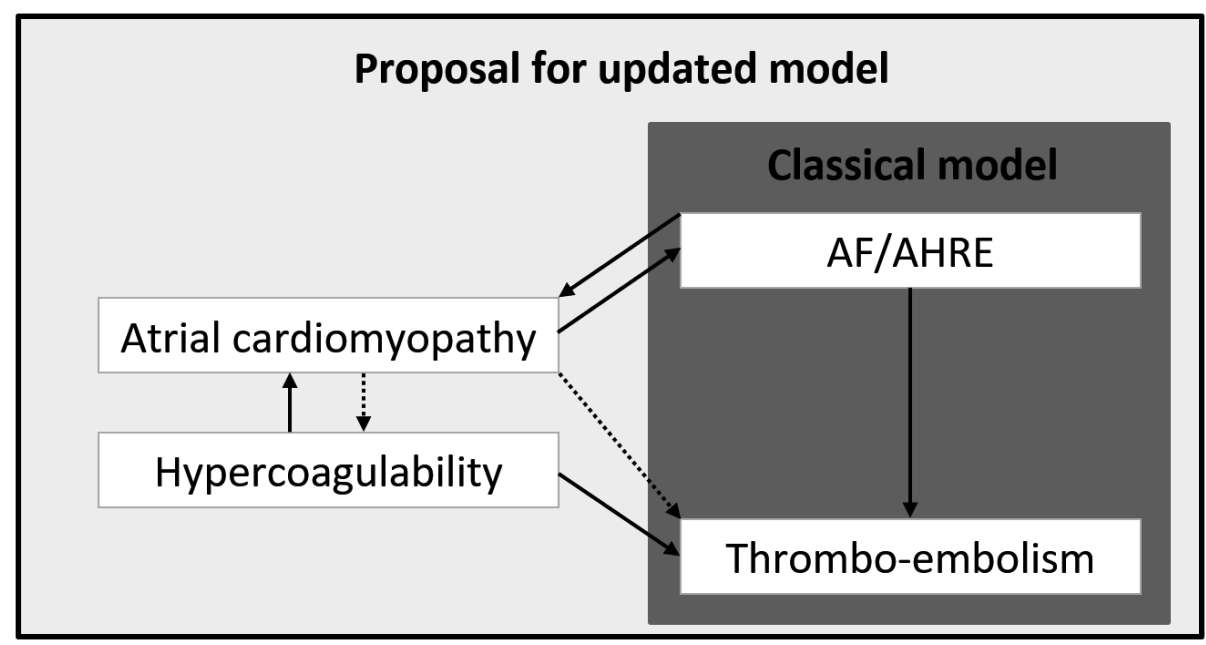

Figure 2. Proposal for an updated model of TE in AF/AHRE

\section{FUTURE DIRECTIONS}

The advancements in diagnostics have improved our understanding of diseases, leading to new and enhanced therapies, whether it is the invention and improvement of the CT scan and the earlier detection of cancer, or laboratory measurements like high sensitive troponin and better detection of cardiac ischemia. This increase in information eventually leads to better treatment and improved patient outcomes. Similarly, the currently changing and improving monitoring possibilities in patients with $\mathrm{AF}$ or suspected $\mathrm{AF}$, will lead to better understanding of the progression of the disease, improve treatment, and as a consequence reduce adverse events due to AF.

The advancements in diagnostics for AF are following each other rapidly. Most of these involve wearables or small devices capable of detecting AF.(66-68) These devices have an important role in screening for $\mathrm{AF}$ and correlating symptoms with heart rhythm. A big downside however, is the intermittent monitoring and the inherent underdiagnosing of patients with asymptomatic AF episodes. Therefore, continuous monitoring is the golden standard and the future. 
As stated previously, we should move away from the binary idea we have regarding AF progression and see it more as a sliding scale. Continuous rhythm monitoring is improving our understanding of AF progression and will continue to do so. The RACE V registry will, once finished, provide us with more answers. In addition to the RACE V, more data is needed regarding continuous rhythm follow-up in patients with AF at different stages of the disease, whether it is with implantable loop recorders or with pacemakers/ICDs with an atrial lead. Especially in this era of low adverse event rates with the current treatments, high patient numbers are needed in order to show an improvement in patient outcomes. For this, big data, machine learning, and artificial intelligence can be used as well.

In addition to better recognition of AF progression through improved rhythm monitoring as a future direction, "avoidance of AF progression may be a therapeutic goal in itself given the difficulties in managing 'advanced' AF", as stated in the consensus document of the second AFNET-EHRA conference.(69) Catheter ablation is known to be less effective in persistent AF compared to paroxysmal AF. $(70,71)$ Therefore, restricting the progression of AF or the remodeling of the atria can be a goal in itself. As we saw in Chapter 2, LVH is a risk factor for AF progression. Could reduction of LVH through treatment with antihypertensive drugs eventually lead to reduced or delayed AF progression? Perhaps, the effect of upstream therapy in AF with RAA (renin-angiotensin-aldosterone) system blockers is based on the reduction in LVH?(72) This hypothesis should be checked prospectively and in a randomized manner. Additionally, the type of LVH should be assessed in this trial with attention to sex differences.

Another advancement in diagnostics for AF patients is the improvements made in the cardiac CT scan. In Chapter 4, we determined the whole heart PAT using semi-automatic software. In the future, automated assessment of only epicardial AT around both atria should be performed. A comparison of manual tracing with automatic detection would be of added value as well, comparing time needed to obtain the assessment and the reliability of automated assessments.

Regarding anticoagulant treatment in patients with AHRE, currently recruiting randomized controlled trials like ARTESiA and NOAH-AFNET 6, will give us more insights in when to treat these patients with anticoagulants. Furthermore, these trials are well suited to investigate the effect of inhibiting hypercoagulability with NOACs on the progression of AF. These post-hoc analyses may be an addition to the RACE $V$ study results. 


\section{REFERENCES}

1. Kirchhof P, Benussi S, Kotecha D, Ahlsson A, Atar D, Casadei B, et al. 2016 ESC Guidelines for the management of atrial fibrillation developed in collaboration with EACTS: The Task Force for the management of atrial fibrillation of the European Society of Cardiology (ESC)Developed with the special contribution of the European Heart Rhythm Association (EHRA) of the ESCEndorsed by the European Stroke Organisation (ESO). Eur Heart J. 2016.

2. de Vos CB, Pisters R, Nieuwlaat R, Prins MH, Tieleman RG, Coelen RJ, et al. Progression from paroxysmal to persistent atrial fibrillation clinical correlates and prognosis. J Am Coll Cardiol. 2010;55(8):725-31.

3. Blum S, Meyre P, Aeschbacher S, Berger S, Auberson C, Briel M, et al. Incidence and predictors of atrial fibrillation progression: A systematic review and meta-analysis. Heart Rhythm. 2019;16(4):502-10.

4. Padfield GJ, Steinberg C, Swampillai J, Qian H, Connolly SJ, Dorian P, et al. Progression of paroxysmal to persistent atrial fibrillation: 10-year follow-up in the Canadian Registry of Atrial Fibrillation. Heart Rhythm. 2017;14(6):801-7.

5. Rider OJ, Lewandowski A, Nethononda R, Petersen SE, Francis JM, Pitcher A, et al. Gender-specific differences in left ventricular remodelling in obesity: insights from cardiovascular magnetic resonance imaging. Eur Heart J. 2013;34(4):292-9.

6. Shah N, Badheka AO, Grover PM, Patel NJ, Chothani A, Mehta K, et al. Influence of left ventricular remodeling on atrial fibrillation recurrence and cardiovascular hospitalizations in patients undergoing rhythm-control therapy. Int $\mathrm{J}$ Cardiol. 2014;174(2):288-92.

7. Berg J, Lindgren $P$, Nieuwlaat $R$, Bouin $O$, Crijns $H$. Factors determining utility measured with the EQ-5D in patients with atrial fibrillation. Qual Life Res. 2010;19(3):381-90.

8. Nagashima K, Okumura Y, Watanabe I, Nakai T, Ohkubo K, Kofune T, et al. Association between epicardial adipose tissue volumes on 3-dimensional reconstructed CT images and recurrence of atrial fibrillation after catheter ablation. Circ J. 2011;75(11):2559-65.

9. Sanghai SR, Sardana M, Hansra B, Lessard DM, Dahlberg ST, Aurigemma GP, et al. Indexed Left Atrial Adipose Tissue Area Is Associated With Severity of Atrial Fibrillation and Atrial Fibrillation Recurrence Among Patients Undergoing Catheter Ablation. Front Cardiovasc Med. 2018;5:76.

10. Kim TH, Park J, Park JK, Uhm JS, Joung B, Lee MH, et al. Pericardial fat volume is associated with clinical recurrence after catheter ablation for persistent atrial fibrillation, but not paroxysmal atrial fibrillation: an analysis of over 600-patients. Int J Cardiol. 2014;176(3):841-6.

11. Stojanovska J, Kazerooni EA, Sinno M, Gross BH, Watcharotone K, Patel S, et al. Increased epicardial fat is independently associated with the presence and chronicity of atrial fibrillation and radiofrequency ablation outcome. Eur Radiol. 2015;25(8):2298309. 
12. Hatem SN, Redheuil A, Gandjbakhch E. Cardiac adipose tissue and atrial fibrillation: the perils of adiposity. Cardiovasc Res. 2016;109(4):502-9.

13. Schotten U, Verheule S, Kirchhof P, Goette A. Pathophysiological mechanisms of atrial fibrillation: a translational appraisal. Physiol Rev. 2011;91(1):265-325.

14. Faber DR, de Groot PG, Visseren FL. Role of adipose tissue in haemostasis, coagulation and fibrinolysis. Obes Rev. 2009;10(5):554-63.

15. Spronk HM, De Jong AM, Verheule S, De Boer HC, Maass $A H$, Lau DH, et al. Hypercoagulability causes atrial fibrosis and promotes atrial fibrillation. Eur Heart J. 2017;38(1):38-50.

16. Fetsch T, Bauer P, Engberding R, Koch HP, Lukl J, Meinertz T, et al. Prevention of atrial fibrillation after cardioversion: results of the PAFAC trial. Eur Heart $\mathrm{J}$. 2004;25(16):1385-94.

17. Israel CW, Gronefeld G, Ehrlich JR, Li YG, Hohnloser SH. Long-term risk of recurrent atrial fibrillation as documented by an implantable monitoring device: implications for optimal patient care. J Am Coll Cardiol. 2004;43(1):47-52.

18. Page RL, Wilkinson WE, Clair WK, McCarthy EA, Pritchett EL. Asymptomatic arrhythmias in patients with symptomatic paroxysmal atrial fibrillation and paroxysmal supraventricular tachycardia. Circulation. 1994;89(1):224-7.

19. Hindricks G, Piorkowski C, Tanner H, Kobza R, Gerds-Li JH, Carbucicchio C, et al. Perception of atrial fibrillation before and after radiofrequency catheter ablation: relevance of asymptomatic arrhythmia recurrence. Circulation. 2005;112(3):307-13.

20. Verma A, Champagne J, Sapp J, Essebag V, Novak P, Skanes A, et al. Discerning the incidence of symptomatic and asymptomatic episodes of atrial fibrillation before and after catheter ablation (DISCERN AF): a prospective, multicenter study. JAMA Intern Med. 2013;173(2):149-56.

21. Piorkowski C, Kottkamp H, Tanner H, Kobza R, Nielsen JC, Arya A, et al. Value of different follow-up strategies to assess the efficacy of circumferential pulmonary vein ablation for the curative treatment of atrial fibrillation. J Cardiovasc Electrophysiol. 2005;16(12):1286-92.

22. Steeds RP, Birchall AS, Smith M, Channer KS. An open label, randomised, crossover study comparing sotalol and atenolol in the treatment of symptomatic paroxysmal atrial fibrillation. Heart. 1999;82(2):170-5.

23. Sweeney MO, Sakaguchi S, Simons G, Machado C, Connett JE, Yang F, et al. Response to the Center for Medicare \& Medicaid Services coverage with evidence development request for primary prevention implantable cardioverter-defibrillators: data from the OMNI study. Heart Rhythm. 2012;9(7):1058-66.

24. Glotzer TV, Daoud EG, Wyse DG, Singer DE, Ezekowitz MD, Hilker C, et al. The relationship between daily atrial tachyarrhythmia burden from implantable device diagnostics and stroke risk: the TRENDS study. Circ Arrhythm Electrophysiol. 2009;2(5):474-80.

25. Charitos El, Purerfellner H, Glotzer TV, Ziegler PD. Clinical classifications of atrial fibrillation poorly reflect its temporal persistence: insights from 1,195 patients 
continuously monitored with implantable devices. J Am Coll Cardiol. 2014;63(25 Pt A):2840-8.

26. Jahangir A, Lee V, Friedman PA, Trusty JM, Hodge DO, Kopecky SL, et al. Long-term progression and outcomes with aging in patients with lone atrial fibrillation: a 30-year follow-up study. Circulation. 2007;115(24):3050-6.

27. Wijffels MC, Kirchhof CJ, Dorland R, Allessie MA. Atrial fibrillation begets atrial fibrillation. A study in awake chronically instrumented goats. Circulation. 1995;92(7):1954-68.

28. Gillis AM, Rose MS. Temporal patterns of paroxysmal atrial fibrillation following DDDR pacemaker implantation. Am J Cardiol. 2000;85(12):1445-50.

29. Piccini JP, Passman R, Turakhia M, Connolly AT, Nabutovsky Y, Varma N. Atrial fibrillation burden, progression, and the risk of death: a case-crossover analysis in patients with cardiac implantable electronic devices. Europace. 2019;21(3):404-13.

30. Diederichsen SZ, Haugan KJ, Brandes A, Lanng MB, Graff C, Krieger D, et al. Natural History of Subclinical Atrial Fibrillation Detected by Implanted Loop Recorders. J Am Coll Cardiol. 2019;74(22):2771-81.

31. Diederichsen SZ, Haugan KJ, Brandes A, Graff C, Krieger D, Kronborg C, et al. Incidence and predictors of atrial fibrillation episodes as detected by implantable loop recorder in patients at risk: From the LOOP study. Am Heart J. 2020;219:117-27.

32. Belen E, Canbolat IP, Bayyigit A, Helvaci A, Pusuroglu H, Kilickesmez K. A new gap in the novel anticoagulants' era: undertreatment. Blood Coagul Fibrinolysis. 2015;26(7):793-7.

33. Moudallel S, Steurbaut S, Cornu P, Dupont A. Appropriateness of DOAC Prescribing Before and During Hospital Admission and Analysis of Determinants for Inappropriate Prescribing. Front Pharmacol. 2018;9:1220.

34. Cappato R, Ezekowitz MD, Klein AL, Camm AJ, Ma CS, Le Heuzey JY, et al. Rivaroxaban vs. vitamin $\mathrm{K}$ antagonists for cardioversion in atrial fibrillation. Eur Heart $\mathrm{J}$. 2014;35(47):3346-55.

35. Coquard C, Moubarak G, Baudet M, Logeart D, Dillinger J-G, Cohen-Solal A. Clinical experience of dabigatran and rivaroxaban in electrical cardioversion of atrial fibrillation. International Cardiovascular Forum Journal. 2015;4:71-2.

36. Nagarakanti R, Ezekowitz MD, Oldgren J, Yang S, Chernick M, Aikens TH, et al. Dabigatran versus warfarin in patients with atrial fibrillation: an analysis of patients undergoing cardioversion. Circulation. 2011;123(2):131-6.

37. Hokusai VTEI, Buller HR, Decousus H, Grosso MA, Mercuri M, Middeldorp S, et al. Edoxaban versus warfarin for the treatment of symptomatic venous thromboembolism. N Engl J Med. 2013;369(15):1406-15.

38. Schulman S, Kakkar AK, Goldhaber SZ, Schellong S, Eriksson H, Mismetti P, et al. Treatment of acute venous thromboembolism with dabigatran or warfarin and pooled analysis. Circulation. 2014;129(7):764-72. 
39. Schulman S, Kearon C, Kakkar AK, Schellong S, Eriksson H, Baanstra D, et al. Extended use of dabigatran, warfarin, or placebo in venous thromboembolism. N Engl J Med. 2013;368(8):709-18.

40. Oldgren J, Budaj A, Granger CB, Khder Y, Roberts J, Siegbahn A, et al. Dabigatran vs. placebo in patients with acute coronary syndromes on dual antiplatelet therapy: a randomized, double-blind, phase II trial. Eur Heart J. 2011;32(22):2781-9.

41. Cheung JW, Keating RJ, Stein KM, Markowitz SM, Iwai S, Shah BK, et al. Newly detected atrial fibrillation following dual chamber pacemaker implantation. J Cardiovasc Electrophysiol. 2006;17(12):1323-8.

42. Healey JS, Martin JL, Duncan A, Connolly SJ, Ha AH, Morillo CA, et al. Pacemakerdetected atrial fibrillation in patients with pacemakers: prevalence, predictors, and current use of oral anticoagulation. Can J Cardiol. 2013;29(2):224-8.

43. Ziegler PD, Glotzer TV, Daoud EG, Singer DE, Ezekowitz MD, Hoyt RH, et al. Detection of previously undiagnosed atrial fibrillation in patients with stroke risk factors and usefulness of continuous monitoring in primary stroke prevention. Am J Cardiol. 2012;110(9):1309-14.

44. Gage BF, van Walraven C, Pearce L, Hart RG, Koudstaal PJ, Boode BS, et al. Selecting patients with atrial fibrillation for anticoagulation: stroke risk stratification in patients taking aspirin. Circulation. 2004;110(16):2287-92.

45. Glotzer TV, Hellkamp AS, Zimmerman J, Sweeney MO, Yee R, Marinchak R, et al. Atrial high rate episodes detected by pacemaker diagnostics predict death and stroke: report of the Atrial Diagnostics Ancillary Study of the MOde Selection Trial (MOST). Circulation. 2003;107(12):1614-9.

46. Healey JS, Connolly SJ, Gold MR, Israel CW, Van Gelder IC, Capucci A, et al. Subclinical atrial fibrillation and the risk of stroke. N Engl J Med. 2012;366(2):120-9.

47. Stroke Risk in Atrial Fibrillation Working G. Comparison of 12 risk stratification schemes to predict stroke in patients with nonvalvular atrial fibrillation. Stroke. 2008;39(6):1901-10.

48. Kaplan RM, Koehler J, Ziegler PD, Sarkar S, Zweibel S, Passman RS. Stroke Risk as a Function of Atrial Fibrillation Duration and CHA2DS2-VASc Score. Circulation. 2019;140(20):1639-46.

49. Ording AG, Horvath-Puho E, Prandoni P, Leisner MZ, Farkas DK, Steffensen FH, et al. Usefulness of CHA2DS2-VASc Score to Predict Stroke Risk Independent of Atrial Fibrillation. Am J Cardiol. 2019;124(7):1059-63.

50. Saliba W, Gronich N, Barnett-Griness O, Rennert G. The role of CHADS2 and CHA2 DS2 -VASc scores in the prediction of stroke in individuals without atrial fibrillation: a population-based study. J Thromb Haemost. 2016;14(6):1155-62.

51. Kamel H, Okin PM, Elkind MS, ladecola C. Atrial Fibrillation and Mechanisms of Stroke: Time for a New Model. Stroke. 2016;47(3):895-900.

52. Bagot $\mathrm{CN}$, Arya R. Virchow and his triad: a question of attribution. $\mathrm{Br} \mathrm{J}$ Haematol. 2008;143(2):180-90. 
53. Inoue H, Nozawa T, Okumura K, Jong-Dae L, Shimizu A, Yano K. Prothrombotic activity is increased in patients with nonvalvular atrial fibrillation and risk factors for embolism. Chest. 2004;126(3):687-92.

54. Kahn SR, Solymoss S, Flegel KM. Nonvalvular atrial fibrillation: evidence for a prothrombotic state. CMAJ. 1997;157(6):673-81.

55. Marin F, Roldan V, Climent VE, Ibanez A, Garcia A, Marco P, et al. Plasma von Willebrand factor, soluble thrombomodulin, and fibrin D-dimer concentrations in acute onset non-rheumatic atrial fibrillation. Heart. 2004;90(10):1162-6.

56. Mitusch R, Siemens HJ, Garbe M, Wagner T, Sheikhzadeh A, Diederich KW. Detection of a hypercoagulable state in nonvalvular atrial fibrillation and the effect of anticoagulant therapy. Thromb Haemost. 1996;75(2):219-23.

57. Dudley SC, Jr., Hoch NE, McCann LA, Honeycutt C, Diamandopoulos L, Fukai T, et al. Atrial fibrillation increases production of superoxide by the left atrium and left atrial appendage: role of the NADPH and xanthine oxidases. Circulation. 2005;112(9):126673.

58. Kaireviciute D, Blann AD, Balakrishnan B, Lane DA, Patel JV, Uzdavinys G, et al. Characterisation and validity of inflammatory biomarkers in the prediction of postoperative atrial fibrillation in coronary artery disease patients. Thromb Haemost. 2010;104(1):122-7.

59. Kumagai K, Fukuchi M, Ohta J, Baba S, Oda K, Akimoto H, et al. Expression of the von Willebrand factor in atrial endocardium is increased in atrial fibrillation depending on the extent of structural remodeling. Circ J. 2004;68(4):321-7.

60. Nakamura Y, Nakamura K, Fukushima-Kusano K, Ohta K, Matsubara H, Hamuro T, et al. Tissue factor expression in atrial endothelia associated with nonvalvular atrial fibrillation: possible involvement in intracardiac thrombogenesis. Thromb Res. 2003;111(3):137-42.

61. Yamashita T, Sekiguchi A, Iwasaki YK, Sagara K, Hatano S, linuma H, et al. Thrombomodulin and tissue factor pathway inhibitor in endocardium of rapidly paced rat atria. Circulation. 2003;108(20):2450-2.

62. Jaber WA, Prior DL, Thamilarasan M, Grimm RA, Thomas JD, Klein AL, et al. Efficacy of anticoagulation in resolving left atrial and left atrial appendage thrombi: $A$ transesophageal echocardiographic study. Am Heart J. 2000;140(1):150-6.

63. Stoddard MF, Dawkins PR, Prince CR, Ammash NM. Left atrial appendage thrombus is not uncommon in patients with acute atrial fibrillation and a recent embolic event: a transesophageal echocardiographic study. J Am Coll Cardiol. 1995;25(2):452-9.

64. Brambatti M, Connolly SJ, Gold MR, Morillo CA, Capucci A, Muto C, et al. Temporal relationship between subclinical atrial fibrillation and embolic events. Circulation. 2014;129(21):2094-9.

65. Daoud EG, Glotzer TV, Wyse DG, Ezekowitz MD, Hilker C, Koehler J, et al. Temporal relationship of atrial tachyarrhythmias, cerebrovascular events, and systemic emboli based on stored device data: a subgroup analysis of TRENDS. Heart Rhythm. 2011;8(9):1416-23. 
66. Lau JK, Lowres N, Neubeck L, Brieger DB, Sy RW, Galloway CD, et al. iPhone ECG application for community screening to detect silent atrial fibrillation: a novel technology to prevent stroke. Int J Cardiol. 2013;165(1):193-4.

67. Tieleman RG, Plantinga Y, Rinkes D, Bartels GL, Posma JL, Cator R, et al. Validation and clinical use of a novel diagnostic device for screening of atrial fibrillation. Europace. 2014;16(9):1291-5.

68. Guhl EN, Schlusser CL, Henault LE, Bickmore TW, Kimani E, Paasche-Orlow MK, et al. Rationale and design of the Atrial Fibrillation health Literacy Information Technology Trial: (AF-LITT). Contemp Clin Trials. 2017;62:153-8.

69. Kirchhof P, Bax J, Blomstrom-Lundquist C, Calkins H, Camm AJ, Cappato R, et al. Early and comprehensive management of atrial fibrillation: executive summary of the proceedings from the 2nd AFNET-EHRA consensus conference 'research perspectives in AF'. Eur Heart J. 2009;30(24):2969-77c.

70. Balk EM, Garlitski AC, Alsheikh-Ali AA, Terasawa T, Chung M, Ip S. Predictors of atrial fibrillation recurrence after radiofrequency catheter ablation: a systematic review. J Cardiovasc Electrophysiol. 2010;21(11):1208-16.

71. Calkins H, Hindricks G, Cappato R, Kim YH, Saad EB, Aguinaga L, et al. 2017 HRS/EHRA/ECAS/APHRS/SOLAECE expert consensus statement on catheter and surgical ablation of atrial fibrillation. Europace. 2018;20(1):e1-e160.

72. Savelieva I, Kakouros N, Kourliouros A, Camm AJ. Upstream therapies for management of atrial fibrillation: review of clinical evidence and implications for European Society of Cardiology guidelines. Part II: secondary prevention. Europace. 2011;13(5):610-25. 


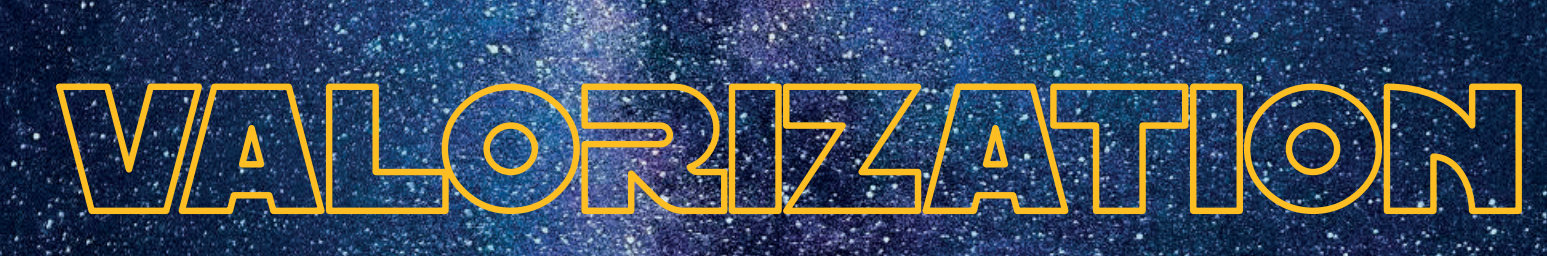

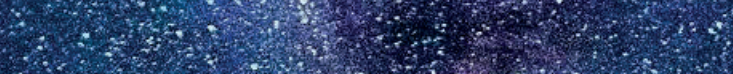

(4) 
Atrial fibrillation (AF) affects a large proportion of the population and the prevalence of AF is expected to increase in the future. In addition to the widespread occurrence, AF is associated with an increased risk of all-cause mortality, heart failure, and ischemic stroke, making it a major public health problem. A significant proportion of total health care costs can be attributed to AF.

\section{Progression of atrial fibrillation}

The progression of AF from paroxysmal to persistent AF occurs frequently and is also associated with patient outcomes, i.e. an increased risk of ischemic stroke and heart failure hospitalizations. Therefore, understanding this process can in the future lead to therapeutic interventions decreasing the progression rate and thereby hopefully decreasing the associated patient outcomes. This will lead to a reduced health care burden, both for the individual and the society. Avoiding AF progression can be a therapeutic goal in itself since advanced AF has shown to be harder to manage, leading to increased hospital visits and medical interventions.

To this aim, minimizing the risk factors leading to AF progression is pivotal, i.e. treating hypertension in order to prevent the development of left ventricular hypertrophy as well as keeping left atrial enlargement to a minimum. The latter is also accomplished by treating underlying comorbidities.

Advancements in medicine lead to improvements in patient management. Whether its improved diagnostics or treatments, patients have always benefited from these advancements. Up till now, AF progression was seen as a binary phenomenon; it either happens or it doesn't. In this thesis, we have implemented continuous rhythm monitoring in AF patients, improving our understanding of AF progression. With this intensified rhythm monitoring in the RACE $V$ trial, we observed in a mid-term analysis that AF progression is not as black and white as we thought. The final results of the RACE $V$ trial with complete followup in 750 patients will give us more definite answers on both the rhythm outcome and its association or relation with patient related outcomes. With this information, we can perhaps limit AF progression and patient outcomes in the future.

\section{Anticoagulant treatment in atrial fibrillation}

In the past, vitamin $\mathrm{K}$ antagonists were the only option in patients with AF regarding thromboembolic prophylaxis. The practical disadvantages of these drug lead to increased health care costs, i.e. by increasing the time to elective electrical cardioversion due to 
subtherapeutic INR values, as we have shown in this thesis. NOACs do not have this disadvantage and can reduce the waiting list for elective cardioversion.

All NOACs have a regular dose and a reduced dose. The latter should only be prescribed in select cases. However, we have observed that patients are both under- and overtreated with NOACs. This leads to patients either being not adequately protected for a thromboembolic event or at unnecessary risk of a bleeding event. Both under- and overtreatment should be reduced in the future.

Finally, for some patient groups it is unknown whether they will benefit from thomboembolic prophylaxis, i.e. patients with atrial high rate events as detected by cardiac implanted electronic devices. In these patients, the thromboembolic risk seems to be lower compared to patients with $A F$, therefore the threshold to initiate anticoagulant treatment is probably higher. In this thesis, we propose an algorithm for this issue. Currently, two randomized controlled trials are ongoing to definitely answer this question. 


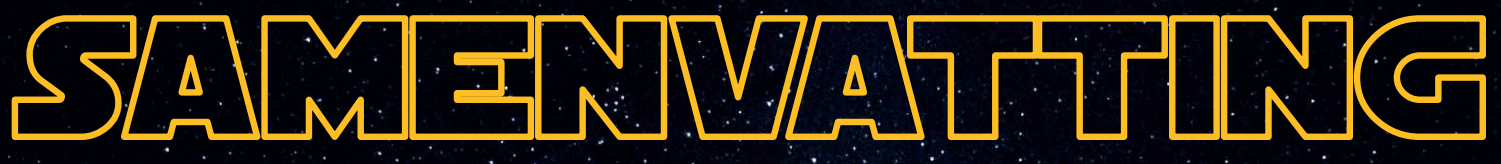


Boezemfibrilleren is de meest voorkomende ritmestoornis bij de mens. In Nederland zijn er naar schatting 250.000 mensen met boezemfibrilleren. Het komt vaker voor bij ouderen en bij mensen met risicofactoren voor het ontstaan van boezemfibrilleren, zoals hoge bloeddruk, suikerziekte en overgewicht. Naar schatting zal het voorkomen van boezemfibrilleren in Nederland door de vergrijzing meer dan verdubbelen in de komende 3 decennia naar 550.000 mensen in 2050 .

In tegenstelling tot kamerritmestoornissen leidt boezemfibrilleren indien onbehandeld niet tot een acute hartstilstand. Wel kan boezemfibrilleren veel klachten veroorzaken, zoals hartkloppingen, kortademigheid of pijn op de borst. Vaak zijn deze klachten een gevolg van een te snelle hartfrequentie. Maar boezemfibrilleren kan ook volledig asymptomatisch zijn.

In het begin van de ziekte heeft een persoon vaak korte aanvallen van boezemfibrilleren. Naarmate de tijd vordert nemen deze aanvallen toe in frequentie en in duur, totdat uiteindelijk de chronische variant van boezemfibrilleren ontstaat. Dit proces noemen we progressie van boezemfibrilleren. Het treedt op bij gemiddeld $7 \%$ van de personen met boezemfibrilleren per jaar.

In de behandeling van boezemfibrilleren wordt vaak als eerste stap medicijnen gegeven om het hartritme te vertragen om zodoende de klachten te doen afnemen. Als dit onvoldoende werkt, wordt overgegaan op anti-aritmica (medicatie die het ontstaan of de duur van boezemfibrilleren remmen). Als ook dit onvoldoende werkt, wordt overgegaan op elektrische cardioversies (een "shock" om het hartritme te herstellen) of ablaties (operatie waarbij inwendig littekens worden gevormd in het hart om zo boezemfibrilleren voor te zijn).

In de behandeling van boezemfibrilleren is daarnaast ook een rol voor antistollingsmedicatie weggelegd. Boezemfibrilleren gaat namelijk gepaard met een verhoogd risico op beroertes oftewel herseninfarcten. Dit risico is alleen verhoogd als een persoon risicofactoren hiervoor heeft, te weten hartfalen, hoge bloeddruk, suikerziekte, leeftijd >65 jaar, eerdere beroerte, vaatlijden of vrouwelijk geslacht. In geval van een verhoogd risico op beroertes wordt er gestart met antistollingsmedicatie. Vroeger konden hiervoor alleen bloedverdunners via de trombosedienst voorgeschreven worden. Bij deze medicijnen moet om de 1-2 weken gecontroleerd worden hoe "dun" het bloed daadwerkelijk is en wordt de dosering van het medicijn hierop aangepast. Tegenwoordig kunnen "NOACs" voorgeschreven worden, dit zijn tabletten met een stabiele dagelijkse dosering waarbij het bloed niet periodiek gecontroleerd dient te worden.

In het eerste gedeelte van dit proefschrift (hoofdstuk 1) hebben we gekeken naar de manier waarop patiënten met boezemfibrilleren worden behandeld in Nederland en België en 
hebben we gekeken naar onderlinge verschillen. Wat met name opviel is dat er relatief veel patiënten ten onrechte een lagere of hogere dosering NOAC kregen. Hierdoor worden deze mensen onder- of overbehandeld en worden respectievelijk niet voldoende beschermd voor het optreden van een eventuele beroerte of hebben juist een verhoogd bloedingsrisico, terwijl dit eigenlijk niet zou hoeven.

In het tweede gedeelte hebben we gekeken naar de risicofactoren voor het optreden van progressie van boezemfibrilleren (hoofdstuk 2 en 4), het effect van de progressie op het kwaliteit van leven (hoofdstuk 3) en of we progressie wel op de juiste manier definiëren (hoofdstuk 5). In dat laatste hoofdstuk zagen we dat hoe beter je kijkt naar het hartritme (met een implanteerbaar apparaatje dat continu het hartritme in de gaten houdt i.p.v. af en toe een hartfilmpje van 10 seconden), je veel beter kunt zien wanneer iemand toename laat zien van boezemfibrilleren. Daarnaast concluderen we dat de progressie van boezemfibrilleren waarschijnlijk niet zo zwart-wit is als we denken. Misschien moeten we afstappen van dat idee en een nieuwe manier bedenken om progressie van boezemfibrilleren te classificeren.

In het derde gedeelte van dit proefschrift hebben we op verschillende manieren gekeken naar de rol van bloedverdunners in de behandeling van boezemfibrilleren. In hoofdstuk 8 zagen we dat de oudere bloedverdunners leiden tot langere wachttijden voor een elektrische cardioversie omdat het bloed vaak niet dun genoeg is om deze veilig uit te kunnen voeren. In hoofdstuk 7 stellen we een behandelschema voor dat gebruikt kan worden voor patiënten met een pacemaker of ICD die korte boezemritmestoornissen laten zien, zonder dat er daadwerkelijk sprake is van boezemfibrilleren. In hoofdstuk 6 onderzoeken we of de NOACs mogelijk kunnen leiden tot het minder voorkomen van boezemfibrilleren. Ondanks dat er in muizenstudies hier aanwijzingen voor zijn, konden wij dit niet aantonen in de mens. 

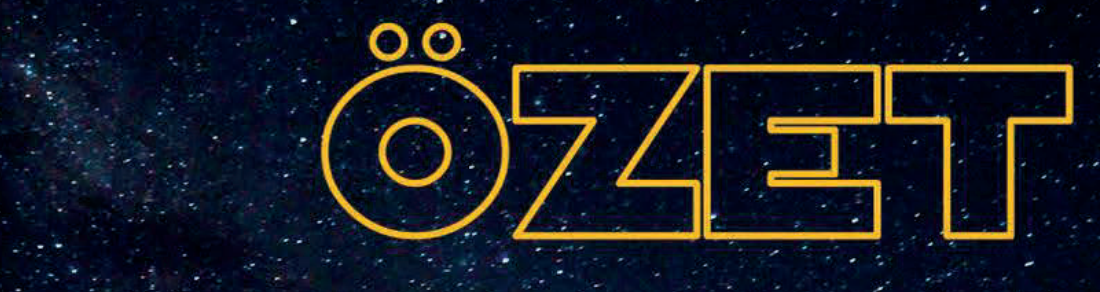
Atriyal fibrilasyon (AF) insan da en sık görülen kalp ritim bozukluğudur. Hollanda'da yaklaşık 250.000, Türkiye'de minimum 800.000 ve maksimum 1.600 .000 insanın atriyal fibrilasyon hastası olduğu düşünülüyor. Yaşlılarda ve yüksek tansiyon, şeker hastalığı ve obezite gibi risk faktörü bulunan insanlarda daha çok görülüyor. Hollanda'daki beklenti, yaşlanan insanların çoğalması ile bu aritminin toplumda görülme sıklığı 2050 senesinde şimdiye oranla ikiye katlanmış olması.

AF, kalbin üstteki iki kulakçığı elektriksel bozulma nedeniyle atması gerektiği şekilde atmadığından kaynaklanır. Ventriküler fibrilasyonun aksine, kalbin durmasına neden olmaz. Lakin hastalarda göğüs ağrısı, yorgunluk, rahatsızıı hissi ve baş dönmesi gibi çeşitli semptomlara neden olabilir. Çoğunlukta bu belirtiler kalbin normalden hızlı çarpmasından kaynaklanır, ama bazı hastalarda AF hiçbir belirti göstermez.

Hastalığın başında ritim bozukluğu nöbetler seklinde gelir, buna paroksismal AF denir. Paroksismal AF genellikle dakikalar veya saatler sürer ve sonunda kendi kendine geçer. Zaman geçtikçe nöbetlerin sayısı ve uzunluğu artar ve sonunda AF sürekli şekilde görülür, buna persistant AF denir, yani kendiliğinden düzelmeme hali. Bu olaya "AF ilerlemesi" denir ve paroksismal AF hastalarının senede ortalama \%7'sinde görülür.

Tedavide ilk hedef kalp hızını haplarla kontrol altına almaktır. Eğer belirtiler yeterince azalmazsa, anti-aritmik haplar verilir. Bu haplar nöbetlerin sayısını ve uzunluğunu azaltır. Eğer bu da işe yaramazsa, elektrik şoku ya da ablasyon tedavisine (damar içinden kalbe ulaşıp, aritmiye neden olan hücrelerin yakılmasına ya da dondurulmasına) ihtiyaç duyulabilir.

Bunun yani sıra, AF'nin tedavisinde antitrombotik tedavinin de önemli yeri vardır. Çünkü AF hastalarında inme riski, kanın kalp kulakçıklarında birikip pıhtı oluşturabilmesi yüzünden, yüksektir. Bu riski yükselten belirli faktörler vardır: yüksek tansiyon, şeker hastalığı, kalp yetmezliği, önceden geçirilmiş inme, vasküler hastalık, 65 yaş üstü olmak ve kadın olmak. Eğer inme riski yüksekse, antitrombotik ilaçlar verilir. Eskiden sadece Varfarin mevcuttu. Bu hapın doz ayarı her hastada değişiktir ve bu nedenle belirli aralıklarla kan testi yapılması gerekir. Piyasaya yeni çıkan DOAK'larda kan testine gerek duyulmaz.

Bu tezin 1. bölümünde Hollanda'da ve Belçika'da $A F$ hastalarının nasıl tedavi gördüğünü ele aldık ve bu iki devleti birbiriyle kıyasladık. Göze batan sonuçlardan biri DOAK kullanan hastaların belirli bir bölümü yanlış tedavi gördüğüdür, almaları gerektiği dozdan fazla ya da az doz aldıklarını gördük.

$\mathrm{Bu}$ tezde ayrıca AF ilerlemesine neden olan risk faktörlerini (2. ve 4. bölüm), AF ilerlemesinin yasam kalitesine etkisini (3. bölüm) ve AF ilerlemesinin tanımını (5. bölüm) 
araştırdık. Bu son bölümde vücuda yerleştirilebilir bir cihazla 200 hastanın kalp ritmini aralıksız bir şekilde inceledik. Normalde kalbin ritmini 10 saniyelik kalp filmi kayıtlarıyla (EKG'yle) inceleriz. Bu araştırmanın sayesinde öğrendik ki: ne kadar iyi bakarsan, o kadar çok görürsün. Kalbin ritmini sürekli inceleyerek, AF ilerlemesinin sandığımız gibi siyah-beyaz bir olay olmadığını öğrendik.

Son olarak AF hastalarının antitrombotik tedavisini araştırdık ve 8. bölümde Varfarin'in elektrik şokunu bekleyen persistant AF hastalarının bekleme süresini gereksizce uzattığını gördük. DOAK'larla bu uzama kolayca önlenebilir. Altıncı bölümde DOAK'ların AF'nin oluşmasına engel olabilme kabiliyetinin olup olmadığını araştırdık. Daha önce farelerde yapılan araştırmalar bu yönde kanılar gösterse de, insanlarda bu efekte rastlayamadık. Yedinci bölümde ise henüz AF tanısı konulmamış kalp pili olan hastaların nasıl antitrombotik haplarla tedavi edilebileceğine dair bir öneri sunduk. 
D) A Nustro(O) D D 
Veel mensen hebben direct of indirect bijgedragen aan de totstandkoming van dit proefschrift, waarvoor ik dank verschuldigd ben.

Allereerst mijn promotor, prof. dr. Harry Crijns. Vanaf onze eerste kennismaking had ik een goed gevoel bij een promotietraject bij $u$. In het begin kwam ik vaak met meer vragen uit onze besprekingen dan ik deze in ging, maar dit werd gelukkig snel minder. Uw vermogen om verbanden te zien, bevindingen scherp te verwoorden en zaken snel geregeld te krijgen hebben mij telkens gemotiveerd om nog beter voorbereid te verschijnen bij de besprekingen. Ook bedankt voor uw gestelde vertrouwen in mij, zowel voor dit promotietraject alsook voor de opleiding tot cardioloog.

Copromotor $d r$. Luermans, beste Justin, ondanks je volle agenda en vele bezigheden maakte je altijd tijd om mij te begeleiden. Je perfectionisme, waar je je onterecht voor verontschuldigt, tilde de artikelen altijd tot een hoger niveau en maakte je supervisie op de AF poli zeer leerzaam. Daarnaast toon je niet alleen interesse in werkgerelateerde zaken, maar ook op persoonlijk vlak. Hierdoor voelt het vaak alsof ik niet met een supervisor maar meer met een collega in gesprek ben. Als ik later groot ben, wil ik een cardioloog worden zoals jij!

Voorzitter, prof. dr. Delhaas, en leden van de beoordelingscommissie, prof. dr. Gorgels, prof. dr. Schurgers, prof. dr. Smeets en prof. dr. Boersma, hartelijk bedankt voor het beoordelen van mijn proefschrift.

Bij de verdediging van dit proefschrift wordt ik bijgestaan door mijn paranimfen, die elk een belangrijke bijdrage hebben geleverd aan het proefschrift en de verdediging:

Elton, mijn grote voorbeeld! Je had ook net zo goed hierboven als tweede copromotor kunnen staan. Vanaf dag één heb je me op sleeptouw genomen en wegwijs gemaakt in de wondere wereld van het onderzoek. Zonder jouw hulp had alles veel langer geduurd. Je bent een onuitputtelijke bron van informatie, iedereen op de kamer klopte bij jou aan voor statistische vragen of voor dat ene Engelse woordje waar we maar niet op kwamen. Gelukkig zat je praktisch continu naast me, zelfs tijdens de lunch. Al was dat op de vrijdagmiddag niet altijd een pretje (pot verwijt de ketel wat betreft muzieksmaak). Je liefde voor oneliners en zwarte koffie heb ik van je overgenomen. Je gevoel voor humor en Hollandse nuchterheid zijn prijzenswaardig. Ik wens je alle geluk toe met Ellis en de kleintjes!

Yvonne, alle stadia die jij aan het begin van het onderzoek doormaakte waren heel herkenbaar. Daar heb je je toch mooi doorheen geslagen, al geloofde je er in het begin zelf niet in. Het was goed om te zien dat je ondanks tegenslagen je weg vond in het onderzoek. 
Je groeide snel uit tot een verbindende factor binnen de groep en hebt ook veel borrels en uitjes georganiseerd, waarvoor speciale dank. Ook bedankt voor je gezelligheid, zowel op de PhD-kamer als tijdens de vele borrels en feestjes die we samen hebben bezocht. Veel succes met het afronden van je onderzoek en tot snel op de werkvloer!

Vier jaar fulltime onderzoek doen kent vele ups-and-downs. Gelukkig zaten we met een aantal collega's in hetzelfde schuitje en konden we lief en leed delen. Als het niet onder werktijd was, dan wel op de borrels, feestjes, ski-reisjes en congressen. Daarom ook een speciale dank aan alle collega's op de onderzoekskamer, op alfabetische volgorde:

Arantxa, bedankt voor je gezelligheid op de kamer en je bijlesjes Spaans aan Elton en mij als we weer eens onwaarheden verkondigden onder invloed van Ben \& Ruurd. Het is bewonderenswaardig hoe je je onderzoek inmiddels al tot een succesvol einde hebt gebracht!

Bouke, onze eerste kennismaking was op B3, waar jij al assistent was toen ik als semi-arts begon. Nu gaan we, na een periode van onderzoek, al carpoolend naar Venlo voor ons Bjaar. Mede dankzij jou zijn we twee keer gaan skiën met de harde kern van de PhD-groep, beide reisjes waren memorabel. Naast je ski skills is met name je liefde voor shotjes me bijgebleven (en het tempo waarmee je ze bestelde). Ook dank voor de 4D-flow opname van mijn boviene aortaboog.

Casper, als kersverse cardioloog kwam je bij ons op de kamer vol jonge broekies, maar je had geen moeite met aanpassen. Dank voor je gezelligheid, zowel in de onderzoekskamer als op de NVVC-congressen.

Floor, a.k.a. Fleur, we zagen elkaar vaker op borrels en de skipiste dan op het werk. Maar het is altijd gezellig om even met je bij te kletsen. Veel succes met het afronden van je onderzoek!

Frederique, a.k.a. Fré-Fré, met jou heb ik het langst samen op de onderzoekskamer gezeten. Enerzijds was je heel netjes, anderzijds kon je om de meest grove grappen lachen. Daarom was je in het begin eigenlijk "one of the guys". In retrospect ben ik blij dat er meer vrouwen op de kamer kwamen om de boel te balanceren (af en toe "ging het gewoon te fur"). Ook bedankt voor al dat organiseren, van de skireisjes tot de PhD-uitjes. Ik heb geen idee hoeveel datumprikkers jij in je 4 jaar onderzoek hebt verzonden, maar een hoop van de sociale activiteiten waren zonder jou niet verder gekomen dan de conceptfase. Ik kijk er naar uit om straks weer collega's te zijn in de kliniek! 
Job, de man van de extremen! Wat een ontwikkeling heb jij doorgemaakt tijdens je promotietijd. Ik mis nog altijd het uurtje Temptation Island op het werk. We moeten trouwens snel weer eens gaan darten!

Jort, veel praatjes, veel grote verhalen, maar altijd met een kern van waarheid! Wie zou ons geloven als we vertelden dat $\mathrm{jij}$ in de villa van Jean-Marie Pfaff met kleren en al in zijn zwembad was gesprongen - nadat hij je nadrukkelijk had verzocht om dat niet te doen - om vervolgens door hem persoonlijk achterna gezeten te worden met een bezem? En dat ik op hetzelfde feestje heb gefacetimed met Ronnie Flex? Ik zou het niet geloven. Gelukkig hebben we de foto's nog. We moesten in het begin wat aan elkaar wennen (lees: ik aan jou), maar ik kan toch oprecht zeggen dat er een vriendschap is ontstaan. Je voorliefde voor BMW's heeft me zelfs beïnvloed in de keuze van mijn auto. Het is zonde dat we elkaar nu zo weinig zien. Het ga je goed!

Manouk, op het eerste gezicht kom je rustig over, maar gelukkig leerden we je echt kennen op de PhD-kamer. Je nam de rol van Fré-Fré snel over, ook wat betreft het organiseren van de uitjes. Succes met je onderzoek en de huisartsopleiding!

Mark, ik zal mijn eerste binnenkomst op de onderzoekskamer nooit vergeten dankzij je reactie. Gelukkig maakte je nadien veel goed. Het is nooit een saai feestje met jou in de buurt. Bewonderenswaardig hoe je werk en privé weet te combineren met 3 kinderen en een project in het buitenland.

Martijn, het congres in Rome was inderdaad een mooie, net zoals de assistentenfeestjes die we trouw samen bezochten. Hopelijk binnenkort weer de volgende!

Masih, door jouw verhalen dacht ik dat de AF-poli en electieve cardioversies verschrikkelijk zouden zijn, gelukkig viel dat reuze mee. Helaas was jij al tegen het einde van je onderzoekstijd toen ik begon. Tot ziens op de werkvloer!

Michiel, harde werker en altijd vrolijk. Je dansmoves zijn me ook bijgebleven. Succes met je onderzoek!

Mindy, je bent niet op je mondje gevallen, wat vaak tot prachtige situaties leidde op de onderzoekskamer. Bedankt voor het regelmatig geven van je ongezouten mening!

Nick, de man uit Maria Hoop, trots op Duitsland en zijn motor. Bewonderenswaardig hoe je zo veel verschillende projecten en taken tegelijkertijd uitvoerde. Veel succes met het afronden van je onderzoek! 
Nikki, je werkethos typeert je. Je hebt met verve het onderzoek van Elton overgenomen en al een aantal mooie artikelen gepubliceerd. Succes met het afronden van je onderzoek en ook in de kliniek!

Sibel, altijd vriendelijk en behulpzaam. Ondanks dat ik je weinig zag omdat je zo ver weg op de uni zat, kon ik altijd bij je terecht als ik vragen had. Veel succes met het afronden van je onderzoek!

Theo, dank voor alle hulp in het begin van mijn onderzoekstijd. Ik zal nooit vergeten hoe je als afsluiter van je eigen promotiefeestje ging hakken!

Twan, het congres in Wenen is toch het eerste waar ik aan moet denken bij jou. En het gemak waarmee jij met iedereen een praatje kan maken. Bedankt voor de gezelligheid en al je praatjes!

Bianca, Jerremy en Luuk, met jullie heb ik helaas maar een korte tijd samen op de PhDkamer gezeten. Jullie hebben alle drie een goede start gemaakt met jullie onderzoek, veel succes met het vervolg!

Ook dank aan de dames van de cardio research, met name Monique voor al je hulp bij de RACE V studie en Suzanne voor je hulp bij de EORP. Mandy, Marie-Louise en Saskia, bedankt voor het implanteren van de Linq's. Sandra en Danielle, bedankt voor het uitvoeren van de vaatmetingen. Saskia en Miriam, dank voor al dat geregel en inplannen van vergaderingen met de baas. Alle polidames, en in het bijzonder Anouk en Francis, bedankt voor jullie hulp op de poli.

Alle cardiologen van het MUMC, en in het bijzonder de AF-poli supervisoren. Beste $d r$. Timmermans, wat was het een genot om met $u$ poli te doen. Wat me het meest is bijgebleven zijn uw kladblaadjes, uw bevlogenheid en het niet vergeten de patiënt te waarschuwen voor de eventueel te verwachten bijwerkingen. $U$ was ook altijd geïnteresseerd in de voortgang van de thesis, waarvoor dank. Beste Dennis en Cees, ondanks dat ik jullie relatief kort als supervisor heb mogen meemaken, heb ik ook van jullie veel geleerd. Hartelijk dank daarvoor.

Dank aan alle arts-assistenten cardiologie van het MUMC voor de hulp bij de onderzoeken en de gezelligheid op de NVVC congressen. Ook dank aan alle PA'ers, assistenten en cardiologen van het VieCuri voor het warme welkom en de goede begeleiding. 
Alle arts-assistenten Interne Geneeskunde en internisten van het Zuyderland, bedankt voor jullie gezelligheid op de werkvloer. Achteraf was de Interne Geneeskunde veel leuker en interessanter dan ik dacht. Dat is voor een groot gedeelte aan jullie te danken!

Ook buiten het ziekenhuis hebben mensen bijgedragen aan de totstandkoming van dit proefschrift, door het tonen van interesse in het onderzoek of het er juist even niet over te hebben:

Armand, Jip en Raymond, a.k.a. de PT-Boys, mijn BFF's. Ik zal toch echt met jullie moeten beginnen. Gedurende een niet onaanzienlijke periode tijdens het onderzoek doen, leefde ik echt van weekend tot weekend en keek ik reikhalzend uit naar onze samenkomsten. Met z'n vieren zijn we een bonte gezelschap aan verschillende persoonlijkheden, oftewel 4 malse makkers. Altijd dolle pret als we samen zijn, met als hoogtepunten de weekendjes weg in Dublin en Berlijn. Moge er nog vele weekendjes en memorabele avonden volgen!

Armand, Jack, Leon, Mostafa, Philippe en Thijs, a.k.a. H.J.C. Myrmidon. Na al die jaren zien we elkaar nog steeds met enige regelmaat, om serieuze maar vooral ook minder serieuze zaken te bespreken. "Tijd voor een debat!" om maar iemand te citeren. Mooi om te zien hoe iedereen zijn eigen weg heeft gevonden. Ik hoop dat we nog vele jaren zullen samenkomen.

Bedankt Nick voor alle gezellige avonden bij jou, bij mij of - en met name - in de kaasbar.

Mia en Cor, bedankt voor jullie vriendschap met mijn ouders en jullie betrokkenheid bij onze familie.

Beste Angela, Ludwig, Rachelle en Rick, bedankt dat jullie mij zo warm hebben ontvangen in de familie.

Al mijn neefjes en nichtjes: Hamide, Hasan en Yağmur, Ayşe, Efe, Feride, Ferdi en Ferhat. Bedankt voor jullie gezelligheid, we moeten snel weer eens afspreken! Daarnaast natuurlijk ook Hilâl abla, Kâzım abi en Leyla yenge, en al mijn ooms en tantes: Hüseyin dayı, Nefise yenge, Turgut dayı, Dudu yenge, Nazlı teyze en Ahmet enişte. Bedankt voor jullie steun en interesse.

Babaanne, anneanne, halalarım, kuzenlerim ve Türkiye'deki tüm akrabalarım, aramızda mesafe olsa da ve senede sadece bir kez görüşebilsek de benimle ne kadar gurur duyduğunuzu biliyorum. Desteğinizi daima hissediyorum. "Şuan araştırma yapıyorum, doktoramla uğraşıyorum" dediğimde işte bu kitaptan bahsediyordum. 
Önder en Merve, in de tijd dat ik dit boekje heb geschreven zijn jullie verloofd, getrouwd en twee keer verhuisd. Als klap op de vuurpijl ook nog een klein mannetje op de wereld gezet. Bewonderenswaardig hoe jullie het voor elkaar krijgen! lk wens jullie alle geluk van de wereld toe met jullie kleine telg. Poyraz, de jongste en schattigste Erküner ter wereld! Je krijgt op dit moment nog weinig mee van de wereld om je heen, maar daar zal snel verandering in komen. Ondanks dat je zo kort op deze wereld bent, heb je me al veel blijdschap bezorgd. Ik kijk er naar uit om je te zien opgroeien.

Özgür, in de tijd dat ik dit boekje heb geschreven ben jij uitgegroeid van tiener tot volwassene (voor de wet dan tenminste, voor mij blijf je nog altijd mijn kleine broertje). Je hebt je havo afgerond en zal beginnen aan je hbo. Ik heb er alle vertrouwen in dat je ook dat met je kenmerkende nonchalance tot een succesvol einde zal brengen. Ik ben trots op je en ik zal er altijd voor je zijn jongen.

Sevgili annem ve babam, üçümüzün de bu günlere kadar gelebilmemizde çok büyük emeğiniz var. Dört senelik araştırma zamanında bazen hastanede tam olarak ne yaptığımı anlatmakta zorluk çeksem de, beni hep desteklediniz. Tüm çalışmalarımın sonucu şuan elinizdeki kitap. Bu güne kadar gösterdiğiniz kayıtsız şartsız desteğiniz için teşekkürler. Benimle ne kadar gurur duyduğunuzu biliyorum.

Lieve Beau, jouw bijdrage aan dit boekje is niet te onderschatten, ook al heb ik je leren kennen na mijn onderzoekstijd. De laatste loodjes zijn het zwaarst, vooral als je het allemaal naast een fulltime baan moet doen. Gelukkig ben jij er om me te motiveren het beste uit mezelf te halen en me met beide benen op de grond te zetten. Sinds jij in mijn leven bent, is mijn leven compleet, je maakt me de gelukkigste man op aarde. Ik zou een apart hoofdstukje aan jou kunnen wijden, maar ik laat mijn dankbaarheid aan jou liever in persoon blijken. Ik hou van je, sjattie. 


\section{GURRICULUM VIIAA}


Ömer Erküner was born on Wednesday $23^{\text {rd }}$ of May 1990 in Maastricht. He obtained his high-school degree in 2008 from the Sint-Maartenscollege in Maastricht, after which he started his medical training at the Faculty of Health, Medicine and Life Sciences at the University of Maastricht. In the last year of his medical training, he performed both the senior clinical internship (supervisor Dr. N. Lencer) and the senior scientific internship (supervisor Prof. Dr. T. Gorgels) at the department of Cardiology at Maastricht University Medical Center. Upon obtaining his

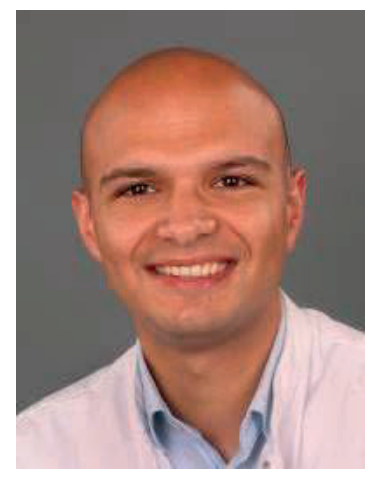
medical degree in August 2014 he worked at the Cardiology department at Zuyderland Medical Center from September 2014 till December 2014. In January 2015 he started working as a PhD-fellow under supervision of Prof. Dr. Harry J.G.M. Crijns at the department of Cardiology at the Maastricht University Medical Center and the Cardiovascular Research Institute Maastricht (CARIM). Apart from the research reported in this thesis, which was presented at national as well as international congresses, he worked as a medical doctor at the specialized atrial fibrillation outpatient clinic and performed elective electrical cardioversions. During the research, he supervised medical students and was the national coordinator for the EURObservational Research Programme on Atrial Fibrillation Long-Term General Registry. In January 2019 he started his training in Cardiology at the Maastricht University Medical Center (supervisors Prof. Dr. H.J.G.M. Crijns and Drs. T. Dinh), as part of which he is currently employed at the VieCuri Medical Center (supervisor Dr. B. Rahel), after performing his residency in Internal Medicine at Zuyderland Medical Center (supervisor Dr. J. Buijs). 
내단

OF PUBLICAIIONS 
Clinical determinants of early spontaneous conversion to sinus rhythm in patients with atrial fibrillation.

Pluymaekers NAHA, Dudink EAMP, Weijs B, Vernooy K, Hartgerink DEJ, Jacobs JS,

Erküner Ö, Marcks NGHM, van Cauteren YJM, Dinh T, Ter Bekke RMA, Sels JEMW,

Delnoij TSR, Geyik Z, Driessen RGH, Linz DK, den Uijl DW, Crijns HJGM, Luermans JGLM. Neth Heart J. 2021 Jan 6. Online ahead of print.

Temporal Patterns and Short-Term Progression of Paroxysmal Atrial Fibrillation: Data from RACE V.

Erküner Ö*, de With $R^{*}$, Rienstra M, Nguyen BO, Körver F, Linz D, ten Cate H, Spronk HMH, Kroon A, Maass A, Blaauw Y, Tieleman R, Hemels M, de Groot J, Elvan A, de Melis M, Scheerder C, Al-Jazairi M, Schotten U, Luermans JGLM, Crijns HJGM, Van Gelder IC. Europace. 2020 Aug 1;22(8):1162-1172.

* Both authors contributed equally

External electrical cardioversion in patients with cardiac implantable electronic devices: Is it safe and is immediate device interrogation necessary?

Pluymaekers NAHA, Dudink EAMP, Boersma L, Erküner Ö, Gelissen M, van Dijk V, Wijffels M, Dinh T, Vernooy K, Crijns HJ, Balt J, Luermans JGLM.

Pacing Clin Electrophysiol. 2018 Oct;41(10):1336-1340.

Effect of Systemic Hypertension With Versus Without Left Ventricular Hypertrophy on the Progression of Atrial Fibrillation (from the Euro Heart Survey).

Erküner Ö, Dudink EAMP, Nieuwlaat R, Rienstra M, Van Gelder IC, Camm AJ, Capucci A, Breithardt G, LeHeuzey JY, Lip GYH, Crijns HJGM, Luermans JGLM.

Am J Cardiol. 2018 Aug 15;122(4):578-583.

Stroke risk in patients with device-detected atrial high-rate episodes.

Erküner Ö, Rienstra M, Van Gelder IC, Schotten U, Crijns HJGM, Luermans JGLM. Neth Heart J. 2018 Apr;26(4):177-181. Review.

The influence of progression of atrial fibrillation on quality of life: a report from the Euro Heart Survey.

Dudink EAMP, Erküner Ö, Berg J, Nieuwlaat R, de Vos CB, Weijs B, Capucci A, Camm AJ, Breithardt G, Le Heuzey JY, Luermans JGLM, Crijns HJGM.

Europace. 2018 Jun 1;20(6):929-934. 
Atherothrombosis and Thromboembolism: Position Paper from the Second Maastricht Consensus Conference on Thrombosis.

Spronk HMH, Padro T, Siland JE, Prochaska JH, Winters J, van der Wal AC, Posthuma JJ, Lowe G, d'Alessandro E, Wenzel P, Coenen DM, Reitsma PH, Ruf W, van Gorp RH, Koenen RR, Vajen T, Alshaikh NA, Wolberg AS, Macrae FL, Asquith N, Heemskerk J, Heinzmann A, Moorlag M, Mackman N, van der Meijden P, Meijers JCM, Heestermans M, Renné T, Dólleman S, Chayouâ W, Ariëns RAS, Baaten CC, Nagy M, Kuliopulos A, Posma JJ, Harrison P, Vries MJ, Crijns HJGM, Dudink EAMP, Buller HR, Henskens YMC, Själander A, Zwaveling S, Erküner Ö, Eikelboom JW, Gulpen A, Peeters FECM, Douxfils J, Olie RH, Baglin T, Leader A, Schotten U, Scaf B, van Beusekom HMM, Mosnier LO, van der Vorm L, Declerck P, Visser M, Dippel DWJ, Strijbis VJ, Pertiwi K, Ten Cate-Hoek AJ, Ten Cate H. Thromb Haemost. 2018 Feb;118(2):229-250.

Poor anticoagulation relates to extended access times for cardioversion and is associated with long-term major cardiac and cerebrovascular events.

Erküner Ö, Claessen R, Pisters R, Schulmer G, Ramaekers R, Sonneveld L, Dudink E, Lankveld T, Limantoro I, Weijs B, Pison L, Blaauw Y, de Vos CB, Crijns HJ. Int J Cardiol. 2016 Dec 15;225:337-341. 